\title{
Konstruktion eines bakteriellen Systems zum Export von Coenzym $B_{12}$
}

\author{
Dissertation \\ zum Erlangen des Doktorgrades \\ der Mathematisch-Naturwissenschaftlichen Fakultäten \\ der Georg-August-Universität zu Göttingen
}

vorgelegt von

Caroline Toeche-Mittler

aus Hamburg

Göttingen 2002 
D7

Referent:

Prof. Dr. G. Gottschalk

Korreferent:

Prof. Dr. W. Liebl

Tag der mündlichen Prüfung: 31. Oktober 2002 
Meiner Mutter, Tilli

und dem kleinen Mops in mir gewidmet 


\section{Inhaltsverzeichnis}

Abkürzungsverzeichnis

$1 \quad$ Einleitung

$2 \quad$ Material und Methoden

$\begin{array}{lll}2.1 & \text { Organismen und Plasmide } & 4\end{array}$

$\begin{array}{lll}2.2 & \text { Nährmedien } & 8\end{array}$

2.2.1 Mineralmedium mit Hefeextraktzusatz (AVERHOFF, 1988; modifiziert) für C. freundii und E. blattae

2.2.2 Hefe-Pepton-Medium für C. freundii (HOLDEMAN et al., 1977) 10

2.2.3 LB (Luria-Bertani)-Medium (SAMBROOK et al., 1989) 10

2.2.4 Lysin-Decarboxylase-Medium (EKLUND und LANKFORD, 1967) 10

2.2.5 M9-Minimalmedium (SAMBROOK et al., 1989, modifiziert) 11

2.2.6 Minimal-Aminosäure-Medium für E. coli DSM 4261 (KRZYCKI and ZEIKUS, 1980, modifiziert)

2.2.7 Mineralagar für E. coli DSM 4261 (KRZYCKI and ZEIKUS, 1980, modifiziert)

2.2.8 SOB-Medium (HANAHAN et al., 1983)

2.2.9 Synthetisches Medium für Propionibacterium freudenreichii subsp. shermanii (SEIFERT, pers. Mitteilung)

2.3 Pufferlösungen

$\begin{array}{ll}\text { 2.3.1 Kaliumphosphat-Puffer } & 13\end{array}$

$\begin{array}{lll}\text { 2.3.2 SSC-Puffer (10-fach) } & 14\end{array}$

2.3.3 TBS-Puffer (10-fach) 14

$\begin{array}{lll}\text { 2.3.4 TBST-Puffer (5-fach) } & 14\end{array}$

$\begin{array}{lll}2.4 & \text { Feste Medien } & 14\end{array}$

$\begin{array}{lll}2.4 .1 & 14\end{array}$

$\begin{array}{lll}2.5 & \text { Zellanzucht } & 15\end{array}$

2.5.1 Aerobe Anzucht 15

$\begin{array}{ll}\text { 2.5.2 Anaerobe Anzucht } & 15\end{array}$

2.5.3 Messung der optischen Dichte 15

2.5.4 Bestimmung des pH-Wertes 15

2.5.5 Reinheitskontrolle 16

$\begin{array}{lll}\text { 2.5.6 Stammhaltung } & 16\end{array}$ 
2.6 Standardtechniken für das Arbeiten mit DNA 16

2.6.1 Vorbehandlung von Geräten und Lösungen 16

$\begin{array}{lll}\text { 2.6.2 Isolierung von Plasmid-DNA } & 17\end{array}$

2.6.2.1 Schnellpräparation von Plasmid-DNA (HOLMES \& QUICKLEY,

1981; RIGGS \& McLACHLAN, 1986)

2.6.2.2 Schnelle Plasmid-Isolierung aus E. coli („Cracking“) 17

2.6.2.3 „Präparative Plasmidisolierung mit dem Wizard Purification Kit“" 18

2.6.3 Reinigung und Konzentrierung von Nukleinsäuren 18

$\begin{array}{lll}\text { 2.6.3.1 Fällung von DNA } & 18\end{array}$

2.6.3.2 Mikrodialyse von Nukleinsäuren $\quad 19$

2.6.3.3 Konzentrationsbestimmung von DNA 19

2.6.3.4 Reinigung von DNA mit dem „Qiaquick Gelextraction-Kit““ 19

$\begin{array}{ll}\text { 2.6.3.5 Reinigung von PCR-Produkten } & 20\end{array}$

2.6.3.6 Gelfiltration von DNA-Lösungen 20

2.7 Gelelektrophorese von Nukleinsäuren $\quad 20$

$\begin{array}{lll}2.7 .1 & \text { Agarosegel-Elektrophorese } & 20\end{array}$

2.7.2 Ethidiumbromid-Färbung und Fotografie von Agarosegelen 21

2.7.3 Größenbestimmung von Nukleinsäuren 21

$\begin{array}{lll}2.8 & \text { PCR (Polymerase-Kettenreaktion) } & 23\end{array}$

2.9 Enzymatische Modifikation von Nukleinsäuren $\quad 24$

2.9.1 Spaltung mit Restriktionsendonukleasen 24

2.9.2 Dephosphorylierung von Vektor-DNA 25

2.9.3 Ligierung von DNA-Fragmenten 25

2.9.4 Radioaktive Markierung von DNA-Fragmenten 26

2.10 Übertragung von DNA und Selektion rekombinanter Klone 27

2.10.1 Übertragung von DNA durch Transformation 27

2.10.1.1 Herstellung kompetenter Zellen (INOUE et al., 1990) 27

2.10.1.2 Transformation von E. coli (INOUE et al., 1990) 27

2.10.1.3 Übertragung von DNA durch Elektroporation (DOWER et al., 1988) 28

2.11 Übertragung von Nukleinsäuren auf Membranen 29

2.11.1 Herstellung von Filtern für die Koloniehybridisierung (BULUWELA et $\begin{array}{ll}e l ., 1989) & 29\end{array}$

2.12 Hybridisierungsmethoden 2

2.12.1 DNA-DNA-Hybridisierung 29

$\begin{array}{ll}2.12 .2 \text { Autoradiographie } & 30\end{array}$

2.13 Sequenzierung von DNA $\quad 3$

2.13.1 Analyse der Sequenzdaten $\quad 30$ 
2.14 Heterologe Genexpression in E. coli, E. blattae, C. freundii und S. typhimurium TA100

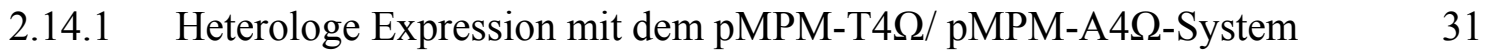

2.14.2 Heterologe Expression mit dem pET-System 33

2.14.3 Heterologe Expression pASK-IBA-System 33

2.15 Zellaufschluß und Extraktherstellung $\quad 34$

2.15.1 Zellernte 34

2.15.2 Zellaufschluß mit der French Presse 34

2.15.3 Zellaufschluß durch Ultraschallbehandlung 35

2.15.4 Cytoplasma- und Membranpräparation 35

2.15.5 Periplasmapräparationen 35

2.15.5.1 Periplasmapräparation (SAMBROCK et al., 1989) 35

2.15.5.2 Periplasmapräparation (WEIß, pers. Mitteilung) 36

2.15.5.3 Periplasmapräparation (HOSHINO \& KAGEYAMA, 1980) 36

2.15.5.4 Periplasmapräparation ( ARMBRECHT, pers. Mitteilung, modif.) 36

2.15.5.5 Periplasmapräparation (IBA Manual, modif.) 37

2.16 Bestimmung der Proteinkonzentration nach BRADFORD (1976) 37

2.17 Einengung von Proteinlösungen $\quad 38$

2.17.1 Einengung mit Polyethylenglycol 38

2.17.2 Einengung mit Centrisart-Röhrchen 38

2.17.3 Dialyse von Proteinlösungen 39

$2.18 \quad$ Polyacryalmid-Gelelektrophorese (PAGE) 39

2.18.1 SDS-PAGE nach SCHÄGGER und VON JAGOW (1987) 39

2.19 Proteinfärbemethoden in Polyacrylamidgelen $\quad 40$

2.19.1 Coomassie-Färbung 41

2.19.2 Silberfärbung (BLUM et al., 1987) 41

2.20 Bestimmung der Molekularmassen von Proteinen 43

2.21 Methoden zur Proteinanreicherung 43

2.21.1 Metall-Chelat-Affinitätschromatographie 43

2.21.1.1 Vorbereitung der Säule 44

2.21.1.2 Proteinaufreinigung unter nativen Bedingungen 44

2.21.1.3 Proteinaufreinigung unter denaturierenden Bedingungen 45

2.21.1.4 Regeneration der Säule 45

2.21.1.5 Ammoniumsulfat-Fällung 45 
2.22 Elektophoretischer Transfer von Proteinen auf Membranen 46

2.22.1 Western Blot (TOBWIN et al., 1979; modif.) 46

2.22.2 Protein-,Dot-Blot”-Verfahren (HAWKES, 1986; modif.) 48

2.23 Immunodetektion von Proteinen auf Blotmembranen 48

2.23.1 Chromogene Methoden 48

2.23.1.1 $\mathrm{Ni}^{2+}$-NTA-Konjugat-Färbung $\quad 48$

2.23.1.2 Färbung mit Substrat für Peroxidase-markierten sekundären Antikörper $\quad 50$

2.23.2 Chemilumineszente Methode 51

2.23.2.1 Detektion mit ECL Plus Substrate (Fa. Amersham Pharmacia Biotech, UK) für peroxidase-markierten sekundären Antikörper 51

2.24 Nachweis des „Green Fluorescent Protein“ im Fluoreszenzmikroskop 52

2.25 Einbettung von Zellen für elektronenmikroskopische Dünnschichtdarstellungen $\quad 52$

2.25.1 Ultramikrotomie 53

2.26 Synthese von ${ }^{14} \mathrm{C}$-markiertem Coenzym $\mathrm{B}_{\mathbf{1 2}}$

2.26.1 Synthese von 5,6-Dimethyl $\left(2-{ }^{14} \mathrm{C}\right)$ Benzimidazol (HÖRIG und RENZ, 1980) 54

2.26.2 Synthese von Coenzym $\mathrm{B}_{12}$ durch Propionibacterium freudenreichii subsp. shermanii (HÖRIG und RENZ, 1980) 55

2.26.3 Nachweis und Isolierung des ${ }^{14} \mathrm{C}$-markierten Coenzym $\mathrm{B}_{12}$ durch Hochdruckflüssigkeitschromatographie (HPLC) 55

2.27 Quantitative Bestimmung von Corrinoiden $\quad 57$

2.27.1 Quantitative Bestimmung von Corrinoiden mittels Plattentest (KRZYCKI und ZEIKUS, 1980; modif.) 57

2.27.2 Photometrische Methode zu quantitativen Corrinoidbestimmung 58

$\begin{array}{llr}2.28 & \text { Bezugsquellen }\end{array}$ 
3 Experimente und Ergebnisse

3.1 Strategie für die Entwicklung eines $B_{12}$-Exporters $\quad 62$

3.1.1 Fusion der Signalsequenz mit den $\mathrm{B}_{12}$-Bindeproteinen $\quad 64$

3.1.1.1 Klonierung von sigtorA mit dem if-Gen in den Vektor pMPM-T4 $\Omega \quad 64$

3.1.1.2 Klonierung von sigtorA mit mutB in den Vektor pMPM-T4 $\Omega \quad 66$

3.2 Experimente zum Nachweis der Expression der sigtorA-if-Genfusion 66

3.2.1 Expressionsstudien unter verschiedenen Bedingungen 68

3.2.2 Experimente zum Nachweis der periplasmatischen Translokation des sigTorA-IF-Hybridproteins 73

3.2.2.1 Nachweis des Intrinsic Faktors im Rohextrakt nach $\mathrm{Ni}^{2+}$-NTA-

Affinitäts-chromatographie $\quad 73$

3.2.2.2 Nachweis des Intrinsic Faktors im Periplasma nach $\mathrm{Ni}^{2+}$-NTA-

3.2.2.3 Konzentrierung des Intrinsic Faktors unter denaturierenden Bedingungen 76

3.2.3 Variation des Transportweges $\quad 80$

3.3 Studien zum Nachweis der Bindung von $B_{12}$ an den IF 82

3.3.1 Abhängigkeit der Corrinoidproduktion von verschiedenen C. freundiiStämmen in An- und Abwesenheit von heterolog produziertem IF 82

3.4 Experimente zum Nachweis der Expression der sigtorA-mutBGenfusion und des korrespondierenden Genproduktes $\quad 83$

3.4.1 Expression von sigtorA-mutB in $\mathrm{B}_{12}$-produzierenden Enterobakterien $\quad 87$

3.4.1.1 Expression in C. freundii $\quad 88$

3.4.1.2 Expression in E. blattae 90

3.5 Experimente zur Lokalisation des Hybridproteins sigTorA-MutB $\begin{array}{ll}\text { im Periplasma } & 91\end{array}$

3.5.1 Umklonierung von sigtorA-mutB in den Vektor pASK-IBA3 92

3.5.2 Translokation von sigTorA-MutB in $\mathrm{B}_{12}$-produzierenden Enterobakterien 94

3.6 Studien zum Nachweis der Cotranslokation von $B_{12}$ und MutB $\quad 97$

3.6.1 Abhängigkeit der Corrinoidproduktion von verschiedenen E. blattaeStämmen in An- und Abwesenheit von heterolog produzierter Methylmalonyl-CoA-Mutase 97

3.6.2 Corrinoidnachweis im Periplasma verschiedener $B_{12}$-Produzenten $\quad 100$ 
4 Diskussion

$\begin{array}{lll}4.1 & \text { Transport von } B_{12} \text { über Membranen } & 102\end{array}$

4.2 Coenzym B $B_{12}$-abhängige und Cobalamin-bindende Proteine 103

4.3 Signalsequenz-abhängiger Proteintransport ins Periplasma 108

4.4 Einfluss der Produktion und des Exports der sigTorAFusionsproteine auf die Coenzym $B_{12}$-Synthese

$\begin{array}{lll}4.5 & \text { Ausblick: } & 120\end{array}$

$5 \quad$ Zusammenfassung $\quad 123$

$6 \quad$ Literaturverzeichnis $\quad 125$

$\begin{array}{lll}7 & \text { Anhang } & 138\end{array}$ 


\section{Abkürzungsverzeichnis}

\begin{tabular}{|c|c|}
\hline Abb. & Abbildung \\
\hline$A p^{r}$ & Ampicillinresistenz \\
\hline APS & Ammoniumpersulfat \\
\hline ATP & Adenosin-5'-triphosphat \\
\hline bidest. & Zweifach destilliert \\
\hline $\mathrm{bp}$ & Basenpaar \\
\hline BSA & Rinderserumalbumin \\
\hline bzw. & beziehungsweise \\
\hline C- & Carboxy \\
\hline C. & Citrobacter \\
\hline${ }^{\circ} \mathrm{C}$ & Grad Celsius \\
\hline ca. & circa \\
\hline $\mathrm{cm}$ & Zentimeter \\
\hline $\mathrm{Cm}$ & Chloramphenicol \\
\hline d & Küvettenschichtdicke \\
\hline $\mathrm{Da}$ & Dalton \\
\hline DCPIP & Dichlorphenolindophenol \\
\hline dest. & destilliert \\
\hline DH & Dehydrogenase \\
\hline d.h. & das heißt \\
\hline DMSO & Dimethylsulfoxid \\
\hline DNA & Desoxyribonukleinsäure \\
\hline DNase & Desoxyribonuklease \\
\hline E. & Escherichia \\
\hline $\mathrm{E}$ & Extinktion \\
\hline$\Delta \mathrm{E}$ & Extinktionsänderung \\
\hline с & Extinktionskoeffizient \\
\hline E-Cup & Eppendorf-Reaktionsgefäß \\
\hline EDTA & Ethylendiamintetraessigsäure \\
\hline et al. & et alteri (und andere) \\
\hline Fa. & Firma \\
\hline g & Erdbeschleunigung, Gramm \\
\hline $\mathrm{h}$ & Stunde \\
\hline Hrsg. & Herausgeber \\
\hline IPTG & Isopropyl- $\beta$-D-thiogalactopyranosid \\
\hline $\mathrm{kb}$ & Kilobasenpaare \\
\hline $\mathrm{kDa}$ & Kilodalton \\
\hline$\lambda$ & Bakteriophage Lambda \\
\hline 1 & Liter \\
\hline LB & Luria-Bertani \\
\hline M & Molar \\
\hline $\mathrm{m}$ & Milli $\left(10^{-3}\right)$, Meter \\
\hline$\mu$ & $\operatorname{Mikro}\left(10^{-6}\right)$ \\
\hline $\min$ & Minute \\
\hline$\mu \mathrm{g}$ & Microgramm \\
\hline$\mu l$ & Mikroliter \\
\hline $\mathrm{mg}$ & Milligramm \\
\hline
\end{tabular}




\begin{tabular}{|c|c|}
\hline $\mathrm{ml}$ & Milliliter \\
\hline $\mathrm{mM}$ & Millimolar \\
\hline$\mu \mathrm{M}$ & Mikromolar \\
\hline mol & $6.023 \times 10^{23}$ \\
\hline N- & Amino- \\
\hline $\mathrm{NAD}(\mathrm{P})^{+}$ & Nicotinadenindinukleotid(phosphat), oxidiert \\
\hline NBT & Nitroblautetrazoliumchlorid \\
\hline $\mathrm{OD}_{\mathrm{x}}$ & Optische Dichte bei einer Wellenlänge von x nm \\
\hline$\Omega$ & Omega \\
\hline$\%$ & Prozent \\
\hline PAGE & Polyacrylamid-Gelelektrophorese \\
\hline PCR & Polymerasekettenreaktion \\
\hline PEG & Polyethylenglykol \\
\hline Pfu & „plaque forming unit“ (Plaque bildende Einheit) \\
\hline $\mathrm{pH}$ & negativer dekadischer Logarithmus der Protonenkonzentration \\
\hline RNA & Ribonukleinsäuren \\
\hline RNase & Ribonuklease \\
\hline RT & Raumtemperatur \\
\hline $\mathrm{s}$ & Sekunde \\
\hline$S$. & Salmonella \\
\hline SDS & Natriumdodecylsulfat \\
\hline SL & Spurenelementelösung \\
\hline sp. & Species \\
\hline $\mathrm{t}$ & Zeit \\
\hline $\mathrm{T}_{4}, \mathrm{~T}_{7}$ & Bakteriophagen der T-Serie \\
\hline TAE & Tris-Acetat-EDTA \\
\hline TEMED & N, N, N’, N`-Tetramethylethylendiamin \\
\hline $\mathrm{TE}$ & Tris-EDTA \\
\hline Tris & Tris-(hydroxymethyl)-aminomethan \\
\hline u.a. & unter anderem \\
\hline $\mathrm{V}$ & Probenvolumen \\
\hline $\mathrm{V}$ & Volt \\
\hline $\mathrm{v} / \mathrm{v}$ & Volumen pro Volumen \\
\hline $\mathrm{w} / \mathrm{v}$ & Masse pro Volumen \\
\hline z. B. & zum Beispiel \\
\hline
\end{tabular}

\section{Abkürzungen für Aminosäuren}

$\begin{array}{llllll}\text { A } & \text { Ala } & \text { Alanin } & \text { M } & \text { Met } & \text { Methionin } \\ \text { C } & \text { Cys } & \text { Cystein } & \text { N } & \text { Asn } & \text { Asparagin } \\ \text { D } & \text { Asp } & \text { Aspartat } & \text { P } & \text { Pro } & \text { Prolin } \\ \text { E } & \text { Glu } & \text { Glutamin } & \text { Q } & \text { Gln } & \text { Glutamin } \\ \text { F } & \text { Phe } & \text { Phenylalanin } & \text { R } & \text { Arg } & \text { Arginin } \\ \text { G } & \text { Gly } & \text { Glycin } & \text { S } & \text { Ser } & \text { Serin } \\ \text { H } & \text { His } & \text { Histidin } & \text { T } & \text { Thr } & \text { Threonin } \\ \text { I } & \text { Ile } & \text { Isoleucin } & \text { V } & \text { Val } & \text { Valin } \\ \text { K } & \text { Lys } & \text { Lysin } & \text { W } & \text { Trp } & \text { Threonin } \\ \text { L } & \text { Leu } & \text { Leucin } & \text { Y } & \text { Tyr } & \text { Tyrosin }\end{array}$




\section{Einleitung}

Vitamin $B_{12}$ ist eine rote wasserlösliche Substanz, die erstmals 1926 von MINOT und MURPHY (1926) als sogenannter Extrinsic Faktor in der Leber des Menschen beschrieben wurde. Erst 20 Jahre später gelang es RICKES et al (1948) und parallel SMITH et al (1948) das Vitamin zu isolieren, dessen gesamter Aufbau durch die Röntgenstrukturanalyse von HODGKIN et al. (1955) aufgeklärt wurde. Vitamin $\mathrm{B}_{12}$ hat eine Porphyrin-ähnliche Grundstruktur, deren Kernstück aus vier miteinander verknüpften Pyrrol-Ringen mit Cobalt als Zentral-Atom besteht. Zwei dieser Ringe sind nicht wie bei den Porphyrinen üblich über eine Kohlenstoff-Wasserstoff-Brücke, sondern direkt miteinander verbunden. Dies unterscheidet den „Corrinring“ des Vitamin $B_{12}$ vom „Porphyrinring“ des Hämoglobins und des Chlorophylls (ZAGALAK, 1982). Neben dem zentralen Ring ist außerdem ein unterer axialer Ligand, eine sogenannte Nukleotid-Schleife, und ein oberer axialer Ligand, ein Cyanid, an der Bildung des Vitamins beteiligt. Vitamin $\mathrm{B}_{12}$ kann nur durch Austausch des Cyanids gegen einen anderen Liganden seine biologische Funktion ausüben. Dabei ist entweder eine Methylgruppe (Methylcobalamin) oder eine 5-Deoxyadenosyl-Gruppe (Adenosylcobalamin) anstelle des Cyanids an das Cobaltatom gebunden (siehe Abbildung 1).

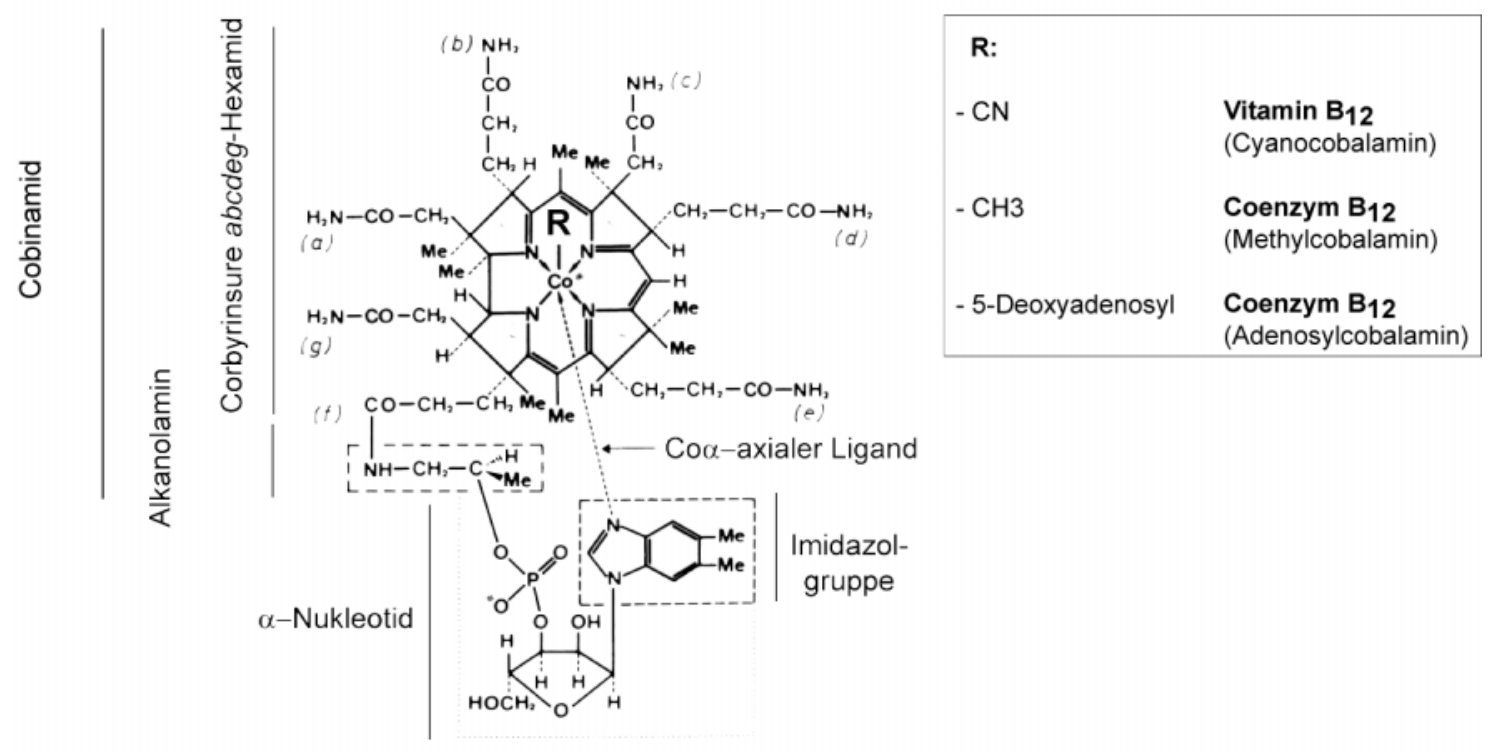


Nach der Aufnahme des Vitamins und seiner Umwandlung zum Coenzym übernimmt es nicht nur in Mikroorganismen, sondern auch in tierischen Zellen wichtige Funktionen. Im Menschen beeinflusst Coenzym $B_{12}$ sowohl das Zellwachstum, als auch die Replikation. Adenosylcobalamin wird für die Umsetzung von L-MethylmalonylCoA zu Succinyl-CoA benötigt, was eine wichtige Reaktion beim Abbau von bestimmten Aminosäuren sowie beim Fettstoffwechsel spielt. Methylcobalamin ist an der Synthese von Methionin beteiligt, indem es eine Methylgruppe vom Methyltetrahydrofolat (Folsäure) auf Homocystein überträgt. Dadurch wird Tetrahydrofolat regeneriert, welches für die DNA-Synthese notwendig ist. Wenn das Blutserum vorwiegend Methytetrahydrofolat enthält, kann bei einem $\mathrm{B}_{12}$-Mangel kein Tetrahydrofolat mehr regeneriert werden. Dies führt letztlich zu einer defekten DNASynthese und zur megaloblastären (perniziösen) Anämie. Heutzutage liegt ein Vitamin $\mathrm{B}_{12}$-Defizit selten an einer zu geringen Zufuhr des Vitamins über die Nahrung, sondern eher an einer unzureichenden Adsorption. Der Intrinsic Faktor (IF) ist eines der drei löslichen Proteine, die an der Aufnahme und dem Transport von $\mathrm{B}_{12}$ im Menschen beteiligt sind. (BALLAL et al., 1997; NEXØ, 1998; ZAGALAK 1982; MARTENS et al., 2002; .KRÄUTLER et al 1998).

Coenzym $\mathrm{B}_{12}$ wird in der Natur ausschließlich von einigen Mikroorganismen wie z. B. Citrobacter freundii, Escherichia blattae, Propionibacterium shermanii und Salmonella typhimurium de novo gebildet. Dabei lassen sich grob zwei verschiedene Synthesewege unterscheiden. Während Pseudomonas denitrificans $\mathrm{B}_{12}$ über den aeroben Zweig bildet, verläuft sie Synthese bei Citrobacter freundii und Escherichia blattae nur unter Ausschluss von Sauerstoff. (ROTH et al., 1996). Etwa 30 enzymkatalysierte Reaktionen werden für die komplette de novo Synthese benötigt. $\mathrm{B}_{12}$ auxotrophe Mikroorganismen, die zu keiner $\mathrm{B}_{12}$-Produktion befähigt sind, müssen es wie auch Menschen und Tiere aus dem umgebenden Medium aufnehmen. Die täglich benötigte Menge für den Menschen liegt bei 1-2 $\mu \mathrm{g}$ (RAUX et al., 2000). Bakterien haben einen geringeren Bedarf an $\mathrm{B}_{12}$.

Weltweit werden mehr als $10 \mathrm{t} \mathrm{B}_{12}$ pro Jahr produziert, wobei es wirtschaftlich z. B. als Vitaminpräparat und Kontaktlinsenpflegemittel eingesetzt wird. Die industrielle Herstellung über einen chemischen Weg ist dabei zu teuer und unrentabel, da die äußerst komplizierte Synthese ungefähr 70 verschiedene Reaktionsschritte beinhaltet. Das $\mathrm{B}_{12}$ wird deshalb nur durch biosynthetische Fermentationsprozesse mit Hilfe von 
genetisch optimierten Mikroorganismen produziert und anschließend durch Cyanolyse aus den Zellen gewonnen (MARTENS et al., 2002). Auf diesem Wege fallen große Menge an Biomasse an.

Ein natürliches System für den Export von $\mathrm{B}_{12}$ aus einer Bakterienzelle ist bislang nicht beschrieben worden. Im Rahmen dieser Arbeit sollte ein solches Transportsystem entwickelt werden. Wie bei der $\mathrm{B}_{12}$-Aufnahme in die Zelle sollte das $\mathrm{B}_{12}$ beim Export ebenfalls an ein $\mathrm{B}_{12}$-bindendes Protein gekoppelt werden, um anschließend zusammen mit diesem aus der Bakterienzelle transportiert zu werden. Als Bindeproteine wurden der menschliche Intrinsic Faktor und die $\mathrm{B}_{12}$-bindende Untereinheit der MethylmalonylCoA-Mutase (MutB) aus Propionibacterium shermanii eingesetzt. Für den Transport über die Cytoplasmamembran konnte der Signalsequenz-abhängige Tat (twin arginine translocation)-Transportweg genutzt werden, der native Enzyme mit gebundenem Cofaktor wie z. B. die Trimethylamin-N-Oxid-Reduktase (TorA) aus Escherichia coli exportiert. Für die Konstruktion des $\mathrm{B}_{12}$-Exporters wurde die Tat-Signalsequenz von TorA mit dem $\mathrm{B}_{12}$-bindenden IF bzw. MutB fusioniert. Anschließend sollten die Hybridproteine heterolog in $\mathrm{B}_{12}$-produzierenden Mikroorganismen gebildet werden mit dem Ziel, $B_{12}$ ins Periplasma der Zellen zu transportieren. 


\section{Material und Methoden}

\subsection{Organismen und Plasmide}

Die im Rahmen dieser Arbeit verwendeten Bakterienstämme sind in Tabelle 1 aufgelistet. In Tabelle 2 sind die verwendeten Klonierungsvektoren und rekombinanten Plasmide zusammengefaßt. Tabelle 3 gibt einen Überblick über die verwendeten PCR-Oligonukleotide.

\section{Tabelle 1: Organismen}

\begin{tabular}{|c|c|c|}
\hline Stamm & relevanter Geno-/ Phänotyp ${ }^{a}$ & Referenz / Herkunft \\
\hline Citrobacter freundii & Wildtyp & DSM 30040 \\
\hline Escherichia blattae & Wildtyp & DSM 4261 \\
\hline Escherichia coli BL21 (DE3) & $\begin{array}{l}\text { hsdF, gal }(\lambda \mathrm{cIts} 857 \text { ind } 1 \mathrm{Sam} 7 \mathrm{nin} 5 \\
\text { lacUV5-T7 gene1), ompTr-, lon }\end{array}$ & STUDIER \& MOFFAT, 1986 \\
\hline Escherichia coli JM109 & $\begin{array}{l}\text { recA1, endA1, gyrA96, thi-, relA1, } \\
\text { hsdR17, supE44, } \lambda-, \Delta(\text { lac-proAB), } \\
\left.\text { [F`traD36 proAB lacI } \text { lacZ }^{\prime} \mathrm{M} 15\right]\end{array}$ & $\begin{array}{l}\text { YANISCH-PERRON et al., } \\
1985\end{array}$ \\
\hline Escherichia coli & Corrinoid-abhängige Mutante & DSM 4261 \\
\hline $\begin{array}{l}\text { Salmonella typhimurium } \\
\text { TA } 100\end{array}$ & S. typhimurium his-, pKM $101\left(\mathrm{Amp}^{\mathrm{R}}\right)$ & $\begin{array}{l}\text { HELLWIG (Universität } \\
\text { Göttingen) }\end{array}$ \\
\hline $\begin{array}{l}\text { Propionibacterium } \\
\text { freudenreichii subsp. } \\
\text { shermanii }\end{array}$ & Wildtyp & DSM 4902 \\
\hline
\end{tabular}


Tabelle 2: Vektoren und rekombinante Plasmide

\begin{tabular}{|c|c|c|c|}
\hline Plasmid & $\begin{array}{l}\text { Größe } \\
\text { (kb) }\end{array}$ & relevante Merkmale & Referenz/Herkunft \\
\hline pASK-IBA3 & 3,2 & $A m p^{r}$ & IBA, Göttingen \\
\hline pBAD-GFP ${ }_{u v}$ & 5,3 & $\mathrm{Amp}^{\mathrm{r}}$ & AG BRAUS, Göttingen \\
\hline $\begin{array}{l}\mathrm{pBluescript}^{\circledR} \mathrm{S} \\
\mathrm{K}^{+}(\mathrm{pSK}+)\end{array}$ & 3,0 & Apr, lacPOZ & STRATAGENE, San Diego, USA \\
\hline pER1 & 4,8 & Tet $^{\mathrm{r}}$, sigtor $A$ & $\begin{array}{l}\text { DANIEL, } \\
\text { persönliche Mitteilung }\end{array}$ \\
\hline $\mathrm{pET} 20 \mathrm{~b}(+)$ & 3,7 & $\begin{array}{l}\text { Amp }^{\mathrm{r}} \text {, lacI, T7-lac-Promotor, pelB, } \\
\text { His }_{6} \text {-Tag, Signal-Peptidase }\end{array}$ & $\begin{array}{l}\text { Fa. CALBIOCHEM- } \\
\text { NOVABIOCHEM GmbH, } \\
\text { Schwalbach }\end{array}$ \\
\hline $\mathrm{pET} 20 \mathrm{~b}(+)$ & 3,7 & $\begin{array}{l}\text { Amp }^{\mathrm{r}} \text {, lacI, T7-lac-Promotor, pelB, } \\
\text { His }_{6} \text {-Tag, Signal-Peptidase }\end{array}$ & $\begin{array}{l}\text { Fa. CALBIOCHEM- } \\
\text { NOVABIOCHEM GmbH, } \\
\text { Schwalbach }\end{array}$ \\
\hline $\mathrm{pHIF}$ & 4,1 & $\begin{array}{l}\text { pBluesriptIIKS(-), IF cDNA } \\
\text { Sequenz }\end{array}$ & $\begin{array}{l}\text { ARNOLD (Ludwig Maximilian } \\
\text { Universität) }\end{array}$ \\
\hline pMB5 & 6,7 & $\operatorname{Tet}^{\mathrm{r}}$ & BOLM, 2000 \\
\hline pMEX2 & 6,3 & $\mathrm{Amp}^{\mathrm{r}}$, mutA, mutB, $\mathrm{pT} 7-7$ & LEADLAY \\
\hline pMPM-A4 $\Omega$ & 6,5 & $\mathrm{Amp}^{\mathrm{r}}$ & MAYER, 1995 \\
\hline pMPM-K $4 \Omega$ & 6,4 & $\begin{array}{l}\mathrm{Kan}^{\mathrm{r}}, \mathrm{Spc}, \operatorname{ara} C, \Omega \text {-interposon, } \\
\text { rrnBTer, rrfB, ParaBAD, pMB1 ori }\end{array}$ & MAYER, 1995 \\
\hline pMPM-T4 $\Omega$ & 6,8 & $\begin{array}{l}\text { Tet }^{\mathrm{r}} \text {, Spc, ara } C, \Omega \text {-interposon, } \\
\text { rrnBTer, rrfB, ParaBAD, pMB1 ori }\end{array}$ & MAYER, 1995 \\
\hline pTM1 & 5,9 & $\operatorname{Tet}^{\mathrm{r}}$ & diese Arbeit \\
\hline pTM2 & 6,7 & $\mathrm{Km}^{\mathrm{r}}$ & diese Arbeit \\
\hline pTM3 & 6,7 & $\mathrm{Amp}^{\mathrm{r}}$ & diese Arbeit \\
\hline pTM4 & 4,7 & $\mathrm{Amp}^{\mathrm{r}}$ & diese Arbeit \\
\hline pTM5 & 6,7 & $\begin{array}{l}\text { Amp }{ }^{\mathrm{r}} \text {, siehe pTM3 + zusätzlich } \\
\text { eingeführte ClaI- Schnittstelle an } \\
\text { Position } 2365 \text { des mutB-Gens }\end{array}$ & diese Arbeit \\
\hline pTM6 & 7,3 & $\begin{array}{l}\text { Amp }{ }^{\mathrm{r}} \text { siehe } \mathrm{pTM} 3+\text { zusätzlich } \\
\text { eingeführtes } g f p \text {-Gen an Position } \\
2365 \text { des mutB-Gens }\end{array}$ & diese Arbeit \\
\hline pTM7 & 5,9 & $A m p^{r}$ & diese Arbeit \\
\hline pTM8 & 5,4 & $A m p^{r}$ & diese Arbeit \\
\hline
\end{tabular}


Tabelle 3: Oligonukleotide

\begin{tabular}{|c|c|}
\hline Bezeichnung & Bemerkung/Schnittstelle \\
\hline \multirow[t]{3}{*}{ Sig1 } & 5'-GGG \\
\hline & CATCACGTCGGCG-3' \\
\hline & Klonierung sigTorA in pMPM-T4 $\Omega /$ EcoRI \\
\hline \multirow[t]{3}{*}{ Sig2r } & 5'-TAAGCCGCCGAGTTGTGCCAGAAAACGCCGACGTGAT \\
\hline & GCCTGAAAGAGAT-3' \\
\hline & Klonierung sigTorA in pMPM-T4 $\Omega$ \\
\hline \multirow[t]{3}{*}{ Sig3 } & 5'-TTTTCTGGCACAACTCGGCGGCTTAACCGTCGCCGGG \\
\hline & ATGCTGGGGCCGT-3' \\
\hline & Klonierung sigTorA in pMPM-T4 $\Omega$ \\
\hline \multirow[t]{3}{*}{$\operatorname{Sig} 4 \mathrm{r}$} & 5'-CCGCAGTCGCACGTCGCGGCGTTAACAATGACGGCCCC \\
\hline & AGCATCCCGGCG-3' \\
\hline & Klonierung sigTorA in pMPM-T4 $\Omega$ \\
\hline \multirow[t]{3}{*}{ Sig5 } & 5'-TTAACGCCGCGACGTGCGACTGCGGCGCAAGCGGCGAC \\
\hline & TGACGCTGTCTA-3’ \\
\hline & Klonierung sigTorA in pMPM-T4 $\Omega$ \\
\hline \multirow[t]{3}{*}{ Sig6r } & 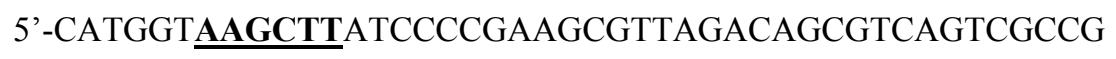 \\
\hline & CTTGCG-3' \\
\hline & 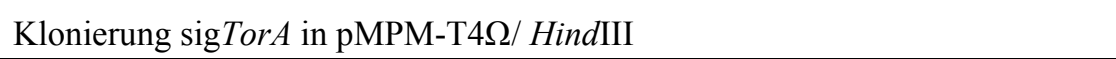 \\
\hline \multirow[t]{3}{*}{ IFMH5 } & 5'-GATGTCTAATGTATAGACAATGTCAGTACCCAGACCCAG \\
\hline & AGTTCATGCTCCGTTCCCTCA-3' \\
\hline & Klonierung des if in pER1/ Tth111I \\
\hline \multirow[t]{3}{*}{ IFMH3' } & 5'-GCGCGGAAGCTTATTAATGGTGATGGTGATGGTGGTACT \\
\hline & GTGTGAQAATTGGCTGTGATGT-3' \\
\hline & Klonierung des if in pER1/ HindIII \\
\hline \multirow[t]{2}{*}{ IF/ EcoRI } & 5'-CGTGAATTCCAGTACCCAGACCCAGAGTTCATGC-3' \\
\hline & Klonierung von if in pET20b/EcoRI \\
\hline \multirow[t]{2}{*}{ IF/ HindIIIr } & 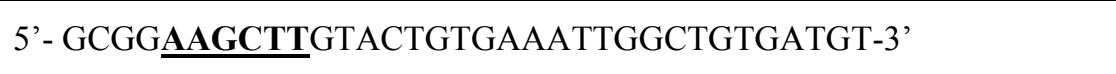 \\
\hline & Klonierung von if in pET20b/ HindIII \\
\hline \multirow[t]{3}{*}{ torA5 } & 5'-GCGTCTAGAgAACAATAACGATCTCTTTCAGGCATCACGTCGGCG \\
\hline & TTTTCTGGCACAA-3’ \\
\hline & Klonierung von sigTor $A$ und $m u t B$ in $\mathrm{pMPM}-\mathrm{T} 4 \Omega / X b a \mathrm{I}$ \\
\hline
\end{tabular}


Fortsetzung Tabelle 3

\begin{tabular}{|c|c|}
\hline Bezeichnung & Bemerkung/Schnittstelle \\
\hline \multirow[t]{3}{*}{ torA3'r } & 5'- TCAACTGAATCAAAACGGGGCAGAGTGCTAGTCGCCGCTTGCGC \\
\hline & CGCAGTCGCACGTC-3' \\
\hline & Klonierung von sigTor $A$ und $m u t B$ in pMPM-T4 $\Omega$ \\
\hline \multirow[t]{2}{*}{ f-mutB/GFP-ApaI } & 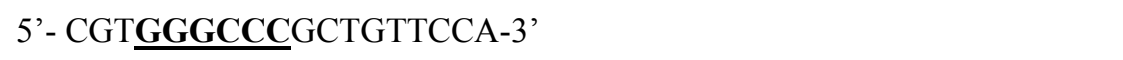 \\
\hline & Klonierung mutB und $g f p$ in pMPM-A $4 \Omega / C l a \mathrm{I}$ \\
\hline \multirow[t]{2}{*}{ r-mutB/GFP-ClaI } & 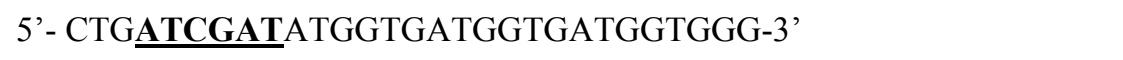 \\
\hline & Klonierung $m u t B$ und $g f p$ in $\mathrm{pMPM}-\mathrm{A} 4 \Omega / A p a \mathrm{I}$ \\
\hline \multirow[t]{2}{*}{ f-GFPuv-ClaI } & 5'-GCGATCGATATGGCTAGCAAAGGAGAAGAA-3' \\
\hline & Klonierung $m u t B$ und $g f p$ in pMPM-A $4 \Omega / C l a \mathrm{I}$ \\
\hline \multirow[t]{2}{*}{ r-GFPuv-ClaI } & 5'-CGCATCGATTCATTATTTGTAGAGCTCATC-3' \\
\hline & Klonierung $m u t B$ und $g f p$ in pMPM-A $4 \Omega / C l a \mathrm{I}$ \\
\hline \multirow[t]{2}{*}{ f-mutB/pET-NotI } & 5'-CTECGGCCGCGATGAGCACTCTGCCCCGTTTTG-3' \\
\hline & Klonierung $m u t B$ in $\mathrm{pET} 20 \mathrm{~b} /$ Not $\mathrm{I}$ \\
\hline \multirow[t]{2}{*}{ r-mutB/pET-NotI } & 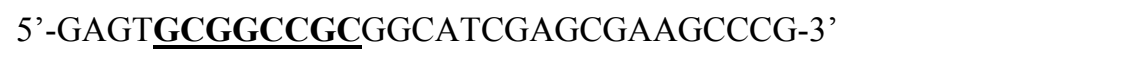 \\
\hline & Klonierung $m u t B$ in $\mathrm{pET} 20 \mathrm{~b} / \operatorname{Not} \mathrm{I}$ \\
\hline f-IBA3torA-mutB- & 5'-ATGGTAGGTCTCAAATGAACAATAACGATCTCTTTCAGGCAT-3' \\
\hline BsaI & Klonierung sigtor $A$ und $m u t B$ in pASK-IBA3, $B s a \mathrm{I}$ \\
\hline r-IBA3torA-mutB- & 5'-ATGGTAGGTCTCAGCGCTGGCATCGAGCGAAGCCCGCA-3' \\
\hline BsaI & Klonierung sigtor $A$ und $m u t B$ in pASK-IBA3, $B s a \mathrm{I}$ \\
\hline
\end{tabular}




\subsection{Nährmedien}

2.2.1 Mineralmedium mit Hefeextraktzusatz (AVERHOFF, 1988; modifiziert) für $C$. freundii und $E$. blattae

$$
\begin{aligned}
& \mathrm{K}_{2} \mathrm{HPO}_{4} \\
& \mathrm{KH}_{2} \mathrm{PO}_{4} \\
& \left(\mathrm{NH}_{4}\right)_{2} \mathrm{SO}_{4} \\
& \mathrm{MgSO}_{4} \times 7 \mathrm{H}_{2} \mathrm{O} \\
& \mathrm{Hefeextrakt} \\
& \mathrm{CoCl}_{2}(50 \mathrm{mM}) \\
& \mathrm{SL}-4 \\
& \mathrm{H}_{2} \mathrm{O}_{\text {bidest }}
\end{aligned}
$$

zusätzlich bei anaeroben Medien:

Cystein- $\mathrm{HCl}$
$14,0 \mathrm{~g}$

$6,0 \mathrm{~g}$

$3,0 \mathrm{~g}$

$0,2 \mathrm{~g}$

$0,2 \mathrm{~g}$

$85,0 \mu 1$

$1,0 \mathrm{ml}$

ad $1000 \mathrm{ml}$

$$
0,2 \mathrm{~g} / 1
$$

Der $\mathrm{pH}-$ Wert wurde auf 7,5 eingestellt.

Dem Medium wurde Glycerin oder Glucose in einer Konzentration von $100 \mathrm{mM}$ zugesetzt.

Spurenelementelösung SL-4 (PFENNIG und LIPPERT, 1966)

$\begin{array}{lrl}\text { EDTA-Na } & 5,00 & \mathrm{~g} \\ \mathrm{FeSO}_{4} \times 7 \mathrm{H}_{2} \mathrm{O} & 2,00 & \mathrm{~g} \\ \mathrm{ZnSO}_{4} \times 7 \mathrm{H}_{2} \mathrm{O} & 0,10 \mathrm{~g} \\ \mathrm{MnCl}_{2} \times 4 \mathrm{H}_{2} \mathrm{O} & 0,03 \mathrm{~g} \\ \mathrm{H}_{3} \mathrm{BO}_{4} & 0,30 \mathrm{~g} \\ \mathrm{CoCl}_{2} \times 6 \mathrm{H}_{2} \mathrm{O} & 0,20 \mathrm{~g} \\ \mathrm{CuCl}_{2} \times 2 \mathrm{H}_{2} \mathrm{O} & 0,01 \mathrm{~g} \\ \mathrm{NiCl}_{2} \times 6 \mathrm{H}_{2} \mathrm{O} & 0,02 \mathrm{~g} \\ \mathrm{NaMoO}_{4} \times 2 \mathrm{H}_{2} \mathrm{O} & 0,03 \mathrm{~g} \\ \mathrm{H}_{2} \mathrm{O}_{\text {bidest }} & \mathrm{ad} 1000 \mathrm{ml}\end{array}$

Der pH-Wert wurde auf 6,7 eingestellt und die Lösung lichtgeschützt bei $4{ }^{\circ} \mathrm{C}$ gelagert. 
Zusatz von Aminosäuren:

\begin{tabular}{|c|c|c|}
\hline Aminosäuren & Stammlösung [mg/ ml] & Endkonzentration $[\mu \mathrm{g} / \mathrm{ml}]$ \\
\hline DL-Alanin & 50 & 100 \\
\hline L-Arginine- $\mathrm{HCl}$ & 11 & 22 \\
\hline L-Asparagin & 10 & 100 \\
\hline L-Aspartat & 10 & 100 \\
\hline L-Cystein-HCl & 11 & 22 \\
\hline Glycin & 50 & 100 \\
\hline L-Glutaminsäure & 10 & 100 \\
\hline L-Glutamin & 20 & 100 \\
\hline L-Histidin-HCl & 11 & 22 \\
\hline L-Isoleucin & 10 & 20 \\
\hline L-Leucin & 10 & 20 \\
\hline L-Lysin-HCl & 44 & 88 \\
\hline DL-Methionen & 10 & 20 \\
\hline L-Phenylalanin & $10($ in $0,001 \mathrm{~N} \mathrm{NaOH})$ & 20 \\
\hline L-Prolin & 15 & 30 \\
\hline DL-Serin & 10 & 100 \\
\hline DL-Threonin & 40 & 80 \\
\hline L-Tryptophan & 4 & 20 \\
\hline L-Tyrosin & 2 (in $0,01 \mathrm{~N} \mathrm{NaOH})$ & 20 \\
\hline DL-Valin & 20 & 40 \\
\hline Adenin & $2($ in $0,03 \mathrm{~N} \mathrm{NaOH})$ & 40 \\
\hline Thymidin & 10 & 4 \\
\hline Thymin & 5 & 2 \\
\hline Uracil & 2 & 40 \\
\hline
\end{tabular}

Die Stammlösungen, falls nicht anders angegeben, wurden in $\mathrm{H}_{2} \mathrm{O}_{\text {bidest }}$ angesetzt, sterilfiltriert und bei $4{ }^{\circ} \mathrm{C}$ gelagert. 
2.2.2 Hefe-Pepton-Medium für C. freundii (HOLDEMAN et al., 1977)

Pepton aus Casein

$5,00 \mathrm{~g}$

Trypton

$3,00 \mathrm{~g}$

Hefeextrakt

$10,0 \mathrm{~g}$

Salzlösung

$40,0 \mathrm{ml}$

$\mathrm{H}_{2} \mathrm{O}_{\text {bidest }}$ ad $1000 \mathrm{ml}$

$\mathrm{pH}$

7,0

Salzlösung:

$\mathrm{CaCl}_{2} \times 2 \mathrm{H}_{2} \mathrm{O}$

$0,2 \mathrm{~g}$

$\mathrm{MgSO}_{4} \times 7 \mathrm{H}_{2} \mathrm{O}$

$0,2 \mathrm{~g}$

$\mathrm{KH}_{2} \mathrm{PO}_{4}$

$1,0 \mathrm{~g}$

$\mathrm{K}_{2} \mathrm{HPO}_{4}$

$1,0 \mathrm{~g}$

$\mathrm{NaHCO}_{3}$

$10,0 \mathrm{~g}$

$\mathrm{NaCl}$

$2,0 \mathrm{~g}$

$\mathrm{H}_{2} \mathrm{O}_{\text {bidest }}$

ad $1000 \mathrm{ml}$

Die Lösung wurde bei $4^{\circ} \mathrm{C}$ gelagert.

\subsubsection{LB (Luria-Bertani)-Medium (SAMBROOK et al., 1989)}

Trypton

$10 \mathrm{~g}$

Hefeextrakt

$5 \mathrm{~g}$

$\mathrm{NaCl}$

$10 \mathrm{~g}$

$\mathrm{H}_{2} \mathrm{O}_{\text {bidest }}$ ad $1000 \mathrm{ml}$

Zur Herstellung von Agarplatten wurde 1,5 \% (w/v) Agar zugefügt.

\subsubsection{Lysin-Decarboxylase-Medium (EKLUND und LANKFORD, 1967)}

Pepton

$5,00 \mathrm{~g}$

Hefeextrakt

$3,00 \mathrm{~g}$

Glucose

$1,00 \mathrm{~g}$

L-Lysin

$5,00 \mathrm{~g}$

Bromkresolpurpur

$0,02 \mathrm{~g}$

$\mathrm{H}_{2} \mathrm{O}_{\text {bidest }}$

ad $1000 \mathrm{ml}$

$\mathrm{pH}$

6,5 


\subsubsection{M9-Minimalmedium (SAMBROOK et al., 1989, modifiziert)}

$\begin{array}{lrl}\mathrm{Na}_{2} \mathrm{HPO}_{4} \times 2 \mathrm{H}_{2} \mathrm{O} & 6 \mathrm{~g} \\ \mathrm{KH}_{2} \mathrm{PO}_{4} & 3 \mathrm{~g} \\ \mathrm{NH}_{4} \mathrm{Cl} & 1 \mathrm{~g} \\ \mathrm{H}_{2} \mathrm{O}_{\text {bidest }} & \text { ad } 972 \mathrm{ml} \\ \mathrm{pH} & 7,4\end{array}$

Für M9-Platten mußten $15 \mathrm{~g}$ Agar und Salze getrennt voneinander autoklaviert und erst nach dem Autoklavieren zusammengegeben werden.

Nach dem Autoklavieren wurden folgende Lösungen steril zugesetzt, die durch Autoklavieren oder im Falle der Thiaminlösung durch Sterilfiltration sterilisiert worden waren:

$\begin{array}{lr}20 \%(\mathrm{w} / \mathrm{v}) \text { Glucoselösung } & 25 \mathrm{ml} \\ 0,1 \mathrm{M} \mathrm{CaCl}_{2} & 1 \mathrm{ml} \\ 1,0 \mathrm{M} \mathrm{MgSO}_{4} & 1 \mathrm{ml} \\ 1 \mathrm{mg} / \mathrm{ml} \mathrm{Thiamin}-\mathrm{HCl} & 1 \mathrm{ml}\end{array}$

2.2.6 Minimal-Aminosäure-Medium für E. coli DSM 4261 (KRZYCKI and ZEIKUS, 1980, modifiziert)

$\begin{array}{lrl}\mathrm{K}_{2} \mathrm{HPO}_{4} & 14,0 \mathrm{~g} \\ \mathrm{KH}_{2} \mathrm{PO}_{4} & 6,0 \mathrm{~g} \\ \left(\mathrm{NH}_{4}\right)_{2} \mathrm{SO}_{4} & 2,0 \mathrm{~g} \\ \mathrm{MgSO}_{4} \times 7 \mathrm{H}_{2} \mathrm{O} & 0,2 \mathrm{~g} \\ \mathrm{Na}_{2}-\mathrm{Citrat}_{2} 2 \mathrm{H}_{2} \mathrm{O} & 1,0 \mathrm{~g} \\ \text { L-Asparagin } & 0,8 \mathrm{~g} \\ \text { L-Arginin } & 0,2 \mathrm{~g} \\ \text { L-Glutamat } & 0,2 \mathrm{~g} \\ \text { Glycin } & 0,2 \mathrm{~g} \\ \text { L-Tryptophan } & 0,2 \mathrm{~g} \\ \text { L-Prolin } & 0,2 \mathrm{~g} \\ \text { L-Histidin } & 0,2 \mathrm{~g} \\ \text { Vitamin } \mathrm{B}_{12} & 40,0 \mathrm{\mu g} \\ \mathrm{H}_{2} \mathrm{O}_{\text {bidest }} & \text { ad } 1000 \mathrm{ml} \\ \text { pH } & 6,8-7,2 & \end{array}$

Kurz vor dem Beimpfen wurde dem Medium noch 50 mM Glucose zugefügt. 
2.2.7 Mineralagar für E. coli DSM 4261 (KRZYCKI and ZEIKUS, 1980, modifiziert)

$\begin{array}{lrl}\mathrm{K}_{2} \mathrm{HPO}_{4} & 7,0 \mathrm{~g} \\ \mathrm{KH}_{2} \mathrm{PO}_{4} & 3,0 \mathrm{~g} \\ \left(\mathrm{NH}_{4}\right)_{2} \mathrm{SO}_{4} & 1,0 \mathrm{~g} \\ \mathrm{MgSO}_{4} \times 7 \mathrm{H}_{2} \mathrm{O} & 0,1 \mathrm{~g} \\ \mathrm{Na}_{2}-\mathrm{Citrat}_{2} \mathrm{H}_{2} \mathrm{O} & 3,0 \mathrm{~g} \\ \text { Agar (Oxoid Agar Bacteriological No.1) } & 15,0 \mathrm{~g} \\ \mathrm{H}_{2} \mathrm{O}_{\text {bidest }} & \text { ad } 1000 \mathrm{ml} \\ \mathrm{pH} & 6,8-7,2\end{array}$

Nach dem Autoklavieren wurde der Agar unter ständigem Rühren auf 50-60 ${ }^{\circ} \mathrm{C}$ abgekühlt und 0,2 g/l Triphenyltetrazoliumchlorid (sterilfiltriert), $50 \mathrm{mM}$ Glucose (autoklaviert) und E. coli DSM 4261 (siehe Tabelle 1) dazugegeben.

\subsubsection{SOB-Medium (HANAHAN et al., 1983)}

Trypton

Hefeextrakt

$\mathrm{NaCl}$

KCL

$\mathrm{MgCl}_{2}$

$\mathrm{MgSO}_{4}$

$$
\begin{array}{rl}
2,0 & \%(\mathrm{w} / \mathrm{v}) \\
0,5 & \%(\mathrm{w} / \mathrm{v}) \\
10 & \mathrm{mM} \\
2,5 & \mathrm{mM} \\
10 \mathrm{mM} \\
10 \mathrm{mM}
\end{array}
$$

Die Magnesiumsalze wurden aus getrennt autoklavierten, jeweils 1-molaren Stammlösungen zugegeben. 
2.2.9 Synthetisches Medium für Propionibacterium freudenreichii subsp. shermanii (SEIFERT, pers. Mitteilung)

$\begin{array}{lrl}\mathrm{K}_{2} \mathrm{HPO}_{4} & 2,0 \mathrm{~g} \\ \mathrm{KH}_{2} \mathrm{PO}_{4} & 0,2 \mathrm{~g} \\ \left(\mathrm{NH}_{4}\right)_{2} \mathrm{HPO}_{4} & 4,2 \mathrm{~g} \\ \mathrm{Na}-\mathrm{Lactat} & 10,0 \mathrm{~g} \\ \text { Na-Dithionit } & 0,1 \mathrm{~g} \\ \mathrm{~K}-P \text { antothenat } & 40,0 \mathrm{mg} \\ \text { Hefeextrakt } & 4,0 \mathrm{~g} \\ \mathrm{MgCl}_{2} \times 6 \mathrm{H}_{2} \mathrm{O} & 0,2 \mathrm{~g} \\ \mathrm{FeSO}_{4} \times 7 \mathrm{H}_{2} \mathrm{O} & 40,0 \mathrm{mg} \\ \mathrm{CoSO}_{4} \times 7 \mathrm{H}_{2} \mathrm{O} & 12,0 \mathrm{mg} \\ \mathrm{Glucose} & 10,0 \mathrm{~g} \\ \mathrm{H}_{2} \mathrm{O}_{\text {bidest }} & \text { ad } 1000 \mathrm{ml} \\ \text { pH } & 6,8 & \end{array}$

Die Glucose, $\mathrm{MgCl}_{2}$ und $\mathrm{FeSO}_{4}$ wurden getrennt autoklaviert und anschließend beigefügt.

\subsection{Pufferlösungen}

\subsubsection{Kaliumphosphat-Puffer}

$\underline{0,1 \mathrm{M}:}$

$\mathrm{K}_{2} \mathrm{HPO}_{4}, \mathrm{pH} 4,0$

$13,6 \mathrm{~g}$

$\mathrm{KH}_{2} \mathrm{PO}_{4} \times 3 \mathrm{H}_{2} \mathrm{O}, \mathrm{pH} 9,0$

$22,8 \mathrm{~g}$

$\mathrm{H}_{2} \mathrm{O}_{\text {bidest }}$

ad $1000 \mathrm{ml}$

$\mathrm{pH}$

7,0 


\subsubsection{SSC-Puffer (10-fach)}

SSC-Puffer:

$\begin{array}{ll}\mathrm{NaCl} & 1,5 \mathrm{M} \\ \mathrm{Na}_{3} \text {-Citrat } & 0,15 \mathrm{M}\end{array}$

\subsubsection{TBS-Puffer (10-fach)}

$\begin{array}{ll}\mathrm{NaCl} & 1,5 \mathrm{M} \\ \text { Tris- } \mathrm{HCl} & 0,1 \mathrm{M} \\ \mathrm{pH} & 7,5\end{array}$

\subsubsection{TBST-Puffer (5-fach)}

$\mathrm{NaCl}$

$$
1,5 \mathrm{M}
$$

Tris- $\mathrm{HCl}$

$0,1 \mathrm{M}$

Tween-20

$0,25 \%(\mathrm{v} / \mathrm{v})$

$\mathrm{pH}$

7,5

\section{$2.4 \quad$ Feste Medien}

Zur Herstellung fester Medien wurde dem Medium 1,5 \% Agar zugesetzt.

\subsubsection{Medienzusätze}

Antibiotika-Stammlösungen sowie IPTG und X-Gal wurden dem autoklavierten und auf mindestens $50{ }^{\circ} \mathrm{C}$ abgekühlten Medium zugesetzt.

Tabelle 4: Medienzusätze

\begin{tabular}{llc}
\hline Medienzusatz & Stammlösung & Endkonzentration \\
\hline Anhydrotetracyclin & $2 \mathrm{mg} / \mathrm{ml}$ in $\mathrm{H}_{2} \mathrm{O}_{\text {bidest }}$ & $0,1 \mu \mathrm{l} / \mathrm{ml}$ \\
Ampicillin & $100 \mathrm{mg} / \mathrm{ml}$ in $50 \%$ Ethanol & $100 \mu \mathrm{g} / \mathrm{ml}$ \\
Chloramphenicol & $20 \mathrm{mg} / \mathrm{ml}$ in Ethanol $(96 \%[\mathrm{v} / \mathrm{v}])$ & $20 \mu \mathrm{g} / \mathrm{ml}$ \\
Kanamycin & $100 \mathrm{mg} / \mathrm{ml} \mathrm{in} \mathrm{H}_{2} \mathrm{O}_{\text {bidest }}$ & $70 \mu \mathrm{g} / \mathrm{ml}$ \\
Tetracyclin & $10 \mathrm{mg} / \mathrm{ml} \mathrm{in} \mathrm{H}_{2} \mathrm{O}_{\text {bidest }}$ & $10 \mu \mathrm{g} / \mathrm{ml}$ \\
IPTG & $100 \mathrm{mg} / \mathrm{ml} \mathrm{in} \mathrm{H}_{2} \mathrm{O}_{\text {bidest }}$ & $40 \mu \mathrm{g} / \mathrm{ml}$ \\
X-Gal & $40 \mathrm{mg} / \mathrm{ml}$ in N,N-Dimethylformamid & $40 \mu \mathrm{g} / \mathrm{ml}$
\end{tabular}

Die Lösung wurde bei $-20^{\circ} \mathrm{C}$ gelagert. 


\section{$2.5 \quad$ Zellanzucht}

\subsubsection{Aerobe Anzucht}

Die areobe Anzucht erfolgte in Reagenzgläsern oder Erlenmeyerkolben. Die Kulturen wurden zur Inkubation wahlweise bei $30{ }^{\circ} \mathrm{C}$ oder $37^{\circ} \mathrm{C}$ geschüttelt. Angeimpft wurde 1-5 \%ig. Zur Überprüfung des Wachstums der Flüssigkulturen wurden regelmäßig Proben entnommen. Die Zunahme der optischen Dichte wurde bei einer Wellenlänge von $600 \mathrm{~nm}$ photometrisch verfolgt (siehe 2.5.3).

\subsubsection{Anaerobe Anzucht}

Anaerobe Kulturen wurden mit einem $10 \%$ igen (v/v) Inokulum aus einer Stammkultur bzw. Vorkultur beimpft oder aber mit einer Einzelkolonie von einer Agarplatte. Im Falle der Einzelkolonie wurde diese zunächst in $100 \mu \mathrm{KP}$-Puffer (siehe 2.3.1) gelöst. Die Inkubation erfolgt bei $30{ }^{\circ} \mathrm{C}$ oder $37^{\circ} \mathrm{C}$. Für Kulturen mit einem Volumen bis zu $10 \mathrm{ml}$ wurden Hungate-Röhrchen (Anaerobe Test Tubes, Hungate Type, $16 \times 125$ mm, Fa. Bellco Glass Inc., Vineland, New Jersey, USA) und für Anzuchten bis 50 ml 125-mlSerumflaschen („Hypovials“, Fa. Pierce, Rockford, England) verwendet. Bei einem Kulturvolumen von bis zu $500 \mathrm{ml}$ fanden 1-1-Serumflaschen (Fa. Müller und Krempel AG, Bülach, Schweiz) Verwendung. Für das Überimpfen wurden sterile Einwegspritzen benutzt.

\subsubsection{Messung der optischen Dichte}

Die optische Dichte von Bakterienkulturen $\left(\mathrm{OD}_{600}\right)$ wurde in $1 \mathrm{ml}$ Plastikküvetten mit einer Schichtdicke von $1 \mathrm{~cm}$ bei $600 \mathrm{~nm}$ in einem UV-VIS Spektrophotometer V-550 (Fa. Jasco, Jena) verfolgt. Als Nullwerte diente unbeimpftes Medium. Bei einer $\mathrm{OD}_{600}$ größer 0,3 wurden entsprechende Verdünnungen mit Medium hergestellt.

\subsubsection{Bestimmung des pH-Wertes}

Der pH-Wert wurde mit einem WTW pH-Meter pH 526 (Fa. WTW GmbH, Weilheim) mit einer Glas-Calomel-Elektrode (Fa. Cahn-Ingold, Frankfurt) bestimmt. Vor den Messungen wurde das Gerät für den entsprechenden Meßbereich mit Eichlösungen ( $\mathrm{pH}$ 4,0 und $\mathrm{pH}$ 7,0 der Fa. Riedel de Haen AG, Hannover) geeicht. 


\subsubsection{Reinheitskontrolle}

Die Reinheit der Bakterienkulturen wurden im Phasenkontrastmikroskop (Fa. Carl Zeiss, Oberkochen) anhand ihrer Zellmorphologie überprüft. Zusätzlich war die Koloniemorphologie nach Vereinzelungsausstrichen ein entscheidendes Kriterium für den Nachweis einer Reinkultur.

C. freundii wurde zusätzlich in Lysin-Decarboxylase Medium (siehe 2.2.4) angezogen Dadurch ist eine Unterscheidung zu den meisten anderen Enterobakterien möglich, die ebenfalls anaerob mit Glycerin als einziger Energie- und Kohlenstoffquelle wachsen können. Diese besitzen im Gegensatz zu C. freundii eine Lysin-Decarboxylase. Beim aeroben Wachstum können diese Enterobakterien durch die Lysin-Decaboxylase das L-Lysin zum basischen Amin-1,5-Diaminopentan umsetzten. Beim Wachstum in Lysin-Decarboxylase Medium färbt sich das Medium dadurch purpur. Die Anzucht von C. freundii in demselben Medium ruft eine Ansäuerung des Mediums hervor, was sich durch eine gelbe Farbreaktion äußert.

\subsubsection{Stammhaltung}

Zur Stammhaltung wurden Kulturen möglichst auf selektiven Nährmedien angezogen. Von diesen Übernachtkulturen wurde $850 \mu 1$ mit $150 \mu 1$ sterilem 87 \%igem Glycerin versetzt, in flüssigem Stichstoff eingefroren und bei $-70{ }^{\circ} \mathrm{C}$ gelagert.

Zur kurzfristigen Stammhaltung wurden die Stämme in $5 \mathrm{ml}$ Flüssigkulturen oder auf Agarplatten bei $-4{ }^{\circ} \mathrm{C}$ gelagert und mindestens alle vier Wochen überimpft.

\subsection{Standardtechniken für das Arbeiten mit DNA}

\subsubsection{Vorbehandlung von Geräten und Lösungen}

Zur Inaktivierung von Nukleasen wurden alle hitzestabilen Geräte und Lösungen für 20 min bei $120{ }^{\circ} \mathrm{C}$ autoklaviert. Hitzelabile Gerät wurden mit $70 \%$ igem Ethanol (v/v) gespült und hitzeempfindliche Lösungen sterilfiltriert (Porengröße 0,2 $\mu \mathrm{m}$, Schleicher und Schüll, Dassel). 


\subsubsection{Isolierung von Plasmid-DNA}

\subsubsection{Schnellpräparation von Plasmid-DNA (HOLMES \& QUICKLEY, 1981; RIGGS \& McLACHLAN, 1986)}

E. coli wurde in $5 \mathrm{ml}$ LB-Medium mit entsprechenden Antibiotikum über Nacht bei $30{ }^{\circ} \mathrm{C}$ oder $37{ }^{\circ} \mathrm{C}$ angezogen, $3 \mathrm{ml}$ des Kulturvolumens in sterile E-Cups überführt, abzentrifugiert (8000 Upm, 3 min; Biofuge 15, Fa. Heraeus Instruments GmbH, Osterode) und das resultierende Pellet in je $350 \mu$ STET-Puffer und $35 \mu$ l LysozymLösung resuspendiert.

\section{STET-Puffer:}

$\begin{array}{lrrl}\mathrm{NaCl} & 100 \mathrm{mM} & 5,8 \mathrm{~g} \\ \text { Tris/ } \mathrm{HCl}(\mathrm{pH} 8,0) & 10 \mathrm{mM} & 121,0 \mathrm{mg} \\ \text { EDTA }(\mathrm{pH} 8,0) & 1 \mathrm{mM} & 29,2 \mathrm{mg} \\ \text { Triton X-100 } & 5 \% & 5,0 \mathrm{ml} \\ \mathrm{H}_{2} \mathrm{O}_{\text {bidest }} & & \mathrm{ad} \mathrm{100} \mathrm{ml}\end{array}$

Lysozym-Lösung:

$10 \mathrm{mg}$ Lysozym/ml $10 \mathrm{mM}$ TE-Puffer $\mathrm{pH}$ 8,0

Es folgte eine Inkubation des Ansatzes für $50 \mathrm{sec}$ bei $100{ }^{\circ} \mathrm{C}$, an die sich ein weiterer Zentrifugationsschritt (14000 Upm, RT, $10 \mathrm{~min})$ anschloss. Während diesem sedimentierten die Proteine und Zelltrümmer, die daraufhin mit einem sterilen Zahnstocher entfernt werden konnten. Die Plasmid-DNA wurden durch Zugabe von $40 \mu \mathrm{l}$ Na-Acetat $(2,5 \mathrm{M} ; \mathrm{pH}$ 5,2) und $420 \mu \mathrm{l}$ Isopropanol zum Überstand sowie fünfminütiger Inkubation bei RT gefällt. Es folgte ein erneuter Zentrifugationschritt (14000 Upm, 5 min) und ein Waschen des Pellets mit $1 \mathrm{ml}$ eiskaltem $70 \%$ iger (v/v) Ethanol. Nachdem das Pellet getrocknet worden war (10-15 min bei RT) konnte es abschließend in $50 \mu \mathrm{l}$ TE-Puffer mit RNase (20 $\mu \mathrm{g}$ RNase/ml TE-Puffer) oder in sterilem Wasser aufgenommen werden.

\subsubsection{Schnelle Plasmid-Isolierung aus E. coli (,Cracking6)}

Diese Methode bietet die Möglichkeit zur schnellen Überprüfung von E. coliTransformanden, deren Plasmide durch Agarose-Gelelektrophorese hinsichtlich ihrer Größe charakterisiert werden sollten. Aufgrund des geringen Reinheitsgrades eignen sich die nach diesem Protokoll isolierten Plasmide nicht zur Weitbeerarbeitung.

Von einer frisch gewachsenen Nährbodenplatte wurde eine Kolonie (Durchmesser mindestens $1 \mathrm{~mm}$ ) mit einer sterilen gelben Pipettenspitze abgenommen und in $50 \mu 1$ $10 \mathrm{mM}$ EDTA pH 8,0 resuspendiert. Ein geringer Teil dieser Resuspensionslösung 
wurde zur erneuten Anzucht auf eine Selektivplatte gegeben, der Rest mit $25 \mu 1$ frisch angesetztem Cracking-Puffer versetzt und für $5 \mathrm{~min}$ bei $70{ }^{\circ} \mathrm{C}$ inkubiert. Nach Abkühlung des Ansatzes auf Eis wurde 1,5 $\mu 14 \mathrm{M} \mathrm{KCl}$ und 0,5 $\mu 10,4 \%$ ige (w/v) Bromphenolblaulösung zugesetzt und für weitere 5 min auf Eis inkubiert. Nach einer Zentrifugation (10 min, $15000 \mathrm{rpm}, 4{ }^{\circ} \mathrm{C}$ ). wurden 15-20 $\mu \mathrm{l}$ des Überstandes zur Überprüfung direkt für die Agarose-Gelelektrophorese eingesetzt.

„Cracking-Puffer":

$\begin{array}{lr}2 \mathrm{~N} \mathrm{NaOH} & 100 \mu \mathrm{l} \\ 10 \% \mathrm{SDS} & 50 \mu \mathrm{l} \\ \text { Sucrose } & 200 \mathrm{mg} \\ \mathrm{H}_{2} \mathrm{O}_{\text {bidest }} & \text { ad } 1 \mathrm{ml}\end{array}$

\subsubsection{3 „Präparative Plasmidisolierung mit dem Wizard Purification Kit““}

Für die Sequenzierung und Klonierung ist ein hoher Reinheitsgrad der verwendeten DNA erforderlich. Der Einsatz des „Wizard DNA-Purification Kits“ für die Isolierung der Plasmid-DNA konnte dies gewährleisten. Die verwendeten Lösungen entstammten dem gekauften Kit.

Zellen einer $3 \mathrm{ml}$ Übernachtkultur wurden in sterile E-Cups überführt, abzentrifugiert (8000 Upm, 8 min; Biofuge 15, Fa. Heraeus Instruments $\mathrm{GmbH}$, Osterode) und das Zellpellet in $200 \mu \mathrm{l}$ „Cell Resuspension Solution“ aufgenommen. Die Zugabe von $200 \mu 1$ „Cell Lysis Solution“ und anschließendes Schwenken des Ansatzes bis dieser seine Trübung verlor, bewirkte die Lyse der Zellen. Die Ausfällung der Proteine erfolgte durch Zugabe von $200 \mu 1$ „Neutralisation Solution“ und erneutem Umschwenken. Nach Zentrifugation (12000 Upm, 5 min) wurde der Überstand mit $1 \mathrm{ml}$ „DNA Purification Resin“ versetzt, gemischt und auf eine Minisäule gegeben, die anschließend mit $2 \mathrm{ml}$ „Wash Solution“ gewaschen wurde. Die Plasmid-DNA wurde

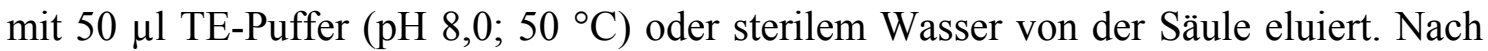
einminütiger Inkubation bei RT folgte ein letzter Zentrifugationsschritt (12000 Upm, $20 \mathrm{sec}$ ) und die Lagerung der DNA bei $4{ }^{\circ} \mathrm{C}$ oder $-20{ }^{\circ} \mathrm{C}$.

\subsubsection{Reinigung und Konzentrierung von Nukleinsäuren}

\subsubsection{Fällung von DNA}

Die Entsalzung oder Konzentrierung von DNA erfolgte durch eine Fällung mit 1 Vol. Ammoniumacetat (7 M), um den Gehalt an monovalenten Kationen zu erhöhen. Durch Zugabe von 2-3 Vol. 96 \%igem Ethanol (v/v) oder 0,8 Vol Isopropanol wurde die DNA präzipitiert und nach Durchmischung entweder für 30 min bei $-20{ }^{\circ} \mathrm{C}$ (Ethanol-Fällung) 
oder für $15 \mathrm{~min}$ bei $4{ }^{\circ} \mathrm{C}$ (Isopropanol-Fällung) inkubiert. Nach anschließender Zentrifugation (15000 Upm, $4{ }^{\circ} \mathrm{C}$ oder RT) zur Sedimentierung der DNA wurde das Pellet zweimal mit eiskaltem 70 \%igen Ethanol (v/v) gewaschen, unter Vakuum getrocknet und in $\mathrm{H}_{2} \mathrm{O}_{\text {bidest }}$ oder TE-Puffer $(\mathrm{pH} \mathrm{8,0)}$ aufgenommen.

\subsubsection{Mikrodialyse von Nukleinsäuren}

Für einige Methoden (z.B. Verdau mit Restriktionsenzymen, Ligationsansätze) führte die Entfernung von störenden niedermolekularen Substanzen wie z.B. Salzen aus DNALösungen zur Erzielung besserer Ergebnisse. Hierfür wurden vorsichtig 20-50 $\mu 1 \mathrm{der}$ DNA-Lösung auf sterile Membranfilter (Porengröße 0,025 $\mu \mathrm{m}$, Fa. Millipore, Eschborn) pipettiert und gegen steriles Wasser dialysiert. Die Membranfilter waren zuvor mit ihrer glänzenden Seite nach oben auf die Wasseroberfläche gelegt worden. Nach einstündiger Dialyse konnte die DNA- Lösung abgenommen werden.

\subsubsection{Konzentrationsbestimmung von DNA}

Die Konzentration von DNA-Lösungen wurde photometrisch durch Messung der Absorption bei einer Wellenlänge von $260 \mathrm{~nm}$ in $1 \mathrm{ml}$ Quarzküvetten der Schichtdicke von $1 \mathrm{~cm}$ bestimmt (Uvikon 810 Photometer, Fa. Kontron AG, Zürich, Schweiz). Die Einstellung des Nullwertes geschah mit derjenigen Lösung, in der auch die DNA aufgenommen worden war.

Folgende Konzentrationen wurden für eine OD $_{260 \mathrm{~nm}}$ von 1 angenommen (SAMBROCK et al., 1989):

doppelsträngige DNA $50 \mu \mathrm{g} / \mathrm{ml}$

einzelsträngige DNA $40 \mu \mathrm{g} / \mathrm{ml}$

Oligonukleotide $\quad 31 \mu \mathrm{g} / \mathrm{ml}$

Zusätzlich wurde noch die Reinheit der DNA durch Absorption bei $280 \mathrm{~nm}$ überprüft. Das Verhältnis von $\mathrm{OD}_{260 \mathrm{~nm}} \mathrm{zu} \mathrm{OD}_{280 \mathrm{~nm}}$ sollte bei reinen DNA- Lösungen 1,8 betragen, geringere Werte weisen auf die Verunreinigungen durch Proteine hin.

Eine weitere Beurteilung der Größe und Reinheit von DNA- Lösungen konnte anhand ihrer Banden im Agarosegel geschehen.

\subsubsection{Reinigung von DNA mit dem „Qiaquick Gelextraction-Kit“"}

Die Methode beruht auf dem Prinzip der reversiblen Bindung von DNA an eine SilicaMembran in Gegenwart von hohen Salzkonzentrationen. Der Kit kann sowohl zur Isolierung von DNA aus Agarosegelen, als auch zur Reinigung aus Verdauansätzen eingesetzt werden. Die Aufreinigung erfolgte mit den Lösungen und nach den im Herstellerprotokoll beschriebenen Arbeitsschritten aus dem kommerziell erhältlichen 
Kit. Die DNA wurde mit $\mathrm{H}_{2} \mathrm{O}_{\text {bidest }}$ eluiert und bis zur weiteren Verwendung bei $-20^{\circ} \mathrm{C}$ verwahrt.

\subsubsection{Reinigung von PCR-Produkten}

Für die Reinigung von PCR-Produkten kam der „Qiaquick PCR Purification“-Kit (Fa. Qiagen $\mathrm{GmbH}$, Hilden) zum Einsatz. Auch bei dieser Methode wird die DNA bei hohen Salzkonzentrationen reversibel an eine Silica-Membran gebunden. Bei der Durchführung wurde nach Anweisung des Herstellers verfahren. Zur Elution der DNA wurde steriles $\mathrm{H}_{2} \mathrm{O}$ genommen und die gereinigte DNA anschließend bei $4{ }^{\circ} \mathrm{C}$ oder $-20{ }^{\circ} \mathrm{C}$ gelagert.

\subsubsection{Gelfiltration von DNA-Lösungen}

Die Abtrennung niedermolekularer Bestandteile, wie z.B einzelner Nukleotide von DNA-Fragmenten, erfolgte durch eine Gelfiltration mit NAP-5-Säulen (Fa. Pharmacia LKB GmbH, Freiburg). Die Säulen wurden mit $10 \mathrm{ml} \mathrm{H}_{2} \mathrm{O}_{\text {bidest }}$ äquilibriert. Danach wurde $0,5 \mathrm{ml}$ DNA-Lösung aufgetragen und mit 1,0 $\mathrm{ml} \mathrm{H}_{2} \mathrm{O}_{\text {bidest }}$ eluiert.

\subsection{Gelelektrophorese von Nukleinsäuren}

\subsubsection{Agarosegel-Elektrophorese}

Elektrophoretische Auftrennungen von DNA-Lösungen erfolgte in Agarosegelen aus 0,8-1,0 \% (w/v) Agarose in 1 x TAE-Puffer, der auch als Elektrophoresepuffer diente.

Sowohl zur analytischen als auch zur präparativen Auftrennung von DNA-Lösungen wurden horizontale Gelkammern mit Gelen der Maße (Länge x Breite) $11 \mathrm{~cm}$ x 6,5 cm oder $14 \mathrm{~cm}$ x $12 \mathrm{~cm}$ eingesetzt. Vor dem Auftragen wurden die DNA-Proben zur Beschwerung mit 0,2 Vol. Stop-Mix versetzt. Die angelegte Spannung betrug 60-80 V und die Laufzeit 1-1,5 h. Zur späteren Größenbestimmung wurden zusätzlich noch $4 \mu \mathrm{l}$ DNA-Längenstandard aufgetragen (siehe 2.7.3)

50 x TAE-Puffer (SAMBROOK et al., 1989):

$\begin{array}{lrrl}\text { Tris } & 2 \mathrm{M} & 242 \mathrm{~g} \\ \text { EDTA }(0,5 \mathrm{M}, \mathrm{pH} 8,0) & 50 \mathrm{mM} & 100 \mathrm{ml} \\ \text { Essigsäure (konz.) } & 1 \mathrm{M} & 57 \mathrm{Ml} \\ \mathrm{H}_{2} \mathrm{O}_{\text {bidest }} & & \mathrm{ad} 1000 \mathrm{ml} \\ \mathrm{pH} & & 8,5\end{array}$


Stop-Mix (SAMBROOK et al., 1989):

$\begin{array}{lrr}\text { EDTA } & 1 \mathrm{mM} & 19 \mathrm{mg} \\ \text { Harnstoff } & 7 \mathrm{M} & 21 \mathrm{~g} \\ \text { Saccharose } & 50 \%(\mathrm{w} / \mathrm{v}) & 25 \mathrm{~g} \\ \text { Bromphenolblau } & 0,1 \%(\mathrm{w} / \mathrm{v}) & 50 \mathrm{mg} \\ \mathrm{H}_{2} \mathrm{O}_{\text {bidest }} & & \text { ad } 50 \mathrm{ml} \\ \mathrm{pH} & & 7,0\end{array}$

Aliquots der autoklavierten Lösungen wurden bei $-20{ }^{\circ} \mathrm{C}$ gelagert.

\subsubsection{Ethidiumbromid-Färbung und Fotografie von Agarosegelen}

Zur Anfärbung der DNA wurden die Gele nach der Elektrophorese in einer Ethidiumbromid-Lösung $\left(1 \mu \mathrm{g} / \mathrm{ml} \mathrm{H}_{2} \mathrm{O}\right)$ gefärbt und anschließend kurz gewässert. Da sich der interkalierende Farbstoff in die DNA einlagert, können aufgund seiner Fluoreszenz die DNA-Banden auf einem UV-Transilluminator bei $254 \mathrm{~nm}$ (Intas, Fa. Sony, Japan) sichtbar gemacht werden. Zur Auswertung und Dokumentation wurden die Gele unter UV-Licht mit Hilfe einer Polaroidkamera (MP4 Landkamera, Fa. Polaroid, Cambridge, USA) mit Orange- und UV-Filter fotografiert.

Mit einem Thermodrucker (Fa. Intas $\mathrm{GmbH}$, Göttingen), der an die Videokamera gekoppelt ist, konnten die Gele abgebildet werden. Als Filmmaterial wurden Polaroidfilme vom Typ 667 (Fa. Kodak, Stuttgart) bzw. Thermopapier (K75HM, Fa. Mitsubishi, Japan) eingesetzt.

\subsubsection{Größenbestimmung von Nukleinsäuren}

Zur Größenbestimmung von gelelektrophoretisch aufgetrennten linearen DNAFragmenten diente der „Ladder-Mix“ (Fa. MBI Fermentas, St. Leon-Rot), der als Längenstandard parallel in demselben Agarose-Gel mitaufgetrennt wurde. Durch anschließenden Vergleich der Laufstrecken der DNA-Probe mit der des Längenstandards konnte die Größe der erhaltenen DNA-Fragmente bestimmt werden. In Tabelle 5 sind die zur Bestimmung herangezogenen Fragmentgrößen angegeben. 
Tabelle 5: DNA-Längenstandard

\begin{tabular}{c}
\hline Ladder-Mix $(\mathrm{kb})$ \\
\hline 10,0 \\
8,0 \\
6,0 \\
5,0 \\
4,0 \\
3,5 \\
3,0 \\
2,5 \\
2,0 \\
1,5 \\
1,2 \\
1,03 \\
0,9 \\
0,8 \\
0,7 \\
0,6 \\
0,5 \\
0,4
\end{tabular}

Und drei weitere kleine Fragmente, die meist im Gel nicht sichtbar waren.

Für die Größenbestimmung von RNA in denaturierenden Formaldehydgelen wurde eine RNA-Ladder (Fa. New England Biolabs GmbH, Freiburg) aus in vitro synthetisierten Fragmenten mit folgenden Größen (in kb) eingesetzt (Tabelle 6).

Tabelle 6: RNA-Längenstandard

\begin{tabular}{c}
\hline Ladder-Mix $(\mathrm{kb})$ \\
\hline 9,0 \\
7,0 \\
5,0 \\
3,0 \\
2,0 \\
1,0 \\
0,5
\end{tabular}




\subsection{PCR (Polymerase-Kettenreaktion)}

Diese Methode der in vitro-Amplifikation von DNA diente neben der Herstellung von spezifischen DNA-Sonden für Hybridisierungsexperimente auch zur Herstellung spezifischer DNA-Fragmente für Klonierungen.

Als Enzym wurde die TakaraEx-Taq-Polymerase (aus Thermus aquaticus, Fa. Takara, Japan, die Amplifikate mit 3'-Überhängen synthetisiert eingesetzt. Um eine möglichst geringe Fehlerrate bei der DNA-Synthese zu gewährleisten, wurden außerdem die VentDNA-Polymerase (Fa. New England Biolabs GmbH, Schwalbach), die Pfu-Polymerase und die Tfl-Polymerase (aus Thermus flavus, Fa. Biozym Diagnostik, Hess. Oldendorf), die sich durch eine $3^{\prime} \rightarrow 5^{\prime}$-Korrektur-Aktivität auszeichnen, verwendet. Die eingesetzten Starteroligonukleotide (Primer) hatten eine Länge von 18-60 Basen (Fa. Life Technologies, Eggenstein und Fa. Metabion, Martinsried). Wenn beide eingesetzte Primer in den gleichen Konzentrationen und mit demselben Schmelzpunkt $\left(\mathrm{T}_{\mathrm{m}}\right)$ vorlagen, konnte eine optimale Amplifikation gewährleistet werden Die Berechnung des Schmelzpunktes erfolgte nach der Formel von CHESTER \& MARSHAK (1993):

$$
\begin{gathered}
\mathrm{Tm}=69,3+0,41(\% \mathrm{G}+\mathrm{C}-\mathrm{Gehalt})-650 / \mathrm{L} \\
\% \mathrm{G}+\mathrm{C}-\text { Gehalt = prozentualer } \mathrm{G}+\mathrm{C}-\text { Gehalt des Primers } \\
\mathrm{L}=\text { Länge des Primers }
\end{gathered}
$$

Durch Einsatz hoher Reaktionstemperaturen ist eine Minimierung von unspezifischen Oligonukleotidbindungen und von Synthese-Abbrüchen, die durch Sekundärstrukturen in der DNA-Matrize hervorgerufen werden, möglich. Der Einbau gezielter Fehlpaarungen in den Starteroligonukleotide ermöglichten es, spezifische Schnittstellen für Restriktionsendonukleasen in das PCR-Produkt $\mathrm{zu}$ inserieren. Das Volumen der Standard-PCR-Reaktionen betrug $30 \mu 1$. Ein Verdunstungsschutz war durch den beheizbaren Deckel des PCR-Blockes gegeben. Es wurden folgende Bestandteile auf Eis zusammenpipettiert:

Matrizen-DNA
Primer 1
Primer 2
dNTP-Gemisch (je $2,5 \mathrm{mM})$
10 x Reaktionspuffer
$\mathrm{MgCl}_{2}(25 \mathrm{mM})$
$\mathrm{BSA}(20 \mathrm{mg} / \mathrm{ml})$
$\mathrm{H}_{2} \mathrm{O}_{\text {bidest }}$
DNA-Polymerase $(2 \mathrm{U} / \mu \mathrm{l})$

Matrizen-DNA

$1,0 \mu \mathrm{g}$

$0,5 \mu \mathrm{M}$

$0,5 \mu \mathrm{M}$

$200 \mu \mathrm{M}$

$3 \mu 1$

$0,5-2,5 \mathrm{mM}$

$0,1 \mathrm{mg} / \mathrm{ml}$

ad 29,5 $\mu 1$

$0,5 \mu \mathrm{l}$ 
Bei mehreren Ansätzen wurde immer einer Mastermix aus den dNTP's, BSA, Puffer und DNA-Polymerase angesetzt, der anschließend auf die einzelnen PCR-Cups verteilt wurde.

Anschließend wurde der Ansatz durchmischt und die Temperaturzyklen mit einem Primus-Cycler (Fa. MWG AG-Biotech, München) oder einer Gradienten-PCR (Fa. Eppendorf, Hamburg) durchgeführt. Das Reaktionsgemisch wurde zunächst 2,5 min bei $94{ }^{\circ} \mathrm{C}$ inkubiert, um eine vollständige Denaturierung der DNA zu gewährleisten. Die Amplifikation erfolgte in 25 bis 30 Zyklen mit folgenden Reaktionsschritten:

$\begin{array}{lcc} & \text { Temperatur } & \text { Zeit } \\ \text { Denaturierung } & 95{ }^{\circ} \mathrm{C} & 35 \mathrm{sec} \\ \text { Anlagerung } & \mathrm{x}{ }^{\circ} \mathrm{C} & 45 \mathrm{sec} \\ \text { Polymerisierung } & 72{ }^{\circ} \mathrm{C} & \mathrm{y} \mathrm{sec}\end{array}$

Die Hybridisierung x lag idealerweise 2 bis $3{ }^{\circ} \mathrm{C}$ unter der Schmelztemperatur der Oligonukleotide, um eine möglichst hohe Spezifität $\mathrm{zu}$ erreichen. Die Polymersisierungzeit y richtete sich nach der verwendeten DNA-Polymerase (siehe Herstellerangaben). Die Spezifität der DNA-Synthese wurde anschließend im Agarosegel überprüft und "Qiaquick PCR Purification"-Kit (siehe 2.6.3.5) gereinigt.

Eine Optimierung der PCR wurde durch Variation einzelner Parameter wie z.B. der Anzahl der zu durchlaufenden Zyklen, der Hybridisierungstemperatur oder auch der Konzentration der Matrizen DNA sowie der Oligonukleotide bewirkt. Desweiteren war es möglich durch Verringerung der $\mathrm{MgCl}_{2}$-Konzentration und durch Zugabe von die Spezifität zu erhöhen.

\subsection{Enzymatische Modifikation von Nukleinsäuren}

\subsubsection{Spaltung mit Restriktionsendonukleasen}

Die sequenzspezifische Spaltung von DNA mit Restriktionsendonucleasen lieferte lineare Fragmente mit definierten Enden. Die DNA-Lösungen wurden mit 0,1 Vol. des vom Enzymhersteller empfohlenen, zehnfach konzentrierten Restriktionspuffers gemischt und mit dem gewünschten Restriktionsenzym versetzt. In analytischen Ansätzen betrug das Gesamtvolumen $20 \mu \mathrm{l}$, wobei etwa 1-2 $\mu \mathrm{g}$ DNA und 3-5 U Enzym/ $\mu \mathrm{g}$ DNA für $3 \mathrm{~h}$ bis über Nacht bei den empfohlenen Temperaturen inkubiert wurden. Präparative Ansätze hatten ein Gesamtvolumen von $100 \mu 1$ und wurden über 
Nacht mit bis zu $15 \mu \mathrm{g}$ DNA verdaut. Das Restriktionsenzym lag im Endvolumen mindestens 1:10 verdünnt vor, um auszuschließen, daß eine Gesamtkonzentration von über $5 \%$ Glycerin sich störend auf die Spaltungsreaktion auswirken könnte (Aufbewahrung der Enzyme in Puffern mit einem Gehalt von 50 \% (v/v) Glycerin). Bei Doppelverdauansätzen wurde ein für beide Enzyme geeigneter Puffer gewählt oder zunächst das Enzym mit den niedrigeren Salzansprüchen eingesetzt und nach 3-15 Stunden Inkubation die Ionenstärke des Verdaupuffers für das zweite Enzym erhöht. Als Alternative bei Produkten der Firma Fermentas konnte ein gemeinsamer Verdau in dem Spezialpuffer „Y-Tango “ “ durchgeführt werden. Falls eine Inaktivierung der Restriktionsenzyme erforderlich war, schloss sich eine Hitzeinaktivierung für 15 min bei $65{ }^{\circ} \mathrm{C}$ an. Zur Überprüfung der Spaltprodukte wurden diese in einem Agarose-Gel aufgetrennt.

\subsubsection{Dephosphorylierung von Vektor-DNA}

Zur Vermeidung von Selbstligation linearisierter Vektor-DNA konnte diese am 5 '-Ende mittels alkalischer Phosphatase dephosphoryliert werden (SAMBROOK et al., 1989).

Die Dephosphorylierung erfolgte direkt im Verdauansatz (GREENE \& GUARENTE, 1987), nachdem dieser abgestoppt worden war. Hierzu wurde 1 U Phosphatase pro $10 \mu \mathrm{g}$ DNA zum Restriktionsansatz gegeben und für 30 min bei $37{ }^{\circ} \mathrm{C}$ inkubiert. Anschließend wurde erneut $1 \mathrm{U}$ Enzym zugegeben und die Inkubation wiederholt. Die Abstoppung erfolgte durch 15-minütige Inkubation bei $65^{\circ} \mathrm{C}$. Für die anschließende Ligation wurde die DNA durch Mikrodialyse (siehe 2.6.3.2) gereinigt.

Bei Vektor-DNA, die mit zwei verschiedenen Enzymen verdaut wurde, entfiel die Dephosphorylierung.

\subsubsection{Ligierung von DNA-Fragmenten}

Bei der Ligation werden Phosphodiesterbindungen zwischen doppelsträngigen DNAFragmenten, die ein freies 3'-Hydroxyl- und 5'-Phosphatende aufweisen, verknüpft.

Ligationen von dephosphorylierter Vektor-DNA mit DNA-Fragmenten wurden in dem vom Hersteller mitgelieferten Puffersystem in $20 \mu \mathrm{l}$ Ansätzen durchgeführt. Um die Ligationseffizienz zu erhöhen wurde die Vektor-DNA-Konzentration der verfügbaren Menge an Insert-DNA so angepasst, dass das molare Verhältnis von Vektor- zu InsertDNA etwa 1:4 betrug. 


$\begin{array}{lr}\left.\text { Vektor-DNA (in } \mathrm{H}_{2} \mathrm{O}\right) & 0,2-2 \mu \mathrm{g} \\ \left.\text { Insert-DNA (in } \mathrm{H}_{2} \mathrm{O}\right) & 0,8-8 \mu \mathrm{g} \\ \text { ATP } 10 \mathrm{mM} & 2 \mu \mathrm{l} \\ 10 \times \mathrm{T}_{4} \text {-Ligase-Puffer } & 2 \mu \mathrm{l} \\ \mathrm{T}_{4} \text {-DNA-Ligase }(1 \mathrm{U} / \mu \mathrm{l}) & 1 \mu \mathrm{l}\end{array}$

Der Ansatz wurde für $1 \mathrm{~h}$ bei RT oder über Nacht bei oder $16{ }^{\circ} \mathrm{C}$ inkubiert und anschließend direkt zur Transformation von E. coli eingesetzt.

Bei „Blunt end“-Ligationen wurden die folgenden Komponenten zusammen für $1 \mathrm{~h}$ bei RT inkubiert:

$\begin{array}{lr}\text { Vektor-DNA } & 0,2-2 \mu \mathrm{g} \\ \text { DNA-Fragmente } & 0,2-3 \mu \mathrm{g} \\ \text { PEG } 50 \%(\mathrm{w} / \mathrm{v}) & 2 \mu \mathrm{l} \\ 10 \times \text { T4-Ligase-Puffer } & 2 \mu \mathrm{l} \\ \text { T4-DNA-Ligase } & 4 \mu \mathrm{l} \\ \mathrm{H}_{2} \mathrm{O}_{\text {bidest }} & \text { ad } 20 \mu \mathrm{l}\end{array}$

\subsubsection{Radioaktive Markierung von DNA-Fragmenten}

DNA-Fragmente, die als Sonden für Hybridisierungen eingesetzt werden sollten, wurden mit Hilfe des „Random Primed Labeling Kits“ (Fa. Gibco BRL, Eggenstein) und $\left[\alpha-{ }^{32} \mathrm{P}\right]$-dATP radioaktiv markiert. Zur Denaturierung wurden 25 bis 50 ng DNA in $25 \mu \mathrm{H}_{2} \mathrm{O}_{\text {bidest }}$ in einem Eppendorf-Reaktionsgefäß mit Schraubdeckel für $10 \mathrm{~min}$ bei $95{ }^{\circ} \mathrm{C}$ inkubiert und danach schnell auf Eis abgekühlt. Die folgenden Bestandteile des Reaktionsansatzes wurden dann auf Eis zusammenpipettiert:

$\begin{array}{lr}\text { denaturierte DNA-Lösung } & 25 \mu \mathrm{l} \\ \text { (10 min bei } 95{ }^{\circ} \mathrm{C}, 5 \text { min auf Eis) } & \\ \text { dCTP, dGTP, dTTP } & \text { je } 2 \mu l \\ \text { Reaktionspuffer } & 15 \mu l \\ \text { denaturierte DNA-Lösung } & 3 \mu 1\end{array}$

(10 min bei $95^{\circ} \mathrm{C}, 5 \mathrm{~min}$ auf Eis)

Die Reaktion wurde durch Zugabe von $1 \mu$ Klenow-Fragment $(2 \mathrm{U} / \mu \mathrm{l})$ gestartet und für $1 \mathrm{~h}$ bei $25^{\circ} \mathrm{C}$ inkubiert. Die DNA-Lösung wurde mit $450 \mu 1 \mathrm{H}_{2} \mathrm{O}_{\text {bidest }}$ versetzt und zur 
Abtrennung nicht eingebauter Nukleotide über eine NAP-5-Säule gelchromatographisch gereinigt.

\subsection{0 Übertragung von DNA und Selektion rekombinanter Klone}

\subsection{1 Übertragung von DNA durch Transformation}

\subsubsection{Herstellung kompetenter Zellen (INOUE et al., 1990)}

$250 \mathrm{ml}$ SOB-Medium wurde mit der Übernacht-Vorkultur von E. coli 3 \%ig angeimpft und in einem Schüttelwasserbad bis $\mathrm{zu}$ einer $\mathrm{OD}_{600 \mathrm{~nm}}$ von ca. 0,6 angezogen. Zur Zellernte wurde die Kultur $10 \mathrm{~min}$ in einem Eisbad geschwenkt und in vorgekühlten GSA-Zentrifugenbechern zentrifugiert (10 min, $\left.6000 \mathrm{Upm}, 4{ }^{\circ} \mathrm{C}\right)$. Das Pellet wurde vorsichtig in $80 \mathrm{ml}$ eiskaltem TB-Puffer (Transformationspuffer) resuspendiert, für 10 min auf Eis inkubiert unter unter den oben angegebenen Bedingungen abzentrifugiert. Nach erneuter vorsichtiger Resuspendierung des Pellets in $20 \mathrm{ml}$ TB-Medium erfolgte langsam und unter Schwenken die Zugabe von 1,5 ml DMSO ( $7 \%$ [v/v] Endkonzentration) und eine 10-minütige Inkubation auf Eis. Aliquots von $200 \mu 1$ wurden zügig in vorgekühlte E-Cups transferiert und in flüssigem Stickstoff schockgefroren. Die so erhaltenen Zellen konnten ohne Verlust der Kompetenz über mehrere Monate bei $-70{ }^{\circ} \mathrm{C}$ gelagert werden.

\section{Transformationspuffer (TB):}

$\begin{array}{lrl}\text { PIPES } & 10 \mathrm{mM} \\ \mathrm{CaCl}_{2} & 15 \mathrm{mM} \\ \mathrm{KCl} & 250 \mathrm{mM} \\ \mathrm{MnCl}_{2} & 55 \mathrm{mM} \\ \mathrm{pH} & 6,7 & \end{array}$

Alle Komponenten mit Außnahme des Mangansalzes wurden zusammengegeben, der $\mathrm{pH}-$ Wert mit $\mathrm{KOH}$ auf 6,7 eingestellt, eine Stunde gerührt und nachjustiert. Anschließend wurde $\mathrm{MnCl}_{2}$ dazugefügt, die Lösung sterilfiltriert und bei $4{ }^{\circ} \mathrm{C}$ gelagert.

\subsubsection{Transformation von E. coli (INOUE et al., 1990)}

Die gemäß 2.10.1.1 hergestellten und in $200 \mu$ l Aliquots gelagerten, kompetenten Zellen wurden zunächst auf Eis aufgetaut. Nach Zugabe des gesamten Ligationsansatzes (20 $\mu$ l) bzw. 1-2 $\mu 1$ Plasmid-DNA und leichtem Mischen wurde der Ansatz 30-45 min auf Eis inkubiert, für $2 \mathrm{~min}$ bei $42{ }^{\circ} \mathrm{C}$ hitzegeschockt und nach zweiminütiger 
Inkubation auf Eis mit $500 \mu 1$ LB-Medium versetzt. Daran schloss sich eine Inkubation für ca. $1 \mathrm{~h}$ bei $37^{\circ} \mathrm{C}$ auf dem Schüttler. Der gesamte Ansatz wurde in 90-100 $\mu 1$ Aliquots auf entsprechenden Selektivagar ausplattiert und bei $37^{\circ} \mathrm{C}$ inkubiert.

\subsubsection{3 Übertragung von DNA durch Elektroporation (DOWER et al., 1988)}

Plasmide können alternativ zu der unter 2.10.1.2 beschriebenen Methode auch durch Elektroporation in die Baktereinzelle transferiert werden. Dabei wird eine hohe Spannung angelegt und hierdurch die Membranen kurzzeitig durchlässig für PlasmidDNA (FIEDLER \& Wirth, 1988) gemacht. Wichtig dabei ist, dass sowohl die Zellen, als auch die verwendete DNA möglichst salzfrei vorliegen.

Der gewünschte E. coli Stamm wurde über Nacht in einer $5 \mathrm{ml}$ LB-Vorkultur angezogen, die dann in eine $250 \mathrm{ml}$ Kultur überführt und bei $30^{\circ} \mathrm{C}$ unter Schütteln bis $\mathrm{zu}$ einer $\mathrm{OD}_{578}$ von 0,5-1,0 inkubiert wurde. Im Anschluß an eine 15-30-minütige Inkubation auf Eis wurden die Zellen geerntet $\left(5000 \mathrm{x} \mathrm{g}, 4{ }^{\circ} \mathrm{C}, 10 \mathrm{~min}\right.$, Sorvall Zentrifuge RC-5B, Fa. Du Pont Instruments, Bad Homburg) und danach zweimal mit jeweils 1 Volumen eiskaltem $\mathrm{H}_{2} \mathrm{O}_{\text {bidest }}$ gewaschen. Es folgte ein weiterer Waschschritt in $10 \mathrm{ml}$ einer eiskalten $10 \%$ igen Glycerinlösung sowie ein kurzer Zentrifugationsschritt (7000 x g, $4{ }^{\circ} \mathrm{C}, 5 \mathrm{~min}$, Sorvall Zentrifuge RC-5B, Fa. Du Pont Instruments, Bad Homburg) und schließlich die Aufnahme des Pellets in $500 \mu \mathrm{l}$ derselben Lösung. Die Zellen konnten sofort verwendet bzw. in Aliquots von $40 \mu \mathrm{l}$ bei $-70{ }^{\circ} \mathrm{C}$ gelagert werden.

Zur Elektroporation wurden pro Ansatz $40 \mu 1$ Zellsuspension auf Eis aufgetaut, in eine sterile vorgekühlte Elektroporationsküvette (Elektrodenabstand $0,2 \mathrm{~cm}$ ) überführt und mit 1 bis $5 \mu$ dialysierter Plasmid-DNA (siehe 2.6.3.2) versetzt. Die Elektroporation erfolgte in einem Gene Pulser ${ }^{\mathrm{TM}}$ (Fa. Bio-Rad Laboratories $\mathrm{GmbH}$, München) bei $25 \mu \mathrm{F}, 200 \Omega$ und $2,5 \mathrm{kV}$, wodurch eine Feldstärke von $12,5 \mathrm{kV} / \mathrm{cm}$ und eine Zeitkonstante von 3,5-4,5 msec erreicht wurde. Nach dem Stromimpuls wurde $1 \mathrm{ml}$ LB-Medium dazugegeben, $60 \mathrm{~min}$ bei $37{ }^{\circ} \mathrm{C}$ inkubiert und anschließend auf Selektivagar ausplattiert. 


\subsection{1 Übertragung von Nukleinsäuren auf Membranen}

\subsubsection{Herstellung von Filtern für die Koloniehybridisierung (BULUWELA et al., 1989)}

Zur Analyse einer großen Anzahl rekombinanter Klone in Hybridisierungsexperimenten (siehe 2.12.1) dienten runde Nylonmembranen mit 8,2 $\mathrm{cm}^{\text {Durchmesser }}$ (Hybond ${ }^{\mathrm{TM}}-\mathrm{N}$, Fa. Amersham Pharamcia, Freiburg).

Je 50-100 Klone wurden auf eine LB-Platte (siehe 2.2.3) mit entsprechendem Antibiotikum übertragen. Nach ca. $20 \mathrm{~h}$ Inkubation bei $37{ }^{\circ} \mathrm{C}$ wurde die Membran aufgelegt, leicht angedrückt und wieder abgezogen, um so das Zellmaterial auf die Membran zu übertragen. Die Inkubation der Platten erfolgte dann für weitere $20 \mathrm{~h}$ bei $37^{\circ} \mathrm{C}$. Anschließend wurde die Nylonmembran mit den Impfstrichen nach oben für 5 min auf Filterpapier (Whatman 3MM) gelegt, das mit 2-fachem SSC-Puffer und $5 \%$ SDS (w/v) getränkt war und dann für 2,5 min bei $600 \mathrm{~W}$ im Mikrowellenherd gebacken. Die auf diese Weise für die Hybridisierung vorbereitete Membran wurde vor der Prähybridisierung mit 5-fachem SSC-Puffer und 0,1\% SDS (w/v) 1 h gewaschen.

$\underline{\text { SSC-Puffer (10-fach): }}$

$\begin{array}{lrl}\mathrm{NaCl} & 1,5 \mathrm{M} \\ \mathrm{Na}_{3} \text {-Citrat } & 0,15 \mathrm{M}\end{array}$

\subsection{Hybridisierungsmethoden}

Die Hybridisierungen erfolgten in Glasröhrchen (Fa. Ochs, Göttingen) in einem Hybridisierungsofen (Hybaid Mini Hybridization Oven; Fa. Biometra, Göttingen) bei den jeweils angegebenen Temperaturen. Die Membranen wurden mit der beladenen Seite nach innen in die Röhrchen plaziert.

\subsubsection{DNA-DNA-Hybridisierung}

Auf Nylonmembranen fixierte DNA wurde mit radioaktiv markierten DNA-Fragmente (siehe 2.9.4) hybridisiert. Vor der eigentlichen Hybridisierung war eine Prähybridisierung notwendig, um unspezifische Bindungsstellen für die DNA-Sonde auf den Nylonmembranen abzusättigen. Hierzu wurden die Membranen in den Hybridisierungsröhrchen mit $10 \mathrm{ml}$ Prähybridisierungsmix versetzt und 1-4 h im Hybridisierungsofen bei $60{ }^{\circ} \mathrm{C}$ inkubiert. Anschließend wurde die radioaktiv-markierte Sonde, die zuvor für $10 \mathrm{~min}$ bei $95^{\circ} \mathrm{C}$ denaturiert und für 5 min auf Eis gehalten wurde, 
zu dem Prähybridisierungsmix gegeben $(0,5 \mathrm{ml}$ Sonde/Hybridisierungsröhrchen mit drei Filtern). Die Membranen wurden dann für $12-16 \mathrm{~h}$ bei $60{ }^{\circ} \mathrm{C}$ inkubiert.

Nach erfolgter Hybridisierung schlossen sich folgende Waschschritte an:

$2 \times 10$ min in 2-fachem SSC-Puffer (siehe 0) bei RT

$2 \times 30 \mathrm{~min}$ in 2-fachem SSC-Puffer mit $1 \%(\mathrm{w} / \mathrm{v})$ SDS bei $42-60{ }^{\circ} \mathrm{C}$

$2 \times 30$ min in 0,1-fachem SSC-Puffer bei RT

Prähybridisierungsmix:

$\begin{array}{lr}\text { Dextransulfat }(50 \%[\mathrm{w} / \mathrm{v}]) & 2 \mathrm{ml} \\ 0,5 \text { Tris- } \mathrm{HCl} & 1 \mathrm{ml} \\ 5 \mathrm{M} \mathrm{NaCl} & 2 \mathrm{ml} \\ \text { SDS-Lösung }(10 \%[\mathrm{w} / \mathrm{v}]) & 2 \mathrm{ml} \\ \mathrm{H}_{2} \mathrm{O}_{\text {bidest }} & \mathrm{ad} 10 \mathrm{ml} \\ \mathrm{pH} & 7,5\end{array}$

\subsubsection{Autoradiographie}

Die Autoradiographie erfolgte mit Hilfe von Autoradiographiekassetten (Storage Phosphor Screen GP, Fa. Kodak, Stuttgart) und eines Phosphoimagers (Storm 860, Fa. Molecular Dynamics GmbH, Krefeld). Zur Quantifizierung wurde das Programm Image Quant für Macintosh Version 1.2 (Fa. Molecular Dynamics GmbH, Krefeld) verwendet. Über diese Programm erfolgte ebenfalls die Quantifizierung des $\mathrm{B}_{12}$-Bindeproteins MutB.

\subsection{Sequenzierung von DNA}

Die Sequenzierung doppelsträngiger Plasmid-DNA (siehe 2.6.2.3 präparative Plasmidisolierung) erfolgte im „Göttinger Genomics Laboratory“ (Institut für Mikrobiologie und Genetik, Universität Göttingen) am ABI PRISM 337 DNASequencer. Einige der Sequenzierungen wurden auch von der Fa. MWG Biotech, Ebersberg durchgeführt.

\subsubsection{Analyse der Sequenzdaten}

Die Sequenzdaten konnten manuell aus den Kurvenverläufen mit dem Programm ABI Edit View 1.0.1 abgeleitet werden.

Die Analyse der Sequenzdaten erfolgte auf Macintosh Computern (Fa. Apple Computer Inc., Cupertino, USA) mit Hilfe des Programms DNA-Strider (MARCK, 1988). Damit 
konnten offene Leserahmen ermittelt und Protein-Sequenzen abgeleitet sowie auf hydrophobe bzw. hydrophile Bereiche untersucht werden. Weitergehende Analysen wurden mit dem „Wisconsin Genetics Computer Group Sequence Analysis Software Package“ (GCG Package, Version 8.0; University of Wisconsin Biotechnology Center, Madison, USA) nach DEVEREUX et al. (1984) durchgeführt. Dazu zählte der im Internet angebotene Service der NCBI, der den Sequenzabgleich durch das Programm „Blast“" mit Daten der PIR-, NBRF-, SWISSPROT-, EMBL- und GENBANKDatenbanken (PEARSON \& LIPMAN, 1988) ermöglichte.

\subsection{Heterologe Genexpression in E. coli, E. blattae, C. freundii und S. typhimurium TA100}

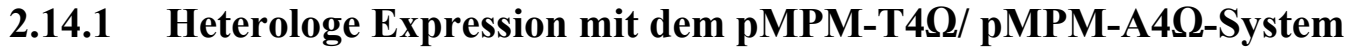

Die Produktion der Hybridproteine sigTorA-IF und sigTorA-MutB wurde mit den Expressionsvektoren pMPM-A $4 \Omega$ (Cloning Vector Collection, Department of Microbial Genetics, National Institut of Genetics, Yata, Japan) und pMPM-T4 $\Omega$ (Cloning Vector Collection, Department of Microbial Genetics, National Institut of Genetics, Yata, Japan) in verschiedenen Stämmen (E. coli DH5a, BL21 (DE3), JM109, KS330, E. blattae, C. freundii und S. typhimurium TA100 durchgeführt.

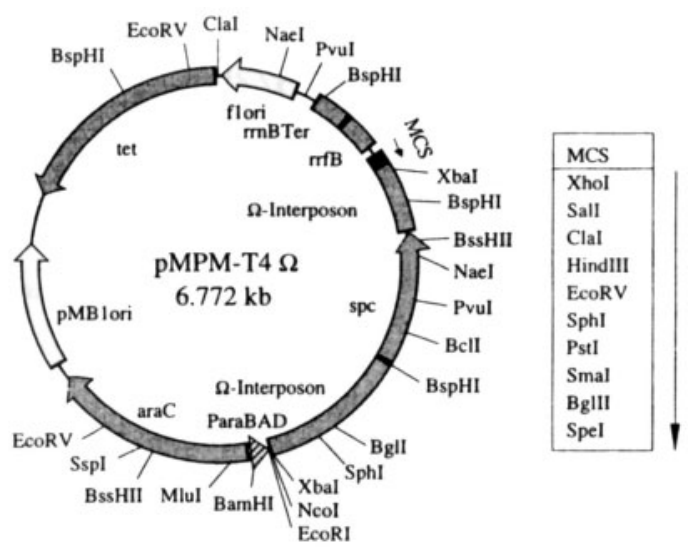

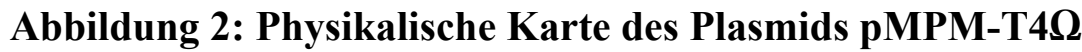




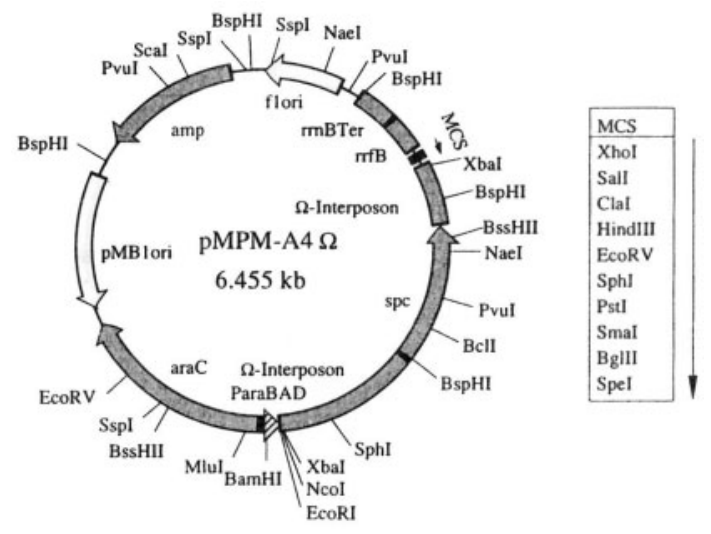

Abbildung 3: Physikalische Karte des Plasmids pMPM-A4 $\Omega$

Aerobe Expression:

Von den geeigneten Transformanden wurde eine Einzelkolonie gepickt und als $5 \mathrm{ml}$ Vorkultur über Nacht bei $37{ }^{\circ} \mathrm{C}$ in entsprechendem Selektivmedium angezogen. Eine Hauptkultur von $30 \mathrm{ml}, 100 \mathrm{ml}$ oder $500 \mathrm{ml}$ wurde 2-5\%ig angeimpft und bei $30{ }^{\circ} \mathrm{C}$ inkubiert. Bei einer $\mathrm{OD}_{600}$ von 0,3-0,6 wurden die Zellen mit 0,5-1 \% Arabinose induziert und mindestens zum Zeitpunkt 0 min und $3 \mathrm{~h}$ nach Induktion jeweils $1 \mathrm{ml}$ Proben gezogen bevor sie nach $3 \mathrm{~h}$ geerntet wurden.

Anaerobe Expression unter $\mathrm{B}_{12}$-produzierenden Bedingungen:

Es wurden je eine Einzelkolonien der Transformanden in $100 \mu 1 \mathrm{KP}-\mathrm{Puffer}$ (siehe 2.3.1) resuspendiert, eine $5 \mathrm{ml}$ Vorkultur (siehe 2.2.1) mit entsprechendem Selektivmedium damit angeimpft und über Nacht bei $37^{\circ} \mathrm{C}$ inkubiert. Diese $5 \mathrm{ml}$ wurden dann in eine weitere Vorkultur von $50 \mathrm{ml}$ überführt und ebenfalls bei $37^{\circ} \mathrm{C}$ über Nacht angezogen. Die Anzucht der Hauptkulturen in Mineralmedium mit Glycerin als einziger Kohlenstoff- und Energiequelle (Inokulum $10 \%$, Kulturvolumen $500 \mathrm{ml}$ ) erfolgte bei $23{ }^{\circ} \mathrm{C}, 30^{\circ} \mathrm{C}$ oder $37^{\circ} \mathrm{C}$ bis zu einer $\mathrm{OD}_{600}$ von ca. 0,6 . Die Zellen wurden mit $0,5-1 \%$ Arabinose induziert und bei den oben angegebenen Temperaturen 8-16 h inkubiert. Während des Versuches wurden Proben mindestens zum Zeitpunkt der Induktion und nach abgeschlossener Induktion genommen. Nach 8-16 h wurde die Kultur geerntet.

Zur Analyse der entnommenen Proben im SDS-Gel wurden diese pelletiert (8000 Upm, $8 \mathrm{~min}$ ), in 50-100 $\mu$ l Probenauftragspuffer aufgenommen und je $20 \mu \mathrm{l}$ für die SDS-PAGE eingesetzt. Durch regelmäßige Messung der optischen Dichte bei $600 \mathrm{~nm}$ konnte das Wachstum der Zellen über den ganzen Versuch kontrolliert werden (siehe 2.5.3). Nach 3 h (aerob) bzw. 8-16 h (anaerob) wurde die Kultur geerntet (siehe 2.15.1). 


\subsubsection{Heterologe Expression mit dem pET-System}

Um Störungen bei dem Transport des menschlichen Intrinsic Factors ins Periplasma mit dem Tat-System auszuschließen, wurde nur der IF in den Vektor pET20b (Fa. Novagin Inc., Madison, USA) inseriert. Dieser Vektor ist im Besitz der pel $B$-Signalsequenz, die für den Transport des rekombinanten Proteins in das Periplasma verantwortlich ist. Hierbei soll die korrekte Faltung unterstützt und ein proteolytischer Abbau verrringert werden. Die Expressionsversuche wurden in E. coli BL21(DE3) bei $37{ }^{\circ} \mathrm{C}$ durchgeführt. Dieser Stamm enthält den defekten, lysogenen Bakteriophagen DE3 des $\lambda$-Phagen. In das int-Gen des $\lambda$-Phagen wurde das Gen der T7-Polymerase unter Kontrolle des lacUV5-Promotors inseriert. Aufgrund des inaktivierten int-Gens benötigt DE3 zur Exzision oder Integration einen Helferphagen (STUDIER et al., 1990). Die Expression der T7-Polymerase lässt sich durch Zugabe von IPTG induzieren. Bei den Plasmiden der pET-Serie handelt es sich um Abkömmlinge des Plasmids pBR322, die als Selektionsmarker das Gen für die $\beta$-Lactamase besitzen.

Analog zu dem unter 2.14.1 beschriebenen Vorgehen wurden Einzelkolonien angezogen und in die $100 \mathrm{ml}$ Hauptkultur überführt (LB-Medium, Ampicillin $100 \mu \mathrm{g} / \mathrm{ml}$ ). Die Induktion erfolgte bei einer $\mathrm{OD}_{600}$ von 0,6 mit 0,2 mM IPTG für $3 \mathrm{~h}$. Auch hier wurden während des Wachstums Proben gezogen, um sie auf einem SDS-Gel zu analysieren.

\subsubsection{Heterologe Expression pASK-IBA-System}

Dieses System bietet eine weitere Möglichkeit neben dem His 6 -tag das Zielproteins im Periplasma zu detektieren. Der Vektor pASK-IBA3 (Fa. IBA, Göttingen) weist einen C-terminalen Strep-tag II auf. Dieser besteht aus insgesamt acht Aminosäuren (WSHPQFEK), die für gewöhnlich keinen Einfluss auf die Faltung des Proteins haben. Sie müssen nicht entfernt werden, da sie u. a. zu keinen Proteinaggregationen führen. Eine Signalsequenz ist nicht vorhanden. 


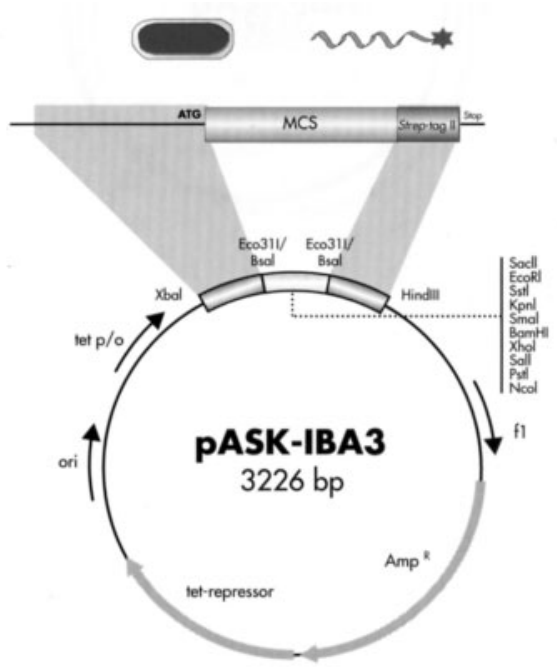

\section{Abbildung 4: physikalische Karte des Plasmids pASK-IBA3}

So konnte MutB aus Propionibacterium shermanii samt sigTorA Signalsequenz der TMAO-Reduktase in das Plasmid inseriert werden. Expressionsstudien wurden wie unter 2.14.1 beschrieben sowohl aerob als auch anaerob durchgeführt. Die Induktion erfolgte mit $20 \mu \mathrm{g}$ Anhydrotetracyclin/100 ml Medium. Für die Expression kamen folgende Organismen zum Einsatz:

- Salmonella typhimurium TA100

- E. blattae

\subsection{Zellaufschluß und Extraktherstellung}

\subsubsection{Zellernte}

Die Zellen des Expressionsversuches wurden bei $4{ }^{\circ} \mathrm{C}$ und $6000 \mathrm{Upm}$ (bei anschließender Periplasmapräparation $4000 \mathrm{Upm}, 20 \mathrm{~min}$ ) für $10 \mathrm{~min}$ im GSA- oder GS3-Rotor (Sorvall Zentrifuge RC-5B, Fa. Du Pont, Bad Homburg) zentrifugiert. Das Pellet wurde anschließend bei $-20^{\circ} \mathrm{C}$ eingefroren.

\subsubsection{Zellaufschluß mit der French Presse}

Für die Gewinnung von Rohextrakten wurden die geernteten Zellen aufgetaut und das Pellet in einem angemessenen Volumen von 0,1 M KP-Puffer (siehe 2.3.1) aufgenommen. Mit einer Spatelspitze Lysozym und DNase (Fa. Boehringer, Mannheim) wurde die Suspension für 30 min auf Eis inkubiert. Der Zellaufschluß fand in einer vorgekühlte Frenchpresszelle (Fa. SLM Amnico, Urbana, USA) bei einem 
Druck von $800 \mathrm{MPa}$ statt. Dieser Vorgang wurde mindestens dreimal wiederholt und die Suspenion stellte den Gesamtzellextrakt dar. Zelltrümmer und restliche intakte Zellen wurden abzentrifugiert (8000 Upm, $4{ }^{\circ} \mathrm{C}, 20 \mathrm{~min}$ ), der erhaltene Überstand als Rohextrakt bezeichnet und bei $-20^{\circ} \mathrm{C}$ eingefroren.

\subsubsection{Zellaufschluß durch Ultraschallbehandlung}

Das Zellpellet wurde in 0,1 M KP-Puffer (siehe 2.3.1) resuspendiert und anschließend mit einer Spatelspitze Lysozym und DNase für 30 min auf Eis inkubiert. Das $2 \mathrm{ml}$ E-Cup mit der Zellsuspension wurde in das Ultraschallgerät (Fa. MSE Baumann, Quickborn) eingespannt und während der gesamten Prozedur im Eisbad gekühlt. Die Ultraschallbehandlung erfolgte für 1-2 min bei einer Amplitude von 60-80 Micron bei einem Zyklus von 0,5 sec bis die Lösung aufklarte. Zwischen den Beschallungen wurde jeweils für 1-2 min pausiert. Alternativ dazu wurde auch ein Ultraschallbad (Sonorex Super 10 P, Bandelin) benutzt und die Proben bei $4{ }^{\circ} \mathrm{C} 4-5$ mal für 1 min beschallt.

Die nach der Ultraschallbehandlung Zentrifugation erhaltenen Rohextrakte konnten bei $-20{ }^{\circ} \mathrm{C}$ bis zur weiteren Bearbeitung gelagert werden.

\subsubsection{Cytoplasma- und Membranpräparation}

Um die Membranfraktion zu gewinnen wurde der Rohextrakt hochtourig abzentrifugiert (120000 x g, $4{ }^{\circ} \mathrm{C}, 1 \mathrm{~h}$, in einer Sorvall OTD-75 Ultrazentrifuge, Fa. Du Pont Bad Homburg) und somit die Cytoplasma- von der Membranfraktion getrennt. Der erhaltene Überstand stellte das Cytoplasma dar und wurde vom Pellet getrennt. Dieses konnte nun in etwa $3 \mathrm{ml} \mathrm{0,1} \mathrm{M} \mathrm{KP-Puffer} \mathrm{(siehe} \mathrm{2.3.1)} \mathrm{resuspendiert,} \mathrm{mit} \mathrm{einem} \mathrm{Homogenisator}$ behandelt und wieder in der Ultrazentrifuge pelletiert werden. Bei der erhaltenen bräunlichen, gelatineartigen Masse handelte es sich um die Membranen, die in ca 1-2 ml Puffer aufgenommen und bei $-20{ }^{\circ} \mathrm{C}$ eingefroren wurden.

\subsubsection{Periplasmapräparationen}

\subsubsection{Periplasmapräparation (SAMBROCK et al., 1989)}

Das eingefrorene Pellet einer $500 \mathrm{ml}$ Kultur wurde zunächst langsam auf Eis aufgetaut, in $20 \mathrm{ml}$ Puffer (30 mM Tris-HCl, $20 \%$ [w/v] Saccharose, $\mathrm{pH} \mathrm{8,0)} \mathrm{resuspendiert} \mathrm{und}$ mit $40 \mu 1$ EDTA (500 mM, pH 8,0, Endkonzentration $1 \mathrm{mM}$ ) versetzt. Es folgte eine Inkubation für $10 \mathrm{~min}$ bei RT auf dem Schüttler. Die Suspension wurde abzentrifugiert (8000 Upm, $4{ }^{\circ} \mathrm{C}, 10 \mathrm{~min}$ ), das Pellet in $20 \mathrm{ml}$ eiskaltem $5 \mathrm{mM} \mathrm{MgSO}_{4}$ aufgenommen und für $10 \mathrm{~min}$ im Eisbad gerührt. Der vorangegangene Zentrifugationsschritt wurde 
wiederholt und damit die Protoplasten pelletiert. Der Überstand enthielt die Periplasmafraktion und wurde bei $-20{ }^{\circ} \mathrm{C}$ aufbewahrt.

\subsubsection{Periplasmapräparation (WEIß, pers. Mitteilung)}

Das aufgetaute Zellpellet eines Induktionsexperiments wurde in $100 \mathrm{ml}(80 \mathrm{~g} / \mathrm{g}$ Zelle, Naßgewicht) eiskaltem Puffer aufgenommen (200 mM Tris-HCl, $20 \%$ [w/v] Saccharose, $100 \mathrm{mM}$ EDTA, pH 9,0) und für 20 min bei $4{ }^{\circ} \mathrm{C}$ geschüttelt. Es folgte ein Zentrifugationsschritt (9000 Upm, $4{ }^{\circ} \mathrm{C}, 12 \mathrm{~min}$ ) nachdem das Pellet dann in $100 \mathrm{ml}$ $10 \mathrm{mM}$ Tris- $\mathrm{HCl} \mathrm{pH} 8,8$ resuspendiert und erneut für $20 \mathrm{~min}$ bei $4{ }^{\circ} \mathrm{C}$ geschüttelt wurde. Mit den Proteinen im Überstand wurde nach wiederholter Zentrifugation (siehe oben) eine Ammoniumsulfatfällung durchgeführt. 100-130 g Ammoniumsulfat wurde unter ständigem Rühren bei $4{ }^{\circ} \mathrm{C}$ langsam zu der Proteinlösung gegeben und anschließend abzentrifugiert (12000 Upm, $4{ }^{\circ} \mathrm{C}, 20 \mathrm{~min}$ ). Das Proteinpellet wurde in $10 \mathrm{ml} \mathrm{0,1 \textrm {M }}$ KP-Puffer (siehe 2.3.1) resuspendiert und ungelöstes Material durch einen abschließenden Zentrifugationsschritt (15000 Upm, $4{ }^{\circ} \mathrm{C}, 10 \mathrm{~min}$ ) entfernt.

\subsubsection{Periplasmapräparation (HOSHINO \& KAGEYAMA, 1980)}

Bei dieser Methode wird die äußere Membran zusätzlich durch Temperaturschock durchlässig gemacht und so die periplasmatischen Proteine freigesetzt. Die aufgetauten Zellen wurden in $50 \mathrm{mM}$ Tris- $\mathrm{HCl}, 200 \mathrm{mM} \mathrm{MgSO}_{4}, \mathrm{pH}$ 7,3 resuspendiert (ca. 0,2 g Zellen/ ml Endkonzentration) und für $10 \mathrm{~min}$ bei $30{ }^{\circ} \mathrm{C}$ inkubiert. Daran schloss sich eine Inkubation auf Eis/ $\mathrm{NaCl}$ an. Dieser Temperaturschock wurde noch einmal wiederholt und die Suspension anschließend abzentrifugiert (8000 Upm, $4{ }^{\circ} \mathrm{C}, 10 \mathrm{~min}$ ). Um restliche Zellen und Trümmer zu entfernen wurde der proteinhaltige Überstand noch mal zentrifugiert (20000 Upm, $4{ }^{\circ} \mathrm{C}, 10 \mathrm{~min}$ ).

\subsubsection{Periplasmapräparation (ARMBRECHT, pers. Mitteilung, modif.)}

$1 \mathrm{~g}$ Zellen (Nassgewicht) des zuvor aufgetauten Pellets wurden in $8 \mathrm{ml}$ GET-Puffer resuspendiert, mit $1 \mathrm{mg} / \mathrm{ml}$ (Endkonzentration) frischem Lysozym versetzt und für 30 min bei RT inkubiert. Danach folgte die Zugabe von $8 \mathrm{ml} \mathrm{H}_{2} \mathrm{O}_{\text {bidest }}$ und ein weiterer Inkubationsschritt für $90 \mathrm{~min}$ bei RT. Nach der Zentrifugation $(11000 \mathrm{x} \mathrm{g}, 10 \mathrm{~min})$ befindet sich die periplasmatischen Fraktion im Überstand.

\section{GET-Puffer:}

$\begin{array}{lrl}\text { Glukose } & 500 \mathrm{mM} \\ \text { EDTA } & 1 \mathrm{mM} \\ \text { Tris-HCl } & 200 \mathrm{mM} \\ \mathrm{pH} & 7,4 & \end{array}$




\subsubsection{Periplasmapräparation (IBA Manual, modif.)}

Das aufgetaute Pellet eines $500 \mathrm{ml}$ Induktionexperiments wurde in $2 \mathrm{ml}$ Puffer $\mathrm{P}$ resuspendiert und in $2 \mathrm{ml}$ E-Cups für 20-30 min auf Eis geschüttelt. Hierbei wurde die äußere Membran durchlässig gemacht, um lösliche periplasmatische Komponenten freizulassen. Anschließend folgte ein Zentrifugationsschritt (14000 Upm, $4{ }^{\circ} \mathrm{C}, 5 \mathrm{~min}$ ), um Spheroplasten zu entfernen. Der Überstand wurde vorsichtig abgenommen, das Pellet erneut in demselben Volumen Puffer $\mathrm{P}$ aufgenommen und wie oben für 20-30 min auf Eis geschüttelt. Es folgte eine abschließende Zentrifugation nach der der Überstand vorsichtig abgenommen und wie der erste proteinhaltige bei $-20{ }^{\circ} \mathrm{C}$ eingefroren wurde.

Puffer P:

$\begin{array}{lrl}\text { Tris- } \mathrm{HCl} & 100 \mathrm{mM} \\ \text { Saccharose } & 20 \%(\mathrm{w} / \mathrm{v}) \\ \text { EDTA } & 100 \mathrm{mM} \\ \mathrm{pH} & 8,0\end{array}$

\subsection{Bestimmung der Proteinkonzentration nach BRADFORD (1976)}

Diese Methode der Konzentrationsbestimmung beruht auf der Bindung des Farbstoffes "Coomassie-Brillant-Blue" an Proteine. Dabei verschiebt sich das Absorptionsmaximum der Farbe von $465 \mathrm{~nm}$ nach $585 \mathrm{~nm}$. Die Zunahme der Absorption bei $585 \mathrm{~nm}$ ist ein Maß für die Proteinkonzentration der Lösung.

$20 \mu 1$ Probe wurden mit $1 \mathrm{ml}$ Bradford-Reagenz vermischt und $5 \mathrm{~min}$ bei RT inkubiert. Die Extinktionsmessung erfolgte in $1 \mathrm{ml}$ Plastikküvetten mit einer Schichtdicke von $1 \mathrm{~cm}$ bei $585 \mathrm{~nm}$ gegen $\mathrm{H}_{2} \mathrm{O}_{\text {bidest }}$ mit Bradford-Reagenz als Leerwert. (UV VIS V-550 Spektralphotometer (Fa. Jasco, Jena). Bei der Proteinbestimmung von ganzen Zellen wurden diese vor der Zugabe des Bradford-Reagenzes mit $50 \mu 11 \mathrm{~N} \mathrm{NaOH}$ versetzt. Die Eichgerade wurde mit Rinderserumalbumin in einem Bereich von 0-20 $\mu$ g Protein aufgenommen.

Bradford-Reagenz:

$\begin{array}{lr}\text { Serva Blau G-250 } & 100 \mathrm{mg} \\ \text { Ethanol }(96 \%[\mathrm{v} / \mathrm{v}]) & 50 \mathrm{ml} \\ \mathrm{H}_{3} \mathrm{PO}_{4}(85 \%[\mathrm{v} / \mathrm{v}]) & 100 \mathrm{ml} \\ \mathrm{H}_{2} \mathrm{O}_{\text {bidest }} & \text { ad } 1000 \mathrm{ml}\end{array}$


Serva Blau G-250 wurde zunächst in Ethanol gelöst, bevor nacheinander die Phosphorsäure und das Wasser zugegeben wurden. Die rotbraune Lösung wurde filtriert und lichtgeschützt bei RT gelagert.

\subsection{Einengung von Proteinlösungen}

\subsubsection{Einengung mit Polyethylenglycol}

Diese Methode der Einengung von Proteinlösungen erfolgte mittels Polyethylenglykol (PEG) 20000, einem Feststoff mit äußerst hydrophilem Charakter. Dazu wurde die Proteinprobe in einen vorbereiteten Dialyseschlauch pipettiert, mit Dialyseklemmen luftblasenfrei verschlossen und in ein Gefäß mit PEG überführt. Wenn nötig, wurde das Polyethylenglykol von Zeit zu Zeit erneuert. Nach dem Einengungsprozess wurde der Dialyseschlauch vorsichtig mit $\mathrm{H}_{2} \mathrm{O}_{\text {bidest }}$ abgewaschen und die Proteinprobe dann in ein neues Gefäß überführt.

\subsubsection{Einengung mit Centrisart-Röhrchen}

Die Einengung geringvolumiger Proteinlösungen (bis 2,5 ml) lässt sich mit Hilfe von Centrisart-Röhrchen (Fa. Sartorius, Göttingen) durchführen. Hierzu wurden die Proben in das schmalere Innenröhrchen, das an einem Ende mit einer Membran mit einer Ausschlussgrenze von $20 \mathrm{kDa}$ ausgestattet war, gefüllt. Das so beschickte Röhrchen wurde dann in das äußere, breitere Röhrchen überführt und solange bei $3000 \mathrm{x}$ g bei $4{ }^{\circ} \mathrm{C}$ zentrifugiert, bis die Lösung ca. 10fach auf $200 \mu \mathrm{l}$ aufkonzentriert war. Nach dem Zentrifugationsschritt befand sich das Konzentrat im inneren Röhrchen während Proteine, die kleiner als $20 \mathrm{kDa}$ waren, mittels der Zentrifugalkraft durch die Membran in das äußere Röhrchen diffundierten. Die Lagerung des Konzentrats erfolgte bei $-70^{\circ} \mathrm{C}$. Zur Reinigung wurden die Außenröhrchen mit einer 0,5 M NaOH-Lösung behandelt und mit $\mathrm{H}_{2} \mathrm{O}_{\text {bidest }}$ gespült. Zum Schutz der Membran wurden die Innenröhrchen nur mit $\mathrm{H}_{2} \mathrm{O}_{\text {bidest }}$ gesäubert. 


\subsubsection{Dialyse von Proteinlösungen}

Die Dialyse diente zum Entsalzen und zum Pufferwechsel von Proteinlösungen. Die verwendeten Visking-Dialyseschläuche (Fa. Serva, Heidelberg) wurden zur Vorbereitung nacheinander in folgenden Lösungen für jeweils 10 min gekocht:

$-2 \%(\mathrm{w} / \mathrm{v}) \mathrm{Na}_{2} \mathrm{CO}_{3}$

$-\mathrm{H}_{2} \mathrm{O}_{\text {bidest }}$

- 2 mM EDTA

$-2 \mathrm{x}$ in $\mathrm{H}_{2} \mathrm{O}_{\text {bidest }}$

Abschließend wurden die Schläuche $1 \mathrm{x}$ in $\mathrm{H}_{2} \mathrm{O}_{\text {bidest }}$ autoklaviert und bei $4{ }^{\circ} \mathrm{C}$ gelagert. Die Dialyse wurde unter ständigem Rühren für mehrere Stunden bei $4{ }^{\circ} \mathrm{C}$ gegen das 1000-2000-fache Volumen durchgeführt.

\subsection{Polyacryalmid-Gelelektrophorese (PAGE)}

\subsubsection{SDS-PAGE nach SCHÄGGER und VON JAGOW (1987)}

Polyacrylamid-Gelelektrophoresen unter denaturierenden Bedingungen wurden in Minigel-Elektrophorese-Kammern (Fa. Bio-Rad, München) mit 8,5 x 8,0 x 0,1 cm Glasplatten durchgeführt.

Trenn- und Sammelgel hatten folgende Zusammensetzung (Menge für 2 Gele):

\begin{tabular}{|c|c|c|c|}
\hline \multirow[t]{5}{*}{ Trenngel: } & Gelpuffer & $3 \mathrm{ml}$ & $3 \mathrm{ml}$ \\
\hline & Acrylamidlösung & $2,25 \mathrm{ml}$ & $2,7 \mathrm{ml}$ \\
\hline & $\mathrm{H}_{2} \mathrm{O}_{\text {bidest }}$ & $3,75 \mathrm{ml}$ & $3,3 \mathrm{ml}$ \\
\hline & APS-Lösung & $45 \mu 1$ & $45 \mu 1$ \\
\hline & TEMED & $4,5 \mu 1$ & $4,5 \mu 1$ \\
\hline \multirow[t]{5}{*}{ Sammelgel: } & Gelpuffer & $1,13 \mathrm{ml}$ & $1,13 \mathrm{ml}$ \\
\hline & Acrylamidlösung & $375 \mu 1$ & 375 \\
\hline & $\mathrm{H}_{2} \mathrm{O}_{\text {bidest }}$ & $3 \mathrm{ml}$ & 3 \\
\hline & APS-Lösung & $45 \mu 1$ & 45 \\
\hline & TEMED & $4,5 \mu 1$ & $4,5 \mu 1$ \\
\hline
\end{tabular}

Zunächst wurden Acrylamidlösung, Gelpuffer und $\mathrm{H}_{2} \mathrm{O}_{\text {bidest }}$ gemischt. Nach der Zugabe von TEMED und APS-Lösung wurde das Gel gegossen und mit $\mathrm{H}_{2} \mathrm{O}_{\text {bidest }}$ überschichtet, um eine ebene Fläche zu erhalten. Nach Polymerisation des Trenngels (ca. $30 \mathrm{~min}$ ) 
konnte das $\mathrm{H}_{2} \mathrm{O}_{\text {bidest }}$ abgenommen und das Sammelgel gegossen werden, in das zur Formung von Geltaschen ein Kamm luftblasenfrei eingesetzt wurde. Nach 30 min war das Gel vollständig polymerisiert und konnte verwendet werden.

Die Proben wurden vor dem Auftragen im Verhältnis 1:3 mit Denaturierungspuffer gemischt. Anschließend wurden die Proben auf das mit Elektrophoresepuffer überschichtete Gel mit Hilfe einer Hamiltonspritze aufgetragen. Die Elektrophorese erfolgte zunächst bei einer Spannung von $100 \mathrm{~V}$, bis die blaue Markerbande das Trenngel erreicht hatte, und wurde dann auf $130 \mathrm{~V}$ erhöht. Als Netzgerät diente ein Gene-Power-Supply GPS 200/400 der Fa. Amersham Pharmacia, Freiburg. Die Elektrophorese wurde beendet, wenn die Markerbande das Gelende erreicht hatte.

Acrylamidlösung:

Acrylamid

Bisacrylamid

$\mathrm{H}_{2} \mathrm{O}_{\text {bidest }}$

Kathodenpuffer:

Tris

Tricine

SDS

$\mathrm{H}_{2} \mathrm{O}_{\text {bidest }}$

$\mathrm{pH}$

Denaturierungspuffer:

Tris

SDS

Serva-Blau G250

Glycerin

2-Mercaptoethanol

$\mathrm{H}_{2} \mathrm{O}_{\text {bidest }}$

$\mathrm{pH}$

\section{Gelpuffer:}

Tris

SDS

$181,7 \mathrm{~g}$

$3 \mathrm{~g}$

$\mathrm{H}_{2} \mathrm{O}_{\text {bidest }}$

$\mathrm{pH}$

$1,5 \mathrm{~g}$

ad $200 \mathrm{ml}$

ad $500 \mathrm{ml}$

8,4

Anodenpuffer:

Tris

$24,2 \mathrm{~g}$

$12,1 \mathrm{~g}$

$\mathrm{H}_{2} \mathrm{O}_{\text {bidest }}$

$\mathrm{pH}$

ad $1000 \mathrm{ml}$

8,9 ad $1000 \mathrm{ml}$

8,5

APS-Lösung:

Ammoniumpersulfat $\quad 0,1 \mathrm{~g}$

$\mathrm{H}_{2} \mathrm{O}_{\text {bidest }}$

ad $1 \mathrm{ml}$

\section{$1,2 \mathrm{~g}$}

$3 \mathrm{mg}$

$3 \mathrm{ml}$

$0,5 \mathrm{ml}$

ad $10 \mathrm{ml}$

6,8

\subsection{Proteinfärbemethoden in Polyacrylamidgelen}

Die Färbung von Proteingelen und Blotmembranen erfolgte unter ständiger Bewegung auf einem Schüttler bei RT. 


\subsubsection{Coomassie-Färbung}

Zur unspezifischen Proteinfärbung mit „Coomassie-Brilliant-Blue“ wurden die Gele 30-60 min in der Färbelösung und anschließend bis zur vollständigen Entfärbung des Hintergrundes in Entfärbelösung geschwenkt. Letztere wurde dabei mehrfach gewechselt. Die gefärbten Gele wurden in Folie eingeschweißt, eingescant und bei $4{ }^{\circ} \mathrm{C}$ aufbewahrt.

Färbelösung:

Entfärbelösung:

$\begin{array}{lrllr}\text { Serva Blau G-250 } & 1,2 & \mathrm{~g} & \text { Methanol } & 330 \mathrm{ml} \\ \text { Methanol } & 227 \mathrm{ml} & \text { Eisessig } & 100 \mathrm{ml} \\ \text { Eisessig } & 46 \mathrm{ml} & \mathrm{H}_{2} \mathrm{O}_{\text {bidest }} & \text { ad } 1000 \mathrm{ml} \\ \mathrm{H}_{2} \mathrm{O}_{\text {bidest }} & 227 \mathrm{ml} & & \end{array}$

\subsubsection{Silberfärbung (BLUM et al., 1987)}

Die Silberfärbung ist eine sehr empfindliche Färbemethode, da selbst geringe Mengen an Protein nachgewiesen werden können. Das Gel wurde dazu nach der Elektrophorese in folgenden Schritten bearbeitet:

1. mindestens $1 \mathrm{~h}$ (höchstens $24 \mathrm{~h}$ ) im Fixierer inkubieren

2. $3 \times 5 \mathrm{~min}$ in $50 \%(\mathrm{v} / \mathrm{v})$ Ethanol waschen

3. $1 \mathrm{~min}$ in der Thiosulfatlösung inkubieren

4. $3 \times 20 \mathrm{sec}$ in $\mathrm{H}_{2} \mathrm{O}_{\text {bidest }}$ waschen

5. 20 min imprägnieren

6. in Entwicklerlösung inkubieren, bis die Banden sichtbar sind (1-20 min)

7. sofort kurz in $\mathrm{H}_{2} \mathrm{O}_{\text {bidest }}$ spülen

8. 10-20 min in Stoplösung inkubieren (bis leichte Trübung entsteht)

9. mindestens 15 min in $\mathrm{H}_{2} \mathrm{O}_{\text {bidest }}$ waschen

Die Gele wurden in Plastikfolie eingeschweißt und sofort mit Hilfe eines Scanners dokumentiert, da die Gefahr des Nachdunkelns bestand. Die Lagerung erfolgte bei $4{ }^{\circ} \mathrm{C}$. 
Fixierer:

$\begin{array}{lr}\text { Methanol } & 50 \mathrm{ml} \\ \text { Eisessig } & 12 \mathrm{ml} \\ \text { Formaldehyd (37\%; v/v) } & 100 \mu l \\ \mathrm{H}_{2} \mathrm{O}_{\text {bidest }} & \text { ad } 100 \mathrm{ml}\end{array}$

Die Methanol-Eisessiglösung wurde auf Vorrat angesetzt; nur Formaldehyd wurde unmittelbar vor Gebrauch zugesetzt.

Thiosulfatlösung:
$\mathrm{Na}_{2} \mathrm{~S}_{2} \mathrm{O}_{3} \times 5 \mathrm{H}_{2} \mathrm{O}$
$2 \mathrm{mg}$
$\mathrm{H}_{2} \mathrm{O}_{\text {bidest }}$
ad $100 \mathrm{ml}$

Die Lösung wurde stets frisch angesetzt.

Imprägnierlösung:

$\begin{array}{lr}\mathrm{AgNO}_{3} & 200 \mathrm{mg} \\ \text { Formaldehyd (37\%; v/v) } & 75 \mu \mathrm{l} \\ \mathrm{H}_{2} \mathrm{O}_{\text {bidest }} & \text { ad } 100 \mathrm{ml}\end{array}$

Die Lösung wurde stets frisch angesetzt.

Entwicklerlösung:

$\begin{array}{lrl}\mathrm{Na}_{2} \mathrm{CO}_{3} \times 10 \mathrm{H}_{2} \mathrm{O} & 6 \mathrm{~g} \\ \text { Thiosulfatlösung (s.o.) } & 2 \mathrm{ml} \\ \text { Formaldehyd (37\%; v/v) } & 50 \mu \mathrm{l} \\ \mathrm{H}_{2} \mathrm{O}_{\text {bidest }} & \text { ad } 100 \mathrm{ml}\end{array}$

Die Lösung wurde stets frisch angesetzt.

Stoplösung:
EDTA
$1,86 \mathrm{~g}$
$\mathrm{H}_{2} \mathrm{O}_{\text {bidest }}$ ad $100 \mathrm{ml}$

Die Lösung wurde mit $\mathrm{NaOH}$ auf einen $\mathrm{pH}-$ Wert von 7,0 titriert und konnte mehrere Wochen gelagert werden. 


\subsection{Bestimmung der Molekularmassen von Proteinen}

Um das Molekulargewichtes von Proteinen in SDS-Gelen und auf Blotmembranen bestimmen $\mathrm{zu}$ können, wurden gleichzeitig auch entsprechende Standardproteine mitaufgetrennt. Die Zusammensetzung und die molekulare Masse sind in Tabelle 7 aufgeführt.

Tabelle 7: Molekulare Massen der Standardproteine für die SDS-PAGE

\begin{tabular}{lcc}
\hline Standardproteine & $\begin{array}{c}\text { „LMW Calibration“-Kit } \\
{[\mathrm{kDa}]}\end{array}$ & $\begin{array}{c}\text {,Prestained Standard Low } \\
\text { Range“b }[\mathrm{kDa}]\end{array}$ \\
\hline Phosphorylase b & 94,0 & 106,0 \\
Rinderserumalbumin & 67,0 & 81,0 \\
Ovalbumin & 43,0 & 47,5 \\
Carboanhydrase & 30,0 & 35,3 \\
Trypsin-Inhibitor & 20,1 & 28,2 \\
Lysozym & & 20,8 \\
Lactalbumin & 14,4 & \\
\hline a „LMW Calibration“-Kit (Fa. Amersham Pharmacia, Freiburg) & \\
",Prestained Standard Low Range“ der (Fa. Bio-Rad München) \\
Abweichende molekulare Massen bei dem „Prestained“ Marker bezüglich der Standardproteine sind auf \\
den kovalent gebundenen Farbstoff zurückzuführen.
\end{tabular}

Die Bestimmung der Molekularmasse erfolgte nach dem Anfärben. Es wurde die Wanderungsstrecke im Gel mit der der Markerproteine verglichen. Die Molekularmasse der unbekannten Proteine konnten aus der erstellten Eichgeraden, die Auftragung des Logarithmus der Molekularmassen der Standardproteine gegen deren RF-Wert ergab, abgelesen werden.

$$
\mathrm{R}_{\mathrm{f}} \text {-Wert }=\frac{\text { Wanderungsstrecke des Proteins }}{\text { Wanderungsstrecke des Farbstoffes }}
$$

\subsection{Methoden zur Proteinanreicherung}

\subsubsection{Metall-Chelat-Affinitätschromatographie}

Das Prinzip der Metall-Chelat-Affinitätschromatographie beruht auf der Komplexierung stark chelatierender Aminosäuren (besonders Histidin) eines Proteins an ein Metallkation (meistens Nickel, Zink oder Kupfer). Das Metallkation wiederum ist über 
Nitrilotriessigsäure (Chelatgruppe) an ein Trägermaterial (Agarose oder Sepharose) gebunden.

Die Metall-Chelat-Chromatographie besitzt im neutralen $\mathrm{pH}-$ Bereich ihre größte Spezifität und Effizienz. Das Protein wird von der Säule eluiert, indem man den $\mathrm{pH}-$ Wert in den sauren Bereich verschiebt oder Histidin durch Zugabe von Imidazol kompetitiv verdrängt.

\subsubsection{Vorbereitung der Säule}

Für die Metall-Chelat-Chromatographie wurde $\mathrm{Ni}^{2+}$-Nitrilotriessigsäure-Agarose (NTAAgarose; Fa. Qiagen GmbH, Hilden) verwendet. Nach dem Einsetzen der unteren Fritte wurden $6 \mathrm{ml} \mathrm{Ni}{ }^{2+}$-NTA-Agarose in eine PD 10-Säule (Fa. Amersham Pharmacia, Freiburg) eingefüllt. Nach der Sedimentation des Trägermaterials wurde die Säule mit dem Zellaufschlusspuffer (siehe 2.21.1.2) gespült und bei $4{ }^{\circ} \mathrm{C}$ aufbewahrt.

\subsubsection{Proteinaufreinigung unter nativen Bedingungen}

Zur Reinigung und damit Konzentrierung löslicher Proteine unter nativen Bedingungen wurde der Rohextrakt mit der $\mathrm{Ni}^{2+}$-NTA-Agarose (äquilibriert mit Zellaufschlußpuffer) gemischt. Die Bindung erfolgte 1-2 h unter Rühren bei $4{ }^{\circ} \mathrm{C}$. Nach dieser Inkubation wurde die Lösung in den Säulenkörper einer PD-10 Säule gefüllt. Nachdem sich die Agarose abgesetzt hatte, wurde der Durchlauf der Säule aufgefangen. Es folgten zwei Waschschritte mit je $4 \mathrm{ml}$ Puffer 1. Eluiert wurde das Protein mit viermal 0,5 ml Puffer 2. Aliquots der einzelnen Fraktionen der Aufreinigung wurden mit Hilfe von SDS-PAGE überprüft.

Nach Gebrauch wurde das Säulenmaterial mit $\mathrm{H}_{2} \mathrm{O}_{\text {bidest }}$ gespült und bei $4{ }^{\circ} \mathrm{C}$ mit $30 \%$ Ethanol gelagert.

Vor einer erneuten Verwendung der Säule wurde das Chromatographiematerial mit Puffer 2 gespült und dann mit dem Zellaufschlusspuffer äquilibriert.

Zellaufschlußpuffer:

$\begin{array}{lrl}\mathrm{KH}_{2} \mathrm{PO}_{4} & 50 \mathrm{mM} \\ \mathrm{NaCl} & 300 \mathrm{mM} \\ \text { Imidazol } & 10 \mathrm{mM} \\ \mathrm{pH} & 8,0 & \end{array}$


$\underline{\text { Puffer 1: }}$

Puffer 2:

$\begin{array}{lrllrl}\mathrm{KH}_{2} \mathrm{PO}_{4} & 50 & \mathrm{mM} & \mathrm{KH}_{2} \mathrm{PO}_{4} & 50 \mathrm{mM} \\ \text { Tris/HCl } & 300 & \mathrm{mM} & \mathrm{NaCl} & 300 \mathrm{mM} \\ \text { Imidazol } & 20 & \mathrm{mM} & \text { Imidazol } & 250 \mathrm{mM} \\ \mathrm{pH} & 8,0 & & \mathrm{pH} & 8,0\end{array}$

\subsubsection{Proteinaufreinigung unter denaturierenden Bedingungen}

Die denaturierende Aufreinigung wurde ebenfalls zur Proteinkonzentrierung eingesetzt und erfolgte analog der Beschreibung für die Reinigung unter nativen Bedingungen. Die Puffer enthielten statt Imidazol nun Harnstoff (Puffer B).

Gewaschen wurde zweimal mit $4 \mathrm{ml}$ Puffer $\mathrm{C}$ und eluiert viermal mit 0,5 ml Puffer D und zweimal mit 0,5 ml Puffer E.

Puffer B:

Harnstoff

$\mathrm{NaH}_{2} \mathrm{PO}_{4}$

Tris/HCl

$\mathrm{pH}$

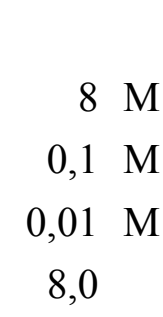

Elutionspuffer D:

Harnstoff

$\mathrm{NaH}_{2} \mathrm{PO}_{4}$

Tris $/ \mathrm{HCl}$

$\mathrm{pH}$

$\begin{array}{rr}8 & \mathrm{M} \\ 0,1 & \mathrm{M} \\ 0,01 & \mathrm{M} \\ 5,9 & \end{array}$

Elutionspuffer E:

$\underline{\text { Puffer C }}$

$\begin{array}{lrl}\text { Harnstoff } & 8 & \mathrm{M} \\ \mathrm{NaH}_{2} \mathrm{PO}_{4} & 0,1 \mathrm{M} \\ \text { Tris } / \mathrm{HCl} & 0,01 \mathrm{M} \\ \mathrm{pH} & 6,3\end{array}$

$\begin{array}{lrl}\text { Harnstoff } & 8 \mathrm{M} \\ \mathrm{NaH}_{2} \mathrm{PO}_{4} & 0,1 \mathrm{M} \\ \text { Tris/HCl } & 0,01 \mathrm{M} \\ \mathrm{pH} & 4,5\end{array}$

\subsubsection{Regeneration der Säule}

Eine Regeneration der $\mathrm{Ni}^{2+}$-NTA-Agarose wurde durchgeführt, wenn eine Farbänderung von grün-blau nach bräunlich-grau auftrat. Durch das chelatierende Agenz EDTA erfolgte die Elution des Nickels von der Säule. Nach einer anschließenden Wiederbeladung mit $\mathrm{Ni}^{2+}$-Ionen stand das Säulenmaterial erneut für mehrere Reinigungszyklen zur Verfügung. Die Regeneration erfolgte anhand des Herstellerprotokolls.

\subsubsection{Ammoniumsulfat-Fällung}

Bei der Ammoniumsulfat-Fällung $\left(\left(\mathrm{NH}_{4}\right)_{2} \mathrm{SO}_{4}\right)$ nutzt man aus, dass durch die Zugabe des Salzes die Wechselwirkung der Proteine mit den Wassermolekülen verhindert und ihre damit ihre Löslichkeit herabgesetzt wird. Die zum Sättigungsgrad benötigte Menge 
wurde Tabelle 8 entnommen und der Proteinlösung langsam unter Rühren bei $4{ }^{\circ} \mathrm{C}$ zugegeben. Damit sich das Ammoniumsulfat schneller löste wurde es zuvor in einem Mörser zerkleinert. Nach erfolgter Zugabe ließ man die Lösung noch für 20 min unter Rühren inkubieren. Das ausgefallene Protein wurde dann bei $15000 \mathrm{x}$ g bei $4{ }^{\circ} \mathrm{C}$ für 15 min abzentrifugiert. Anschließend wurde das Proteinpellet in KP-Puffer (siehe 2.3.1) aufgenommen (1/10 des Ausgangsvolumens).

Tabelle 8: Nomogramm zur Bestimmung der Ammoniumsulfatmenge zur Einstellung einer gewählten Konzentration (in \% Sättigung) (modifiziert nach GREEN \& HUGHES, 1955)

\begin{tabular}{|c|c|c|c|c|c|c|c|c|c|c|c|c|c|c|c|c|c|c|}
\hline \multirow{3}{*}{\multicolumn{2}{|c|}{ 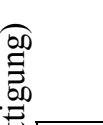 }} & \multicolumn{17}{|c|}{ Endkonzentration Ammoniumsulfat (\% Sättigung) } \\
\hline & & 10 & 20 & 25 & 30 & 33 & 35 & 40 & 45 & 50 & 55 & 60 & 65 & 70 & 75 & 80 & 90 & 100 \\
\hline & & \multicolumn{17}{|c|}{ zugegebenes Ammoniumsulfat (g/l) } \\
\hline 焉 & 0 & 56 & 114 & 144 & 176 & 196 & 209 & 243 & 277 & 313 & 351 & 390 & 430 & 472 & 516 & 561 & 662 & 767 \\
\hline \multirow{4}{*}{$\frac{\overbrace{}^{\circ}}{\overparen{c}}$} & 10 & & 57 & 86 & 118 & 137 & 150 & 183 & 216 & 251 & 288 & 326 & 365 & 406 & 449 & 494 & 592 & 694 \\
\hline & 20 & & & 29 & 59 & 78 & 91 & 123 & 155 & 189 & 225 & 263 & 300 & 340 & 382 & 424 & 520 & 619 \\
\hline & 25 & & & & 30 & 49 & 61 & 93 & 125 & 158 & 193 & 230 & 267 & 307 & 348 & 390 & 485 & 583 \\
\hline & 30 & & & & & 19 & 30 & 62 & 94 & 127 & 162 & 198 & 235 & 273 & 314 & 356 & 449 & 546 \\
\hline \multirow{2}{*}{ בे } & 33 & & & & & & 12 & 43 & 74 & 107 & 142 & 177 & 214 & 252 & 292 & 333 & 426 & 522 \\
\hline & 35 & & & & & & & 31 & 63 & 94 & 129 & 164 & 200 & 238 & 278 & 319 & 411 & 506 \\
\hline \multirow{2}{*}{ ఏ } & 40 & & & & & & & & 31 & 63 & 97 & 132 & 168 & 205 & 245 & 285 & 375 & 469 \\
\hline & 45 & & & & & & & & & 32 & 65 & 99 & 134 & 171 & 210 & 250 & 339 & 431 \\
\hline \multirow{2}{*}{ 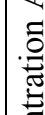 } & 50 & & & & & & & & & & 33 & 66 & 101 & 137 & 176 & 214 & 302 & 392 \\
\hline & 55 & & & & & & & & & & & 33 & 67 & 103 & 141 & 179 & 264 & 353 \\
\hline 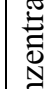 & 60 & & & & & & & & & & & & 34 & 69 & 106 & 143 & 227 & 314 \\
\hline \multirow[t]{2}{*}{ ฮे } & 65 & & & & & & & & & & & & & 34 & 70 & 107 & 190 & 275 \\
\hline & 70 & & & & & & & & & & & & & & 35 & 72 & 153 & 237 \\
\hline สี & 75 & & & & & & & & & & & & & & & 36 & 115 & 198 \\
\hline \multirow[t]{2}{*}{ 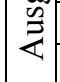 } & 80 & & & & & & & & & & & & & & & & 77 & 157 \\
\hline & 90 & & & & & & & & & & & & & & & & & 79 \\
\hline
\end{tabular}

\subsection{Elektophoretischer Transfer von Proteinen auf Membranen}

\subsubsection{Western Blot (TOBWIN et al., 1979; modif.)}

Die Methode des elektrophoretischen Proteintransfers auf Membranen (TOWBIN et al., 1979) wurde sowohl für den spezifischen Nachweis von Proteinen mit der $\mathrm{Ni}^{2+}$-NTAKonjugatfärbung (siehe 2.23.1.1) als auch für die Färbung mit spezifischen Antikörpern (siehe 2.23.1.2) angewandt. Der Western-Blot wurde in einer Mini-Blot-Apparatur („Mini Trans-Blot ${ }^{\circledR}$ Electrophoretic Transfer Cell“, Fa. Bio-Rad Laboratories GmbH, München) durchgeführt. Nach der SDS-PAGE wurden das Gel sowie auf Gelgröße zugeschnittene 2 Lagen Whatman Papier (Whatman 3 MM, Schleicher und Schuell $\mathrm{GmbH}$, Dassel) und die gewünschte Membran zusammen mit den beiden Glasfiberpads 
10 min in gekühltem Transfer-Puffer getränkt. Anschließend wurde der Blot luftblasenfrei in der Gelhalterungskassette auf der Anodenseite aufgebaut:

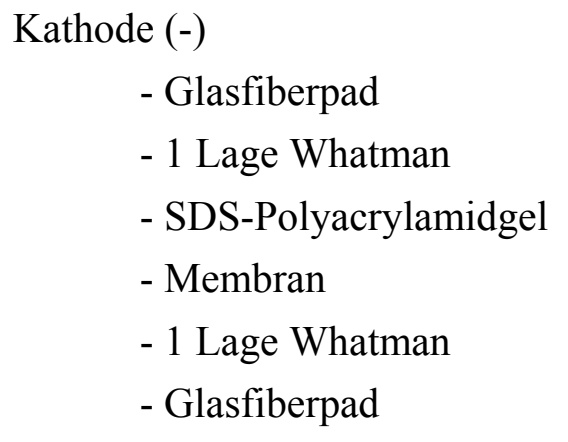

Anode $(+)$

Die Oberflächen des Whatman-Papiers, des Gels und der PVDF-Membran wurden jeweils mit Transferpuffer abgesättigt und die Kassette durch Andrücken der Anodenseite auf die Kathodenseite fest verschlossen. Zusammen mit der BlotElektrodeneinheit wurde die Kassette in die mit Puffer gefüllte Blot-Kammer eingesetzt. Der Transfer erfolgte bei einer Spannung von $120 \mathrm{~V}$ und $4{ }^{\circ} \mathrm{C}$ für $1 \mathrm{~h}$.

Transfer-Puffer:

Tris $25 \mathrm{mM}$

Glycin $192 \mathrm{mM}$

Methanol $(20 \%[\mathrm{v} / \mathrm{v}])$ $200 \mathrm{ml}$

$\mathrm{H}_{2} \mathrm{O}_{\text {bidest }}$ ad $1000 \mathrm{ml}$

$\mathrm{pH}$ $8,1-8,4$

Den pH-Wert nicht mit Säure oder Base einstellen; lag der pH außerhalb dieses Bereichs, wurde der Puffer neu angesetzt).

Bei der vor dem Western-Blot durchgeführten SDS-PAGE wurde ein sogenannter „Prestained Marker“ (LMW, Fa. Bio-Rad Laboratories GmbH, München; siehe 2.20) verwendet.

Anhand dieser bereits gefärbten Banden konnte der Proteintransfer überprüft werden. Dadurch entfiel ein Färbeschritt mit Ponceau S. Die Membran konnte direkt nach dem Western-Blot der gewünschten Färbung unterzogen werden.

Als Alternative zur Benutzung von Nitrocellulosemembranen wurden auch hydrophobe Polyvinylidendifluorid-Membranen (PVDF-Membranen, Fa. Millipore, Eschborn) eingesetzt. Dabei musste darauf geachtet werden, dass diese zunächst in $100 \%$ Methanol voräquilibriert wurden. 


\subsubsection{Protein-,Dot-Blot"-Verfahren (HAWKES, 1986; modif.)}

Alternativ zu 2.22.1 konnten Proteine mittels „Dot-Blot“-Verfahrens auf Membranen übertragen werden ohne vorher in einem SDS-Polyacrylamidgel aufgetrennt zu werden. Hierfür wurden nur Nitrocellulose-Membranen verwendet werden, da diese nicht wie die PVDF-Membranen zuvor in 100 \% Methanol quellen mussten. Bei dem Verfahren wurden definierte Konzentrationen bzw. Volumina einer Proteinlösung direkt auf die Membran getropft, die Membran für ca.10 min bei RT getrocknet und dann verwendet.

\subsection{Immunodetektion von Proteinen auf Blotmembranen}

Geblottete Antigene bieten die Möglichkeit sie mit Konjugaten oder Antikörpern anzufärben. Bei der Verwendung von Antikörpern hängt die Spezifität der Immunfärbung von der Spezifität des primären und sekundären Antikörpers und deren eingesetzten Konzentrationen ab.

\subsubsection{Chromogene Methoden}

\subsubsection{1 $\mathrm{Ni}^{2+}$-NTA-Konjugat-Färbung}

Dieses Verfahren dient dem Nachweis von bestimmten Proteinen auf Blotmembranen. Es beruht auf der Affinität des mit alkalischer Phosphatase gekoppelten $\mathrm{Ni}^{2+}$-NTAKonjugats (Fa. Qiagen GmbH, Hilden) zu mehreren aufeinanderfolgenden Histidinresten (His 6 -Tag) eines Proteins. Ein solcher His ${ }_{6}$-Tag kann mit Hilfe geeigneter Vektoren carboxy- oder aminoterminal an rekombinante Proteine angehängt werden. Histidin fungiert dabei als Elektronendonator an der Proteinoberfläche und bindet so an Metallionen wie z.B. Nickel (HOCHULI, 1988; YIP et al., 1989). Solche Komplexe können durch den Umsatz geeigneter Substrate von der alkalischen Phophatase anhand der resultierenden Farbänderung sichtbar gemacht werden. 
Die Inkubationen und das Waschen der Membran wurden unter Schwenken bei RT nach folgendem Protokoll durchgeführt:

- 2 x 10 min in TBS-Puffer waschen

- $1 \mathrm{~h}$ bis über Nacht (dann bei $4{ }^{\circ} \mathrm{C}$ ) in Blockpuffer inkubieren

- 3 x 10 min in TBST-Puffer waschen

- $1 \mathrm{~h}$ in $\mathrm{Ni}^{2+}$-NTA-Konjugat-Stammlösung/TBST-Puffer (1:1000) inkubieren

- 3 x 10 min in TBST-Puffer waschen

- Behandlung mit Färbelösung, bis die Banden deutlich sichtbar sind

- 2 x $10 \mathrm{sec}$ in $\mathrm{H}_{2} \mathrm{O}_{\text {bidest }}$ spülen

- zum Abstoppen der Reaktion 5 min in Trichloressigsäure (3 \% [v/v]) inkubieren

- 2 x $10 \mathrm{sec}$ in $\mathrm{H}_{2} \mathrm{O}_{\text {bidest }}$ spülen

Die Membran wurde in Plastikfolie eingeschweißt, sofort mit Hilfe eines Scanners dokumentiert und bei RT getrocknet.

$\underline{\text { TBS-Puffer (10-fach) }}$ (siehe 2.3.3)

TBST-Puffer (5-fach) (siehe 2.3.4)

Puffer A:

$\mathrm{NaCl}$

$\mathrm{MgCl}_{2}$

Tris $/ \mathrm{HCl}$

$\mathrm{pH}$
Blockpuffer:

$3 \%(\mathrm{w} / \mathrm{v})$ BSA in TBS-Puffer

Lagerung bei $4{ }^{\circ} \mathrm{C}$, nicht autoklavieren und nach maximal einer Woche frisch ansetzten

NBT-Stammmlösung:

4-Nitroblau-Tetrazoliumchlorid

$5 \%[\mathrm{w} / \mathrm{v}]$

N,N'-Dimethylformamid

$7 \mathrm{ml}$

$\mathrm{H}_{2} \mathrm{O}_{\text {bidest }}$

ad $10 \mathrm{ml}$

Lagerung bei $-20{ }^{\circ} \mathrm{C}$

BCIP-Stammlösung:

5-Brom-4-chlor-3-indolyl-phosphat

$5 \%[\mathrm{w} / \mathrm{v}]$

N,N`-Dimethylformamid

ad $10 \mathrm{ml}$

Lagerung bei $-20{ }^{\circ} \mathrm{C}$ 
Färbelösung:

NBT-SL

$66 \mu 1$

BCIP-SL

$33 \mu 1$

Puffer A

$10 \mathrm{ml}$

Die Lösung wurde direkt vor Gebrauch frisch angesetzt.

\subsubsection{Färbung mit Substrat für Peroxidase-markierten sekundären Antikörper}

Dieses Verfahren diente zur Detektion des menschlichen Intrisic Faktors, MutB, des Strep-TagII, des Chaperons DnaK und des Maltose-bindenden Proteins (MBP). Bei dieser Methode wurde im Gegensatz zu 2.23.1.1 mit zwei verschiedenen Antikörpern (AK) gearbeitet, wodurch das System sensitiver wird: einem primären, für das zu detektierende Antigen-spezifischen-AK und einem sekundären, peroxidasegekoppelten-AK. Bei dem sekundären Antikörper handelte es sich entweder um antiKanninchen-AK oder anti-Maus-AK, je nachdem in welchem Organismus der primäre AK produziert worden war. Analog der $\mathrm{Ni}^{2+}$-NTA-Konjugat-Färbung kann auch hierbei das entsprechende Protein durch Umsatz geeigneter Substrate von der Peroxidase anhand des Farbumschlags sichtbar gemacht werden.

Die nachfolgenden Schritte zur Inkubation und zum Waschen der Membran wurden unter Schwenken bei RT durchgeführt:

- 2 x 10 min in TBS-Puffer (siehe 2.3.3) waschen

- $1 \mathrm{~h}$ bis über Nacht (dann bei $4{ }^{\circ} \mathrm{C}$ ) in Blockpuffer inkubieren

- 3 x 10 min in TBST-Puffer (siehe 2.3.4) waschen

- $2 \mathrm{~h}$ in primären AK /TBST-Puffer (Konz. 1:1000-1:7000) inkubieren

- 3 x 10 min in TBST-Puffer waschen

- 1-2 h in sekundärem AK/TBST-Puffer (Konz. 1:2000) inkubieren

- Detektion mit Substrat für die Peroxidase, Inkubation bis Banden sichtbar werden

(5 min-1 h); hierbei nicht mehr Schwenken

- Abstoppen mit $\mathrm{H}_{2} \mathrm{O}_{\text {bidest }}$

Die Membran wurde in Plastikfolie eingeschweißt und mit Hilfe eines Scanners dokumentiert. Anschließend noch mal für 30 min bis über Nacht in $\mathrm{H}_{2} \mathrm{O}_{\text {bidest }}$ bei $4{ }^{\circ} \mathrm{C}$ gelagert (verstärkt Bandenintensität) und gegebenenfalls wiederholt eingescant.

Peroxidase-Substrat:

Color development reagent ${ }^{\mathrm{a}}$ $15 \mathrm{mg}$

eiskaltes Methanol

6-7 ml

TBS-Puffer (siehe 2.3.3)

ad $30 \mathrm{ml}$

a: 4-Chloro-1-Naphthol, Fa. Bio-Rad Laboratories GmbH, München 
Das Color development reagent wurde in zuerst in Methanol gelöst und anschließend mit TBS-Puffer aufgefüllt. Die Reaktion wurde durch Zugabe von $200 \mu$ l eiskaltem $\mathrm{H}_{2} \mathrm{O}_{2}$ gestartet.

Folgende primäre Antikörper kamen zum Einsatz:

- polyklonales IF-spezifisches-Antiserum aus dem Kanninchen

- monoklonaler IF-spezifischer-Antikörper aus der Maus

- monklonaler Histidin-spezifischer-Antikörper (Penta Histidin) aus der Maus

- polyklonales DnaK-spezifisches Antiserum aus dem Kanninchen

- polyklonales MBP-spezifisches Antiserum aus dem Kanninchen

- polyklonaler Strep-TagII-spezifischer Antikörper aus dem Kanninchen

- polyklonales Strep-TagII-spezifisches Antiserum aus dem Kanninchen

\subsubsection{Chemilumineszente Methode}

\subsubsection{Detektion mit ECL Plus Substrate (Fa. Amersham Pharmacia Biotech,} UK) für peroxidase-markierten sekundären Antikörper

Peroxidase-markierte Antikörper katalysieren die Oxidation von Luminol und lösen damit eine Chemilumineszenz aus. Das dabei entstehende Licht kann mit Autoradiographiekassetten und einem Phosphoimager (siehe 2.12.2) gemessen werden. Die ECL-Reaktion ist etwa 10-mal sensitiver als die Blotentwicklung mit alkalischer Phosphatase (siehe 2.23.1.1) und läuft in Sekunden bis Minuten ab. Wegen der erhöhten Sensitivität sind die Waschschritte nach dem Blocken intensiver als unter 2.23.1.1 beschrieben:

- geblottete Membran 2 x 2 min in Puffer1 waschen

Waschprozeß nach der Inkubation mit dem $\underline{1}$. Antikörper:

- Membran 2 x mit Puffer 1 spülen

- 15 min in Puffer 1 waschen

- $\quad 3$ x 5 min mit Puffer 1 spülen

Waschschritte nach der Inkubation mit dem 2. Antikörper:

- Membran 2 x mit Puffer 1 spülen

- 15 min in Puffer 1 waschen

- $\quad 3$ x 5 min mit Puffer 1 spülen 
Für die Detektion wurden Lösung A und B (Fa. Amersham Pharmacia Biotech, UK) im Verhältnis 40:1 gemischt und auf die Membranoberfläche aufgetragen. Nach 1 min wurde der Blot in Haushaltsfolie eingeschlagen und im Phosphoimager bei $430 \mathrm{~nm}$ ausgewertet.

Puffer 1:

entweder TBST (siehe 2.3.4):

oder:

$\underline{\text { PBST: }}$

$\mathrm{KH}_{2} \mathrm{PO}_{4} \quad 4 \mathrm{M}$

$\mathrm{Na}_{2} \mathrm{HPO}_{4} \quad 16 \mathrm{mM}$

$\mathrm{NaCl} \quad 115 \mathrm{mM}$

Tween $20 \quad 0,25-0,1 \%[\mathrm{v} / \mathrm{v}]$

$\mathrm{pH} \quad 7,3$

\subsection{Nachweis des „Green Fluorescent Protein“ im Fluoreszenzmikroskop}

Zum Nachweis der Produktion des „Green Fluorescent Protein“ (GFP) wurden 2-3 $\mu$ 1 aus den entsprechenden Zellkulturen auf einen Objektträger gegeben und mit einem Deckgläschen bedeckt, was anschließend gut fixiert wurde. Die Analyse der Zellen erfolgte im Fluoreszenzmikroskop Axiovert S100 von Zeiss, GFP-Filter: Anregung BP 450-490, Emission BP 500-550.

\subsection{Einbettung von Zellen für elektronenmikroskopische Dünnschichtdarstellungen}

Für Ultradünnschnitte von Zellen wurden diese nach der Lowicryl (Temperaturmethode) eingebettet. Die Anzucht der Zellen erfolgte dabei aerob in $100 \mathrm{ml} \mathrm{LB}$ und anaerob in $500 \mathrm{ml}$ Mineralmedium (siehe 2.2.1, 2.14.1 und 2.14.3). Anschließend wurden die Zellen geerntet und zweimal mit KP-Puffer (siehe 2.3.1) gewaschen (Zentrifugationsschritte bei $4{ }^{\circ} \mathrm{C}, 10 \mathrm{~min}$, Sorvall Rotor SS34 bzw. GS-3 Becher). Den in 1-2 ml KP-Puffer resuspendierten Zellen wurde 0,2 \% Glutaraldehydlösung und 0,3 \% p-Formaldehydlösung zugesetzt (pro Ansatz je 3-4 ml Lösung). Dieser Ansatz wurde über Nacht bei $4{ }^{\circ} \mathrm{C}$ gelagert, bevor die fixierten Bakterien dreimal in PBS gewaschen wurden $\left(4{ }^{\circ} \mathrm{C}, 10 \mathrm{~min}\right.$, Sorvall Rotor SS34). Das in ein 1,5 ml-Eppendorf-Reaktionsgefäß überführte Zellpellet wurde daraufhin mit $2 \%$ igem auf $40{ }^{\circ} \mathrm{C}$ erwärmten Agar (in PBS) sorgfältig gemischt, wobei das Verhältnis 
von Pelletvolumen und Agarlösung 1:1 betragen mußte und anschließend für 10 min auf Eis abgekühlt wurde. Um die in Agar eingebetteten Zellen aus dem Reaktionsgefäß zu befreien, wurde die Spitze mit eine Klinge abgeschnitten und der Inhalt auf einen Glasobjektträger geschoben, wo dieser in ca. $2 \mathrm{~mm}$ Stücke geschnitten wurde. Diese Stücke mußten, um ein Austrocknen zu vermeiden, sofort in 3,5 ml Präparatengläser (12 x $35 \mathrm{~mm}$, Ochs) weiterverarbeitet werden.

Die anschließende Infiltration der Agarblöckchen mit Methanollösung bzw. Kunstharzlösung verlief nach folgendem Schema:

- 15 min bei $0{ }^{\circ} \mathrm{C}$ in $15 \%$ Methanol

- 30 min bei $0{ }^{\circ} \mathrm{C}$ in $30 \%$ Methanol

- 50 min bei $-20{ }^{\circ} \mathrm{C}$ in $50 \%$ Methanol

- 30 min bei $-35{ }^{\circ} \mathrm{C}$ in $70 \%$ Methanol

- 30 min bei $-35{ }^{\circ} \mathrm{C}$ in $95 \%$ Methanol

- 2 x 30 min bei $-35^{\circ} \mathrm{C}$ in $100 \%$ Methanol

$-1 \mathrm{~h}$ bei $-35{ }^{\circ} \mathrm{C}$ in $50 \%$ Methanol $+50 \%$ Lowicryl K4M-Harz

- $2 \mathrm{~h}$ bei $-35{ }^{\circ} \mathrm{C}$ in $33 \%$ Methanol $+66 \%$ Lowicryl K4M-Harz

- 1 x Wechseln und dann übers Wochenende bei $-35^{\circ} \mathrm{C}$ in $100 \%$ Harz

Die Proben wurden nach dieser Behandlung in Gelatinekapseln überführt, die mit $100 \% \mathrm{~K} 4 \mathrm{M}-$ Harz gefüllt wurden und folgend für mindestens $24 \mathrm{~h}$ bei $-35{ }^{\circ} \mathrm{C}$ (+ UVLicht) dann bei RT mit UV-Licht polymerisiert.

Zusammensetzung des Kunstharzes (Serva):

- Vinylcyclohexendioxid (ERL 4206)

$15,0 \mathrm{~g}$

- DER 732 (oder DER 736 nur 9,0 g)

$13,5 \mathrm{~g}$

- Nonenylbernsteinsäureanhydrid (NSA)

$39,0 \mathrm{~g}$

- $\alpha$-Dimethylaminoethanol (S1)

$0,6 \mathrm{~g}$

\subsubsection{Ultramikrotomie}

Die polymerisierten Proben wurden mit einer Diamantfräse (TM 60, Reichert, Österreich) so angespitzt, daß ein Pyramidenstumpf mit einer quadratischen Spitze von maximal $0,5 \mathrm{~mm}^{2}$ Oberfläche entsteht. Die Dünnschnitte wurden mit einem Ultramikrotom (Ultrome III, LKB. Bromma, Schweden) unter Verwendung von Glasmessern angefertigt.

Die Messer wurden aus $25 \mathrm{~mm}$ breiten und 6,5 mm dicken Glasstreifen (LKB, Bromma, Schweden) mit einem Messerbrecher (Knifemaker LKB 7800) hergestellt und besaßen bei einem Gegenstück von ca. $0,5 \mathrm{~mm}$ Dicke einen realen Winkel um $55^{\circ}$ an der 
Messerkante. Sie wurden mit einem Kunststofftrog zur Aufnahme von filtrierten $\mathrm{H}_{2} \mathrm{O}_{\text {bidest. }}$, auf dem die Schnitte abflottierten, versehen und konnten mehrere Tage ohne Qualitätsverlust gelagert werden.

Die auf der Wasseroberfläche abflottierten Ultradünnschnitte besaßen bei silberner Interferenzfarbe eine Dicke von 50-60 nm. Die Schnitte wurden mit formvarbeschichteten Kupfergrids aufgenommen.

Die Inkubation der Ultradünn-Schnitte auf den Grids erfolgte mit zunächst für $90 \mathrm{~min}$ mit primären Strep-TagII Antikörpern (1:100 Verdünnung). Nach den folgenden Waschschritten für $15 \mathrm{~s}$ mit PBS $+0,01 \%$ Tween-20, 2 × 5 min mit PBS $+0,01 \%$ Tween-20 und $5 \mathrm{~s}$ mit PBS wurden die Ultradünn-Schnitte für $45 \mathrm{~min}$ mit den sekundären immunogold-markierten anti-Kanninchen Antikörpern (EM Goat Antirabbit IgG; 1:50 Verdünnung) inkubiert. Danach konnten die Grids erneut gewaschen werden (15 s mit PBS + 0,01\% Tween-20, 2 × 5 min mit PBS + 0,01\% Tween-20 und $10 \mathrm{~s}$ mit $\mathrm{H}_{2} \mathrm{O}_{\text {dest }}$ ). Danach mussten sie über Nacht auf Filterpapier getrocknet werden.

\subsection{Synthese von ${ }^{14} \mathrm{C}$-markiertem Coenzym $\mathrm{B}_{12}$}

Zur Untersuchung von $\mathrm{B}_{12}$-Bindungen von Proteinen mittels Dot-Blot-Verfahren (siehe 2.22.2) sollte ${ }^{14} \mathrm{C}$-markiertes Coenzym $B_{12}$ synthetisiert werden, da dies nicht käuflich zu erwerben ist. Die ${ }^{14} \mathrm{C}$-Markierung sollte dabei an der Dimethylbenzimidazol-Einheit des Coenzym $\mathrm{B}_{12}$ erfolgen.

\subsubsection{Synthese von 5,6-Dimethyl $\left(2-{ }^{14} \mathrm{C}\right)$ Benzimidazol (HÖRIG und RENZ, 1980)}

Die Synthese von 5,6-Dimethyl $\left(2-{ }^{14} \mathrm{C}\right)$ benzimidazol erfolgte durch chemische Umsetzung von 1,2-Diamino-4,5-Dimethylbenzen (136 $\mathrm{mg}$ in 0,4 $\mathrm{ml} \mathrm{H}_{2} \mathrm{O}_{\text {bidest }}$ ) mit $\mathrm{Na}\left({ }^{14} \mathrm{C}\right)$ Formiat $(50 \mu \mathrm{Ci})$. Diese beiden Substanzen wurden zunächst mit $0,1 \mathrm{ml}$ Ameisensäure und $1 \mathrm{ml} \mathrm{HCl}(2 \mathrm{M})$ versetzt und für $1,5 \mathrm{~h}$ bei $100{ }^{\circ} \mathrm{C}$ erhitzt. Nach diesem Hitzeschritt folgte eine Inkubation über Nacht bei RT mit anschließender Fällung durch ca. $10 \mathrm{ml}$ Ammoniak (2 M). Das Präzipitat wurde durch Filtration getrennt und mit $\mathrm{H}_{2} \mathrm{O}_{\text {bidest }}$ gewaschen. Getrocknetes 5,6-Dimethyl $\left(2-{ }^{14} \mathrm{C}\right)$ benzimidazol wurde dann in eine Fermentation mit Propionibacterium freundenreichii subsp. shermanii eingesetzt (siehe 2.1). 


\subsubsection{Synthese von Coenzym $B_{12}$ durch Propionibacterium freudenreichii subsp. shermanii (HÖRIG und RENZ, 1980)}

Die Biosynthese von Coenzym $\mathrm{B}_{12}$ in P. freudenreichii subsp. shermanii kann in zwei Schritten vollzogen werden. Während des anaeroben Wachstums in Gegenwart von Cobaltsalzen erfolgt die Synthese der Corrin-Einheit. Die anschließende aerobe Inkubation induziert die Biosynthese von 5,6-Dimethylbenzimidazol. Das dann gebildete Cobinamid wird zu Coenzym $\mathrm{B}_{12}$ umgesetzt. Unter anaeroben Bedingungen synthetisiert $P$. freudenreichii subsp. shermanii nur Coenzym $\mathrm{B}_{12}$, wenn 5,6-Dimethylbenzimidazol zugeführt wird.

Die Glucosefermentation von $P$. freudenreichii subsp. shermanii erfolgte in 1-1-Serumflaschen mit dem unter 2.2.9 beschriebenen synthetischen Medium bei $30{ }^{\circ} \mathrm{C}$ unter anaeroben Bedingungen. Am 2. und 4. Inkubationstag erfolgte die Zugabe des radioaktiv markierten 5,6-Dimethylbenzimidazols (5 bis $10 \mathrm{mg}$ gelöst in Ethanol $\left[70 \%\right.$; v/v]). Nach 6 bis 8 Tagen hatte sich genug Coenzym $B_{12}$ gebildet, und die Zellen wurden durch Zentrifugation (6000 x g, $10 \mathrm{~min})$ geerntet. Der Aufschluß der Zellen erfolgte durch Autoklavieren bei $121{ }^{\circ} \mathrm{C}$ für $20 \mathrm{~min}$. Die Zelltrümmer wurden durch Zentrifugation entfernt (15000 x g, $\left.30 \mathrm{~min}, 4{ }^{\circ} \mathrm{C}\right)$. Nach dem Zellaufschluß mußte wegen der Lichtempfindlichkeit des Coenzym $\mathrm{B}_{12}$ unter Rotlicht gearbeitet werden.

\subsubsection{Nachweis und Isolierung des ${ }^{14}$ C-markierten Coenzym $B_{12}$ durch Hochdruckflüssigkeitschromatographie (HPLC)}

Das gebildete radioaktiv markierte Coenzym $\mathrm{B}_{12}$ (siehe 2.26.2) wurde mittels einer Hochdruckflüssigkeitschromatographie (HPLC) an einer $\mu$ Bondapak C18-Säule (19 mm $\mathrm{x} 15 \mathrm{~cm}, \mathrm{Fa}$. Waters $\mathrm{GmbH}$, Eschborn) gereinigt. Anhand der verschiedenen Retentionszeiten können dabei verschiedene Substanzen getrennt werden. Die Zuordnung der Retentionszeiten erfolgt mit Hilfe von Standards, die nur eine Substanz enthalten und die ebenfalls auf die Säule aufgetragen werden. Aus den auftretenden Peakflächen kann auf die Substanzmenge geschlossen werden. Hierzu wurde für die jeweiligen Substanzen eine Eichgerade aufgenommen. Wurden die Säulen längere Zeit nicht genutzt, mußte das ganze System mit $20 \%$ Ethanol gespült werden. Die HPLCAnlage (Fa. Kontron, Eching) bestand aus folgenden Komponenten: 2 HPLC-Pumpen 42, Mischer M 491, Detektor 43, Multiport und einem AT-Computer mit entsprechender Software (Programm MT2). Als Laufmittel dienten die Lösungen A und B, die vor Gebrauch filtriert (Cellulosenitrat-Filter, Porengröße 0,2 $\mu \mathrm{m}$, Fa. Sartorius, Göttingen) wurden. Die Fließgeschwindigkeit betrug $5 \mathrm{ml} / \mathrm{min}$, ein Lauf dauerte 44 min. Dabei wurde folgender Gradient eingestellt: 


$\begin{array}{cccc}\text { Zeit (min) } & \text { Flußrate (ml/min) } & \text { Lösung A (\%) } & \text { Lösung B (\%) } \\ 0 & 5,0 & 100 & 0 \\ 7 & 5,0 & 75 & 25 \\ 19 & 5,0 & 60 & 40 \\ 23 & 5,0 & 0 & 100 \\ 27 & 5,0 & 0 & 100 \\ 31 & 5,0 & 100 & 0 \\ 33 & 0,1 & 100 & 0\end{array}$

Als Eichsubstanzen wurden Hydroxy- $\mathrm{B}_{12}$, Cyano- $\mathrm{B}_{12}$, Methyl- $\mathrm{B}_{12}$ und Coenzym $\mathrm{B}_{12}$ in einer Konzentration von $0,05 \mathrm{mg} / \mathrm{ml}$ verwendet. Von diesen Lösungen wurden $50 \mu \mathrm{l}$ injiziert. Die Detektion erfolgte am UV-Detektor bei $360 \mathrm{~nm}$. Von den zu untersuchenden Proben wurde $1 \mathrm{ml}$ injiziert. Pro Lauf konnten durch 4-maliges Injizieren $4 \mathrm{ml}$ Probe aufgearbeitet werden.

Lösung A:

Lösung B:

Na-Acetat $x 3 \mathrm{H}_{2} \mathrm{O}$

$8,95 \mathrm{~g}$

Methanol

41

Tetrabutylammonium-

$5,88 \mathrm{ml}$

Essigsäure

$0,4 \mathrm{ml}$

hydroxid (TBAH)

Lösung B

$210,5 \mathrm{ml}$

TBAH

$5,88 \mathrm{ml}$

$\mathrm{H}_{2} \mathrm{O}_{\text {bidest. }}$

ad 41

Der pH von 4,6 wurde mit Essigsäure vor Zugabe von Lösung B eingestellt.

Das so isolierte, radioaktiv markierte Coenzym $\mathrm{B}_{12}$ lag sehr verdünnt vor und wurde daher mittels einer Vakuumzentrifugation (Vakuumzentrifuge Savant AS160, Fa. Savant Instruments Inc., Holbrook, USA) eingeengt. Die schon erwähnten Eichsubstanzen wiesen folgende Retentionszeiten auf:

$\begin{array}{cc}\text { Eichsubstanz } & \text { Retentionszeit (min) } \\ \text { Cyano- }_{12} & 17,76 \\ \text { Coenzym } B_{12} & 20,35 \\ \text { Methyl-B } & \\ \text { Hydroxy}_{12} & 21,79 \\ \text { He } & 22,06\end{array}$




\subsection{Quantitative Bestimmung von Corrinoiden}

\subsubsection{Quantitative Bestimmung von Corrinoiden mittels Plattentest (KRZYCKI und ZEIKUS, 1980; modif.)}

Der $\mathrm{B}_{12}$-Plattentest ermöglicht es Corrinoide in Zellextrakten oder Überständen nachzuweisen. Der Test beruht auf der Tatsache, daß E. coli DSM 4261 aufgrund einer Punktmutation im metE-Gen, welches für eine $\mathrm{B}_{12}$-unabhängige Methionin-Synthase kodiert, auf seine alternative $\mathrm{B}_{12}$-abhängige Methionin-Synthase, kodiert durch metH, angewiesen ist. Daher ist dieser Stamm in Methionin-freiem Medium auf die $\mathrm{B}_{12}$ abhängige Methionin-Synthase und damit auch auf das Vorhandensein von $\mathrm{B}_{12}$ angewiesen.

Der Duchmesser dieser Zonen ist proportional zum Wachstum der E. coli Mutante und damit auch proportional zur $\mathrm{B}_{12}$-Konzentration in der Probe.

Die $\mathrm{B}_{12}$-auxotrophe E. coli-Mutante wurde in die Testplatten (siehe 2.2.7) eingegossen. Dazu wurde eine $50 \mathrm{ml}$ Hauptkultur mit Minimal-Aminsosäure Medium (siehe 2.2.6) mit einer $5 \mathrm{ml}$ über Nacht Vorkultur angeimpft. Bei einer $\mathrm{OD}_{600}$ von ca. 2,0 wurde die Zellen geerntet, dreimal mit $20 \mathrm{ml} 0,9 \% \mathrm{NaCl}$ gewaschen und anschließend indemselben Volumen $\mathrm{NaCl}$ resuspendiert. 0,7 $\mathrm{ml}$ dieser gewaschenen Zellsuspension diente als Inokulum für $500 \mathrm{ml}$ auf $50{ }^{\circ} \mathrm{C}$ abgekühlten Mineralagar (siehe 2.2.7). Außerdem wurde dem Agar noch das Reduktionsmittel Triphenyltetrazoliumchlorid beigefügt. Auf die Platten wurden je 4 sterile Filterplättchen $(\varnothing 0,9 \mathrm{~cm}, \mathrm{Fa}$. Schleicher $\&$ Schuell, Dassel) gelegt und mit 10-15 $\mu$ l Probe und demselben Volumen $\mathrm{B}_{12}$-Eichlösungen zentral beladen. Die Eichkurve wurde mit Coenzym $\mathrm{B}_{12}$ und/oder Vitamin $B_{12}$ der Konzentrationen 0 / 0,05 / 0,25 / 0,1 / 5,0 $\mu \mathrm{g} / \mathrm{ml}$ aufgenommen. Sowohl von den Proben als auch von den Eichlösungen wurden immer Doppelbestimmungen durchgeführt. Die Inkubation der Platten erfolgte für $16-24 \mathrm{~h}$ bei $37^{\circ} \mathrm{C}$. Enthielten die Proben $\mathrm{B}_{12}$, ließen sich nach Inkubation der Platten rote Zonen um die Plättchen erkennen. Das Wachstum der Mutante im Medium bewirkt die Reduktion des Triphenyltetrazoliumchlorids im Agar, was sich durch eine rote Färbung auszeichnet. Um die $\mathrm{B}_{12}$-Konzentionen zu bestimmen, wurden die Durchmesser der roten Zonen um die Filterplättchen ausgemessen. Das Wachstum und damit der Durchmesser der roten Zone ist proportional zu der $\mathrm{B}_{12}$-Konzentration in der aufgetragenen Lösung.

Die Zellen aus den Induktionsversuchen wurden nach der Ernte dreimal mit 0,1 M KP-Puffer (siehe 2.3.1) gewaschen, um mögliche $\mathrm{B}_{12}$ - und Methionin-Verunreinigungen aus dem Medium zu entfernen.

Als Proben wurden Periplasma, Cytoplasma und Rohextrakte aus verschiedenen Expressionstudien eingesetzt. 


\subsubsection{Photometrische Methode zu quantitativen Corrinoidbestimmung}

Das Prinzip dieser Methode besteht darin, alle in der Probe enthaltenen Corrinoide in die lösliche Dicyano-Form umzusetzen und störende Komponenten wie Proteine und Lipide auszufällen und abzuzentrifugieren. Zur Bestimung der Corrinoide wurde ein Spektrum der zuvor aufgearbeiteten Proben zwischen 350 und $650 \mathrm{~nm}$ aufgenommen (Plastikküvette $\mathrm{d}=1 \mathrm{~cm}$, Messung gegen Luft) und der $\mathrm{B}_{12}$-Gehalt dann durch Bestimmung der Absorptionsunterschiede bei 580 und $650 \mathrm{~nm}$ mit Hilfe des molaren Extinktionskoeffizienten des Dicyanocobalamins $\left(\Delta \epsilon_{580-640}=7,3 \mathrm{mM}^{-1} \mathrm{x} \mathrm{cm}^{-1}\right)$ berechnet. Alternativ wurde der $\mathrm{B}_{12}$-Gehalt auch mit Hilfe des Extinktionskoeffizienten für Dicyanocobalamin bei $580 \mathrm{~nm}$ und $367 \mathrm{~nm}\left(\epsilon_{540}=7800 \mathrm{mM}^{-1} \mathrm{x} \mathrm{cm}^{-1}, \epsilon_{367}=23800\right.$ $\mathrm{mM}^{-1} \mathrm{x} \mathrm{cm}^{-1}$ ) berechnet und der Mittelwert bestimmt. Der Wert bei $376 \mathrm{~nm}$ sollte dabei etwa 3-4 mal so hoch wie der bei $580 \mathrm{~nm}$ sein. Als Standard wurde sowohl Hydroxyals auch Cyano- $B_{12}$ eingesetzt.

Für die Umsetzung der Corrinoide aus einer Probe in die Dicyanoform wurden nachfolgende Schritte durchgeführt:

- $1 \mathrm{ml}$ Probe mit 0,2\%(w/v) $\mathrm{NaCN}$ oder $\mathrm{KCN}$ für 30 min bei RT im dunkeln inkubieren

- Lösung mit Eisessig auf pH 4 ansäuern

- Proben für $20 \mathrm{~min}$ bei $100^{\circ} \mathrm{C}$ kochen

- abkühlen und mit $10 \mathrm{~N} \mathrm{KOH}$ auf pH 11 titrieren

- erneut Zugabe von 4-5 mg NaCN oder KCN

- 30 min bei 13000 Upm und RT zentrifugieren, um ausgefallene Proteine zu entfernen

- $\quad$ vom Überstand ein Spektrum zwischen 350 und $650 \mathrm{~nm}$ fahren

Bei den eingesetzten Proben handelte es sich sowohl um Periplasma, als auch um Cytoplasma und Rohextrakt. Um die Proben der einzelnen Fraktionen untereinander vergleichen zu können wurden die Proteingehalte einander angeglichen. 


\subsection{Bezugsquellen}

Standardchemikalien wurden, soweit nicht anders im Text angegeben, mit dem Reinheitsgrad „pro analysis“ oder „reinst“ von den Firmen Boehringer (Mannheim),

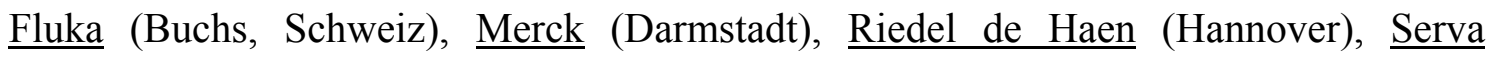
(Heidelberg) und Sigma (Taufkirchen) verwendet. Die Bezugsquellen weiterer Chemikalien, Enzyme, Verbrauchsmaterialien und Kits sind nachfolgend aufgeführt:

\section{ALDRICH-CHEMIE, Steinheim}

TEMED

Amersham Pharmacia, Freiburg:

NAP-5-Säulen, PD 10-Säulen, „HMW Calibration-Kit“, „LMW-Calibration“-Kit, Nylonmembranen

BIOTREND, Köln

Mouse Anti-Intrinsic Factor IgG1

BIORAD, München

Peroxidase-konjugierter Goat Anti-Rabbit IgG

Biozym GmbH, Hess. Oldendorf:

Tfl DNA Polymerase

Dianova, Hamburg:

Peroxidase-konjugierter Goat Anti-Mouse IgG $(\mathrm{H}+\mathrm{L})$

DSM-Deutsche Sammlung von Mikroorganismen und Zellkulturen GmbH:

E. coli DSM 4261, Propionibacterium freudenreichii subsp. shermanii 4902

Eurogentec, Seraing, Belgien:

Agarose

Gerbu Biotechnik GmbH, Gaiberg:

IPTG, X-Gal, Ampicillin, Acrylamid, Bisacrylamid, Mops, SDS 4x, Tween 20 
Gibco BRL, Eggenstein:

Hefeextrakt, Random Primed Labeling Kit

Hartmann Analytic, Braunschweig:

$[\alpha-32 P]-d A T P$

IBA GmbH, Göttingen:

Strep-Tag II Antikörper

MBI Fermentas GmbH, St. Leon-Rot:

Ladder-Mix, Nukleotide; Restriktionsendonukleasen, T4-DNA-Ligase, Taq-Polymerase

Millipore, Eschborn:

Mikrodialyse-Filter

New-England Biolabs GmbH, Freiburg:

Restriktionsendonukleasen, RNA-Leiter, Vent-Polymerase, Anti-MBP Antiserum

Oxoid, Basingstone, England:

Agar, Trypton, Hefeextrakt

Promega, Deutschland GmbH, Mannheim:

Wizard $^{\mathrm{TM}}$ Plus Minipreps DNA Purificaton System, BCIP, NBT

Qiagen GmbH, Hilden:

„RNeasy ${ }^{\mathrm{TM}}$ Total RNA“-Kit, $\mathrm{Ni}^{2+}$-Nitrilotriessigsäure-Agarose, „Qiaquick PCR Purification“-Kit, „Qiaquick Gel Extraction“-Kit, RNA/DNA Maxi Kit, Ni ${ }^{2+}$-NTA-APKonjugat, Penta-His-Antikörper

Sartorius AG, Göttingen:

Sterilfilter

Schleicher \& Schuell, Dassel

Antibiotika-Filterplättchen

$\underline{\text { Sigma Chemie GmbH, Deisenhofen }}$

Cyano-B $\mathrm{B}_{12}$, Hydroxy- $\mathrm{B}_{12}$ 
Takara, Japan:

TakaraEx Taq-Polymerase

Whatman, Maidstone, England:

Whatman-Filterpapier 3MM

Die verwendeten Gase $\left(\mathrm{N}_{2}, \mathrm{H}_{2}, \mathrm{~N}_{2} / \mathrm{CO}_{2}\right.$ mit einem Reinheitsgrad von 99,99\%) wurden von der Firma Messer Griesheim GmbH (Kassel) bezogen. 


\section{Experimente und Ergebnisse}

Vitamin $B_{12}\left(\right.$ Cyano- $\left.B_{12}\right)$ ist ein wasserlösliches Vitamin, welches als exogene Vorstufe zur Synthese von Coenzym $B_{12}$ verwendet werden kann. Nach der Aufnahme kann Cyano- $B_{12}$ in biologisch aktive Formen (Adenosyl- oder Methyl-B $\mathrm{B}_{12}$ ) umgewandelt werden (ZAGALAK, 1982). In der Natur wird $B_{12}$ als Coenzym nur von Mikroorganismen gebildet (ROTH et al., 1996). Einen essentiellen Bedarf an $\mathrm{B}_{12}$ haben sowohl Menschen, Tiere als auch Mikroorganismen. Pflanzen und Pilze hingegen benötigen es nicht (DUDA et al., 1967). Produziert wird $\mathrm{B}_{12}$ z. B. von Propionsäurebakterien, Pseudomonaden, Streptomyceten oder Salmonellen. Andere Bakterien, die nicht in der Lage sind das $B_{12}$ selbst zu bilden, müssen es aus dem umgebenden Milieu aufnehmen. Somit existieren zwar Aufnahmesysteme für $\mathrm{B}_{12}$, ein natürliches Exportsystem ist bislang aber nicht bekannt.

Im Mittelpunkt dieser Arbeit steht nun die Entwicklung eines Systems mit dessen Hilfe Coenzym $B_{12}$ aus einer $B_{12}$-produzierenden Bakterienzelle exportiert werden kann.

\subsection{Strategie für die Entwicklung eines $\mathrm{B}_{12}$-Exporters}

Es wurde ein System angestrebt, in dem $B_{12}$ im Cytoplasma einer Bakterienzelle an ein $\mathrm{B}_{12}$-bindendes Protein gekoppelt und zusammen mit diesem ins Periplasma exportiert wird (siehe Abbildung 5). Entscheidend dabei ist, dass das Bindeprotein in seiner nativen Form vorliegt, um zusammen mit dem Cofaktor über die Cytoplasmamembran transportiert werden $\mathrm{zu}$ können. Ungeeignet sind signalsequenzabhängige Transportsysteme bei denen die Proteine ungefaltet exportiert und erst im Periplasma gefaltet werden (z.B. Sec-System; WICKNER et al., 1991). Das vor einigen Jahren entdeckte Tat-(Twin-Arginine-Translocation) Transportsystem hingegen ermöglicht den Transport nativer Proteine mit gebundenen Cofaktoren z. B. Molybdopterin, Flavin. Dieser generelle zweite Protein-Export-Weg ist weit verbreitet unter Bakterien beispielsweise in E. coli, Zymomonas mobilis oder Wolinella succinogenes zu finden (RODRIGUE et al., 1999). Signalpeptide dieses Transportweges weisen alle das TwinArginin-Motiv S/T-R-R-X-F-L-K auf (BERKS, 1996, BOGSCH et al.; 1998; SARGENT et al., 1998; MORI und CLINE, 1998; SANTINI et al., 1998; WEINER et al, 1998). 


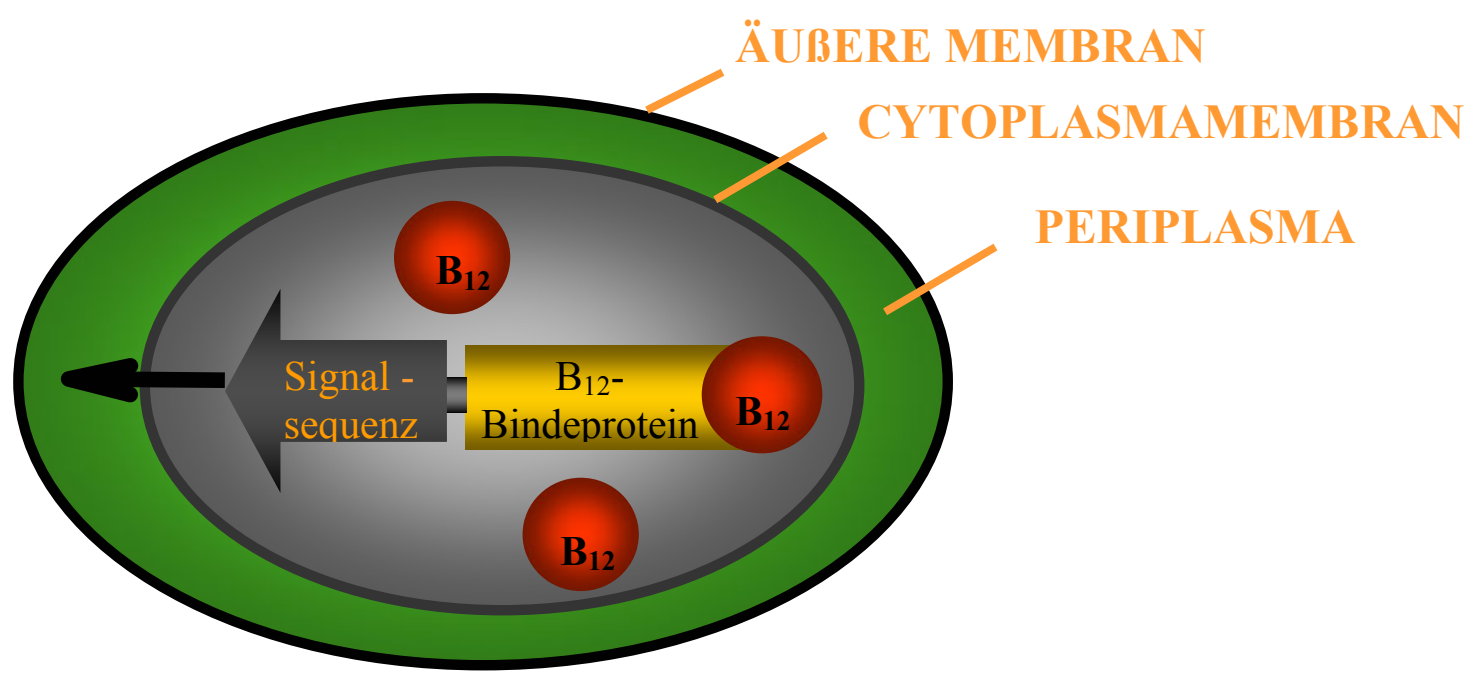

\section{Abbildung 5: Modell für den Export von $B_{12}$ aus einer Gram-negativen Bakterienzelle}

Ein gut untersuchtes Protein, welches über den Tat-Weg transportiert wird, ist die Trimethylamin-N-Oxid-Reduktase (TorA) aus E. coli. Dieses periplasmatische Enzym enthält Molybdopterin als Cofaktor. Die Reduktion von Trimethylamin-N-Oxid zu Trimethylamin ermöglicht es, E. coli anaerob auf nicht-fermentativen C-Quellen wie z.B. Glycerin zu wachsen (MÉJEAN et al., 1994). Für diese TorA-Signalsequenz (sigTorA) ist außerdem bereits der Export eines heterologen Proteins über den Tat-Weg gelungen, welches normalerweise über den Sec-Weg transportiert wird (CHRISTÓBAL et al., 1999). Das TorA-Signalpeptid sollte im Rahmen dieser Arbeit den Export des $\mathrm{B}_{12}$-bindenden Proteins ermöglichen. Als Linker zwischen Signalsequenz und $\mathrm{B}_{12}$-Bindeprotein wurden die ersten fünf Aminosäuren des reifen TorA Proteins genommen (AQAAT).

Bei der Auswahl des Intrinsic Factors (IF) aus dem Menschen und der MethylmalonylCoA-Mutase (MMCoAM) aus Propionibacterium shermanii als $\mathrm{B}_{12}$-Bindeproteine war neben der hohen Bindekapazität (KRÄUTLER, 1998)) für $\mathrm{B}_{12}$ (IF: $10^{12} 1 / \mathrm{mol}$ ), auch die bereits vorhandene Kristallstruktur ausschlaggebend (EVANS und MANCIA, 1998; NEXØ, 1998).

Der menschliche IF ist einer von drei löslichen $\mathrm{B}_{12}$-bindenden Proteinen, die an der Aufnahme und dem Transport von $\mathrm{B}_{12}$ beteiligt sind. Der IF wird im Magen produziert, bindet $\mathrm{B}_{12}$ und transportiert es zu den intestinalen Zellen (KRÄUTLER, 1998). Cyano-, Hydroxy-, Methyl-, Adenosyl-B 12 werden dabei gleich gut gebunden. Der IF hat eine Größe von etwa $55 \mathrm{kDa}$, schrumpft aber nach der Bindung von $\mathrm{B}_{12}$. Weiterhin ist er stark glykosyliert, was aber von geringer Bedeutung für die Erkennung und Bindung des Cobalamins ist, dafür aber die Degradation des IF im intestinalen Kanal zu 
verhindern scheint . Fehlen $12 \%$ des C-terminalen Endes des IF so ist er nicht mehr in der Lage, $\mathrm{B}_{12}$ zu binden (NEXØ, 1998).

Die MMCoAM ist ein $\alpha \beta$-Heterodimer mit einer Größe von $150 \mathrm{kDa}$. Sie katalysiert die Adenosyl $\mathrm{B}_{12}$-abhängige reversible Umwandlung von Methylmalonyl-CoA zu SuccinylCoA. Die von mutB kodierte $\alpha$-Kette beinhaltet sowohl die N-terminale SubstratBindedomäne als auch die C-terminale $\mathrm{B}_{12}$-Bindedomäne (MANCIA et al., 1996; MANCIA und EVANS, 1998). Deshalb wurde nur die $\alpha$-Untereinheit, kodiert durch $m u t B$, für die Konstruktion eines Transporterproteins ausgewählt.

Für die Auswahl des Vektors zur Expression der Gene für die Signalsequenz und das $\mathrm{B}_{12}$ - Bindeprotein musste zunächst berücksichtigt werden, dass viele Gram-negative $\mathrm{B}_{12}$-Produzenten wie $C$. freundii Ampicillin-resistent sind. Aus diesem Grunde wurden zunächst zwei verschiedene Expressionsvektoren ausgewählt, die alle die gleiche

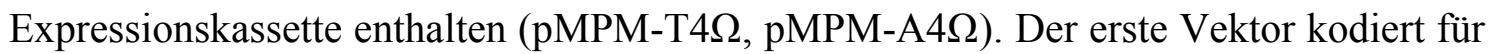
eine Tetracyclin-, und der zweite für eine Ampicillin-Resistenz. Da der $\mathrm{B}_{12}$-Produzent E. blattae nicht Ampicillin-resistent ist, wurde auch der Vektor mit AmpicillinResistenz ausgewählt. Beide Plasmide besitzen eine höhere Kopienzahl und einen Arabinose Promotor, der bei geeigneter Klonierung die Induktion der Proteinsynthese ermöglicht. Dabei werden ara-negative Stämme mit etwa 0,001 \% und ara-positive Stämme mit ca. $1 \%$ Arabinose induziert.

Im weiteren Verlauf der Arbeit wurde noch auf andere Expressionsvektoren zurückgegriffen, die an entsprechender Stelle im Text erwähnt sind.

\subsubsection{Fusion der Signalsequenz mit den $B_{12}$-Bindeproteinen}

\subsubsection{Klonierung von sigtorA mit dem if-Gen in den Vektor pMPM-T4 $\Omega$}

Um die Expression des gewünschten Gens in dem Vektor pMPM-T4 $\Omega$ zu gewährleisten, musste die torA-Signalsequenz in die EcoRI-Schnittstelle des Vektors kloniert werden. Diese Vorarbeiten waren bereits von E. RÜNGELING durchgeführt worden. Dabei wurde die Sequenz, die für das Signalpeptid der TMAO-Reduktase (torA) kodiert mit sechs Oligopeptiden (siehe Tabelle 3) mittels PCR generiert (siehe 2.8). Die Anlagerung der Oligonukleotide erfolgte für jeweils $20 \mathrm{~s}$ bei $55^{\circ} \mathrm{C}$. Daran schloss sich die Polymerisation der DNA bei $72{ }^{\circ} \mathrm{C}$ für $20 \mathrm{~s}$ an, wobei 20 Zyklen durchlaufen wurden. Durch die geeignete Wahl der Oligopeptide wurde am 5'-terminalen Ende des Gens eine EcoRI-Schnittstelle inseriert und am 3'-terminalen Ende ein Linker angehängt, welcher der Sequenz für die ersten fünf Aminsosäuren des reifen TorA-Proteins entsprach und eine Tth111I-Schnittstelle enthielt, über die die Sequenz des IF angehängt wurde. Außerdem enthält das PCR-Produkt am 3'-Ende eine 
Erkennungssequenz für HindIII, die für die Klonierung in den pMPM-T4 $\Omega$ Vektor diente (siehe Tabelle 2). Das gereinigte 180 bp PCR-Produkt (siehe 2.6.3.5) wurde ebenso wie der Vektor mit den Restriktionsenzymen EcoRI und HindIII verdaut (siehe 2.9.1). Um eine Religation des Vektors zu verhindern wurde dieser zusätzlich einem PstI-Verdau unterzogen. Die beiden Komponenten wurden vor dem Einsatz in der Ligation gereinigt (siehe 2.6.3.4). Bei der anschließenden Klonierung wurde das auf dem pMPM-T4 $\Omega$ Plasmid vorliegende 2200 bp große $\Omega$-Interposon herausgeschnitten. Die korrekte Insertion wurde durch Sequenzierung bestätigt. Das resultierende Konstrukt wurde als pER1 bezeichnet und wies eine Größe von 4,8 kb auf (persönliche Mitteilung E. RÜNGELING).

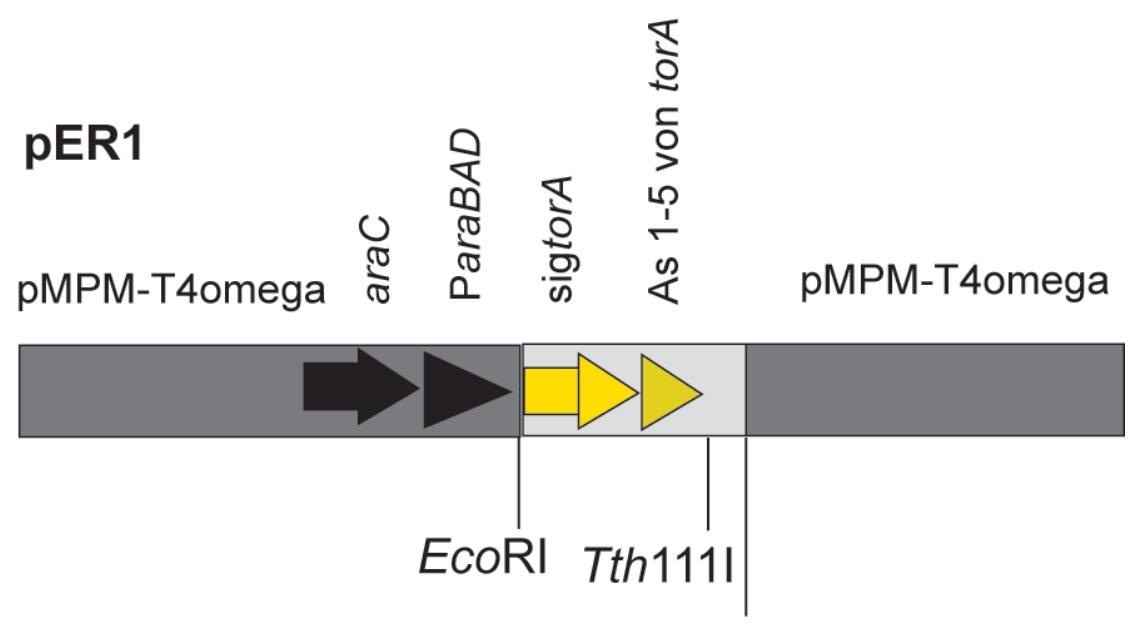

HindIII

\section{Abbildung 6: Schematische Darstellung des Vektors pER1}

In den Expressionsvektor pER1 konnte die Sequenz des IF über die HindIII- und Tth111I-Schnittstelle kloniert werden. Die dafür notwendigen Erkennungssequenzen des IF und die Sequenz für den C-terminalen His $_{6}$-Tag wurden über PCR mit den Oligonukleotiden IFMH5' und IFMH3' sowie dem Plasmid pHIF (siehe Tabelle 3 und Tabelle 2) als Matrize amplifiziert. Die Oligonukleotidanlagerung erfolgte für $40 \mathrm{~s}$ bei $62{ }^{\circ} \mathrm{C}$ und die Kettenverlängerung für $80 \mathrm{~s}$ bei $72{ }^{\circ} \mathrm{C}$. Dabei wurden 25 Zyklen durchlaufen. Nach der Klonierung des 1,2 kb PCR-Fragmentes in den Vektor pER1 über die Restriktionsschnittstellen Tth111I und HindIII konnte die korrekte Insertion durch Sequenzierung bestätigt werden. Das entsprechende Konstrukt pTM1 umfasste eine Größe von 5,9 kb. Der C-terminale His $_{6}$-Tag ermöglichte eine Detektion des Hybridproteins mit Hilfe von Western-Blot-Analysen (siehe 2.22.1). 


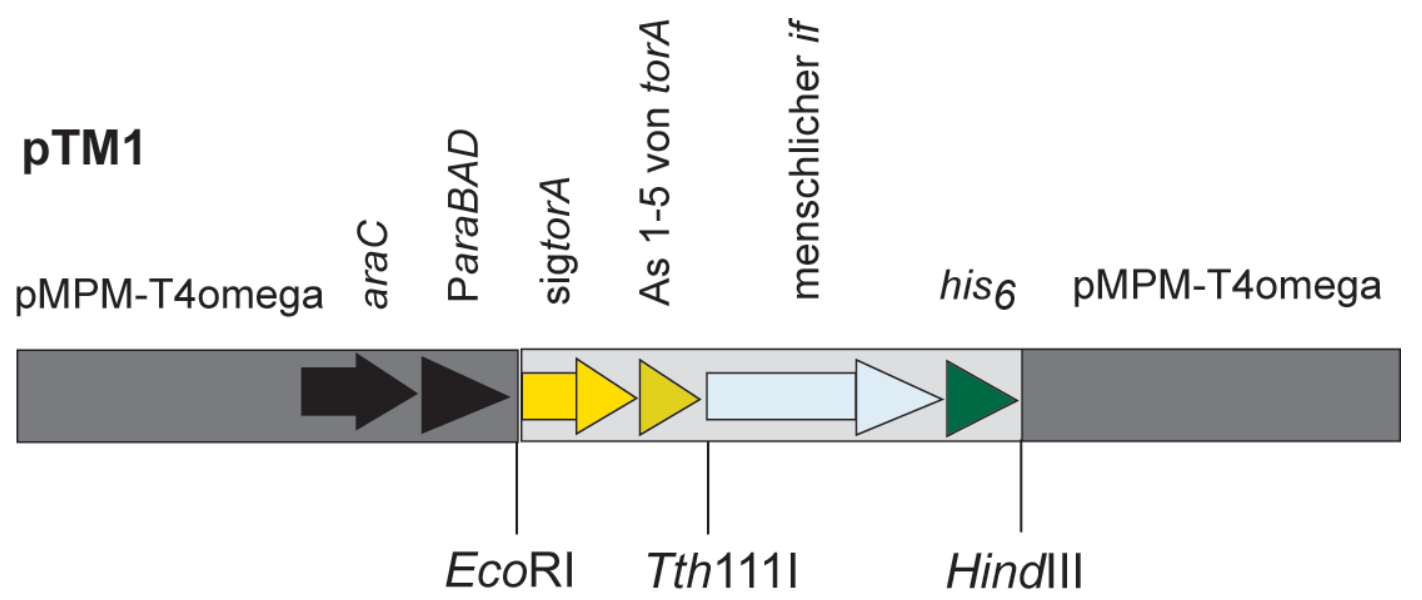

\section{Abbildung 7: Schematische Darstellung des Vektors pTM1}

\subsubsection{Klonierung von sigtor A mit mutB in den Vektor pMPM-T4 $\Omega$}

Die Fusion der torA-Signalsequenz mit dem mutB-Gen erfolgte, wie von BOLM 2000 beschrieben, ebenfalls über PCR. Der resultierende Vektor mit dem Namen pMB5 hatte eine Größe von 6,7 kb (siehe Tabelle 2).

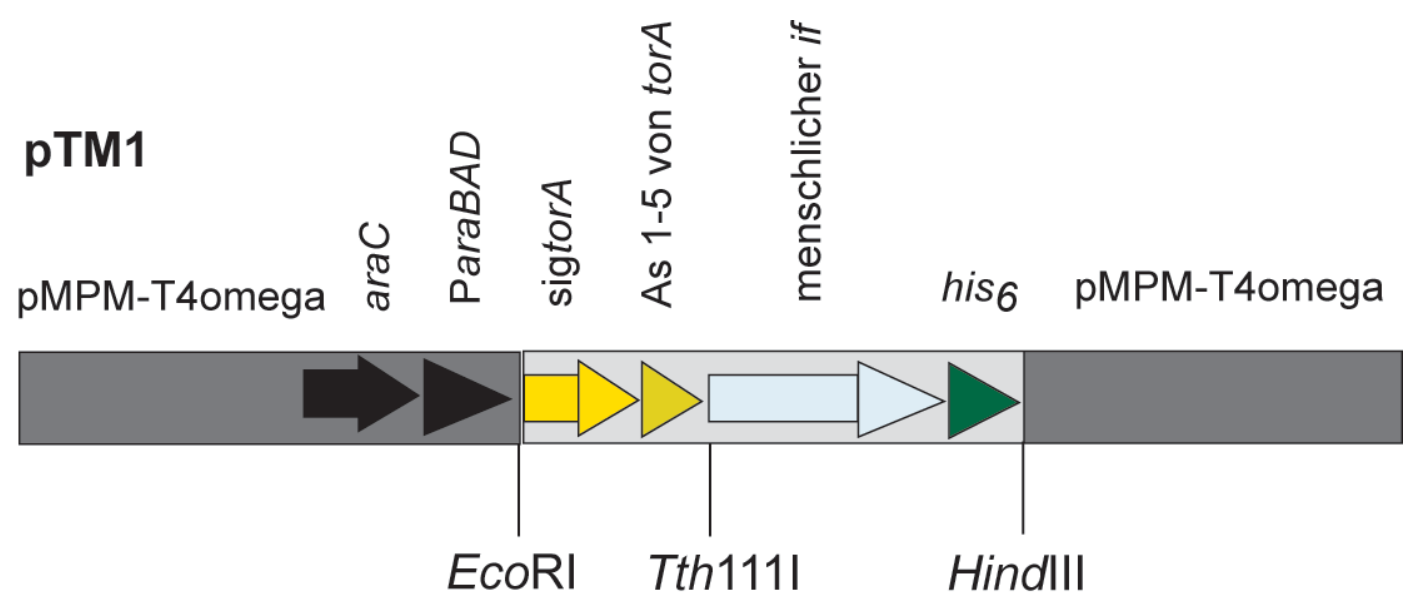

Abbildung 8: Schematische Darstellung des Vektors pMB5

\subsection{Experimente zum Nachweis der Expression der sigtorA-if-Genfusion}

Die einleitenden Studien zum Nachweis des heterolog produzierten sig-TorA-IF Proteins wurden mit dem Konstrukt pTM1 aerob in den E. coli-Stämmen DH5 $\alpha$, BL21(DE3) und JM109 durchgeführt. Als Expressionsvektor lag das Plasmid pMPM-T4 $\Omega$ zugrunde. Kontrollexperimente wurden mit dem Plasmid pER1 
durchgeführt, welches nur für die Signalsequenz sigtorA und nicht für das if-Gen kodiert.

Die Anzucht der Hauptkulturen erfolgte wie unter 2.14.1 beschrieben in $100 \mathrm{ml}$ LB-Medium. Die Induktion der Genexpression wurde bei einer $\mathrm{OD}_{600}$ von 0,4 durchgeführt. Die während des Wachstums gezogenen Proben wurden zur Analyse des Proteinmusters auf ein SDS-Polyacrylamidgel aufgetragen (siehe 2.18.1). Dabei ließ sich in E. coli BL21 (DE3)/pTM3 im Verlauf des Experiments keine Veränderung im Proteinmuster erkennen, und eine zusätzliche Bande im Molekularmassenbereich von $55 \mathrm{kDa}$, welche dem sigTorA-IF-Hybridprotein entspricht, trat nicht auf. Auch durch den Stammwechsel fand keine Änderung statt (Daten nicht gezeigt). Somit erfolgte keine signifikante Produktion von IF, die mit Hilfe dieser Methode detektiert werden konnte. Zum Nachweis der Produktion des sigTorA-IF in geringen Mengen wurde daher eine sensitivere immunochemische Methode durchgeführt.

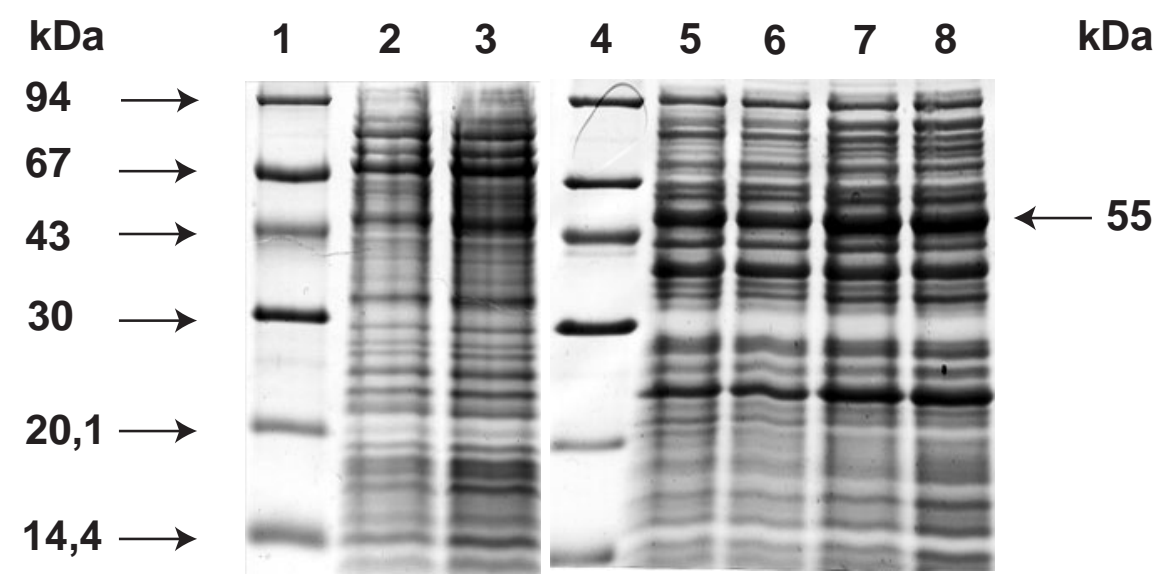

\section{Abbildung 9: Vergleich der SDS-PAGE-Analyse der Produktion von sigTorA und sigTorA-IF in E. coli BL21(DE3)}

Dargestellt ist ein 12 \%iges SDS-Gel. Der Induktor ist in Klammern angegeben.

Spur 1: Proteinstandard

Spur 2: E. coli BL21(DE3)/pER1 (0,5\% Arabinose) dierekt nach Induktion

Spur 3: E. coli BL21(DE3)/pER1(0,5\% Arabinose) $2 \mathrm{~h}$ nach Induktion

Spur 4: E. coli BL21(DE3) pTM1 (0,5\% Arabinose) direkt nach Induktion

Spur 5: E. coli BL21(DE3) pTM1 (0,5\% Arabinose) $1 \mathrm{~h}$ nach Induktion

Spur 6: E. coli BL21(DE3) pTM1 (0,5\% Arabinose) $2 \mathrm{~h}$ nach Induktion

Spur 7: E. coli BL21(DE3) pTM1 (0,5\% Arabinose) $3 \mathrm{~h}$ nach Induktion

Hierzu wurde Gesamtzellextrakt der Stämme DH5 $\alpha$ und BL21(DE3) aus den induzierten Kulturen gelelektrophoretisch aufgetrennt und auf eine PVDF-Membran übertragen. Der Nachweis erfolgte durch Western-Blot-Analyse mit polyklonalen gegen IF-gerichteten Antikörpern (siehe 2.22.1und 2.23.1.2). 


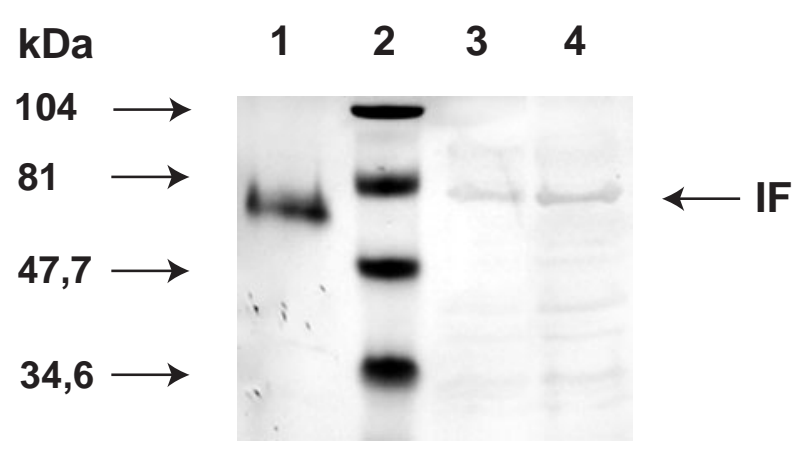

\section{Abbildung 10: Western-Blot mit Gesamtzellextrakten nach Expression von sigtorA-if in E. coli BL21(DE3) und DH5a}

Dargestellt ist eine mit IF-spezifischen Antikörpern behandelte und mit Peroxidase Substrat gefärbte Nitrocellulose-Membran nach Tranfer der Proteine aus einem 12 \%igen SDS-Gel.

Spur 1: nativer IF aus dem Schwein

Spur 2: prestained Proteinstandard

Spur 3: E. coli BL21(DE3)/pTM1 (0,5\% Arabinose)

Spur 4: E. coli DH5a/pTM1 (0,5\% Arabinose)

Dabei zeigte sich, dass das Fusionsprotein in geringen Mengen gebildet worden war. In den Western-Blot-Analysen traten in den Kulturen der Stämme DH5 $\alpha$ und BL21(DE3) Signale im erwarteten Molekularmassenbereich auf (siehe Abbildung 10, Spuren 3 und 4). Diese Experimente belegten, dass prinzipiell eine heterologe Produktion des Intrinsic Faktors in E. coli erfolgte.

\subsubsection{Expressionsstudien unter verschiedenen Bedingungen}

Da nur wenig IF während der Expression gebildet worden war, sollten im Folgenden die Bedingungen während der Expressionsexperimente variiert und dadurch eine Optimierung der Produktion erwirkt werden.

Zunächst wurde die Konzentration des Induktors Arabinose variiert. Die Gene für sigtorA-if stehen unter der Kontrolle des ParaBAD Promotors, welcher durch Arabinose induzierbar ist. Die verwendeten Expressionsstämme von E. coli zählen zu den ara-positiven Stämmen, da sie im Besitz eines chromosomalen ara-Operons sind und somit auf Arabinose wachsen können. Gene, die unter der Kontrolle des ParaBAD Promotors stehen, erreichen bei ara-positiven Mikroorganismen eine maximale Induktion nach der Zugabe von $1 \%$ Arabinose. Bei ara-negativen Organismen genügt schon eine Konzentration von 0,001 \% an Arabinose (MAYER, 1995). Um die optimale Konzentration für die Induktion der sigtorA-if Expression zu bestimmen, wurde diese mit unterschiedlichen Arabinose-Konzentrationen von $0,05 \%, 0,1 \%, 0,5 \%$ und $1 \%$ induziert. 
Die 100 ml-Hauptkulturen wurden wie unter 2.14.1 beschrieben in LB-Medien angezogen. Es wurden jeweils bei $0 \mathrm{~min}, 1 \mathrm{~h}$ und $3 \mathrm{~h}$ nach Induktion mit verschiedenen Konzentrationen an Arabinose Proben entnommen und das Proteinmuster durch SDSPAGE analysiert. Die SDS-PAGE-Analyse ließ erkennen, dass bei keiner der Proben aus den Expressionsversuchen mit verschiedenen Arabinosekonzentrationen eine zusätzliche Bande im erwarteten Molekularmassenbereich von IF auftrat. Unterschiede im Proteinmuster der verschiedenen Proben waren unabhängig von der eingesetzten Arabinosekonzentration nicht $\mathrm{zu}$ verzeichnen. Die entsprechenden WesternImmunoblots zeigten keine Signale bei Arabinosekonzentrationen unter 0,5\% und keine stärkeren Signale bei Konzentrationen von $0,5 \%$ und $1 \%$ im Vergleich zu der in Abbildung 10 gezeigten Signalstärke (Daten nicht gezeigt). Deshalb wurde in weiteren Studien mit diesem Expressionssystem bei ara-positiven Stämmen eine ArabinoseKonzentration von $1 \%$ eingesetzt.

Als nächstes wurden Experimente mit und ohne Zusatz von $\mathrm{B}_{12}$ durchgeführt. E. coli gehört zu den Mikroorganismen, die nicht in der Lage sind $\mathrm{B}_{12}$ selbst zu synthetisieren und muss es deshalb aus dem umgebenden Milieu aufnehmen. In den Experimenten zur Expression des sigtorA-if Hybridgens in E. coli-Stämmen fand die Anzucht der Hauptkultur in LB-Medium (siehe 2.2.3) statt. In dem zur Herstellung des LB-Mediums verwendeten Hefeextrakts befinden sich grundsätzlich auch geringe Mengen an $\mathrm{B}_{12}$. Die Sättigung von IF mit $\mathrm{B}_{12}$ half, das Protein gegen Protease-Aktivitäten zu stabilisieren (GORDON, et al., 1997). Um auszuschließen, dass die geringe Produktion des IF an einer $\mathrm{zu}$ niedrigen Konzentration von $\mathrm{B}_{12}$ im Medium lag, wurden Expressionsexperimente in Gegenwart von zugesetztem $B_{12}(2-4 \mu \mathrm{g} / \mathrm{ml}$ Medium) durchgeführt. Es wurden drei 500 ml-Kulturen verwendet, wobei die erste kein zusätzliches $\mathrm{B}_{12}$ erhielt, den beiden anderen Kulturen aber 1 bzw. 2 mg B $\mathrm{B}_{12}$ zugefügt wurde. Die Probenentnahme erfolgte direkt vor der Induktion der sigtorA-if Expression und $3 \mathrm{~h}$ danach. Beim Vergleich der Proben im SDS-Polyacrylamidgel wies keine der $3 \mathrm{~h}$ nach Induktion entnommenen Proben aus den unterschiedlichen Kulturen eine zusätzliche oder stärker hervortretende Bande im Molekularmassenbereich des Proteins auf (Daten nicht gezeigt). Der korrespondierende Western-Blot wies keinen Unterschied bei der produzierten Menge an IF in Abhänggkeit von zugeführtem $\mathrm{B}_{12}$ auf. Die erhöhte $\mathrm{B}_{12}$-Konzentration im Medium führte also $\mathrm{zu}$ keiner verbesserten heterologen Produktion des Hybridproteins sigTorA-IF in E. coli.

Weiterhin erfolgten Studien bei geringerer Wachstumstemperatur. Die heterologe Expression fremder Gene stellt eine hohe und zusätzliche Belastung für die Zelle dar. Die Verringerung der Wachstumstemperatur hat zu Folge, dass die Zellen langsamer wachsen und somit auch die Produktion des sigTorA-Proteins verlangsamt wird. Ein mögliches zeitliches Problem bei der Produktion, korrekten Faltung, B $_{12}$-Bindung und 
anschließenden Translokation des Intrinsic Faktors könnte durch eine geringere Wachstumstemperatur umgangen werden. Die 500 ml-Kulturen von E. coli DH5 $\alpha$ /pTM1 in LB-Medium wurden bei $30^{\circ} \mathrm{C}$ bis zu einer $\mathrm{OD}_{600}$ von 0,4 angezogen und nach der Induktion mit Arabinose für $5 \mathrm{~h}$ bis zu einer $\mathrm{OD}_{600}$ von 2,3 bei $28{ }^{\circ} \mathrm{C}$ inkubiert. Bei der anschließenden SDS-PAGE-Analyse der Proben, ließ sich allerdings wie bei den zuvor bei $37{ }^{\circ} \mathrm{C}$ angezogenen Kulturen keine zusätzliche Bande im Molekularmassenbereich von IF nachweisen. Die Analyse der Proben durch WesternImmunoblot war ebenfalls negativ. Die Expressionsstudien wurden deshalb im weiteren bei einer Temperatur von $37^{\circ} \mathrm{C}$ durchgeführt.

Da die bisherigen Bedingungsänderungen während der Expression in E. coli zu keiner gesteigerten Produktion von IF geführt hatten, sollte die Expression von sigtorA-if in dem $\mathrm{B}_{12}$-Produzenten $C$. freundii überprüft werden. Dabei fanden die Expressionstudien sowohl aerob (nicht $\mathrm{B}_{12}$-produzierende Bedingungen) als auch anaerob mit Glycerin als einziger C-Quelle ( $\mathrm{B}_{12}$-produzierende Bedingungen) statt. Citrobacter freundii gehört zu den Organismen, die anaerob ohne externe Elektronenakzeptoren mit Glycerin als einziger Kohlenstoff- und Energiequelle wachsen können. Glycerin unterliegt dabei einer Disproportionierung. Die Enzyme des oxidativen Zweigs setzen Glycerin zu Dihydroxyacetonphosphat um. Die dabei anfallenden Reduktionsäquivalente werden im reduktiven Zweig verbraucht. Die Coenzym-B ${ }_{12}$-abhängige Glycerin-Dehydratase bildet dabei aus Glycerin 3-Hydroxypropionaldehyd, der anschließend weiter zu 1,3-Propandiol reduziert wird (DANIEL et al., 1995 a und b, ABELES et al.,1961). Durch die $\mathrm{B}_{12}$-Abhängigkeit der Glycerin-Dehydratase ist nur dann ein anaerobes Wachstum von $C$. freundii in $\mathrm{B}_{12}$-freiem Mineralmedium mit Glycerin als einziger Kohlenstoff-Quelle möglich, wenn der Organismus das benötigte $\mathrm{B}_{12}$ de novo synthetisiert.

Die aeroben Expressionsstudien in C. freundii mit dem Plasmid pTM1 fanden in $50 \mathrm{ml}$ Hefe-Pepton-Medium (siehe 2.2.2) statt. Die anaerobe heterologe Expression von sigtorA-if in C. freundii wurde in $5 \mathrm{ml}$ Hungate-Röhrchen in Mineralmedium (siehe 2.2.1) vorgenommen. Da der Organismus unter anaeroben Bedingungen eine geringere Wachstumsrate hatte, wurde die Genexpression von sigtorA-if über $24 \mathrm{~h}$ verfolgt. Die Induktion der Transkription erfolgte ebenfalls mit Arabinose. Die während des Wachstums gezogenen Proben wurden zur näheren Untersuchung auf ein SDS-Gel aufgetragen (siehe Abbildung 11 und Abbildung 9). 
A)

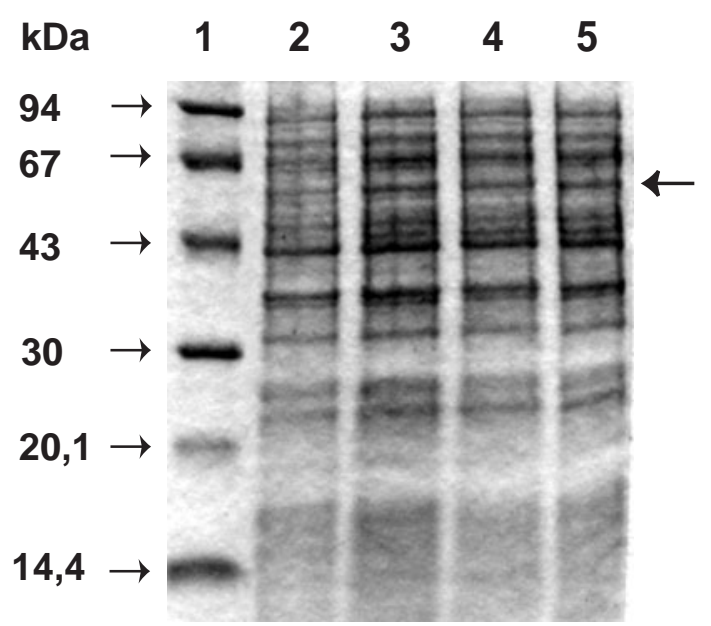

B)

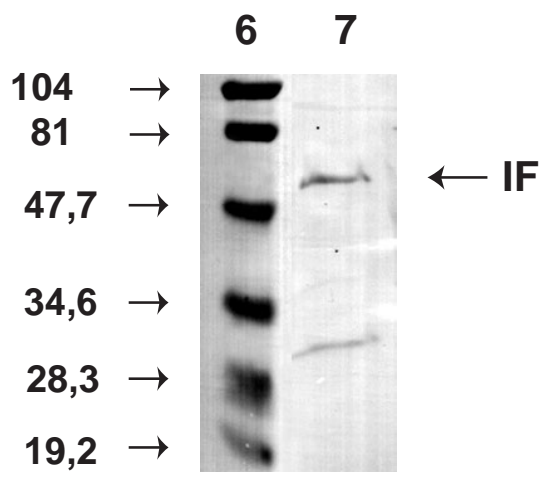

\section{Abbildung 11: Analyse der aeroben Produktion des Fusionsproteins sigTorA-IF in C. freundii durch SDS-PAGE (A) und Western-Immunoblot (B)}

(A) Gesamtzellextrakte (je $7 \mu \mathrm{l}$ ) wurden im $12 \%$ igen SDS-Gel aufgetrennt (siehe 2.17.1), das mit Coomassie-Blau gefärbt wurde. Die Pfeile kennzeichnen das produzierte Protein.

Spur 1: Proteinstandard

Spur 2: C. freundii/pTM1 vor Induktion

Spur 3: C. freundii/pTM1 $1 \mathrm{~h}$ nach Induktion

Spur 4: $C$. freundii/pTM1 $2 \mathrm{~h}$ nach Induktion

Spur 5: C. freundii/pTM1 3 h nach Induktion

(B) Nachweis des N-terminalen $\mathrm{His}_{6}$-Tags von sigTorA-IF mit Hilfe der $\mathrm{Ni}^{2+}$-NTA-Färbung (siehe 2.23.1.1).

Spur 6: Proteinstandard

Spur 7: Gesamtzellextrakt von C. freundii/pTM1 3 h nach Induktion

Bei der aeroben heterologen Produktion von sigTorA-IF zeigte die SDS-PAGE-Analyse im erwarteten Bereich von $55 \mathrm{kDa}$ eine Bande, die im Verlauf des dreistündigen Induktionsexperiments stärker hervortrat (siehe Abbildung $11 \mathrm{~A}$ ). Dass es sich dabei um das Hybridprotein sigTorA-IF handelte, wurde anschließend im Western-Blot durch Detektion des His $_{6}$-Tags mit $\mathrm{Ni}^{2+}$-NTA-Konjugat nachgewiesen (siehe 2.22.1 und 2.23.1.1). Neben der gefärbten Bande des sigTorA-IF Proteins trat noch eine weitere bei etwa $30 \mathrm{kDA}$ auf. Bei dieser handelt es sich vermutlich um ein wirtseigenes, histidinhaltiges Protein, das im Zuge der $\mathrm{Ni}^{2+}$-NTA-Konjugatbehandlung mitangefärbt wurde. 
A)

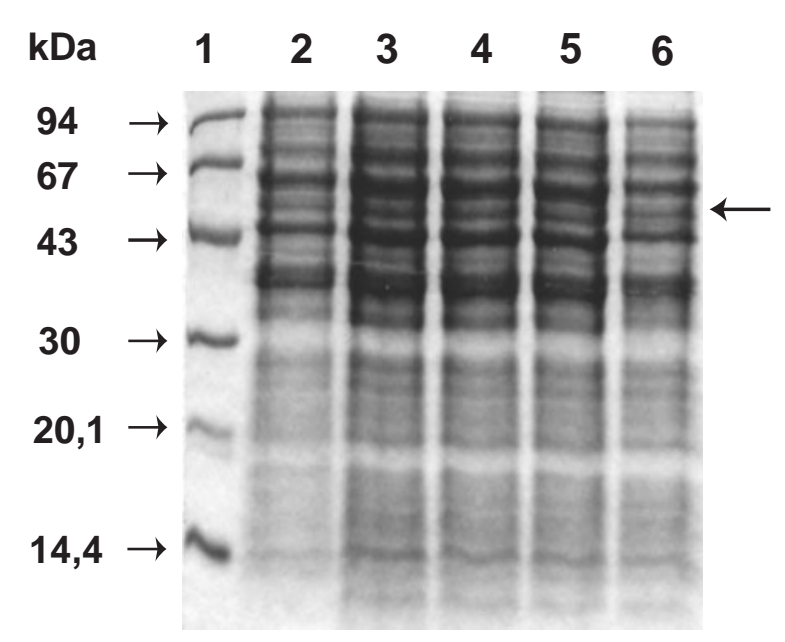

B)

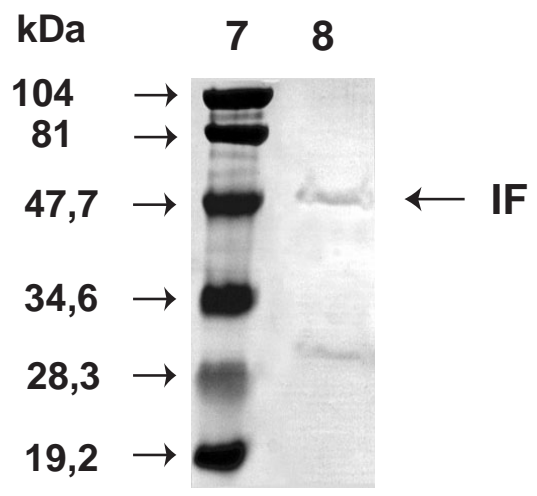

\section{Abbildung 12: Analyse der anaeroben Produktion von sigTorA-IF durch SDS- PAGE (A) und Western-Blot (B)}

(A) Je $7 \mu$ Gesamtzellextrakt wurden im $12 \%$ igen SDS-Gel aufgetrennt (siehe 2.18.1), das anschließend mit Coomassie-Blau gefärbt wurde. Die Pfeile kennzeichnen das produzierte Protein.

Spur 1: Proteinstandard

Spur 2: C. freundii/pTM1 vor Induktion

Spur 3: C. freundii/pTM1 $2 \mathrm{~h}$ nach Induktion

Spur 4: C. freundii/pTM1 $4 \mathrm{~h}$ nach Induktion

Spur 5: C. freundii/pTM1 $6 \mathrm{~h}$ nach Induktion

Spur 6: C. freundii/pTM1 $24 \mathrm{~h}$ nach Induktion

(B) Nachweis des N-terminalen $\mathrm{His}_{6}$-Tags von sigTorA-IF mit Hilfe der $\mathrm{Ni}^{2+}$-NTA-Färbung (siehe 2.23.1.1)

Spur 7: Proteinstandard

Spur 8: Gesamtzellextrakt von C. freundii pTM1 $24 \mathrm{~h}$ nach Induktion

Bei der SDS-PAGE Analyse, der während des aneroben Wachstums gezogenen Proben, ließ sich allerdings keine stärker hervortretende Bande im Bereich von $55 \mathrm{kDa}$ nachweisen (siehe Abbildung 12 A). Die Untersuchung des Gesamtzellextraktes (Probe $24 \mathrm{~h}$ nach Induktion) aus der anaerob induzierten Kultur von $C$. freundii/pTM1 zeigte im Western-Blot (siehe 2.22.1), dass auch unter anaeroben $B_{12}$-produzierenden Bedingungen das Hybridprotein sigTorA-IF gebildet worden war (siehe Abbildung 12 B). Der Nachweis des His $_{6}$-Tags erfolgte mit alkalischer Phosphatase gekoppeltem $\mathrm{Ni}^{2+}$-NTA-Konjugat. Auch in diesem Fall wurde ein histidinhaltiges Wirtsprotein aus C. freundii bei der Behandlung mitangefärbt. Damit konnte ebenfalls in dem $\mathrm{B}_{12}$-Produzenten $C$. freundii die heterolge Produktion von sigTorA-IF nachgewiesen werden.

Das $\mathrm{B}_{12}$ im Cytoplasma einer Bakterienzelle soll nach dem entwickelten Modell zusammen mit dem Intrinsic Faktor ins Periplasma transloziert werden. Nachdem gezeigt worden ist, dass der Intrinsic Faktors sowohl in nicht $\mathrm{B}_{12}$-produzierenden E. coli-Stämmen (DH5 $\alpha$ und JM109) als auch in dem $\mathrm{B}_{12}$-Produzenten C. freundii 
heterolog gebildet wurde, war es notwendig den Transport von IF ins Periplasma nachzuweisen. Da das sigTorA-IF sowohl in den Gesamtzellextrakten von E. coli/pTM1, als auch von $C$. freundii/pTM1 nur in geringen Mengen detektiert wurde, konnte von einer noch geringeren Konzentration des Hybridproteins im Periplasma ausgegangen werden. Daher erschien eine Konzentrierung vor der Western-BlotAnalyse notwendig.

\subsubsection{Experimente zum Nachweis der periplasmatischen Translokation des sigTorA-IF-Hybridproteins}

Der C-terminale klonierte His $_{6}$-Tag des sigtorA-if-Gens ermöglicht nicht nur die Detektion des Zielproteins im Western-Blot, sondern bietet auch die Möglichkeit das sigTorA-IF Protein über Metall-Chelat-Affinitätschromatographie mittels $\mathrm{Ni}^{2+}$-NTAAgarose zu reinigen. Mit dieser Reinigung ist gleichzeitig auch die Konzentrierung des Proteins verbunden. Um zu überprüfen, ob die Reinigungsmethode über $\mathrm{Ni}^{2+}$-NTAAgarose für dieses Hybridprotein auch zu einer Konzentrierung von sigTorA-IF führt, wurde die Reinigung mittels Metall-Chelat-Affinitätschromatographie zunächst an Rohextrakten und erst später an periplasmatischen Fraktionen vorgenommen.

\subsubsection{Nachweis des Intrinsic Faktors im Rohextrakt nach $\mathrm{Ni}^{2+}$-NTA-Affinitäts- chromatographie}

Nach der Produktion des sigTorA-IF Proteins mit Hilfe des Plasmids pTM1 in E. coli DH5 $\alpha$ wurden die Zellen aufgeschlossen und der Rohextrakt daraus präpariert (siehe 2.15.2). Das Enzym konnte dann aus dem Rohextrakt über den C-terminalen His ${ }_{6}$-Tag durch eine Metall-Chelat-Affinitätschromatographie mittels $\mathrm{Ni}^{2+}$-NTA-Agarose unter nativen Bedingungen konzentriert werden (siehe 2.21.1.2). 


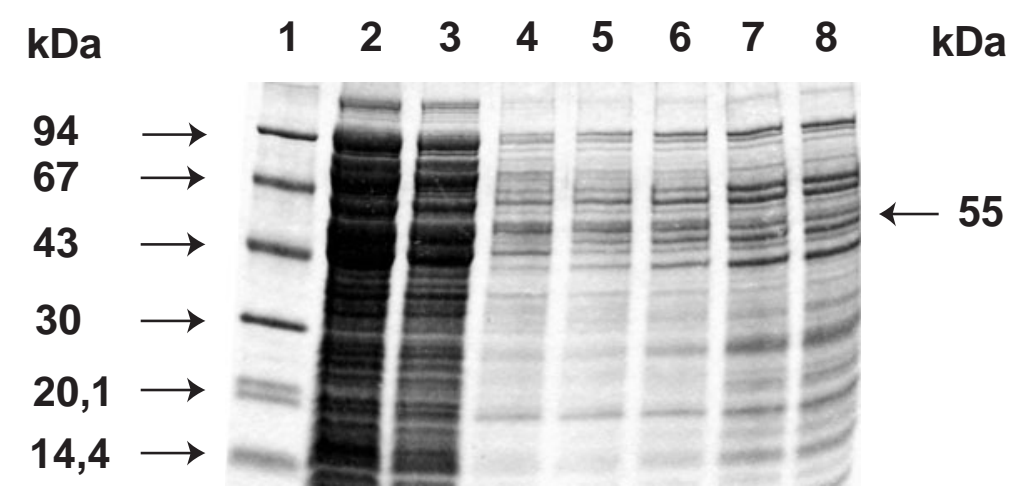

\section{Abbildung 13: SDS-PAGE-Analyse der Konzentrierung des sigTorA-IF Proteins aus dem Rohextrakt über Affinitätschromatographie an $\mathrm{Ni}^{2+}$ NTA-Agarose unter nativen Bedingungen}

Das $12 \%$ ige SDS-Gel wurde mit Coomassie Brilliant Blue gefärbt.

Spur 1: Proteinstandard

Spur 2: Durchlauf

Spur 3-4: Waschfraktion 1 und 2

Spur 5-8: Eluat 1-4

Wie man aus Abbildung 13 entnehmen kann, konnte das Protein durch Affinitätschromatographie an $\mathrm{Ni}^{2+}$-NTA-Agarose nicht erfolgreich gereinigt und konzentriert werden. Trotz der geringen Konzentration an Imidazol während der Bindung und der Waschschritte, konnte eine Bindung von kontaminierenden Proteinen an die $\mathrm{Ni}^{2+}$-NTA-Matrix nicht verhindert werden. Die Eluate (siehe Abbildung 13, Spuren 5-8) beinhalteten trotz der beiden Waschschritte noch große Mengen an Fremdprotein. In den vier Spuren der Eluate war zwar eine schwache Bande bei $55 \mathrm{kDa}$ zu erkennen, die in den letzten beiden Schritten noch stärker hervortrat, aber parallel dazu wurde eine Vielzahl von Fremdproteinen ebenfalls eluiert.

Die Konzentrierung von sigTorA-IF aus dem Rohextrakt mittels $\mathrm{Ni}^{2+}$-NTA-Agarose nach der Expression der korrespondierenden Gene in E. coli DH5 $\alpha$ wurde anschließend unter denaturierenden Bedingungen durchgeführt (siehe 2.21.1.3), da die native Konzentrierung zu keinem Reinigungserfolg geführt hatte. Die denaturierende Methode ermöglicht es, sowohl unlösliche als auch Proteine, bei denen der His ${ }_{6}$-Tag aufgrund der Proteinstruktur nicht frei zugänglich ist, einzusetzen. Der His $_{6}$-Tag wird dabei vollständig entfaltet, so dass die Bindung an die Ni-NTA-Matrix verbessert und somit die Effizienz der Konzentrierung erhöht wird (WINGFIELD, 1995). Der Rohextrakt wurde ebenfalls, wie bei der Konzentrierung unter nativen Voraussetzungen beschrieben, präpariert und anschließend zur Konzentrierung auf eine $\mathrm{Ni}^{2+}$-NTAAgarosesäule aufgetragen. 


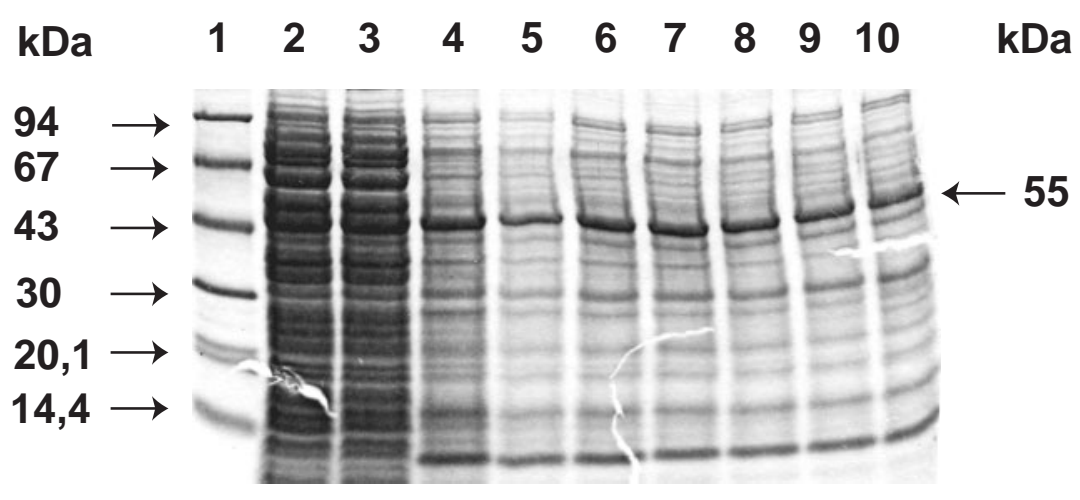

\section{Abbildung 14: SDS-PAGE-Analyse der Konzentrierung des sigTorA-IF Proteins aus dem Rohextrakt über Affinitätschromatographie an $\mathrm{Ni}^{2+}$ - NTA-Agarose unter denaturierenden Bedingungen}

Das 12\% ige SDS-Gel wurde mit Coomassie-Brilliant-Blue gefärbt.

Spur 1: $\quad$ Proteinstandard

Spur 2: $\quad$ Durchlauf

Spur 3-4: Waschfraktion 1 und 2

Spur 5-8: Eluat 1-4

Spur 9-10: Eluat 5-6

Aus Abbildung 14 wird deutlich, dass neben dem sigTorA-IF noch eine Reihe weiterer Proteine unspezifisch an das Säulenmaterial gebunden hatten. Die insgesamt vier Waschschritte reichten nicht aus, um die zusätzlich an die Säule gebundenen Fremdproteine abzutrennen. Dennoch ist im Vergleich zur Konzentrierung unter nativen Bedingungen $\mathrm{zu}$ erkennen, dass insgesamt zwei Banden, eine bei $55 \mathrm{kDa}$ und eine kleinere Bande bei $10 \mathrm{kDa}$ (siehe Abbildung 14, Spur 5-10), eine deutlich höhere Intensität im Vergleich zu den restlichen Proteinen aufwiesen. Die Methode unter denaturierenden Bedingungen führte demnach $\mathrm{zu}$ einer Verbesserung der Konzentrierungseffizienz des sigTorA-IF Hybridproteins.

Anschließend wurden die Proben aus den beiden Konzentrierungsprozeduren im Western-Blot analysiert. Mit Hilfe der $\mathrm{Ni}^{2+}$-NTA-Konjugatfärbung konnte die Identität der $55 \mathrm{kDa}$ sigTorA-IF Bande nachgewiesen werden. Die größte Menge an Protein enthielten zwei Eluate aus der denaturierenden Aufreinigung. Da das sigTorA-IF Protein nach der Produktion nicht in unlöslichen Aggregaten vorliegt, kann davon ausgegangen werden, dass der His 6 -Tag ohne Zusatz von denaturierenden Agenzien nicht vollständig zugänglich ist. Es ließ sich also festhalten, dass eine Konzentrierung über Metall-Chelat-Affinitätschromatographie möglich ist. In weiteren Experimenten sollte eine Konzentrierung des sigTorA-IF aus dem Periplasma deshalb nach der Methode unter denaturierenden Bedingungen erfolgen. 


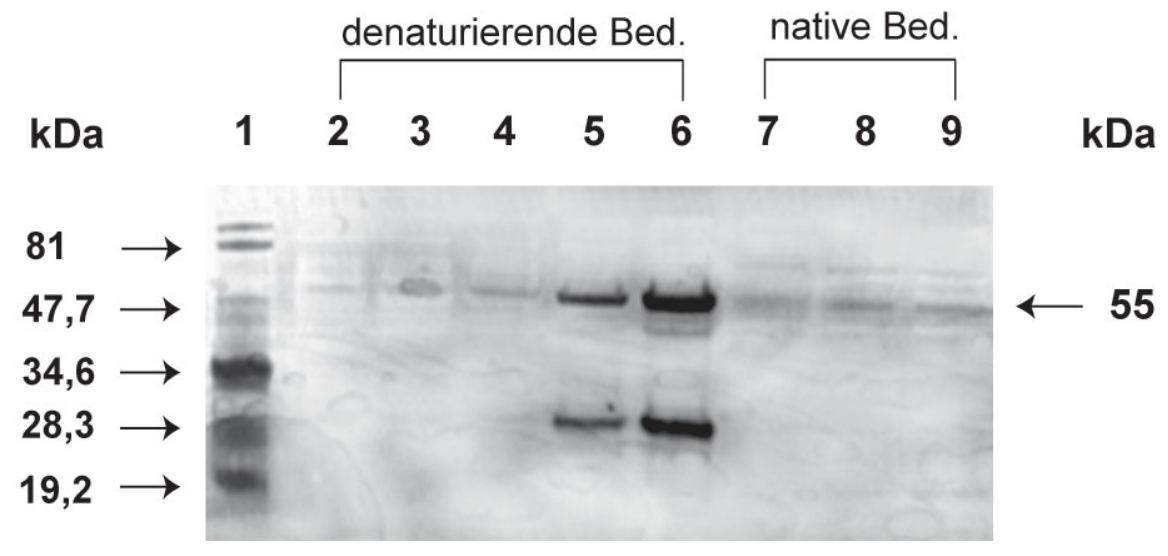

\section{Abbildung 15: Nachweis des C-terminalen His6-Tags des konzentrierten Proteins sigTorA-IF mit Hilfe der $\mathrm{Ni}^{2+}$-NTA-Konjugat-Färbung}

Dargestellt ist eine mit $\mathrm{Ni}^{2+}$-NTA-Konjugat gefärbte Nitrocellulose-Membran (siehe 2.23.1.1) nach Transfer der Proteine aus einem 12 \%igen SDS-Gel.

Spur 1: Proteinstandard

Spur 2: Waschschritt 2 aus der Konzentrierung unter denaturierenden Bedingungen

Spur 3-6: Eluate 3-6 aus der Konzentrierung unter denaturierenden Bedingungen

Spur 7-9: Eluate 2-4 aus der Konzentrierung unter nativen Bedingungen

\subsubsection{Nachweis des Intrinsic Faktors im Periplasma nach $\mathrm{Ni}^{2+}$-NTA- Affinitätschromatographie}

Voraussetzung für einen $\mathrm{B}_{12}$-Exporter ist die Translokation des Bindeproteins ins Periplasma. Im Folgenden sollte der Transport des sigTorA-IF Proteins aus dem Cytoplasma ins Periplasma nachgewiesen werden. Dazu wurden Induktionsexperimente in $E$. coli und $C$. freundii durchgeführt und das Periplasma zunächst nach dem Protokoll von SAMBROCK et al., 1989 präpariert (siehe 2.15.5.1).

\subsubsection{Konzentrierung des Intrinsic Faktors unter denaturierenden Bedingungen}

Es wurde eine Konzentrierung von sigTorA-IF im Periplasma angestrebt, um die Detektion des Hybridproteins in dieser Fraktion zu erleichtern. Die Anzucht der E. coli/pTM1-Kulturen erfolgte wie unter 2.14.1 beschrieben in einem Volumen von $500 \mathrm{ml}$. Drei Stunden nach Induktion der Kultur mit Arabinose wurden die Zellen geerntet und anschließend das Periplasma präpariert (siehe 2.15.5.1). Das sigTorA-IF Protein der periplasmatischen Fraktion konnte anschließend mit Hilfe des $\mathrm{His}_{6}$-Tags über die $\mathrm{Ni}^{2+}$-NTA-Affinitätschromatographie konzentriert werden (siehe 2.21.1.3). 


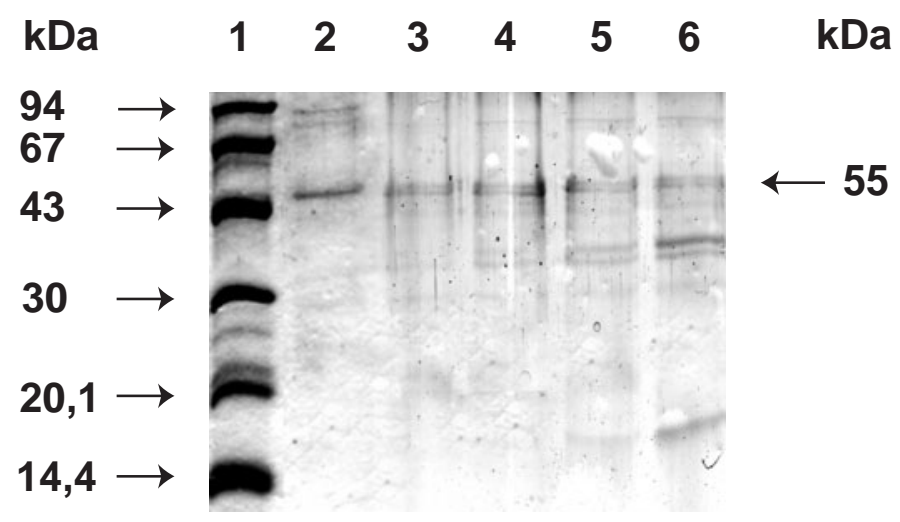

\section{Abbildung 16: SDS-PAGE-Analyse der Konzentrierung des sigTorA-IF Proteins aus dem Periplasma über Affinitätschromatographie an $\mathrm{Ni}^{2+}$-NTA-Agarose unter denaturierenden Bedingungen}

Die Färbung des SDS-Gels erfolgte mit Coomassie Brilliant Blue.

Spur 1: Proteinstandard

Spur 2: Waschfraktion der Konzentrierung unter denaturierenden Bedingungen

Spur 3-6: Eluate 1-4 aus der Konzentrierung unter denaturierenden Bedingungen

Die SDS-PAGE-Analyse zeigte, dass bereits im Waschschritt eine Bande im Bereich von $55 \mathrm{kDa}$ des sigTorA-IF auftrat(siehe Abbildung 16, Spur 2), die sich auch in den Eluaten wiederfand (siehe Abbildung 16, Spuren 3-6). Zusätzlich wurden in der letzten Elutionsfraktion noch zwei kleinere Proteine $(36 \mathrm{kDa}$ und $16 \mathrm{kDa})$ von der Säule abgelöst, wobei es sich vermutlich um die unspezifische Bindung eines Wirtsproteins mit Histidin-Resten handelte. Die Identität des SigTorA-IF Proteins konnte in dem korrespondierenden Western-Blot in Eluatfraktion 2 nachgewiesen werden (siehe Abbildung 17 A, Spur 6). In allen anderen Fraktionen der Konzentrierung des Periplasmas wurde kein Signal erhalten. Die Proben aus der Eluaten 1-4 wurden anschließend zusammen über Ausschlusschromatographie mit Hilfe von CentrisartRöhrchen (siehe 2.17.2) weiter konzentriert und erneut einer Western-Blot-Analyse unterzogen (siehe 2.22.1). Wie in Abbildung $17 \mathrm{zu}$ erkennen, konnte in der Eluatfraktion eine schwache Bande bei etwa $50 \mathrm{kDa}$ und zwei weitere bei $33 \mathrm{kDa}$ und $23 \mathrm{kDa}$ (siehe Abbildung 17, Spur 2) detektiert werden. Bei diesen zusätzlichen Banden könnte es sich wiederum um histidinhaltige E. coli Wirtsproteine handeln oder aber um Degradationsprodukte des sigTorA-IF-Fusionsproteins. 
(A)

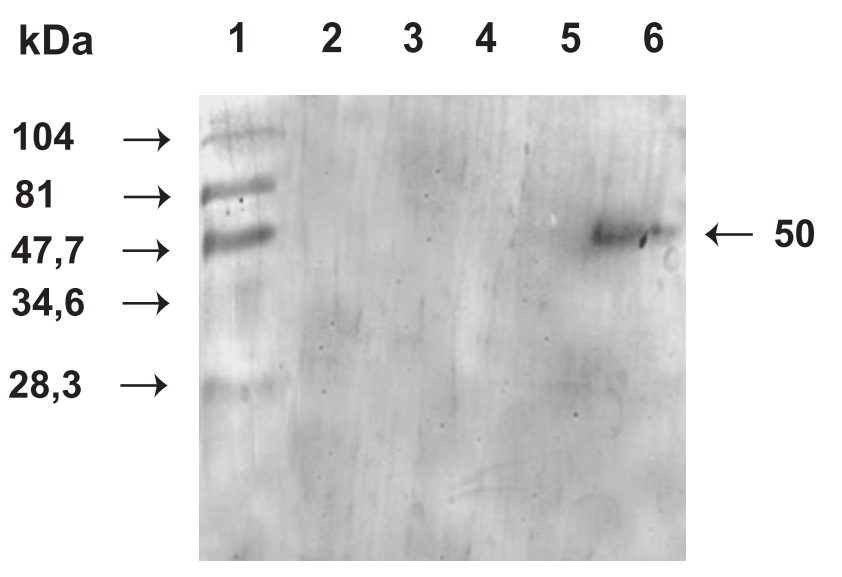

(B)

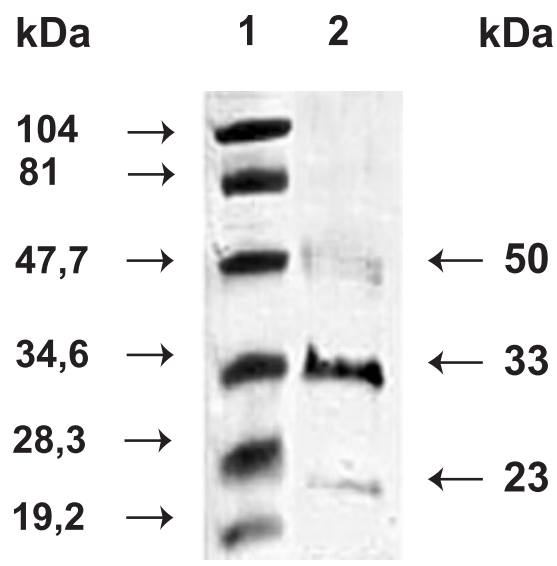

\section{Abbildung 17: Western-Blot-Analysen zum Nachweis von sigTorA-IF im Periplasma nach Konzentrierung über Affinitäts- chromatographie an $\mathrm{Ni}^{2+}$-NTA-Agarose (A) und Einengung über Centrisart-Röhrchen (B)}

(A) Über Affinitätschromatographie konzentriertes sigTorA-IF wurde mit Hilfe des C-terminalen His $_{6}$-Tags nachgewiesen.

Dargestellt ist eine PVDF-Membran nach Transfer der Proteine aus einem 12 \%igen SDS-PAGE (siehe 2.18.1).

Spur 1: $\quad$ Proteinstandard

Spur 2: $\quad$ Waschfraktion der Konzentrierung des Periplasmas unter denaturierenden Bedingungen

Spur 3 und 4: Eluat 3 und 4 der Konzentrierung des Periplasmas unter denaturierenden Bedingungen Spur 5 und 6: Eluat 1 und 2 der Konzentrierung des Periplasmas unter denaturierenden Bedingungen

(B) Nachweis des über Ausschlusschromatographie weiter konzentrierten sigtorA-IF im Western-Blot. Dargestellt ist eine $\mathrm{Ni}^{2+}$-NTA-Konjugat gefärbte PVDF Membran (siehe 2.23.1.1) nach Transfer der Proteine aus einem 12 \%igen SDS-Gel (siehe 2.18.1).

Spur 1: Proteinstandard

Spur 2: Eluatfraktionen 1-4 aus (A) weiter eingeengt

Die Konzentrierung des sigTorA-IF über $\mathrm{Ni}^{2+}$-NTA-Affinitätschromatographie und die anschließende weitere Einengung der erhaltenen Eluate mit Hilfe der CentrisartRöhrchen ermöglichten es, dass Hybridprotein im Periplasma nachzuweisen. Dennoch konnte nur ein geringer Konzentrierungserfolg verzeichnet werden. Aus diesem Grund sollte nach einer alternativen Methode gesucht werden, um die Menge von sigTorA-IF im Periplasma signifikant zu erhöhen und damit die Detektion des Proteins im WesternBlot zu verbessern.

Im weiteren wurde an Stelle von Affinitäts- und Ausschlusschromatographie die fraktionierte Ammoniumsulfat-Fällung zur Konzentrierung von sigTorA-IF aus der periplasmatischen Fraktion eingesetzt. Die Anzucht von E. coli/pTM1 erfolgte in $500 \mathrm{ml}$ LB-Medium. Anschließend wurde das Periplasma, wie unter 2.15.5.2 beschrieben, präpariert. Die Fällung der Proteine erfolgte in $10 \%$ Schritten (siehe 
2.21.1.5). Daraufhin wurden Proben aus den einzelnen Fraktionen durch SDS-PAGE aufgetrennt und einem Western-Immunoblot unterzogen (siehe 2.22.1).

A)

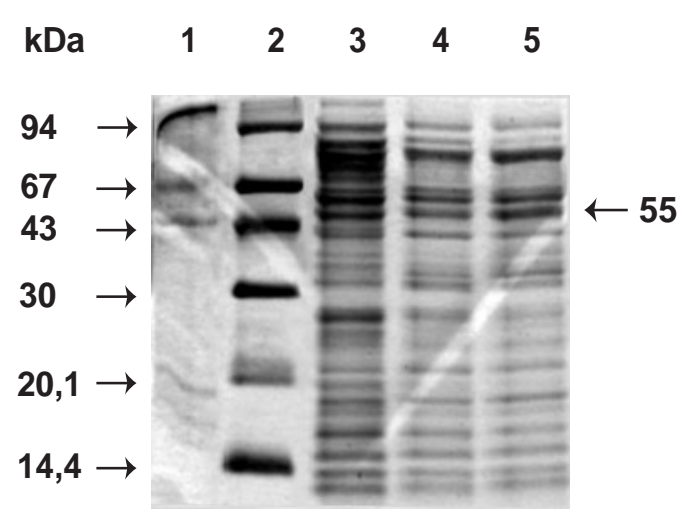

B)

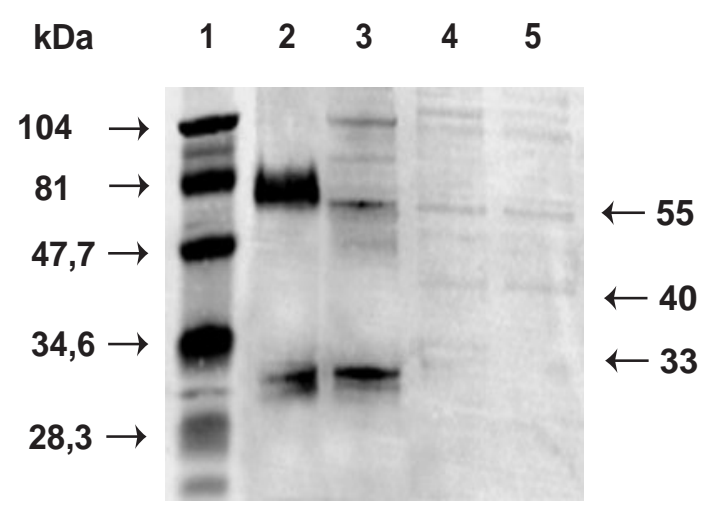

\section{Abbildung 18: Analyse der Anreicherung von sigTorA-IF im Periplasma mittels Ammoniumsulfatfällung durch SDS-PAGE (A) und Western- Blot (B)}

(A) SDS-PAGE und Färbung mit Coomassie-Blau wurden wie unter 2.18.1 und 2.19.1 durchgeführt. Spur 1: nativer IF aus dem Schwein

Spur 2: Proteinstandard

Spur 3: Periplasma-Probe aus der Sättigung mit $60 \%$ Ammoniumsulfat Spur 4: Periplasma-Probe aus der Sättigung mit $70 \%$ Ammoniumsulfat Spur 5: Periplasma-Probe aus der Sättigung mit $80 \%$ Ammoniumsulfat

(B) Dargestellt ist eine mit polyklonalen IF-spezifischen Antikörpern behandelte PVDF-Membran. Spur 1: Proteinstandard

Spur 2: nativer IF aus dem Schwein

Spur 3: Periplasma-Probe aus der Sättigung mit $60 \%$ Ammoniumsulfat Spur 4: Periplasma-Probe aus der Sättigung mit $70 \%$ Ammoniumsulfat Spur 5: Periplasma-Probe aus der Sättigung mit $80 \%$ Ammoniumsulfat

Dabei zeigte sich, dass nur die periplasmatischen Proben aus der Sättigung mit 60-80 \% Ammoniumsulfat auch im Western-Blot ein Signal für das sigTorA-IF Hybridprotein bei etwa $55 \mathrm{kDa}$ lieferten. Diese Proben enthielten noch zwei weitere kleinere Banden, eine bei $40 \mathrm{kDa}$ und eine bei $33 \mathrm{kDa}$. Das stärkste Signal bei $55 \mathrm{kDa}$ enthielt die Fraktion aus der Sättigung mit $60 \%$ Ammoniumsulfat. Allerdings führte auch diese Methode nicht $\mathrm{zu}$ einer signifikant höheren Konzentration des sigTorA-IF Hybridproteins im Periplasma. Diese Methode wurde ebenfalls unter $\mathrm{B}_{12}$-produzierenden Bedingungen in $C$. freundii/pTM1 durchgeführt. Dies ergab hinsichtlich der Menge an transloziertem sigTorA-IF im Periplasma ein vergleichbares Ergebnis (Daten nicht gezeigt). 
Ferner wurden verschiedene Methoden zur Präparation des Periplasma ausprobiert. Keine der unter 2.15.5 beschriebenen Methoden führte zu einer gesteigerten Menge an detektierbarem sigTorA-IF-Fusionsprotein im Periplasma.

Trotz der geringen Menge an Intrinsic Faktor, der im Periplasma nachgewiesen werden konnte, sollte untersucht werden, ob es durch den Einsatz des $\mathrm{B}_{12}$-Exporters zu einem Transport des Coenzym $\mathrm{B}_{12}$ ins Periplasma kommt. Mit Hilfe des $\mathrm{B}_{12}$-Plattentests (KRZYCKI und ZEIKUS, 1980; modifiziert) ist es möglich, Corrinoide quantitativ nachzuweisen (siehe 2.27.1). Im folgenden sollte der Gehalt an $B_{12}$ in der periplasmatischen Fraktion verschiedener Stämme von $C$. freundii bestimmt werden. Die Anzucht von C. freundii/pTM1, C. freundii/pER1 und dem Wildtyp von $C$. freundii erfolgte anaerob in $500 \mathrm{ml}$ Mineralmedium (siehe 2.2.1) und die Expression von sigtorA-if in pTM1 wurde mit Arabinose induziert. Um einen gemeinsamen Bezugspunkt zu haben, wurden die präparierten periplasmatischen Proben (siehe 2.15.5.4) anschließend alle auf die gleiche Proteinkonzentration eingestellt $(0,6 \mathrm{mg} / \mathrm{ml})$. Die Auswertung der Platten zeigte, dass im Periplasma von C. freundii/pTM1 im Vergleich zu C. freundii/pER1 und dem Wildtyp kein $\mathrm{B}_{12}$ nachgewiesen werden konnte.

\subsubsection{Variation des Transportweges}

Der Transport des Intrinsic Faktors ins Periplasma wurde mit Hilfe der Signalsequenz der periplasmatischen TMAO-Reduktase durchgeführt. Der Transport erfolgte dabei über den Tat-Weg. Der Austausch dieser Signalsequenz sollte klären, ob durch die Nutzung eines anderen Transportweges mehr IF ins Periplasma transloziert wird. Deshalb wurde die torA-gegen die pelB-Signalsequenz ersetzt. Das pelB-Gen kodiert für die periplasmatisch lokalisierte Pektat-Lyase B aus Erwinia caratovora (LEI et al., 1987). Diese Signalsequenz ermöglicht den Transport des rekombinanten Proteins ins Periplasma über den sogenannten Sec-Weg.

Der eingesetzte Vektor pET20b(+) gehört zu den Vektoren der pET-Serie und besitzt eine pelB-Signalsequenz Das pET-System ist ein häufig verwendetes System zur Produktion rekombinanter Proteine in E. coli. Es basiert auf dem T7-RNAPolymerase/Promotor-System, das durch IPTG induzierbar ist. Der verwendete Wirtsstamm ist E. coli BL21(DE3), der das Gen für die T7-RNA-Polymerase unter der Kontrolle des lacUV5 Promotors auf dem Chromosom trägt (STUDIER et al., 1990). 


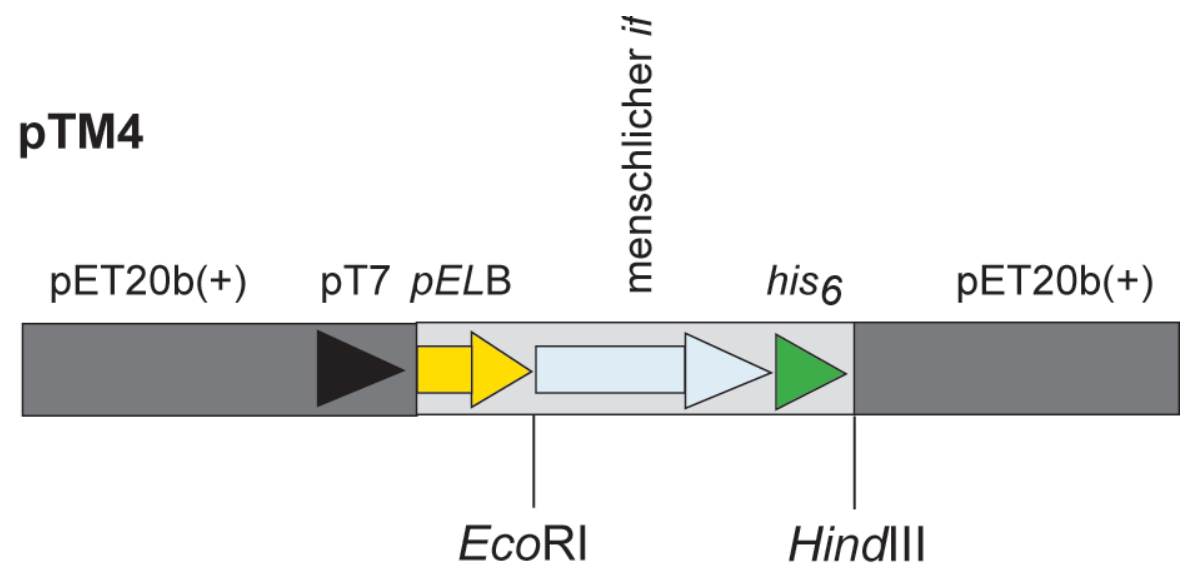

\section{Abbildung 19: Schematische Darstellung des Vektors pTM4}

Für die Klonierung in den Vektor pET20b(+) wurde das if-Gen über PCR mit den Oligonukleotiden IF/EcoRI und IF/HindIIIr sowie dem Plasmid pHIF als Matrize amplifiziert (siehe Tabelle 3 und Tabelle 2). Die Anlagerung der Oligonukleotide erfolgte bei $60^{\circ} \mathrm{C}$ für 1 min. Es schloss sich eine Polymerisation der DNA bei $72{ }^{\circ} \mathrm{C}$ für $1: 15 \mathrm{~min}$ an, wobei 25 Zyklen durchlaufen wurden. Das amplifizierte if-Gen wies am 5'-Ende eine Erkennungsstelle für das Restriktionsenzym EcoRI und am 3'-Ende eine Erkennungsstelle für das Restriktionsenzym HindIII auf. Das gereinigte PCR-Produkt wurde ebenso wie der Vektor mit den Enzymen EcoRI und HindIII verdaut in den Vektor pET20b(+) ligiert. Die korrekte Insertion wurde durch Sequenzierung bestätigt. Das entsprechende Konstrukt wurde als pTM4 bezeichnet (siehe Tabelle 2).

Für die Produktion des IF wurde eine 100 ml-Kultur von E. coli BL21 (DE3)/pTM4, wie unter 2.14 .2 beschrieben, angezogen. Anschließend erfolgte die Präparation des Periplasmas (siehe 2.15.5.2). Es wurden Gesamtzellextrakt- und Periplasma-Proben nach der Auftrennung im SDS-Gel auf eine PVDF-Membranen übertragen und zum einen mit $\mathrm{Ni}^{2+}$-NTA-Konjugat und zum anderen mit polyklonalen gegen IF gerichteten Antikörpern behandelt (siehe 2.23.1.2). Dabei erbrachte die Färbung mit $\mathrm{Ni}^{2+}$-NTAKonjugat weder im Gesamtzellextrakt noch im Periplasma ein Signal im erwarteten Molekularmassenbereich von $55 \mathrm{kDa}$. Die Behandlung mit den polyklonalen Antikörpern zeigte hingegen nur im Gesamtzellextrakt eine schwache $55 \mathrm{kDa}$ Bande von sigTorA-IF (Daten nicht gezeigt). Dies ließ die Vermutung zu, dass zwar eine Expression stattgefunden hatte, aber nur geringe Mengen an rekombinantem IF Protein vorlagen. Ein Transport dieses Proteins ins Periplasma konnte nicht nachgewiesen werden. Somit führte die Variation des Transportweges $\mathrm{zu}$ keiner verbesserten Translokation von IF ins Periplasma. 


\subsection{Studien zum Nachweis der Bindung von $\mathrm{B}_{12}$ an den IF}

Für die Analyse der $\mathrm{B}_{12}$-Bindung während der Translokation wurde zur Erhöhung der Detektionseffizienz ${ }^{14} \mathrm{C}$-radioaktiv markiertes Coenzym $\mathrm{B}_{12}$ hergestellt (siehe 2.26). E. coli DH5 $\alpha /$ pTM1 wurde wie unter 2.14 .1 beschrieben in $100 \mathrm{ml}$ LB-Medium angezogen. Zeitgleich zur Induktion erfolgte die Zugabe von ${ }^{14} \mathrm{C}$-Coenzym $\mathrm{B}_{12}$. Die Radioaktivität der eingesetzten Coenzym $\mathrm{B}_{12}$ Menge pro Experiment betrug 91-181,7 Becquerel. Zusätzlich fand ein weiteres Experimente mit Kulturen von E. coli/pTM1 und als Kontrolle E. coli/pER1 in Medien mit einem Überschuss von Coenzym $B_{12}$ statt (10 mg bzw. $100 \mathrm{mg} / \mathrm{l}$ ). Eine Bindung von $\mathrm{B}_{12}$ zeichnet sich dabei durch eine rote Bande im nativen Gel aus. Die anschließend präparierten Rohextrakte (siehe 2.15.2) wurden in einer nativen Gradienten-PAGE, bei dem der Cofaktor nicht von seinem Bindeprotein abgelöst wird, aufgetrennt. Bei keinem der beiden Experimente konnte eine Bindung des $\mathrm{B}_{12}$ an den Intrinsic Faktor nachgewiesen werden. Da sich bereits in den Rohextrakten keine Radioaktivität mehr bestimmen ließ, wurde daraus gefolgert, dass die Radioaktivität des hergestellten ${ }^{14} \mathrm{C}$-Coenzym $\mathrm{B}_{12}$ für dieses Experiment zu gering war. Nicht außer acht zu lassen ist außerdem die Tatsache, dass insgesamt nur geringe Mengen an IF-Bindeprotein in den Zellen detektiert werden konnten, so dass letztlich $\mathrm{zu}$ wenig IF für den Nachweis der $\mathrm{B}_{12}$-Bindung mit radioaktivem Coenzym-B 12 zur Verfügung standen.

\subsubsection{Abhängigkeit der Corrinoidproduktion von verschiedenen C.freundii- Stämmen in An- und Abwesenheit von heterolog produziertem IF}

Durch quantitative Bestimmung des Corrinoidgehaltes wurde der Einfluss der heterologen Produktion des Intrinsic Faktors auf die Produktion von $\mathrm{B}_{12}$ in vier verschiedenen $C$. freundii-Stämmen untersucht. Dabei sollte analysiert werden, ob die Bindung von $\mathrm{B}_{12}$ an IF und der geringe Export aus der Zelle durch Abfall der internen $\mathrm{B}_{12}$-Konzentration $\mathrm{zu}$ einer verstärkten Produktion von $\mathrm{B}_{12}$ führt. Hierzu wurden C. freundii-Kulturen mit den IF-Plasmiden pTM1 und pHIF und die Negativkontrollen C. freundii/pSK und C. freundii/pMPM-T4 (siehe Tabelle 2) anaerob in $500 \mathrm{ml}$ Mineralmedium (siehe 2.2.1) mit den entsprechenden Antibiotika inkubiert und die Genexpression induziert. Die Anzucht erfolgte unter $\mathrm{B}_{12}$-produzierenden Bedingungen (siehe 3.2.1 und 2.14.1). Nach Bestimmung der Proteinkonzentrationen wurden die in den präparierten Rohextrakten (siehe 2.15.2) enthaltenen Corrinoide in die lösliche Dicyano-Form umgesetzt und störende Komponenten wie Proteine und Lipide ausgefällt. Zur Bestimmung der Corrinoide wurde ein Spektrum der zuvor aufgearbeiteten Proben zwischen 350 und $650 \mathrm{~nm}$ aufgenommen (siehe 2.27.2). 
Tabelle 9: Mittelwerte der $B_{12}$-Konzentrationen im Rohextrakt aus der verschiedenen $C$. freundii-Kulturen

\begin{tabular}{lc}
\hline Organismus & $\begin{array}{c}\text { Mittelwert } \\
\text { B }\end{array}$ \\
\hline C. freundii/pTM1 1 -Konzentration $[\mu \mathrm{g} / \mathrm{mg}$ Protein $]$
\end{tabular}

Es konnte gezeigt werden, dass die geringe Bildung von IF in $C$. freundi/pTM1 gegenüber der Kontrolle $C$. freundi/pMPM-T4 $\Omega$ eine um $17 \%$ gesteigerte Produktion von $\mathrm{B}_{12}$ aufwies. Im Vergleich zum Experiment mit $C$. freundi/pSK konnte keine Steigerung festgestellt werden. Dagegen enthielten die Rohextrakte der Kulturen, die mit dem Plasmid pHIF angezogen worden waren, die größte Menge an $\mathrm{B}_{12}$. Somit kann festgehalten werden, dass die geringe Produktion von IF wahrscheinlich mit einer Steigerung der $\mathrm{B}_{12}$-Produktion verbunden ist.

Zusammenfassend ließ sich feststellen, dass der Einsatz des IF als $\mathrm{B}_{12}$-Bindeprotein in dem Exporter-Modell zu keiner detektierbaren Menge an $\mathrm{B}_{12}$ im Periplasma geführt hatte. Das wiederum könnte damit zusammenhängen, dass nur sehr wenig IF im Periplasma nachgewiesen werden konnte. Damit schien der IF ungeeignet für den Einsatz im $B_{12}$-Exporter-Modell. Weitere Studien wurden deshalb mit dem alternativen $\mathrm{B}_{12}$-Bindeprotein MutB durchgeführt.

\subsection{Experimente zum Nachweis der Expression der sigtorA-mutB- Genfusion und des korrespondierenden Genproduktes}

Anfänglich sollte die heterologe Expression des Fusionsgens sigtorA-mutB aus dem Konstrukt pMB5 (siehe 3.1.1.2; BOLM, 2000) in verschiedenen E. coli-Stämmen bestätigt werden. Erste Experimente wurden in E. coli BL21 (DE3)/pMB5 und JM109/pMB5 durchgeführt. Die Anzucht in $50 \mathrm{ml}$ LB-Medium erfolgte wie unter 2.13.1 beschrieben und die Expression der Gene wurde mit Arabinose induziert. Die SDS-PAGE-Analyse, der vor und nach Induktion der Genexpression genommenen Proben zeigte, dass im Laufe des Experiments eine zusätzliche Proteinbande mit einer Molekularmasse von $94 \mathrm{kDa}$ auftrat (siehe Abbildung 20). Diese entsprach der aus der Sequenz von tor $A-m u t B$ abgeleiteten Molekularmasse. Damit konnte die heterologe Expression von sigtor $A-m u t B$ in den beiden $E$. coli-Stämmen bestätigt werden. 


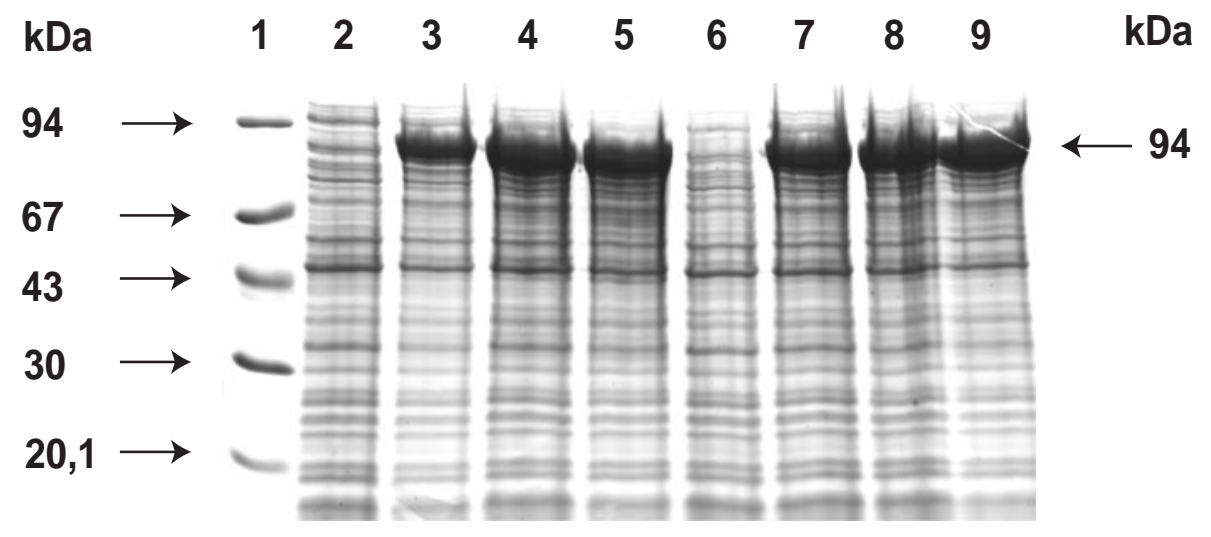

\section{Abbildung 20: SDS-PAGE-Analyse der Produktion des Fusionsproteins sigTorA- MutB in E. coli BL21(DE3) und JM109}

Dargestellt ist ein 12 \%iges SDS-Gel, das mit Coomassie-Blau gefärbt wurde (siehe 2.18.1 und 2.19.1).

Spur 1: Proteinstandard

Spur 2: Gesamtzellextrakt E. coli JM109/pMB5 direkt nach Induktion

Spur 3: Gesamtzellextrakt E. coli JM109/pMB5 1 h nach Induktion

Spur 4: Gesamtzellextrakt E. coli JM109/pMB5 2 h nach Induktion

Spur 5: Gesamtzellextrakt E. coli JM109/pMB5 3 h nach Induktion

Spur 6: Gesamtzellextrakt E. coli BL21 (DE3)/pMB5 direkt nach Induktion

Spur 7: Gesamtzellextrakt $E$. coli BL21 (DE3)/pMB5 $1 \mathrm{~h}$ nach Induktion

Spur 8: Gesamtzellextrakt E. coli BL21 (DE3)/pMB5 2 h nach Induktion

Spur 9: Gesamtzellextrakt E. coli BL21 (DE3)/pMB5 3 h nach Induktion

Im weiteren erfolgten Expressionsstudien in den beiden $\mathrm{B}_{12}$-Produzenten $C$. freundii und S. typhimurium TA100, die zunächst aerob unter nicht $\mathrm{B}_{12}$-produzierenden Bedingungen durchgeführt wurden (siehe 3.2.1). Dabei wurden die $C$. freundii-Kulturen in Hefe-Pepton-Medium (siehe 2.2.2) und die S. typhimurium-Kulturen in LB-Medium angezogen (siehe 2.14.1). Bei der SDS-PAGE-Analyse des Verlaufs des Expressionsversuches ließ sich ebenfalls nach Induktion mit Arabinose eine zusätzliche Bande im Molekularmassenbereich von sigTorA-MutB nachweisen (94 kDa; siehe Abbildung 21 und Abbildung 22). Die größte Proteinmenge von sigTorA-MutB wies C. freundii/pMB5 $1 \mathrm{~h}$ nach Induktion auf (siehe Abbildung 21, Spur 4). 


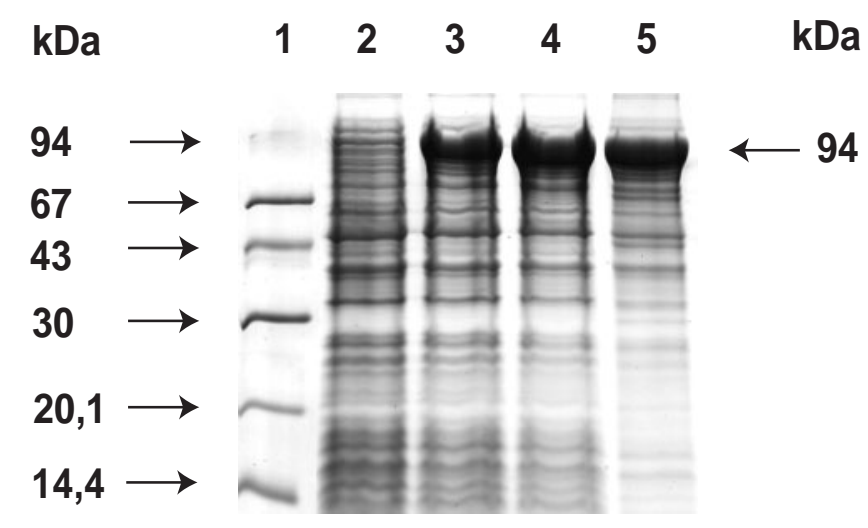

\section{Abbildung 21: Analyse der Produktion von sigTorA-MutB in $C$. freundii im SDS-Gel}

Dargestellt ist ein 12 \%iges SDS-Gel, das mit Coomassie-Blau gefärbt wurde (siehe 2.18.1 und 2.19.1).

Spur 1: Proteinstandard

Spur 2: Gesamtzellextrakt $C$. freundii/pMB5 direkt nach Induktion

Spur 3: Gesamtzellextrakt $C$. freundii/pMB5 $1 \mathrm{~h}$ nach Induktion

Spur 4: Gesamtzellextrakt $C$. freundii/pMB5 2,5 h nach Induktion

Spur 5: Gesamtzellextrakt $C$. freundii/pMB5 3,5 h nach Induktion

Die Analyse des Proteinmusters der Proben aus der Expression der sigtorA-mutBGenfusion in S. typhimurium zeigte im SDS-PAGE, dass bereits nach 30 min eine zusätzliche sigTorA-MutB Bande auftrat und $2 \mathrm{~h}$ nach Induktion die maximale Produktionsmenge des Fusionsproteins erreicht war (siehe Abbildung 22, Spur 4). Die Identität der SigTorA-MutB-Fusionsproteine aus den beiden Experimenten wurde anschließend durch Western-Blot-Analysen mit Antikörpern bestätigt, die gegen den His $_{6}$-Tag gerichtet waren (Daten nicht gezeigt).

Für die Expression von sigtor $A-m u t B$ in dem $\mathrm{B}_{12}$-Produzenten E. blattae war zunächst die Umklonierung des Fusionsgens in einen Vektor mit anderem Selektionsmarker notwendig, da der Wildtyp von E. blattae bereits eine natürliche Resistenz gegen Tetracyclin aufweist. Aus diesem Grunde wurde als Expressionsvektor das Plasmid pMPM-A4 $\Omega$ mit Ampicillin-Resistenz ausgewählt (siehe Abbildung 3). Es gehört zur gleichen Gruppe wie der Vektor pMPM-T4 $\Omega$ (siehe Abbildung 2). Für die Umklonierung von sigtor $A-m u t B$ aus dem Vektor pMPM-T4 $\Omega$ wurde die entscheidende Sequenz mit Hilfe des Restriktionsenzyms $X b a \mathrm{I}$ herausgeschnitten und über diese Schnittstelle in pMPM-A $4 \Omega$ kloniert. Dabei wurde auch ein $2 \mathrm{~kb}$-Stück aus dem Vektor eliminiert und damit das $\Omega$-Interposon entfernt. Durch Sequenzierung konnte die korrekte Insertion von sigtor $A-m u t B$ bestätigt werden. Das Konstrukt wurde als pTM3 bezeichnet. 


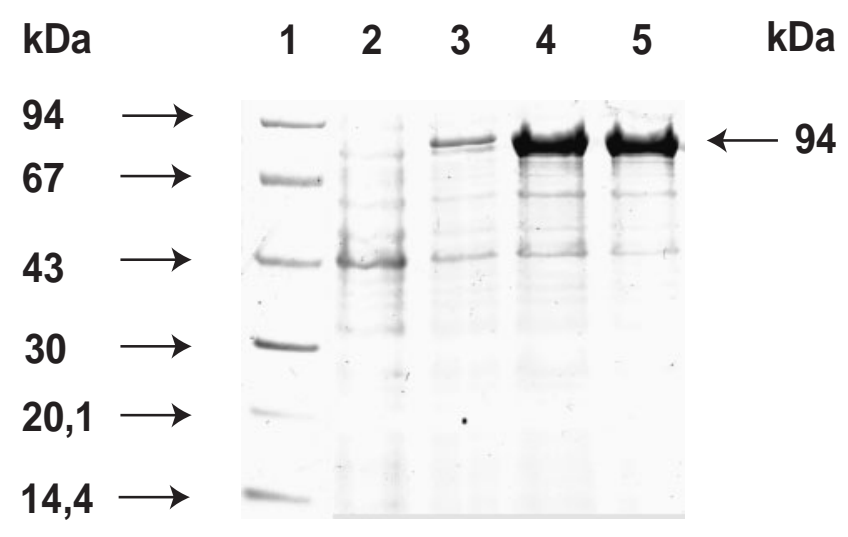

Abbildung 22: SDS-PAGE-Analyse der Produktion von sigTorA-MutB in S. typhimurium TA100

Das 12 \%ige SDS-Gel war anschließend mit Coomassie Brilliant Blue gefärbt worden (siehe. 2.18.1 und 2.19.1).

Spur 1: Proteinstandard

Spur 2: Gesamtzellextrakt S. typhimurium TA100/pMB5 direkt nach Induktion

Spur 3: Gesamtzellextrakt $S$. typhimurium TA100/pMB5 0,5 h nach Induktion

Spur 4: Gesamtzellextrakt $S$. typhimurium TA100/pMB5 $2 \mathrm{~h}$ nach Induktion

Spur 5: Gesamtzellextrakt $S$. typhimurium TA100/pMB5 3 h nach Induktion

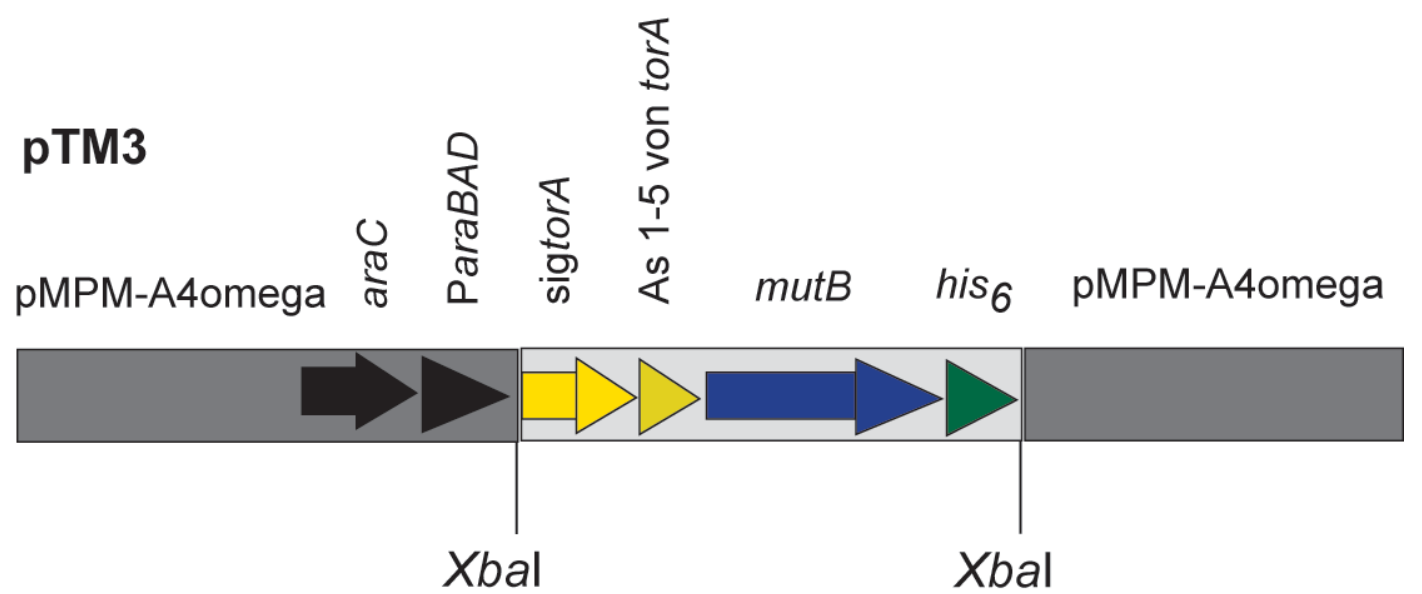

\section{Abbildung 23: Schematische Darstellung des Vektors pTM3}

Zunächst wurde wie bei $C$. freundii die aerobe Expression des Fusionsproteins in E. blattae/pTM3 im 100 ml-Maßstab untersucht (siehe 2.14.1). Die SDS-PAGEAnalyse der während des Wachstums gezogenen Proben ließ eindeutig eine zusätzliche Proteinbande im Molekularmassenbereich des Hybridproteins sigTorA-MutB nach Induktion der Genexpression erkennen (94 kDa; siehe Abbildung 24, Spur 3). Im Vergleich dazu ließ sich in der Negativ-Kontrolle (E. blattae Wildtyp), die unter den gleichen Bedingungen angezogen worden war, keine zusätzliche Proteinbande in 
diesem Bereich erkennen (Daten nicht gezeigt). Eine Expression der sigtorA-mutBGenfusion und die Bildung des korrespondierenden Genproduktes konnte mit Hilfe des Konstruktes pTM3 in E. blattae erfolgen.

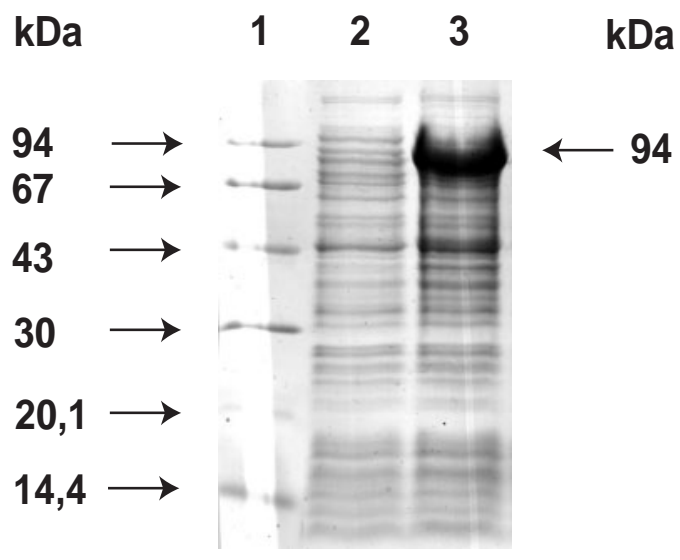

\section{Abbildung 24: Analyse der Produktion von sigTorA-MutB in E. blattae im SDS- PAGE}

Das 12 \%ige SDS-Gel wurde mit Coomassie-Blau gefärbt (siehe 2.18.1 und 2.19.1).

Spur 1: Proteinstandard

Spur 2: Gesamtzellextrakt E. blattae/pTM3 direkt vor Induktion mit $0,5 \%$ Arabinose

Spur 3: Gesamtzellextrakt E. blattae/pTM3 3 h nach Induktion mit 0,5\% Arabinose

Damit war belegt, dass eine starke heterologe Produktion des sigTorA-MutBFusionsproteins in C. freundii, S. typhimurium TA100 und E. blattae stattfand.

\subsubsection{Expression von sigtor $A-m u t B$ in $B_{12}$-produzierenden Enterobakterien}

Die Funktion des $\mathrm{B}_{12}$-Exporters setzt die Produktion der TorA-Signalsequenz mit dem MutB-Bindeprotein in einem $\mathrm{B}_{12}$-produzierenden Organismus voraus. Aus diesem Grunde wurde im folgenden die Expression der sigtorA-mutB-Genfusion unter Bedingungen durchgeführt, die eine $\mathrm{B}_{12}$-Produktion der Wirtsstämme $C$. freundii und E. blattae ermöglichen. Nicht nur C. freundii (siehe 3.2.1) sondern auch E. blattae ist in der Lage Cobalamin de novo bei anaerobem Wachstum mit Glycerin als einziger Energie- und Kohlenstoffquelle zu synthetisieren. Die Glycerin-Dehydratase ist ein $\mathrm{B}_{12}$-abhängiges Enzym und setzt Glycerin zu $\beta$-Hydroxypropionaldehyd um, das zu 1,3-Propandiol reduziert werden kann. Durch diese Reaktion kommt es zu einem Ausgleich der Reduktionsäquivalente, die durch die Oxidation von Glycerin zu Dihydroxyacetonphosphat mit Hilfe der Glycerin-Dehydrogenase angefallen sind. Enthält das Kulturmedium also kein zusätzliches $\mathrm{B}_{12}$, so muß E. blattae wie auch C. freundii für ein anaerobes Wachstum mit Glycerin das Coenzym selbst synthetisieren. (LAWRENCE et al., 1996; ROTH et al., 1996). 


\subsubsection{Expression in $C$. freundii}

Hierzu wurde C. freundii/pMB5 in 500 ml-Maßstab unter anaeroben Bedingungen mit Glycerin als alleinige Kohlenstoff- und Energiequelle kultiviert (siehe 2.14.1). Da das eingesetzte Mineralmedium kein $B_{12}$ enthielt, war ein Wachstum des Organismus mit dieser Kohlenstoff-Quelle nur bei gleichzeitiger Produktion von $\mathrm{B}_{12}$ möglich (siehe 3.2.1). Nach Induktion der Zellen mit Arabinose wurden diese noch für weitere $18 \mathrm{~h}$ inkubiert und die Produktion des Fusionsproteins durch Probennahme zu verschiedenen Zeitpunkten verfolgt. Die Analyse des Proteinmusters der Proben im SDS-PAGE ließ erkennen, dass im Verlauf des Wachstums der Zellen nach Induktion eine zusätzliche Bande bei etwa $94 \mathrm{kDa}$ hervortrat, die aufgrund der Molekularmasse dem Fusionsprotein zuzuordnen war (siehe Abbildung 25, Spur 3 und 4). Die Expression der sigtorA-mutB-Genfusion unter $\mathrm{B}_{12}$-synthetisierenden Voraussetzungen (siehe 2.14.1) konnte damit belegt werden.

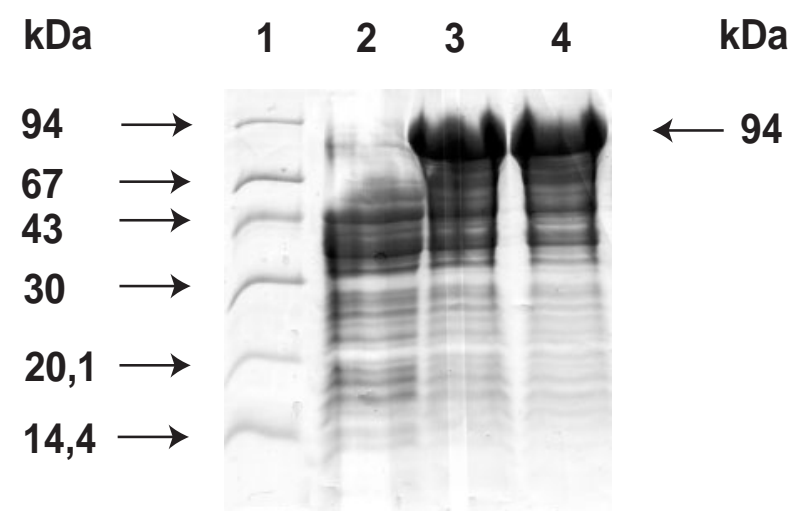

\section{Abbildung 25: Heterologe Produktion von sigTorA-MutB in $C$. freundii bei gleichzeitiger Bildung von $B_{12}$}

Die Färbung des 12 \%igen SDS-Gels erfolgte mit Coomassie Brilliant Blue (siehe 2.18.1 und 2.19.1).

Spur 1: Proteinstandard

Spur 2: Gesamtzellextrakt $C$. freundii direkt nach Induktion

Spur 3: Gesamtzellextrakt $C$. freundii $2,5 \mathrm{~h}$ nach Induktion

Spur 4: Gesamtzellextrakt $C$. freundii $18 \mathrm{~h}$ nach Induktion

Der Nachweis der Produktion des Hybridproteins sigTorA-MutB in den $\mathrm{B}_{12}$-Produzenten sollte anschließend durch Western-Blot-Analysen bestätigt werden. Dazu wurde Gesamtzellextrakt von C. freundii/pMB5-Kulturen, die anaerob in Mineralmedium mit Glycerin gewachsenen waren, gelelektrophoretisch im SDS-PAGE aufgetrennt und die Proteine anschließend auf eine PVDF-Membran übertragen. Als Negativ-Kontrolle wurden auch Gesamtzellextrakte von C. freundii/pER1, die unter den gleichen Bedingungen kultiviert worden waren, mitgeführt. Die dann folgende Immunopräzipitation wurde mit monoklonalen gegen den $\mathrm{His}_{6}$-Tag gerichteten 
Antikörpern durchgeführt. Die Färbung erfolgte wie unter 2.23.1.2 beschrieben. Dabei trat ein starkes Signal bei $94 \mathrm{kDa}$ auf, welches aufgrund der Molekularmasse dem sigTorA-MutB Fusionsprotein zugeordnet werden konnte. (siehe Abbildung 26, Spur 2). Der Vergleich mit dem Gesamtzellextrakt von C. freundii/pER1, der nur das Gen für die torA-Signalsequenz auf dem Plasmid trägt, zeigte dagegen kein Signal dieser Größe (siehe Abbildung 26, Spur 3). Auf diese Weise konnte die Produktion des sigTorA-MutB Fusionsproteins bei gleichzeitiger Bildung von $\mathrm{B}_{12}$ bestätigt werden.

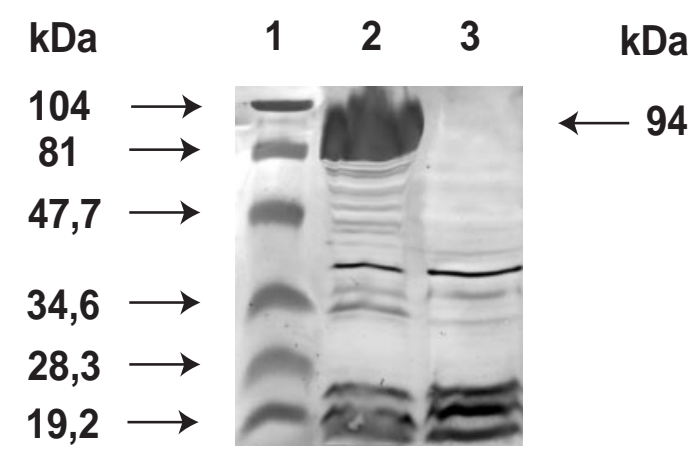

\section{Abbildung 26: Nachweis der anaeroben Produktion des Fusionsproteins sigTorA-MutB durch Western-Blot-Analysen}

Spur 1: Proteinstandard

Spur 2: Gesamtzellextrakt C. freundii/ pMB5

Spur 3: Gesamtzellextrakt $C$. freundii/ pER1

Die Detektion des sigTorA-MutB Fusionsproteins erfolgte bislang mit Hilfe des His $_{6}$-Tags. Da die Verwendung von $\mathrm{Ni}^{2+}$-NTA-Konjugat oder Penta-His-Antikörpern bei der Immunodetektion oft $\mathrm{zu}$ einem starken Hintergrund führten, sollte als weitere Detektionsmöglichkeit das fluoreszierende „Green Fluorescent Protein“ (GFP eingesetzt werden. Das GFP der Qualle Aequorea victoria ist ein häufig genutztes Markerprotein, um die Expression und Regulation von Genen zu untersuchen. Korrekt gefaltetes GFP bildet ein stark fluoreszierendes internes Chromophor. Es wird ohne Export-Signal synthetisiert (MARGOLIN, 2000). CRAMERI et al.,1996 konstruierten ein synthetisches $g f p$-Gen, welches sich durch eine stärkere Fluoreszenz auszeichnete und zudem im Gegensatz zum Wildtyp $g f p$-Gen besonders in E. coli kaum noch in Einschlusskörpern aggregierte. 


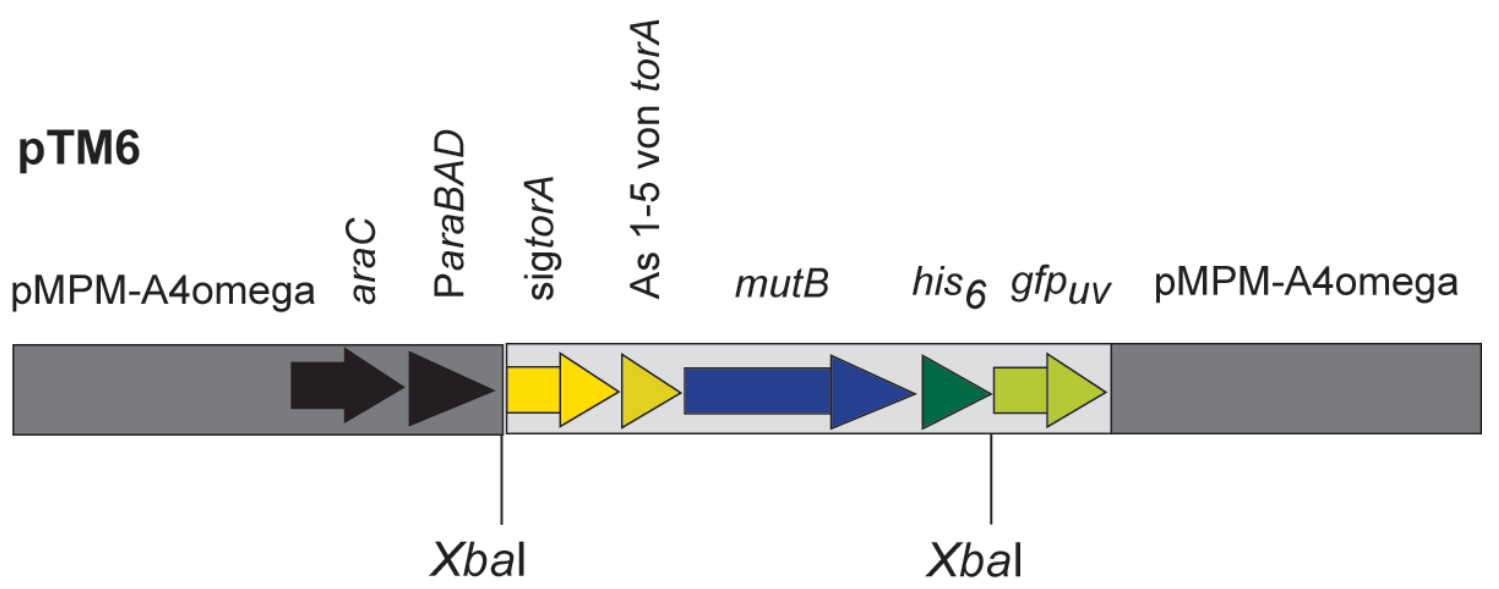

\section{Abbildung 27: Schematische Darstellung des Vektors pTM6}

Diese $g f p_{\text {uv }}$ Sequenz wurde C-terminal an die Sequenz für die sechs Histidinreste kloniert. Für die Klonierung wurde das $g f p_{\mathrm{uv}}$-Gen über PCR (siehe 2.8) mit den Primern f-GFP ${ }_{\mathrm{uv}}-\mathrm{ClaI}$ und $\mathrm{r} \mathrm{GFP}_{\mathrm{uv}}-\mathrm{ClaI}$ sowie dem Plasmid pBAD-GFP ${ }_{\mathrm{uv}}$ als Matrize amplifiziert (sieheTabelle 3 und Tabelle 2). Die Anlagerung der degenerierten Primer wurde zunächst für jeweils $45 \mathrm{~s}$ bei $53{ }^{\circ} \mathrm{C}$ gefolgt von der Kettenverlägerung bei $72{ }^{\circ} \mathrm{C}$ für 1:35 min durchgeführt, wobei 3 Zyklen durchlaufen wurden. Während der folgenden 27 Zyklen lagerten sich die Primer bei $62{ }^{\circ} \mathrm{C}$ für $45 \mathrm{~s}$ an die DNA an. Die Bedingungen der Polymerisation wurden nicht verändert. Mit Hilfe der Oligonukleotide wurde sowohl 5'- als auch 3'-terminal die Erkennungssequenz für das Enzym ClaI eingeführt. Das erhaltene Fragment hatte eine Größe von 760 bp. Weiterhin musste für die Klonierung von $g f p_{u v}$ über PCR eine ClaI-Schnittstelle hinter die Sequenz für den $\mathrm{His}_{6}$-Tag in den Vektor pTM3 eingeführt werden. Dabei kamen die Oligonukleotide f-mutB/ GFP-ApaI und r-mutB/ GFP-ClaI und als Matrize das Plasmid pTM3 zum Einsatz (siehe Tabelle 3 und 2). In den ersten drei Zyklen konnten sich die degenerierten Oligonukleotide für $45 \mathrm{~s}$ bei $54{ }^{\circ} \mathrm{C}$ an die DNA anlagern und die Kettenverlängerung erfolgte bei $72{ }^{\circ} \mathrm{C}$ für $45 \mathrm{~s}$. In den direkt anschließenden 27 Zyklen erfolgte die Anlagerung an das Matrize bei $58^{\circ} \mathrm{C}$ für $45 \mathrm{~s}$ und die Kettenverlängerung wie in den zuvor abgelaufenen 3 Zyklen. Die Größe des erhaltenen PCR Produkts betrug 313 bp. Nachdem die notwendige ClaI-Schnittstelle mit Hilfe des $m u t B$-PCR-Produkt in den Vektor pTM3 eingeführt worden war, konnte die Klonierung des $g f p$-PCR-Produkt über diese ClaI-Schnittstelle in den Vektor pTM3 erfolgen. Die korrekte Insertion wurde durch Sequenzierung bestätigt und das Konstrukt als pTM6 bezeichnet (siehe Tabelle 2 und

Abbildung 27).

\subsubsection{Expression in E. blattae}

Für die heterologe Expression der sigtorA-mutB-gfp-Genfusion in E. blattae wurde zunächst der Vektor pTM6 durch Elektroporation übertragen (siehe 2.10.1.3). Nach erfolgreicher Expression unter aeroben Wachstumsbedingungen (Daten nicht gezeigt) sollte im Folgenden die sigtorA-mutB-Genfusion unter $\mathrm{B}_{12}$-produzierendenVoraussetzungen exprimiert und die Produktion des korrespondierenden Genproduktes durch Fluoreszenzmikroskopie überprüft werden. Der Expressionsversuch erfolgte deshalb anaerob unter $\mathrm{B}_{12}$-synthetisierenden Voraussetzungen, im 500 ml-Maßstab (siehe 2.14.1). Dabei wurden sowohl Zellen aus induzierten, als auch nicht induzierten Kulturen sowie als Kontrolle der Wildtyp von E. blattae unter dem Fluoreszenzmikroskop analysiert. Während bei den induzierten Kulturen von 
E. blattae/pTM6 nahezu alle Zellen fluoreszierten (siehe Abbildung 28 A), leuchteten bei den nicht induzierten Kulturen nur vereinzelt einige Zellen sehr schwach (siehe Abbildung 28 B). Bei den Wildtyp-Zellen war nach Induktion keine Fluoreszenz zu beobachten (Daten nicht gezeigt). Dieses Ergebnis bestätigte die heterologe Produktion des sigTorA-MutB-GFP Fusionsproteins in E. blattae unter $\mathrm{B}_{12}$-produzierenden Voraussetzungen.

(A)

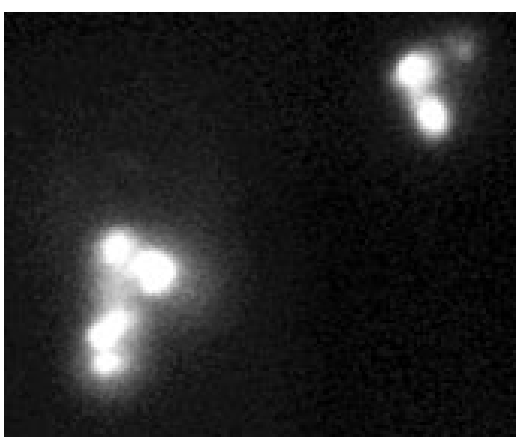

(B)

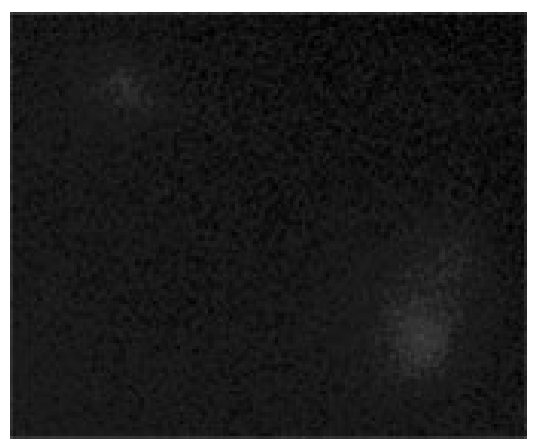

Abbildung 28: Nachweis der Produktion von sigTorA-MutB mit dem Konstrukt pTM6 in E. blattae durch Fluoreszenz

(A): Fluoreszenzmikroskopische Aufnahmen der Zellen aus induzierten Kulturen von E. blattae/pTM6

(B): Fluoreszenzmikroskopische Aufnahmen der Zellen aus nicht induzierten Kulturen von E. blattae/pTM6

\subsection{Experimente zur Lokalisation des Hybridproteins sigTorA-MutB im Periplasma}

Nachdem die Expression von sigtor $A-m u t B$ und damit auch die heterologe Produktion des Fusionsproteins in verschiedenen Stämmen gezeigt werden konnte, war im weiteren die Translokation des $\mathrm{B}_{12}$-Bindeproteins ins Periplasma entscheidend. Vorerst wurde der Transport bei aerober Anzucht der Zellen untersucht, da im Vergleich zu anaerob gewachsenen Kulturen aufgrund der höheren Energieausbeute höhere Zelldichten erreicht werden und somit mehr $\mathrm{B}_{12}$-Bindeprotein transloziert werden kann. Die Inkubation der 100 ml-Kulturen von E. coli BL21 (DE3)/pMB5 geschah wie unter 2.14.1 beschrieben in LB-Medium. Anschließend wurden sowohl die präparierte periplasmatische Probe (siehe 2.15.5.4) als auch das restliche Zellpellet einer Analyse im Western-Blot unterzogen (siehe 2.22.1). Die Immunodetektion zeigte, dass die periplasmatische Probe eine sigTorA-MutB-Bande im Bereich von $94 \mathrm{kDa}$ aufwies (siehe Abbildung 29, Spur 2), somit also eine Translokation des Fusionsproteins aus dem Cytoplasma stattgefunden hatte. Bei dem Vergleich mit dem Rohextrakt (siehe 
Abbildung 29, Spur 3) war allerdings zu erkennen, dass sich ein großer Teil des sigTorA-MutB-Hybridproteins noch im Cytoplasma oder der Membranfraktion befand. Dies wurde auch durch die Untersuchungen nach Trennung in Cytoplasma- und Membranfaktion bestätigt (siehe 2.15.4).

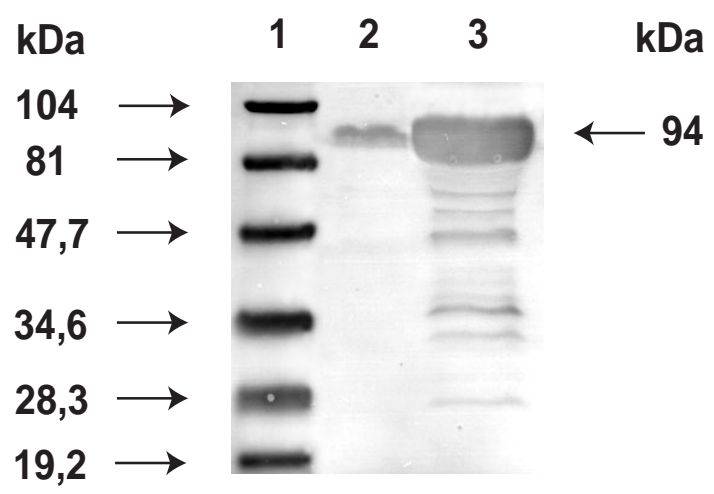

\section{Abbildung 29: Nachweis der Translokation von sigTorA-MutB ins Periplasma von E. coli BL21 (DE3) im Western-Immunoblot}

Dargestellt ist eine mit monoklonalen gegen den His $_{6}$-Tag-gerichteten Antikörpern behandelte PVDFMembran.

Spur 1: Proteinstandard

Spur 2: Periplasma E. coli BL21 (DE3)/pMB5

Spur 3: Zellpellet E. coli BL21 (DE3)/pMB5

\subsubsection{Umklonierung von sigtorA-mutB in den Vektor pASK-IBA3}

Der Nachweis von sigTorA-MutB im Periplasma von E. blattae durch Western-BlotAnalysen mit Hilfe des gegen den $\mathrm{His}_{6}$-Tag-gerichteten Antikörpers wurde, wie bereits erwähnt, oft durch eine starke Hintergrundreaktion erschwert. Daher wurde im weiteren versucht, diesen Nachweis durch ein anderes Detektionssystem zu ersetzten. Hierzu wurde ein Strep-TagII verwendet, der aus dem Vektor pASK-IBA3 stammt (siehe Tabelle 2). Bei dem „Tag“ handelt es sich um acht Aminosäuren (WSHPQFEK). Der Vektor pASK-IBA3 weist eine Ampicillin Resistenz auf und enthält keine Signalsequenz. Der Strep-TagII ist am C-terminalen Ende lokalisiert. 


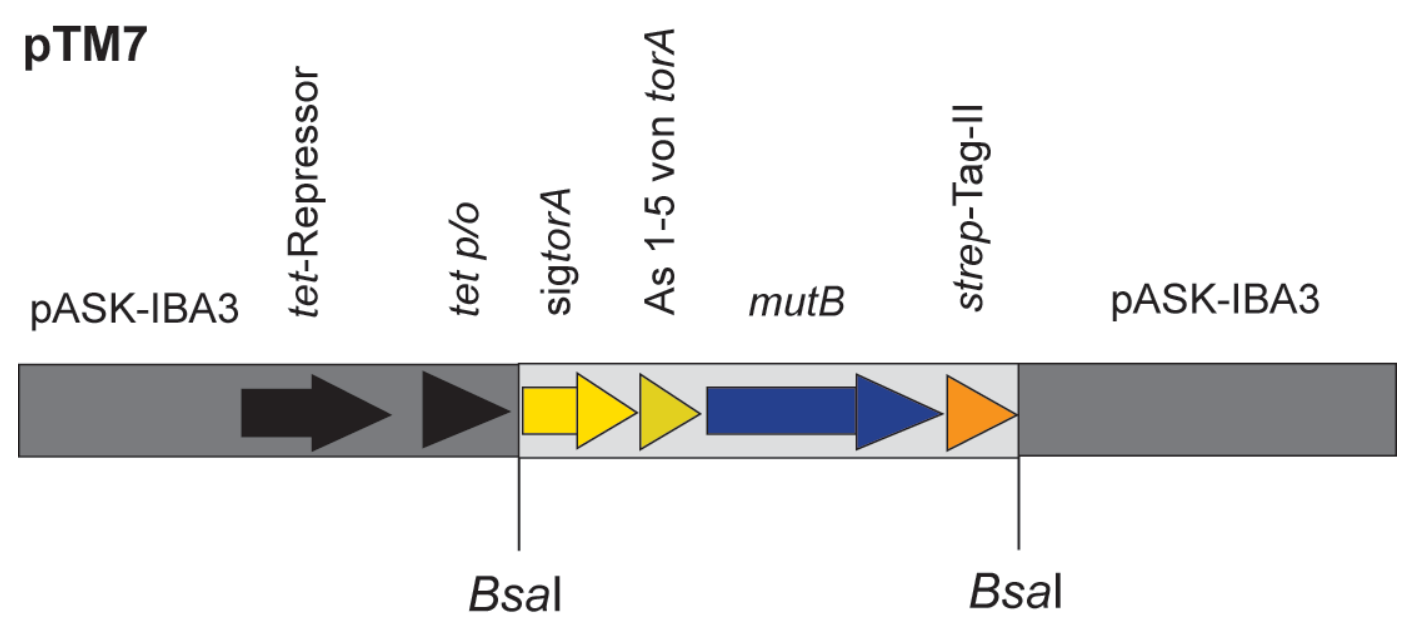

\begin{abstract}
Abbildung 30: Schematische Darstellung des Vektors pTM7
Für die Klonierung von sigtorA-mutB in den Expressionsvektor pASK-IBA3 wurde über PCR sowohl 3'-, als auch 5'-terminal die Erkennungssite für BsaI amplifiziert. Hierfür wurden die Primer f-IBA3torA-mutB-BsaI und r-IBA3torA-mutB-BsaI herangezogen (siehe Tabelle 3). Die Anlagerung an das Template pMB5 erfolgte in den ersten drei Zyklen für $45 \mathrm{~s}$ bei $60{ }^{\circ} \mathrm{C}$ und in den folgenden 27 Zyklen für $45 \mathrm{~s}$ bei $64^{\circ} \mathrm{C}$. Die Kettenverlängerung wurde bei allen 30 Zyklen bei $72{ }^{\circ} \mathrm{C}$ für 5,10 min durchgeführt. Die Klonierung in den Vektor pASK-IBA3 erfolgte über die $B s a I$-Schnittstelle. Die korrekte Insertion von sigtorA-mutB wurde anschließend durch Sequenzierung bestätigt. Das Konstrukt wurde als pTM7 bezeichnet.
\end{abstract}

Für die folgende Expression wurde das Plasmid pTM7 über Elektroporation in E. blattae transferiert. Die Expression erfolgte aerob im 100 ml-Maßstab nach den unter 2.14.3 beschriebenen Methoden. Da die sigtorA-mutB Gene nun unter der Kontrolle des tet-Promotors standen, erfolgte die Induktion der Genexpression mit Anhydrotetracyclin. Bei der SDS-PAGE-Analyse des Expressionsversuches konnte nach Induktion der Genexpression eine Proteinbande im Molekularmassenbereich von sigTorA-MutB identifiziert werden (Daten nicht gezeigt). Daraufhin wurde die Expression unter den gleichen Bedingungen wiederholt und anschließend die periplasmatische Fraktion aus den Zellen gewonnen (siehe 2.14.5.5). Über WesternBlot-Analyse ließ sich im Periplasma eindeutig ein Signal mit der Molekularmasse von sigTorA-MutB detektieren. (siehe Abbildung 31, Spur 3). In der als Negativ-Kontrolle gewonnenen periplasmatischen Fraktion des Wildtyps, der unter gleichen Bedingungen angezogen worden war, ließ sich kein Signal nachweisen. Dies belegte eine durch pTM7 vermittelte Translokation von sigTorA-MutB ins Periplasma von E. blattae. Wie aus Abbildung $31 \mathrm{zu}$ ersehen, trat mit Hilfe des gegen den Strep-TagII-gerichteten Antikörpers keine starke Hintergrundreaktion mehr im Western-Blot auf. Somit erfolgten alle weitere Expressionen von sigTorA-MutB in E. blattae mit dem Konstrukt pTM7. 


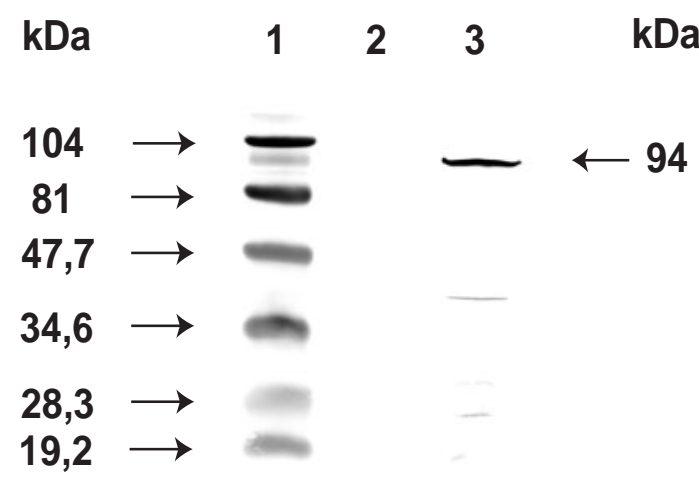

\section{Abbildung 31: Western-Blot-Analyse zum Nachweis der Translokation von sigTorA-MutB ins Periplasma von E. blattae}

Dargestellt ist eine PVDF-Membran nach Behandlung mit polyklonalen gegen den Strep-Tag gerichteten Antikörpern.

Spur 1: Proteinstandard

Spur 2: Periplasma aus Wildtyp von E. blattae

Spur 3: Periplasma aus E. blattae/pTM7

\subsubsection{Translokation von sigTorA-MutB in $B_{12}$-produzierenden Enterobakterien}

Um die Voraussetzung für die Funktion des $\mathrm{B}_{12}$-Exporters zu erfüllen, musste noch der Beweis für die Translokation des MutB aus dem Cytoplasma unter $\mathrm{B}_{12}$-produzierenden Konditionen erbracht werden. Hierzu wurden die Stämme C. freundii/pMB5 und E. blattae/pTM7 eingesetzt.Die heterologe Expression von sigTorA-MutB erfolgte nach den unter 2.13.1 und 2.14.3 beschriebenen Methoden anaerob in $500 \mathrm{ml}$ Volumina. Zusätzlich wurden dem Medium noch eine Reihe von Aminosäuren und $20 \mathrm{mM}$ Fumarat als externer Elektronenakzeptor beigefügt (siehe 2.2.1). Dadurch sollten die anaeroben Wachstumsraten und die Zelldichten erhöht werden, so dass mehr Fusionsprotein heterolog gebildet werden konnte. Nach der Induktion der Expression des sigtor $A-m u t B$-Fusionsgens in den $\mathrm{B}_{12}$-Produzenten E. blattae/pTM7 und C. freundii/pMB5 konnte das Periplasma aus den Zellen präpariert werden (siehe 2.15.5.5). Anschließend wurden außerdem aus den restlichen Zellpellets die Cytoplasma- und Membranfraktionen gewonnen. Die Analyse der verschiedenen Fraktionen von E. blattae erfolgte im Western-Blot mit Antikörpern, die gegen den Strep-TagII-gerichteten waren (siehe 2.23.1.2). Dabei zeigte sich, dass in E. blattae/pTM7 das Fusionsprotein ins Periplasma transportiert worden war (siehe Abbildung 32, Spur 2). Die Cytoplasma- und Membranfraktionen wiesen ebenfalls ein Signal im Molekularmassenbereich von sigTorA-MutB (94 kDa) auf, allerdings in geringerer Intensität als im Periplasma. Die Periplasma-, Cytoplasma- und MembranFraktionen von $C$. freundii/pMB5 brachten vergleichbare Ergebnisse in den WesternBlot-Analysen, die mit Hilfe des gegen den His ${ }_{6}$-Tag-gerichteten Antikörpers 
durchgeführt wurden (Daten nicht gezeigt). Es konnte also gezeigt werden, dass ein Großteil des sigTorA-MutB Hybridproteins in den beiden $B_{12}$-produzierenden Enterobakterien ins Periplasma transloziert wurde.

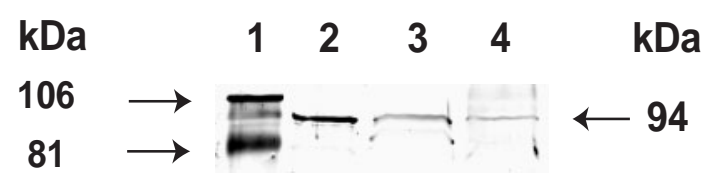

\section{Abbildung 32: Nachweis des sigTorA-IF im Periplasma, Cytoplasma und in den Membranen von E. blattae im Western-Blot}

Abgebildet ist eine PVDF-Membran, die mit polyklonalem gegen den Strep-TagII-gerichtetem Antiserum inkubiert wurde.

Spur 1: Proteinstandard

Spur 2: Periplasma von E. blattae/pTM7

Spur 3: Cytoplasma von E. blattae/pTM7

Spur 4: Membranen von E. blattae/pTM7

Zur Überprüfung der Reinheit des präparierten Periplasmas wurden diese Proben noch in zwei weiteren Western-Blot-Analysen untersucht. Diese erfolgten zum einen durch den Nachweis eines bekannten typischen periplasmatisch-lokalisierten Proteins. Hierzu wurde das Maltose-Bindeprotein (MBP) verwendet. Zum anderen wurde die Reinheit des Periplasmas überprüft. Im Falle einer Verunreinigung ließe sich nicht mehr eindeutig feststellen, ob das im Periplasma detektierte sigTorA-MutB tatsächlich transloziert worden war. Das Vorhandensein solcher Verunreinigungen konnte mit Hilfe eines Antiserums gegen ein typisch cytoplasmatisches Enzym, dem Chaperon DnaK, untersucht werden.

Zur Detektion beider Proteine wurde sowohl die periplasmatische als auch die cytoplasmatische Probe (Abbildung 32, Spur 2 und 3) in zwei Western-Blots mit beiden Antiseren inkubiert (siehe 2.23.1.2). Die Analyse der Blots zeigte, dass sich im Periplasma nur das periplasmatische MBP und kein cytoplasmatisches DnaK nachweisen ließ (siehe Abbildung 33 A, Spur 2 und B, Spur 5). Somit war bestätigt, dass es sich bei der präparierten Fraktion um Periplasma handelte, welches keine signifikanten cytoplasmatischen Anteile beinhaltet. Dagegen wies das Cytoplasma als Kontrolle wie erwartet nur geringe Mengen an MBP und eine eindeutige Bande im Molekularmassenbereich von DnaK auf (siehe Abbildung 33A, Spur 3 und B, Spur 6). 


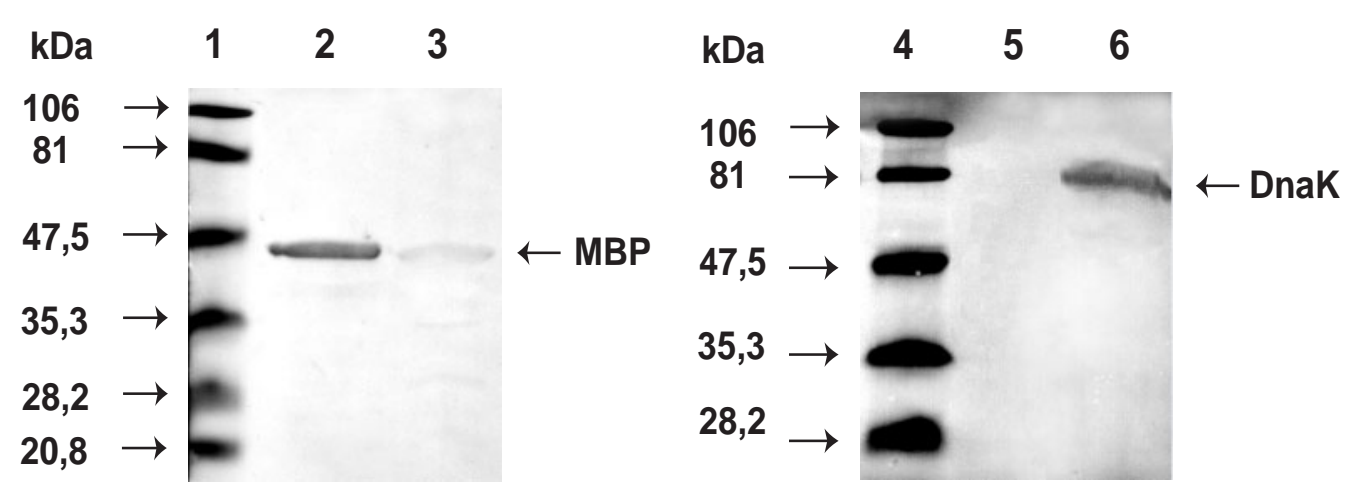

\section{Abbildung 33: Nachweis des Maltose-Bindeproteins MBP (A) und des Chaperons DnaK (B) in Zellfraktionen von E. blattae/pTM7 im Western-Blot}

(A) Die Western-Blot-Analyse wurde mit Antiserum durchgeführt, welches gegen das MBP-gerichtet ist (siehe 2.23.1.2).

Spur 1: Proteinstandard

Spur 2: Periplasma von E. blattae/pTM7

Spur 3: Cytoplasma von E. blattae/pTM7

(B) Dargestellt ist eine mit MBP-spezifischem Antiserum durchgeführte Western-Blot-Analyse (siehe 2.22.1).

Spur 4: Proteinstandard

Spur 5: Periplasma von E. blattae/pTM7

Spur 6: Cytoplasma von E. blattae/pTM7

Die Translokation des sigTorA-MutB ins Periplasma konnte ebenfalls mit Hilfe von elektronenmikroskopischen Aufnahmen bestätigt werden. Die Einbettung der Zellen erfolgte dabei nach der Lowicryl-Methode (siehe 2.25). Die Detektion des Hybridproteins wurde mit IgG-Maus-Antikörpern, die gegen den Strep-TagII gerichtet sind und mit Gold-markierten Anti-Maus-Antikörpern durchgeführt. Während der Wildtyp von E. blattae keinerlei Markierung in der Zelle aufwies waren in E. blattae/pTM7 sowohl cytoplasmatische als auch periplasmatische Markierungen zu erkennen. Dabei ließ sich im Periplasma geringfügig mehr sigTorA-MutBFusionsprotein nachweisen.

Mit der bestätigten Translokation des $\mathrm{B}_{12}$-Bindeproteins MutB aus dem Cytoplasma ins Periplasma unter $\mathrm{B}_{12}$-produzierenden Voraussetzungen waren die Bedingungen für einen Transport des $\mathrm{B}_{12}$ aus dem Cytoplasma gegeben. 
A)

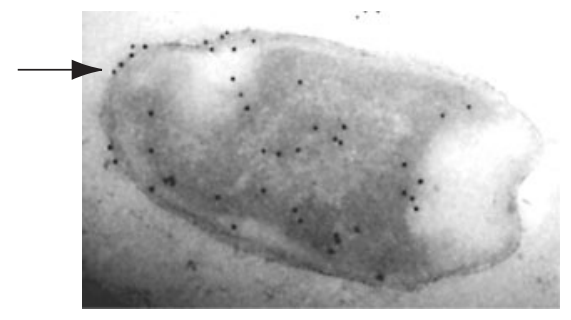

B)

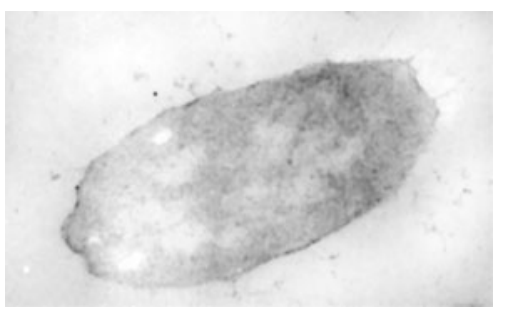

Abbildung 34: Elektronenmikroskopische Aufnahmen zum Nachweis der Translokation von sigTorA-MutB in E. blattae

Die Arbeiten wurden von der Abteilung von Herrn Prof. Dr. Mayer in Göttingen angefertigt nach der unter 2.25 beschriebenen Methode durchgeführt.

(A): anaerob gewachsene Zelle von E. blattae/pTM7 nach Induktion

(B): aerob gewachsene Zelle des E. blattae Wildtyps

\subsection{Studien zum Nachweis der Cotranslokation von $B_{12}$ und MutB}

In dem Modell für den $\mathrm{B}_{12}$-Exporter ist die Bindung des Coenzyms in der Zelle an das $\mathrm{B}_{12}$-Bindeprotein notwendig. Nachdem die Translokation des $\mathrm{B}_{12}$-Bindeproteins gezeigt werden konnte, sollte in folgenden Experimenten die Cotranslokation mit $\mathrm{B}_{12}$ belegt werden. Dazu wurde zunächst untersucht, ob eine Abhängigkeit zwischen der Produktion des Corrinoids und dem heterolog gebildeten MutB besteht.

\subsubsection{Abhängigkeit der Corrinoidproduktion von verschiedenen E. blattae- Stämmen in An- und Abwesenheit von heterolog produzierter Methylmalonyl-CoA-Mutase}

Mit Hilfe des $\mathrm{B}_{12}$-Plattentests (KRZYCKI et al., 1980) wurde eine quantitative Corrinoidbestimmung mit den Rohextrakten verschiedener Stämme durchgeführt. Ziel war es zu untersuchen, inwieweit die vermehrte Produktion des Coenzym $\mathrm{B}_{12}$-bindenden Proteins MutB eine Steigerung der $\mathrm{B}_{12}$-Synthese bewirkt. Dazu wurden E. blattae-Stämme mit und ohne das sigTorA-MutB-Fusionsprotein eingesetzt. Die in dem Test verwendete E. coli-Mutante DSM 4261 ist aufgrund einer defekten $\mathrm{B}_{12}$-unabhängigen Methionin-Synthase bei Wachstum in Methionin-freiem Medium auf die Aktivität der $\mathrm{B}_{12}$-abhängigen Methionin-Synthase und damit auf das Vorhandensein von $\mathrm{B}_{12}$ angewiesen. Zur Herstellung der Testplatten wurde nach der Methode unter 2.27.1 verfahren.

Die Rohextrakte (je $2 \mathrm{ml}$ ) wurden aus anaerob im 50 ml-Maßstab inkubierten Kulturen von rekombinanten E. blattae-Stämmen mit dem sigTorA-MutB-Fusionsprotein 
(E. blattae/pTM3, E. blattae/pTM6, E. blattae/pTM7) und als Kontrolle aus dem Wildtyp von E. blattae gewonnen (siehe 2.15.2). Dabei waren durch die Anzuchtbedingungen unter anaeroben Bedingungen in Gegenwart von Glycerin (siehe 2.14.1) die Voraussetzungen für die $B_{12}$-Synthese der Stämme gegeben. Von allen Kulturen wurden mindestens drei Parallelansätze bearbeitet und im Plattentest immer Doppelbestimmungen durchgeführt. Die Induktion der Genexpression des Fusionsgens erfolgte dabei mit Arabinose (E. blattae/pTM3, E. blattae/pTM6) bzw. Anhydrotetracyclin (E. blattae/pTM7). Der Proteingehalt aller getesteten Rohextrakte wurde auf $7 \mathrm{mg} / \mathrm{ml}$ eingestellt, um eine Vergleichbarkeit der Ergebnisse zu gewährleisten. Pro Testansatz wurden $15 \mu \mathrm{l}$ (entsprechend $0,1 \mu \mathrm{g}$ Protein) von insgesamt $2 \mathrm{ml}$ Rohextrakt eingesetzt.

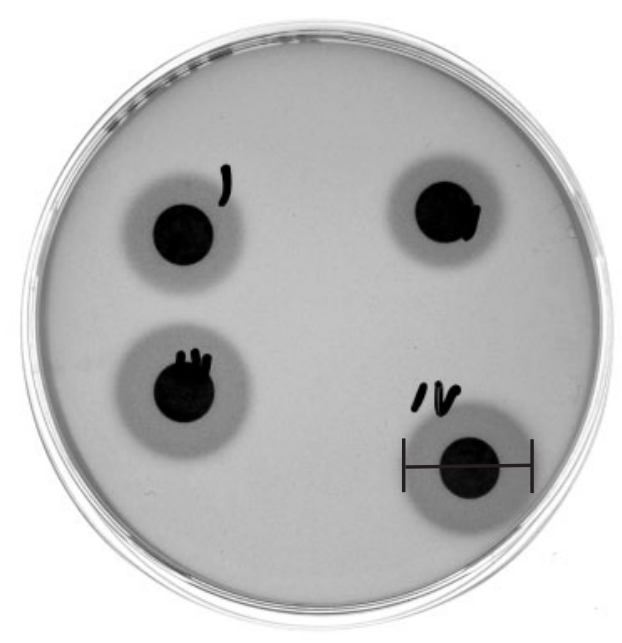

\section{Abbildung 35: Abbildung einer Testplatte der quantitativen Bestimmung von $B_{12}$}

Die Durchmesser der Zonen um die Filterplättchen sind proportional zur $\mathrm{B}_{12}$-Konzentration der aufgetragenen Probe.

Zur Ermittlung der $\mathrm{B}_{12}$-Eichgeraden wurden die Durchmesser der roten Zonen um die Filterplättchen der $\mathrm{B}_{12}$-Eichlösungen ausgemessen (siehe 2.27.1). Anschließend konnte die eingesetzte $\mathrm{B}_{12}$-Menge der Eichwerte mit dem Durchmesser der Zonen in Beziehung gesetzt werden. Die Berechnung der $\mathrm{B}_{12}$-Konzentrationen in den verschiedenen Rohextrakten (siehe Abbildung 36 und Tabelle 9) erfolgte mit Hilfe der $\mathrm{B}_{12}$-Eichgeraden. 


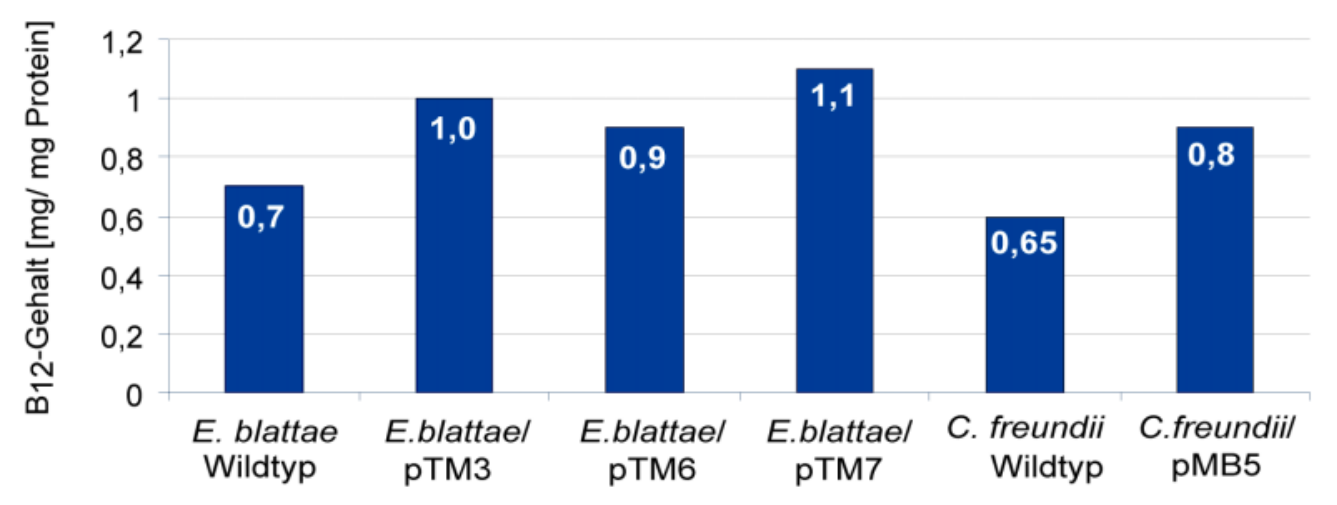

\section{Abbildung 36: Graphische Darstellung der im Plattentest erhaltenen Mittelwerte der $B_{12}$-Gehalte im Rohextrakt verschiedener $B_{12}$ - Produzenten}

Die Werte wurden aus drei verschiedenen Kulturen in unabhängigen Testdurchläufen ermittelt, die wiederum in Doppelbestimmungen durchgeführt worden waren.

Tabelle 9: ermittelte $B_{12}$-Konzentrationen in den verschiedenen Rohextrakten

Organismus $\quad B_{12}$-Konzentration $[\mu \mathrm{g} / \mathrm{ml}$ RE]
E. blattae Wildtyp
4,7
E. blattae/pTM3
6,6
E. blattae/pTM6
6,0
E. blattae/pTM7
7,3
C. freundi Wildtyp
4,3
C. freundii/pMB5
5,3

Sowohl für die E. blattae-Stämme als auch für den C. freundii-Stamm konnte dabei gezeigt werden, dass die heterologe Produktion von sigTorA-MutB eine erhöhte $\mathrm{B}_{12}$-Bildung zur Folge hatte (siehe Abbildung 36 und Tabelle 9). Dabei konnte eine Steigerung von 28-57\% ermittelt werden. Die geringste Konzentration an gebildetem $\mathrm{B}_{12}$ wies der Rohextrakt von E. blattae/pTM6 und die größte der Rohextrakt von E. blattae/pTM7 auf. 


\subsubsection{Corrinoidnachweis im Periplasma verschiedener $B_{12}$-Produzenten}

Abschließend sollte die Frage untersucht werden, ob der Einsatz des $B_{12}$-Exporters den Transport von Coenzym $\mathrm{B}_{12}$ ins Periplasma bewirkt. Dazu wurden die periplasmatischen Proben aus den anaeroben 500 ml-Kulturen von verschiedenen E. blattae- und C. freundii-Stämmen untersucht, in denen die Translokation des sigTorA-MutB-Fusionsprotein bereits im Western-Blot nachgewiesen werden konnte (siehe Abbildung 32). Die Quantifizierung des $\mathrm{B}_{12}$-Bindeproteins $\mathrm{MutB}$ in den Periplasma-Proben erfolgte durch Western-Blot-Analyse (siehe 2.23.2.1 und 2.22.1). Durch den Einsatz verschiedener Konzentrationen eines Strep-TagII-Proteins konnte eine Eichgerade erstellt und über diese die MutB-Konzentration in den periplasmatischen Proben ermittelt werden. Für die Bestimmung der $\mathrm{B}_{12}$-Konzentration im Periplasma wurde erneut die Plattentest-Methode von KRZYCKI et al., 1980 herangezogen (siehe 2.27.1). Die in Abbildung 37 dargestellten Werte konnten wie in 3.6.1 beschrieben mit Hilfe der aus den $\mathrm{B}_{12}$-Eichlösungen erstellten $\mathrm{B}_{12}$-Eichgeraden bestimmt werden (siehe 2.27.1).

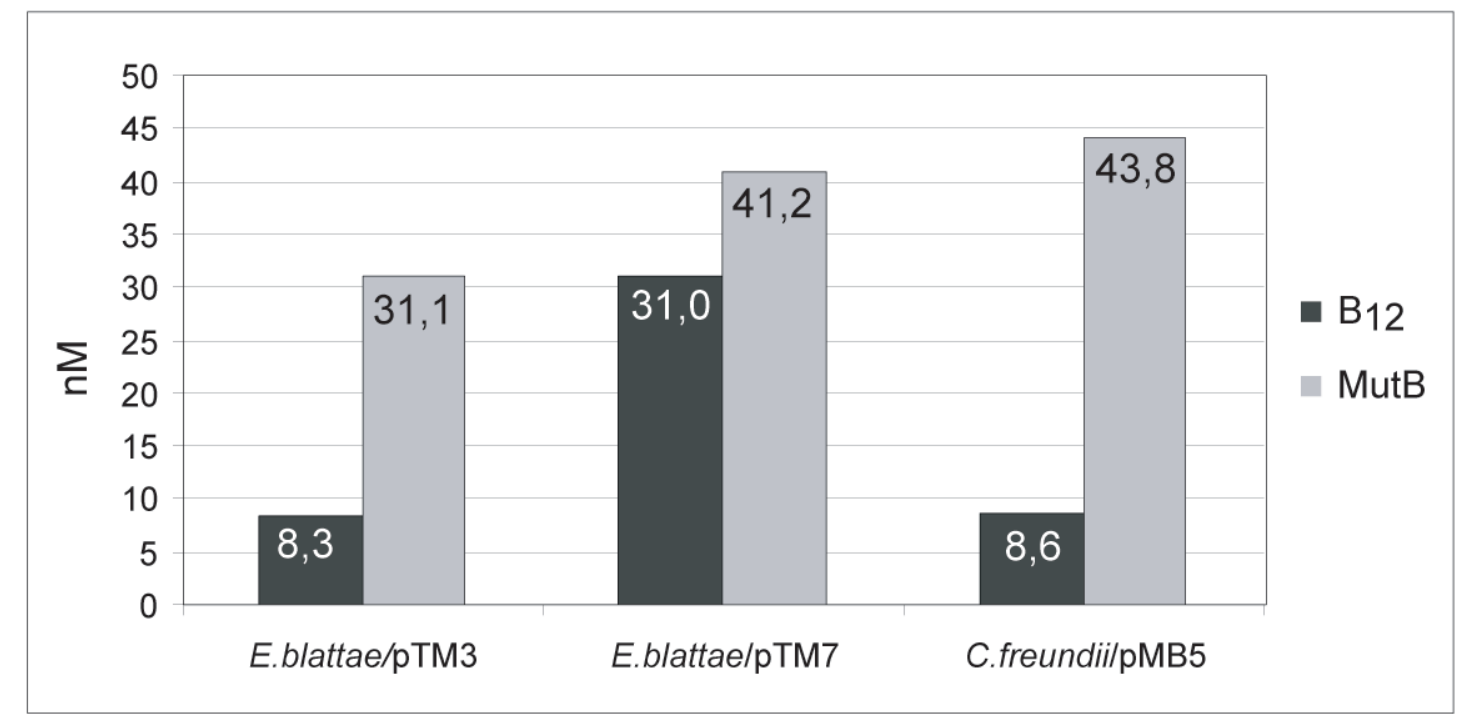

\section{Abbildung 37: Verhältnis von MutB und $B_{12}$ im Periplasma verschiedener $B_{12}$-Produzenten}

Die Werte wurden aus vier verschiedenen Kulturen in unabhängigen Testdurchläufen ermittelt, die wiederum in Doppelbestimmungen durchgeführt worden waren.

Für alle eingesetzten Stämme konnte gezeigt werden, dass eine Cotranslokation von $\mathrm{B}_{12}$ mit dem Bindeprotein MutB stattgefunden hatte. Dabei variierten die ermittelten Verhältnisse von transloziertem MutB $\mathrm{zu} \mathrm{B}_{12}$ zwischen 1,3 und 5,1 $\mathrm{zu} 1$ (siehe Abbildung 37). In C. freundii/pMB5 wurde von allen drei Stämmen am meisten MutB 
Protein im Verhältnis zum Coenzym $B_{12}$ ins Periplasma transloziert. Der Stamm E. blattae/pTM7 wies die größte Menge an $\mathrm{B}_{12}$ pro Bindeprotein im Periplasma. Somit konnte für den konstruierten $\mathrm{B}_{12}$-Exporter, bestehend aus der TorA-Signalsequenz und $\mathrm{B}_{12}$-Bindeprotein MutB, der Nachweis für den Transport von $\mathrm{B}_{12}$ ins Periplasma erbracht werden. 


\section{Diskussion}

\subsection{Transport von $\mathrm{B}_{12}$ über Membranen}

Einige Mikroorganismen wie z. B. Citrobacter freundii, Escherichia blattae oder Klebsiella $s p$. vermögen das für verschiedene Reaktionen benötigte Coenzym $\mathrm{B}_{12}$ selbst $\mathrm{zu}$ synthetisieren. Andere $\mathrm{B}_{12}$-auxotrophe Mikroorganismen müssen es dagegen aus dem umgebenden Milieu aufnehmen (LAWCRENCE et al., 1991). Beim Import von $\mathrm{B}_{12}$ entstehen zwei Probleme für die bakterielle Zelle. Zum einen sind Cobalamine zu groß, um über die Porine der äußeren Membran aufgenommen zu werden, und zum anderen kommt $\mathrm{B}_{12}$ nur in äußerst geringen Konzentrationen in der Umgebung vor. Deshalb ist ein hoch-affines Transportsystem für die Passage über die äußere Membran erforderlich. Ein weiteres System sorgt dann für den $\mathrm{B}_{12}$-Transport über die Cytoplasamamembran. (BRAUN, 1995; ROTH et al., 1996). Mit Hilfe des membrangebundenen Transporterproteins BtuB wird das Cobalamin aus dem Medium gebunden und durch Interaktion von BtuB mit TonB ins Periplasma transportiert. TonB ist in der Cytoplasmamembran verankert und durchspannt den periplasmatischen Raum (siehe Abbildung 38; CARDIEUX et al., 1999). Um für den Transport notwendige strukturelle Änderungen hervorzurufen, nutzt das TonB die protonmotorische Kraft. Für die Bindung des Cobalamins an BtuB ist der Cotransport von Calcium notwendig (BRADBEER et al., 1990). Nach der aktiven Konzentrierung des Cobalamins durch das BtuB/ TonB-System im Periplasma wird es, wie bereits von VAN BIBBER et al., 1999 postuliert und von CARDIEUX et al., 2002 bestätigt, auf das periplasmatische Bindeprotein BtuF übertragen. Möglicherweise unterstützt BtuF dabei die Abtrennung des Cobalamins vom BtuB. Der Transport über die innere Membran ist an die Hydrolyse von ATP gebunden und wird durch einen ABC-Transporter bewerkstelligt. Dieser setzt sich aus den Membranproteinen BtuC und BtuD zusammen (ROTH et al., 1996).

Im Gegensatz zum Aufnahmesystem von $\mathrm{B}_{12}$ ist für einen $\mathrm{B}_{12}$-Export in der Natur bislang kein Beispiel beschrieben worden. Im Rahmen dieser Arbeit konnte ein solches System konstruiert werden. Bei der Entwicklung des $\mathrm{B}_{12}$-Exporters wurde berücksichtigt, dass der Import des Cobalamins über beide Membranen ausschließlich mit Hilfe von Bindeproteinen erfolgt. Deshalb wurde für den Exporter auch ein Bindeprotein-abhängiges System verwendet. Hierbei wurde das $\mathrm{B}_{12}$ in der Zelle an ein Bindeprotein gebunden und zusammen mit diesem über die Cytoplasmamembran transportiert. 


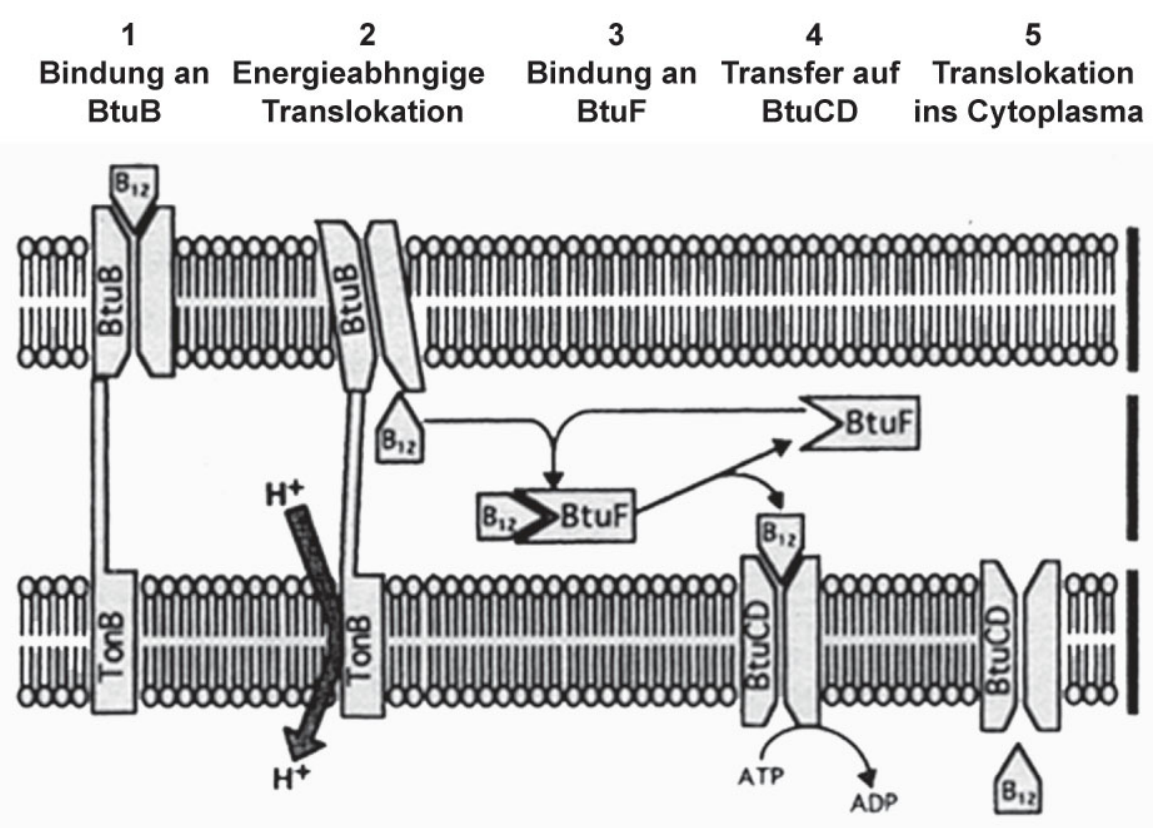

Abbildung 38: B 12 -Aufnahme in E. coli aus BRADBEER (1991)

\subsection{Coenzym $\mathrm{B}_{12}$-abhängige und Cobalamin-bindende Proteine}

Vitamin $\mathrm{B}_{12}$ übernimmt nach seiner Umwandlung zum Cofaktor nicht nur in Mikroorganismen, sondern auch in tierischen Zellen eine wichtige Funktion (ISHIDA et al., 1994). Die physiologische Rolle der $B_{12}$-Derivate ist dabei eng mit ihrer Funktion als Coenzyme in enzymatischen Reaktionen verbunden. (KRÄUTLER, 1998). Sie besitzen die Fähigkeit an Proteine zu binden, um daraufhin mit Substratmolekülen zu reagieren. $\mathrm{B}_{12}$-Cofaktoren kommen in zwei aktiven Formen, dem Methylcobalamin (MeCbl) und dem Adenosylcobalamin (5'-Deoxy-5'-adenosylcobalamin; AdoCbl) vor (siehe Abbildung 39). Beim MeCbl ist das Cobaltatom an die Methylgruppe und beim AdoCbl an 5'-Deoxyadenosin gebunden. 

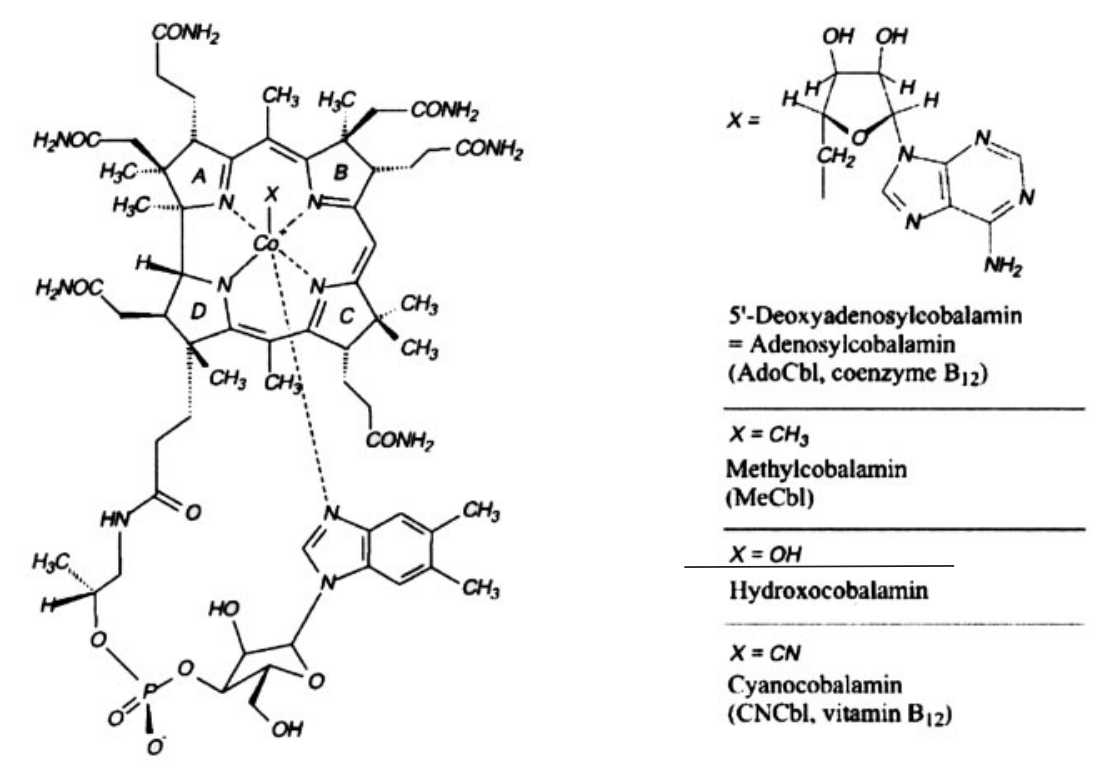

\section{Abbildung 39: Struktur des Vitamin $B_{12}$ und der $B_{12}$-Cofaktoren aus MARTENS et al. (2002)}

Die Spaltung der Cobalt-Kohlenstoff-Bindung in den beiden Cofaktoren erfolgt dabei auf ganz unterschiedliche Weise, die stark von der Natur ihrer Alkyl-Gruppen bestimmt wird (GOLDING et al., 1998). Während bei MeCbl durch Methyl-Transfer eine heterolytische Spaltung vorliegt und Nukleophile gebildet werden, wird bei AdoCbl die Bindung zwischen dem Cobalt und dem Kohlenstoff homolytisch gespalten und es entstehen freie Radikale.

Methylcobalamin-abhängige Enzyme katalysieren den Transfer von Methylgruppen, die dabei vorübergehend auf das Cobalt des Methylcobalamins übertragen werden. Sie sind an der Synthese von Methionin, Acetat und Methan beteiligt. Ein gut charakterisiertes Enzym aus der Gruppe der Methyltransferasen ist die Methionin Synthase von E. coli. Sie unterstützt die Übertragung eine Methylgruppe vom Methyltetrahydrofolat zum Homocystein (LUDWIG \& MATTHES, 1997; ZAGALAK, 1982). E. coli besitzt neben dieser $\mathrm{B}_{12}$-abhängigen auch eine $\mathrm{B}_{12}$-unabhängige Methionin-Synthase (WU et al., 1992). Außerdem sind $B_{12}$-abhängige Methyltransfersen auch aus methanogenen Archaen und acetogenen Bakterien bekannt (BLAYLOCK and STADMAN 1967; WOOD, 1991).

Adenosylcobalamin-abhängige Enzyme sind an verschiedenen Umlagerungsreaktionen beteiligt, wozu Spaltungen von Kohlenstoff-Kohlenstoff-, Kohlenstoff-Sauerstoff- und Kohlenstoff-Stickstoff-Verbindungen gehören. Diese Reaktionen gehören zu Abbauwegen, die anaeroben Bakterien die Fermentation von verschiedenen 
Kohlenstoffquellen wie z. B. Glycerin oder Ethanolamin ermöglichen (DANIEL et al., 1999; LUDWIG \& MATTHES, 1997). Eine Ausnahme stellt die RibonukleotidReduktase dar. Sie reduziert Ribonukleotid-Triphosphate zu DesoxyribonukleotidTriphosphaten, die für die DNA-Synthese benötigte werden. In einigen Mikroorganismen wie Lactobacillus leichmanii wird diese Reaktion von der Adenosylcobalamin-abhängigen Ribonukleotid-Reduktase katalysiert (BLAKLEY, 1965). Insgesamt 12 verschiedene Adenosylcobalamin-abhängige Enzyme lassen sich aufgrund ihrer Substrate in drei Untergruppen einteilen. Sie bewirken Umlagerung von Amino- oder Hydroxylgruppen in Amino-Alkoholen oder Diolen mit nachfolgender Deaminierung bzw. Dehydratisierung zu Aldehyden. Zur Gruppe der Dehydratasen und Deaminasen zählen die Glycerin-Dehydratase, die Diol-Dehydratase und die Ethanolamin-Ammonium-Lyase. Die Mutasen stellen eine weitere Gruppe dar. Sie katalysieren Veränderungen am Kohlenstoffskelett. $\mathrm{Zu}$ ihnen gehören die Methylmalonyl-CoA-Mutase, die Glutamat-Mutase, die $\alpha$-Methylenglutarat-Mutase und die Isobutyryl-CoA-Mutase. Die dritte Gruppe stellen die Aminomutasen mit der L- $\beta$ Lysin-[D- $\alpha$-Lysin]-5,6-Aminomutase, der D-Ornithin-4,5-Aminomutase und der LLeucin-2,3-Aminomutase dar. Sie katalysieren die 1,2-Umlagerungen einer Aminogruppe in einer Aminosäure und scheinen nur in Clostridien vorzukommen. Als zusätzliches Coenzym benötigen diese Pyridoxalphosphat (MARSH, 1999).

Corrinoid-abhängige Enzyme sind vor allem in der Mikroorganismenwelt vertreten. Bei Tieren und bei Menschen sind nur die Homocystein-Mehtyltransferase und die Methylmalonyl-CoA-Mutase bekannt (ZAGALAK, 1982). Die cytoplasmatische Methionin-Synthase benötigt Methylcobalamin, um durch Methylierung von Homocystein Methionin zu gewinnen, wobei Methyltetrahydrofolat als Methyldonor fungiert. Adenosylcobalamin hingegen ist in den Mitochondrien an der Isomerisierung von Methylmalonyl-CoA zu Succinyl-CoA durch die Methylmalonyl-CoA-Mutase beteiligt (BANERJEE, 1998). Diese Reaktion spielt eine Rolle beim Metabolismus von Propionyl-CoA, dass aus dem Abbau von Thymin, Valin, Methionin oder ungeradzahligen Fettsäuren hervorgeht (MARTENS et al., 2002).

An der Aufnahme und dem Transport von Cobalamin aus der Nahrung des Menschen sind drei lösliche Proteine beteiligt: der Intrinsic Faktor (IF), Transcobalamin (TC) und Haptocorrin (HC). Diese Proteine stellen sicher, dass die geringen Mengen an $\mathrm{B}_{12}$, die mit der Nahrung aufgenommen werden, auch zu den beiden intrazellulären Enzymen, Methionin-Synthase und Methylmalonyl-CoA-Mutase, gelangen (KRÄUTLER, 1998). Der Intrinsic Faktor hat seinen Namen von dem früher als Extrinsic Faktor bezeichneten Vitamin $\mathrm{B}_{12}$ und wird im Magen produziert. Dort übernimmt er das vom Haptocorrin im Speichel gebundene Cobalamin. Anschließend wird der IF-Cobalamin-Komplex im Intestinaltrakt von Rezeptoren absorbiert und auf Haptocorrin und Transcobalamin 
übertragen, um auf diesem Wege in die Zelle zu gelangen. Das meiste Cobalamin wir in die Leber und Niere transportiert. In den Zellen wird dann das Cobalamin in die zwei enzymatisch aktiven Coenzym-Formen umgewandelt (NEXØ, 1998).

Der Intrinsic Faktor ist einer der beiden $\mathrm{B}_{12}$-Bindeproteine, die zur Konstruktion des $\mathrm{B}_{12}$-Exporter im Rahmen dieser Arbeit ausgewählt wurden. Er weist eine Größe von etwa $50 \mathrm{kDa}$ auf und ist natürlicherweise stark glykosyliert. Zwar scheint die Glykosylierung von geringerer Bedeutung für die Bindung des $B_{12}$ und die anschließende Kopplung an den Rezeptor zu sein. Dafür schützt sie mit großer Wahrscheinlichkeit den Intrinsic Faktor vor Degradation. Nicht glykosylierter IF ist somit funktionell identisch zum glykosylierten Protein (GORDON, 1997).

Lokalisiert ist der IF auf dem Chromosom 11, weist neun Exons und 8 große Introns und eine TATA-Box auf. Fehlen $12 \%$ des C-terminalen Endes, so ist er nicht mehr in der Lage $B_{12}$ zu binden (NEXØ, 1998). Die Aminosäure-Reste 29 bis 62 von insgesamt 399 des reifen IF, stellen die Rezeptorbindestelle dar (siehe Abbildung 40; TANG et al., 1992).

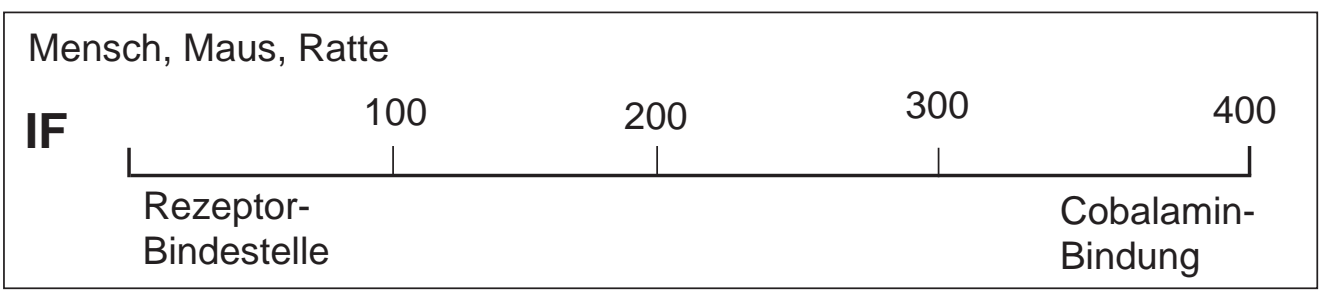

\section{Abbildung 40: Proteinstruktur des menschlichen Intrinsic Faktors aus NEXØ, (1998)}

Der Intrinsic Faktor wurde besonders wegen seiner hohen Bindekapazität als $\mathrm{B}_{12^{-}}$ Bindeprotein ausgewählt, wobei Hydroxy- Methyl-, 5'-Deoxyadenosyl und Cyanocobalamin etwa gleich gut gebunden werden. (KRÄUTLER, 1998; NEXØ, 1998). Durch die Bindung von $B_{12}$ wird der Radius des Intrinsic Faktors reduziert. Die molare Binderate von IF zu Cobalamin liegt bei 30:1, es werden also $1 \mathrm{ng} \mathrm{B}_{12}$ von $30 \mathrm{ng}$ Intrinsic Faktor gebunden.

Viele verschiedene prokaryotische Expressionssysteme wurden bereits getestet und alle als unzureichend befunden, da sich in keinem von ihnen reproduzierbare Mengen an Intrinsic Faktor detektieren ließen. GORDON (1997) gelang es mit Hilfe des Bakulovirus das Protein in geringer Konzentration (1-3 mg/ 1 Medium) zu synthetisieren. Das Expressionssystem der methylotrophen Hefe Pichia pastoris hingegen ermöglichte die Produktion des menschlichen IF mit einer Rate von 
10-40 mg/l. Für die Klonierung in den Expressionsvektor pPIC9 war dabei die Signalsequenz des IF entfernt worden. Western-Blot-Analysen zur Detektion des menschlichen IF in Pichia pastoris hatten gezeigt, dass neben der Bande bei $55 \mathrm{kDa}$ auch drei zusätzliche, aber schwächere Signale bei 32, 28 und $23 \mathrm{kDa}$ auftraten. Dabei handelte es sich vermutlich um Degradationsprodukte der größeren IF-Bande (WEN et al., 1999).

In den Experimenten zu dieser Arbeit wurde das if-Gen mit Hilfe des Konstruktes pTM1 (siehe Abbildung 7) in E. coli DH5a exprimiert. Es gelang dabei nur eine geringe heterologe Produktion durch SDS-PAGE- und Western-Blot-Analysen nachzuweisen (siehe 3.2). Außerdem traten neben der schwachen 55-kDa Bande des IF auch noch kleinere Proteinbanden bei den Analysen hervor (siehe Abbildung 10 und Abbildung 16 bis Abbildung 18). Es wäre denkbar, dass es sich bei diesen Banden um Degradationsprodukte des IF handelt, da in E. coli keine Glykosylierung der Proteine stattfindet. Damit fehlte der natürliche Schutz des IF vor dem Abbau durch Proteasen. Somit ist es wahrscheinlich, dass der heterolog produzierte IF zum Großteil abgebaut wurde. Dies erklärt die geringen Produktionsmengen im Rahmen dieser Arbeit, die zur Folge hatten, dass nur wenig IF im Cytoplasma vorlag, welches ins Periplasma transportiert werden konnte. Daher liegt es nahe, dass sich aufgrund der geringen IFKonzentration kein $\mathrm{B}_{12}$-Export ins Periplasma nachgewiesen ließ. Der IF schien somit ungeeignet für den Einsatz im $\mathrm{B}_{12}$-Exporter-Modell. Weitere Studien wurden deshalb mit einem alternativen $B_{12}$-Bindeprotein durchgeführt.

Als zweites $\mathrm{B}_{12}$-Bindeprotein wurde die Methylmalonyl-CoA-Mutase aus Propionibakterium shermanii für die Konstruktion des $\mathrm{B}_{12}$-Exporters ausgesucht, da ihre Kristallstruktur bereits aufgeklärt ist (MANCIA et al., 1996). In dem Grampositiven Mikroorganismus ist das Adenosylcobalamin-abhängige Enzym an der Fermentation von Pyruvat zu Propionat beteiligt. Dabei katalysiert es die Interkonversion zwischen Methylmalonyl-CoA und Succinyl-CoA. Die MethylmalonylCoA-Mutase ist ein $\alpha \beta$-Heterodimer mit einer Molekularmasse von $150 \mathrm{kDa}$ (MANCIA et al., 1996). Die Bindung des Substrates oder Inhibitors erfolgt durch die N-terminale Domäne der $80 \mathrm{kDa} \alpha$-Kette. Die C-terminale Domäne der gleichen Kette bindet das Coenzym $B_{12}$. Kodiert wird die $\alpha$-Untereinheit von $m u t B$. Da die $\beta$-Untereinheit nicht an der Bindung des Coenzyms beteiligt ist, wurde für die Konstruktion eines Transporterproteins nur die $\alpha$-Kette der Methylmalonyl-CoA-Mutase verwendet, um die Molekularmasse des $\mathrm{B}_{12}$-Bindeproteins möglichst gering $\mathrm{zu}$ halten (EVANS and MANCIA, 1998). Dazu wurde das mutB-Gen mit der Tat-Signalsequenz der TMAOReduktase aus E. coli fusioniert. Die Expressionsstudien in E. coli JM109 und BL21 (DE3), S. typhimurium, C. freundii und E. blattae hatten gezeigt, dass im Gegensatz 
zum IF große Mengen an MutB heterolog produziert werden konnten (siehe Abbildung Abbildung 20 bis Abbildung 22 und Abbildung 24 bis Abbildung 26).

\subsection{Signalsequenz-abhängiger Proteintransport ins Periplasma}

Viele lösliche oder membrangebundene Proteine müssen in oder über Membranen transportiert werden, um ihren endgültigen Funktionsort zu erreichen (SCHATZ und DOBBERSTEIN, 1996). Die meisten Proteine werden durch die von SecY und SecE geformte Pore exportiert. Dabei existieren zwei verschiedene Mechanismen, um die Proteine $\mathrm{zu}$ der als Translokon bezeichneten SecYE-Pore $\mathrm{zu}$ geleiten. Integrale Membranproteine werden durch direkte Interaktion ihres Signalankers mit dem bakteriellen ,signal recognition particle“ (SRP) spezifisch erkannt. Dabei werden, außer SecYE, keine weiteren Sec-Proteine für die Integration in die Membran benötigt. Bei dem zweiten Mechanismus werden Präproteine mit einer Signalsequenz synthetisiert und anschließend mit Hilfe von cytoplasmatischen Chaperonen zu den spezifischen Rezeptoren in der Membran geleitet. Diese Signalpeptide werden nach der Translokation abgespalten. Ein Großteil der periplasmatisch lokalisierten Enzyme wird über den Sec (secretory)-Weg transportiert (siehe Abbildung 41; WICKNER et al., 1991). SecB fungiert dabei als Chaperon und dirigiert die Präproteine zur Cytoplasmamembran. Außerdem hält es die Vorläuferproteine in einem unvollständigen Faltungszustand, der für die Translokation erforderlich ist (COLLIER et al., 1988). SecB liegt als Heterodimer im Cytoplasma vor und weist im Gegensatz zu vielen anderen Chaperonen keine ATPase-Aktivität auf. Nach der Interaktion von SecB mit SecA wird das Präprotein auf SecA transferiert. Sobald ein ATP an SecA gebunden hat, löst sich SecB von der Membran, um ein neues Präprotein zu binden. Die ATPase SecA spielt eine Schlüsselrolle bei der Translokation der Vorläuferproteine über die Cytoplasmamembran. Durch wiederholte ATP-Bindung liefert sie die für die Reaktion benötigte Energie. Die Bindung an den SecYEG Komplex aktiviert das SecA für die Erkennung von SecB und der Präproteine. Die Membranproteine SecD, SecG, SecF und YajC sind nicht direkt an der Proteintranslokation beteiligt, stabilisieren aber beispielsweise die aktive Konformation von SecA. Ausgelöst durch die Bindung des Präproteins an SecA tauscht es ein gebundenes ADP gegen ein ATP an einer seiner beiden Bindungsstellen aus. Die Energie, die bei der ATP-Bindung entsteht, ermöglicht die Insertion der SecA-Domäne zusammen mit der Signalsequenz und der N-terminalen Region des Vorläuferproteins in der Membran. Nach der Insertion kann das Präprotein durch ATP-Hydrolyse freigesetzt werden. Das SecA wird durch die Bindung und Hydrolyse eines weiteren ATP an der zweiten Bindestelle aus der Membran 
freigegeben. Durch wiederholte Zyklen der SecA-Präprotein-Bindung, ATP-Bindung und -Hydrolyse und der Dissoziation des SecA Moleküls von der Membran wird eine schrittweise Translokation des gesamten Präproteins über die Membran bewirkt (siehe Abbildung 41). Anschließend wird das Signalpeptid von der Signalpeptidase abgespalten. Die Vorläuferproteine, die über den Sec-Weg transportiert werden, enthalten die Informationen dafür nicht nur in der Signalsequenz, sondern auch im reifen Teil des Proteins. (MÜLLER et al., 2001; FEKKES and DRIESSEN, 1999; KUMAMOTO, 1991; KUMAMOTO et al., 1985).

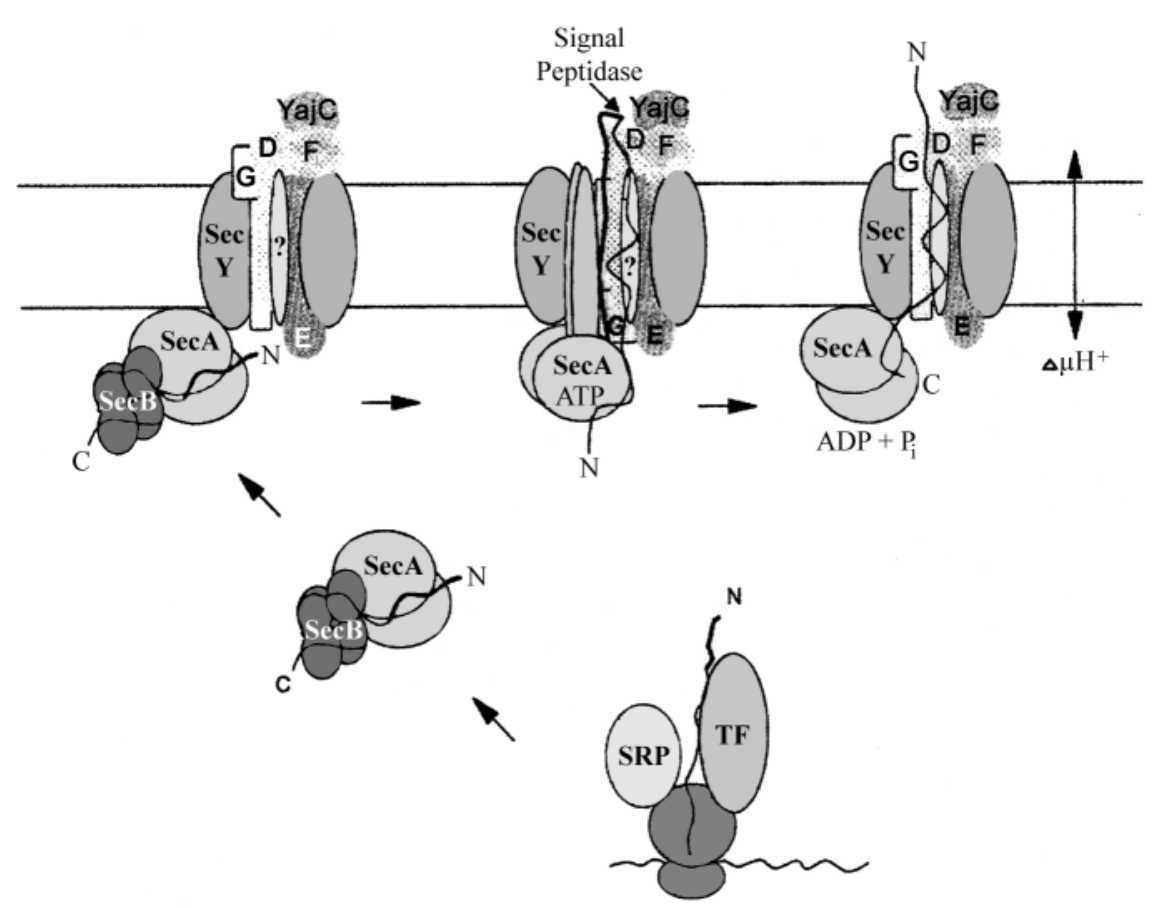

\section{Abbildung 41: Schematische Darstellung der Proteinsekretion über den Sec- Transportweg aus MÜLLER et al. (2001)}

Das Periplasma enthält nur etwa $4 \%$ des gesamten Zellproteins. Viele verschiedene Signalpeptide konnten bislang für die erfolgreiche Translokation von Proteinen ins Periplasma von E. coli eingesetzt werden. Dazu gehören beispielsweise prokaryotische Signalsequenzen wie die der Alkalischen Phosphatase PhoA und des Outer Membrane Proteins OmpA (DENÈFLE et al., 1989), der $\beta$-Lactamase aus E. coli (KADONOGA et al., 1984) oder der Pectat Lyase PelB aus Erwinia carotovoa (LEI et al., 1987). Allerdings ermöglicht eine Signalsequenz nicht automatisch eine effiziente Proteintranslokation über die Cytoplasmamembran. So konnten menschliche Immunoglobuline durchaus erfolgreich in Bakterien produziert und transloziert werden, während die Produktion von T-Zell-Rezeptorvarianten trotz der strukturellen 
Ähnlichkeit zu den Immunoglobulinen sich als weit schwieriger erwies. Obwohl das Signalpeptid in korrekter Weise abgespalten wurde, konnte kein Protein im Periplasma detektiert werden. WÜLFING and PLÜCKTHUN (1994) gelang es durch Induktion der Hitzeschockproteine zusammen mit der Überexpression von DsbA, was zum DsbSystem gehört und die Bildung von Disulfidbrücken bei Proteinen der Zellhülle katalysiert, immerhin Fragmente von korrekt gefalteten T-Zell-Rezeptorproteinen im Periplasma nachzuweisen. Es wurde davon ausgegangen, dass dabei eine große Anzahl von verschiedenen Chaperonen induziert worden war, darunter auch bislang unbekannte periplasmatisch lokalisierte. Neben den Signalpeptiden sind auch andere strukturelle Merkmale der Proteine an dem Membrantransport beteiligt. Strategien für die effizientere Translokation der Proteine ins Periplasma beinhalten auch die Zugabe von Komponenten, die an dem Transport beteiligt sind. Allerdings sind noch nicht alle an der Translokation mitwirkenden Mechanismen vollständig aufgeklärt. (MAKRIDES, 1996; WALL and PLÜCKTHUN, 1995; CHEAH et al., 1994).

Im Rahmen dieser Arbeit wurde die Expression des IF auch mit Hilfe des Vektors pET 20b(+) untersucht. Dabei sollte der Transport des Proteins über den Sec-Weg erfolgen, da die vorausgegangenen Experimente nur zu einer sehr geringen Transportrate des IFProteins über den Tat-Weg geführt hatten. In dem Expressionsvektor pET $20 \mathrm{~b}(+)$ erfolgt die periplasmatische Translokation mit Hilfe der $p E L B-S i g n a l s e q u e n z$ aus Erwinia caratovora (siehe 3.3.3). Auch bei dem Transport über das Sec-System wurden nur minimale Mengen an IF ins Periplasma transloziert. Möglicherweise fehlen für die korrekte Faltung des menschlichen IF im Cytoplasma der eingesetzten Expressionsstämme (beim Transport über den Tat-Weg) und im Periplasma (beim Transport über den Sec-Weg) ganz entscheidenden Komponenten. Denkbar wäre, dass die geringe Produktion und damit auch Translokation des IF in den verwendeten prokaryotischen Organismen eine Folge der unzureichenden Faltung des Proteins ist.

Ein entscheidendes Kriterium der Translokation über den Sec-Weg ist, dass durch die SecYE Pore nur unvollständig gefaltete Proteine transportiert werden können. In dem konstruierten $\mathrm{B}_{12}$-Exporter soll der Export von $\mathrm{B}_{12}$ ins Periplasma erst nach Bindung an das $\mathrm{B}_{12}$-Bindeprotein durch den anschließenden Transport des Enzym-CobalaminKomplexes erfolgen. Dafür muss das Bindeprotein bereits im Cytoplasma nativ vorliegen. Ein Transport über den Sec-Weg ist somit nicht möglich. 


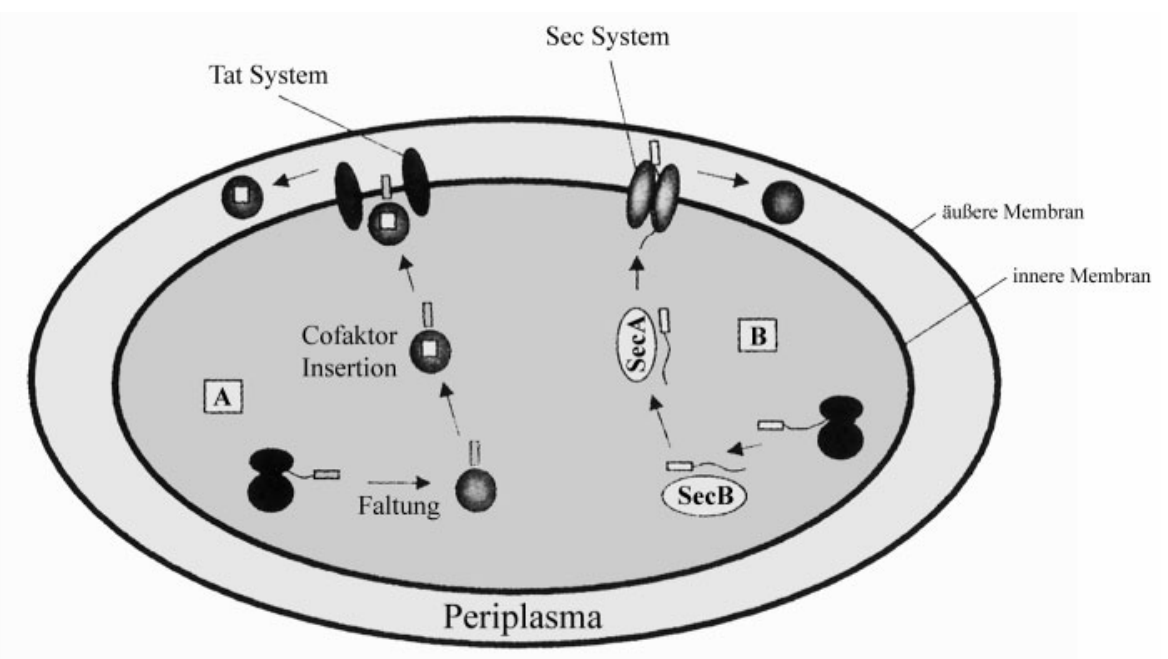

\section{Abbildung 42: Schematische Darstellung des Proteinexports über den Sec- und den Tat-Transportweg aus ROBINSON (2000)}

Seit Anfang der 90.er Jahre ist ein weiterer genereller Protein-Exportweg in Bakterien bekannt, der sich deutlich vom Sec-Weg unterscheidet. Dieser Transportweg wurde als Tat (für „twin arginine translocation“) -System bezeichnet, da die beteiligten Signalpeptide ein charakteristisches Motiv, bestehend aus zwei Arginin-Resten, aufweisen. Alternativ wird der Tat-Weg auch als Mtt (membrane targeting and transport) -Weg bezeichnet, da dieser Transportweg auch für integrale Membranproteine wie die Formiat-Dehydrogenase O von E. coli (BENOIT et al., 1998) genutzt wird (WEINER et al., 1998).

Ein ganz entscheidendes Merkmal des Proteintransportes über den Tat-Weg ist, dass nur gefaltete Proteine transportiert werden. Die Molekularmasse der Proteine spielt dabei eine untergeordnete Rolle. Das kleinste bekannte Substrat des Tat-Systems ist das $9 \mathrm{kDa}$ HIPIP (,high potential iron-sulfur protein“) von Chromatium vinosum, dessen Durchmesser bei 20 bis 30 Á liegt (CHARTER et al, 1974). Der größte bekannte Proteinkomplex hingegen, der durch das Tat-System transportiert wird, ist die $142 \mathrm{kDa}$ große FdnGH Untereinheit der Formiat-Dehydrogenase von E. coli (BERG et al., 1991). Der Durchmesser dieser Untereinheit beträgt 70 Á. Die beiden $B_{12}$-Bindeproteine IF $(55 \mathrm{kDa})$ und MutB $(80 \mathrm{kDa})$, die für den $\mathrm{B}_{12}$-Exporter ausgewählt wurden, liegen damit im Größenbereich, der durch das Tat-System transportiert wird.

Eine Vielzahl von Proteinen, die über diesen Weg ins Periplasma oder die Membran transloziert werden, sind Cofaktor-abhängig. Der Cofaktor wird dabei bereits im Cytoplasma vor dem Export an das Enzym gebunden. Dazu gehören beispielsweise die Trimethyl-N-Oxid-Reduktase (TorA) aus E. coli, (SARGENT et al., 1999), die 
Glucose-Fructose-Oxidoreduktase von Zymomonas mobilis (WIEGERT et al., 1996) oder die Aldehyd-Dehydrogenase aus Acetobacter polyoxogenes (TAMAKI et al,.1989). Bei den Cofaktoren handelt es sich um Eisen-Schwefel-Cluster, Molybdopterin Cofaktoren, einige Kupfer-Cluster, NAD ${ }^{+}$und FAD. Ist die Cofaktor Bindung blockiert, so wird das Vorläuferprotein im Cytoplasma angehäuft. Das wiederum lässt vermuten, dass die Cofaktorbindung eine Voraussetzung für den Export dieser Proteine ist. (BERKS 1996; SANITNI et al., 1998). Es werden aber auch Proteine ohne Cofaktoren über den Tat-Transportweg aus dem Cytoplasma geschleust, da sie vermutlich entweder cytoplasmatische Faktoren für die Faltung benötigen oder sich zu schnell und eng falten, um über den Sec-Weg transportiert werden zu können (BERKS, 1996; BRÜSER et al., 1998).

Der bakterielle Tat-Weg weist strukturelle und mechanistische Ähnlichkeiten zu dem $\Delta \mathrm{pH}$-abhängigen Protein-Import Weg auf. Dort sind Signalpeptide mit einem TwinArginin-Motiv für die Aufnahme von Proteinen über die Thylakoidmembran von Chloroplasten durch die $\Delta \mathrm{pH}$-getriebene Protein-Translokase verantwortlich (BRINKS et al., 1998). Beide Wege erfordern ähnlich Komponenten und Signale für den Transport der Proteine, was eine evolutionäre Verwandtschaft vermuten lässt. So gelang es MORI und CLINES (1998) das bakterielle Tat-Signalpeptid der kleinen Untereinheit der Hydrogenase 1 (HyaA) von E. coli mit dem Plastocyanin zu fusionieren und anschließend einen effizienten Transport des Fusionsproteins über die Thylakoidmembran nachzuweisen (DALBEY and ROBINSON, 2000; CHADDOCK et al., 1995; SETTLES and MAERTIENSSEN, 1998).

Tat-Signalpeptide haben eine ähnliche Einteilung in Amino (N)-Terminus, $\alpha$-helicale Kernregion (H-Region) und C-terminale Region wie die Signalpeptide des Sec-Weges. Allerdings weisen sie einige unverwechselbar Unterschiede auf. Der wichtigste davon ist das konservierte Sequenz-Motiv (S/T)-R-R-X-F-L-K an der Grenze zwischen der Nund H-Region. Zunächst wurde angenommen, dass die beiden Arginin-Reste essentiell für einen effizienten Transport und völlig invariabel sind (BERKS, 1996). Die Substitution ein oder beider Arginin-Reste gegen ein oder zwei Lysin-Reste in der Signalsequenz der Glucose-Fructose Oxidoreduktase aus Zymomonas mobilis hatte die vollständige Blockierung des Protein-Exports zur Folge (HALBIG et al., 1999). Ebenso konnte kein Transport mehr nachgewiesen werden, nachdem das erste Arginin in dem Konsensus-Motiv der Signalsequenz der Nitrat-Oxidoreduktase aus Pseudomonas stutzeri durch ein Aspartat ersetzt worden war (DREUSCH et al., 1997). Andere Studien zeigten allerdings, dass der Austausch des ersten Arginins durch verschiedene Aminosäuren in dem Fusionsprotein bestehend aus der Tat-Signalsequenz der Hydrogenase von Desulfovibrio vulgaris und der $\beta$-Lactamase von E. coli nur zu einer Hemmung und nicht zu einer kompletten Unterbindung des Exports führte (NIEVIÈRE 
et al., 1992). Auch die Substitution eines Arginins gegen ein Lysin in der Signalsequenz von SurfI aus E. coli führte nur zu einem stark verlangsamten Export des Proteins (STANLEY et al., 2000). HINSLEY et al. (2001) fanden schließlich in der Tetrathionat Reduktase aus Salmonella enterica das erste und bislang einzige natürlich vorkommende Tat-Signalpeptid, das nur ein Arginin enthält und trotzdem voll funktionstüchtig ist. In einigen Tat-Signalpeptide scheinen die beiden Arginine nicht obligatorisch für die Translokation zu sein. Die anderen Aminosäuren des KonsensusMotivs kommen mit einer Häufigkeit von mehr als 50 \% vor (BERKS 1996).

Die Tat-Signalpeptide haben eine durchschnittliche Länge von 26 bis 58 Aminosäuren und sind damit im Mittel um 14 Aminosäuren länger als die Signalpeptide des SecWeges (siehe Abbildung 43). Hervorgerufen wird dieses Merkmal durch eine ausgedehnte N-Region. Die C-Region enthält basische Aminosäuren, die korrespondierende Sec-Region weist dagegen kaum geladene Reste in der Nähe der Spaltstelle für die Signalpeptidase auf. Die H-Region enthält viele Glycin- und Threonin- Reste, aber nur wenige Leucin-Reste und ist deutlich weniger hydrophob als die entsprechende Region der Sec-Signalpeptide.

A

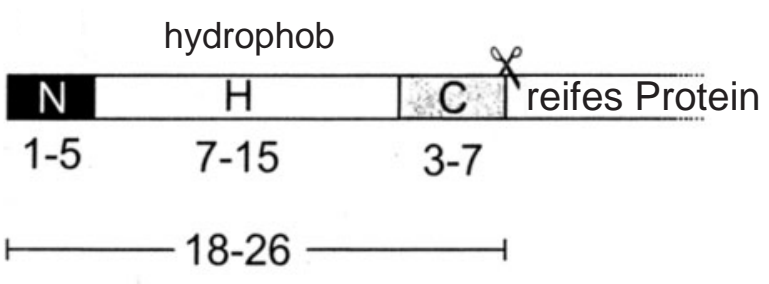

B

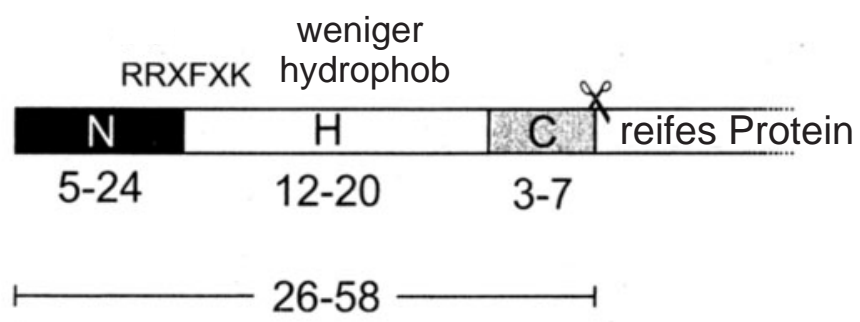

\section{Abbildung 43: Vergleich des Sec-Signalpeptids (A) mit dem Tat-Signalpeptid (B) aus FEKKES und DRIESSEN (1999)}

Die Schere kennzeichnet die Stelle, an der die Signalpeptidase das Signalpeptid nach der Translokation abspaltet.

BOGSCH et al. (1997) und CHRISTÓBAL et al. (1999) beschrieben, dass in den TatSignalpeptiden nicht nur die Informationen für den Transport über den Tat-Weg, sondern auch Signale zu Verhinderung der Translokation über den Sec-Weg enthalten 
sind. Die Interaktion mit dem Sec-Weg wird durch eine Kombination der relativ geringen Hydrophobizität in der H-Region und dem Vorhandensein von basischen Aminosäure-Resten in der C-Region verhindert. Die Rolle der übrigen Aminosäuren der Konsensus-Sequenz ist bislang noch nicht erforscht worden. Auch ist noch nicht bekannt an welcher Stelle der Sec-verhindernde Effekt einwirkt. Es wird vermutet, dass durch die Interaktion mit SecA oder SecB ein Transport über den Sec-Weg verhindert wird (BOGSCH et al., 1997; BERKS et al., 2000).

Durch Studien in E. coli konnten vier Gene identifiziert werden, die am Proteinexport beteiligt sind. Während tatABC in einem Operon organisiert sind, bildet tatE eine unabhängige Transkritptionseinheit. „Knockout“ Experimente zeigten, dass für einen Protein-Export über den Tat-Weg mindestens TatB, TatC und entweder TatA oder TatE notwendig sind, wobei TatA wichtiger zu sein scheint als TatE (WEINER et al., 1998; SARGENT et al., 1998; BOGSCH et al., 1998; SARGENT et al., 1999). Bei allen vier Tat-Proteinen handelt es sich um integrale Membranproteine (MÜLLER et al., 2001). TatA, B und E sind homolog zu Hcf106, der ersten identifizierten Komponente aus dem $\Delta$-pH-abhängigen Weg. Neben TatA, B und E sind noch zwei weitere Tat-Proteine, TatC und TatD, bekannt. TatD ist ein wasserlösliches cytoplasmatisches Enzym, dessen Deletion keinen Defekt im Transportsystem hervoruft (SARGENT et al.,1998). TatC ist dagegen ein essentielles, stark hydrophobes Protein, das vermutlich sechs transmembrane Helices enthält (BOGSCH et al., 1998). Es wird angenommen, dass es von TatB durch Bildung eines Komplexes stabilsiert wird, da es ohne TatB zu einer schnellen Degradation von TatC kommt. Dabei könnte TatC als Bindestelle für das Vorläuferprotein dienen (SARGENT et al., 1999).

Bislang ist noch nicht geklärt, wie genau diese Proteine zu der Bildung der Translokase beitragen und ob bzw. wie sie an der Erkennung der Tat-Signalsequenz beteiligt sind. BERKS et al. (2000) postulierten u. a. ein Modell, in dem die Pore von vielen Kopien der TatABE-Proteine gebildet wird. Dabei formen die N-terminalen transmembranen Helices dieser Proteine die Pore und die C-Termini kontrollieren den Zugang an der cytoplasmatischen Seite. Durch die zirkuläre Struktur könnten die einzelnen Untereinheiten aneinander entlang gleiten und sich dadurch den verschiedenen Durchmessern der transportierten Proteine anpassen. SARGENT et al. (2001) konnten durch Isolierung eines $600 \mathrm{kDa}$ TatAB-Komplexes die postulierte Interaktion zwischen diesen beiden Proteinen bestätigen. Weiterhin nehmen sie an, dass es sich bei TatA um die Hauptkomponente der Pore handelt. BOLHUIS et al. (2001) fanden dagegen heraus, dass die Proteine TatA, B und $\mathrm{C}$ zusammen einen $600 \mathrm{kDa}$ Komplex bilden. So beschrieben sie ein Modell, in dem aufgrund der Größe des Komplexes mehrere TatA, $\mathrm{B}$ und $\mathrm{C}$ Untereinheiten die Pore ausbilden. Als einzige offensichtliche Energiequelle 
für die Translokation bakterieller Tat-Substrate kommt die protonmotorische Kraft in Frage. Wie sie genutzt wird ist aber noch unbekannt (MÜLLER et al., 2001).

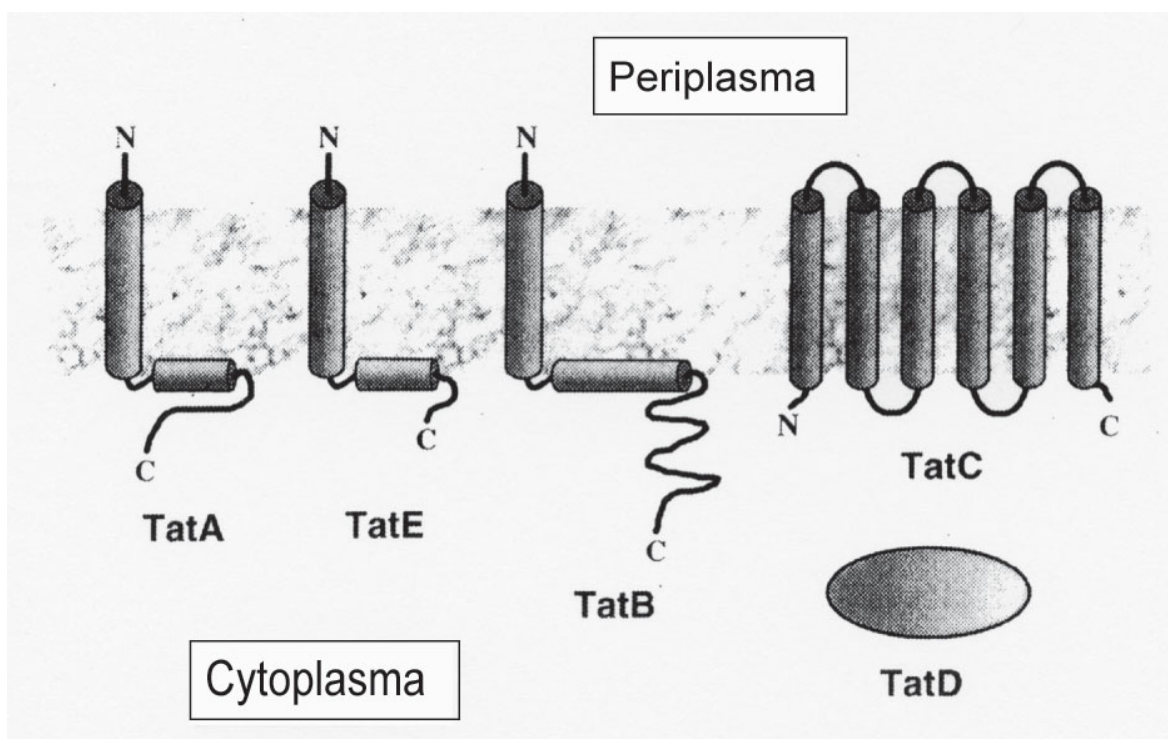

\section{Abbildung 44: Modell für den Aufbau der Strukturgene des Tat-Weges aus BERKS et al. (2000)}

Für die Konstruktion des $\mathrm{B}_{12}$-Exporters in dieser Arbeit wurde die Signalsequenz der Trimethylamin-N-Oxid Reduktase (TorA) aus E. coli (siehe Abbildung 45) mit den $\mathrm{B}_{12}$-Bindeproteinen IF oder MutB fusioniert. Der Export des löslichen TorA-Enzyms über den Tat-Weg ist besonders eingehend untersucht worden (SANTINI et al., 1998; WEINER et al., 1998; SARGENT et al., 1999). Es handelt sich dabei um ein unter anaeroben Bedingungen synthetisiertes periplasmatisches Molybdoenzym. Es reduziert Trimethylamin-N-Oxid zu Trimethylamin und ermöglicht dem Organismus dadurch alternative Elektronenakzeptoren zu nutzen. Die TMAO-Reduktase wird von dem torA Gen des torCAD Operons kodiert, dessen Expression bei der Anwesenheit von TMAO durch das Zweikomponentensystem TorS/TorR induziert wird (ANSALDI et al., 1999). Das korrespondierende Genprodukt setzt sich aus zwei identischen 90 kDaUntereinheiten zusammen (SILVESTRO et al., 1989). Das TorA-Vorläuferprotein besitzt eine N-terminale Signalsequenz von 39 Aminosäuren Länge (MÉJAN et al., 1994). 


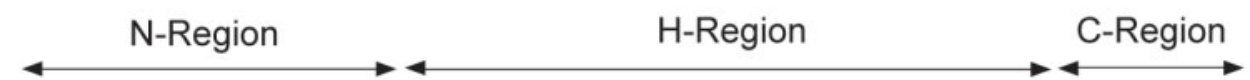 \\ E. coli TorA: MNNNDLFQASRRRLAQLGGLTVAGMLGPSLLTPRRATA VAQAA}

\section{Abbildung 45: Aminosäuresequenz des Signalpeptids der Trimethylamin-N-Oxid Reduktase (TorA) aus E. coli aus MÉJAN et al. (1994)}

Die Konsensus Sequenz ist durch dick gedruckte Buchstaben hervorgehoben.

Das schwarze Dreieck markiert die Stelle, an der das Signalpeptid nach der Translokation abgespalten wird.

Das Tat-Signalpeptid weist die zuvor beschriebenen Merkmale von Tat-Signalpeptiden auf. Die N-Region des TorA-Signalpeptids beinhaltet 13 Aminosäure-Reste mit einer insgesamt positiven Ladung und das doppelte Arginin-Motiv. Die H-Region besteht aus vorwiegend hydrophoben Resten und die C-Region mit ihren 6 Aminosäuren weist die A-T-A-Erkennungsstelle für die Signalpeptidase auf. Um eine reibungslose Abspaltung des Signalpeptids bei dem in dieser Arbeit entwickelten $\mathrm{B}_{12}$-Exporter zu gewährleisten, wurde zusätzlich die Gen-Sequenz für die ersten fünf Aminosäuren des reifen TorAProteins zwischen der Signalsequenz und dem $\mathrm{B}_{12}$-Bindeprotein in den Fusionsgenen sigtorA-if- und sigtor $A-m u t B$ kloniert. Die Wahl des Tat-Signalpeptids fiel auf die TorA-Signalsequenz, da sie bereits mehrfach erfolgreich eingesetzt wurde, um Proteine über den Tat-Weg zu translozieren, die normalerweise über den Sec-Weg ins Periplasma gelangen. So fusionierten beispielsweise SANTINI et al., (2001) die TorA-Signalsequenz mit dem GFP (,green fluorescent“ Protein) aus Quallen. Anschließend gelang es ihnen, korrekt gefaltetes GFP nach der Translokation über den Tat-Weg im Periplasma von E. coli nachzuweisen. In einer anderen Studie konnte die periplasmatische GFOR (Glucose-Fructose-Oxidoreduktase) aus Zymomonas mobilis nur mit Hilfe der TorA-Signalsequenz ins Periplasma von E. coli transloziert werden. Ein Transport nach Expression mit dem natürlichen Signalpeptid des GFOR-Enzyms, welches ebenfalls ein Twin-Arginin-Motiv aufweist, fand dagegen in E. coli nicht statt. Dies war ein Hinweis darauf, dass Tat-Signalpeptide nicht universell von TatTranslokasen erkannt werden. Da die Expressionsstudien des $\mathrm{B}_{12}$-Exporters zunächst in E. coli und anschließend in dem nahe verwandten $\mathrm{B}_{12}$-produzierenden Enterobakterium $C$. freundii erfolgen sollten, wurden ein Tat-Signalpeptid aus E. coli genommen. Mit Hilfe der TorA-Signalsequenz aus E. coli gelang es in dieser Arbeit, das Fusionsprotein sigTorA-MutB ins Periplasma von E. coli BL21 (DE3) zu transportieren (siehe Abbildung 29). Dabei war aber noch ein erheblicher Anteil im Cytoplasma und den Membranen verblieben. Weiterhin war es möglich, das Fusionsprotein auch unter anaeroben Bedingungen in den Enterobakterien C. freundii und E. blattae in großen Mengen zu produzieren (siehe Abbildung 31). Die sich anschließenden Experimente zur Translokation des Fusionsproteins in C. freundii und E. blattae unter anaeroben 
Bedingungen führten dann zur Translokation des größten Teils von sigTorA-MutB ins Periplasma (siehe Abbildung 32). Es konnte damit gezeigt werden, dass generell eine Translokation der $\mathrm{B}_{12}$-bindenden Untereinheit aus $P$. shermanii (MutB) über den TatWeg möglich ist und auf diese Weise mit Hilfe der TorA-Signalsequenz aus E. coli ein Transport von MutB über die Cytoplasmamembran auch unter anaeroben $\mathrm{B}_{12}$ produzierenden Bedingungen erfolgt.

\subsection{Einfluss der Produktion und des Exports der sigTorA- Fusionsproteine auf die Coenzym $B_{12}$-Synthese}

Die Cobalamin-Biosynthese stellt einen der komplexesten Synthesewege dar, die in der Natur vorkommen. Dabei sind etwa 30 enzymkatalysierte Reaktionen an der kompletten de novo Synthese beteiligt. Die Produktion von Coenzym $\mathrm{B}_{12}$ ist auf einige Bakterien wie z. B. Citrobacter freundii, Escherichia blattae und Archaeen beschränkt. Die Cobalamin-Synthese besteht grob aus der Synthese der Corrinring-Komponenten, der Ausbildung des unteren axialen Liganden und dem Zusammensetzen aller Komponenten zum Coenzym $B_{12}$. Im ersten Teil wird Uroporphyrinogen III zu Cobinamid umgewandelt, im zweiten Teil wird Dimethylbenzimidazol (DMB) gebildet und im letzten Abschnitt werden Cobinamid, DMB und die Phosphoribosylreste zusammengefügt.

Es existieren zwei verschiedene biosynthetische Wege: ein aerober, Sauerstoffabhängiger Weg, bei dem Cobalt zu einem vergleichsweise späten Zeitpunkt in den Corrin-Ring inseriert wird und ein anaerober, Sauerstoff-unabhängiger Weg, bei dem das Cobalt sehr viel früher eingebaut wird (BLANCHE et al., 1993). Der aerobe Syntheseweg ist bei Pseudomonas denitrificans und der anaerobe bei Propionibacterium shermanii und Salmonella typhimurium untersucht worden.

Die Coenzym Formen des $\mathrm{B}_{12}$ gehören zu einer Familie von prosthetischen Gruppen, den Tetrapyrrol-Derivaten. Dazu zählen Moleküle wie Häm, Chlorophyll, Sirohäm und Coenzym $\mathrm{F}_{430}$. Sie alle weisen im Zentrum der prosthetischen Gruppe ein charakteristisches Metall-Ion auf (Magnesium, Eisen oder Cobalt) (WARREN et al., 1990). Mit Ausnahme der $\alpha$-Gruppe der Proteobakterien beginnen alle Synthesewege mit dem C-5 Skelett des Glutamats. Im ersten Schritt wird tRNA-gebundenes Glutamat zu Glutamat-1-Semialdehyd reduziert. Das Aldehyd wird anschließend durch intramolekulare Umwandlung der Aminogruppe zu 5-Aminolävulinsäure umgesetzt. Zwei 5-Aminolävulinsäure-Moleküle werden zum ersten Pyrrol-Derivat, dem Porphobilinogen kondensiert. Vier dieser Pyrrol-Moleküle bilden im folgenden durch Polymerisation, Umlagerungsreaktionen und Ringschlüsse das Uroporphyrinogen III (JAHN et al, 1996, MARTENS et al., 2002). Während die Decarboxylierung des 
Uroporphyrinogen III zur Biosynthese von Häm und Chlorophyll führt, wird durch die Methylierung dieses Moleküls Precorrin-2 synthetisiert. Die bei der letzten Reaktion benötigten zwei Methylgruppen stammen vom S-Adenosyl-L-Methionin, die von einer einzigen Methyltransferase eingebaut werden (WOODCOCK et al., 1998). An der Stelle des Precorrin-2 teilen sich die beiden Biosynthesewege für Cobalamin. Während beim aeroben Zweig Precorrin-2 durch eine weitere Methyltransferase methyliert wird, woraus das Precorrrin-3A resultiert, wird das Precorrin-2 im anaeroben Weg mit Cobalt chelatiert, wobei Cobalt-Precorrin-2 entsteht. Von diesem Punkt an unterscheiden sich also die beiden Wege grundlegend: der Sauerstoff-unabhängige Zweig beginnt an dieser Stelle mit dem Einbau des Cobalt, während im Sauerstoff-abhängigen Weg dieser Einbau erst neun Reaktionsschritte später erfolgt. Bemerkenswert ist auch, dass sich die Cobalt-Chelatasen der beiden Wege dadurch unterscheiden, dass nur die Chelatase des aeroben Zweiges ATP benötigt. Aufgrund der frühen Cobalt-Insertion innerhalb des einen Weges handelt es sich bei dem Großteil der Intermediate um Cobalt-Komplexe und die benötigten Enzyme weisen eine ganz unterschiedliche Substratspezifität auf als die Metall-freien Intermediate des Sauerstoff-abhängigen Weges. Durch eine Reihe von verschiedenen Reaktionen wie z. B Methylierungs-, Amidierungs- und Adenolysierungschritten entsteht Adenosyl-Cobyrinsäure. Nachdem die anaeroben und aeroben Biosynthesewege des Cobalamins sich ab dem Precorrin-2 geteilt haben, verlaufen sie ab der Adenosyl-Cobyrinsäure wieder analog. Durch Anlagerung eines Aminopropanols an die Propionsäure-Seitenkette entsteht aus Adenosyl-Cobyrinsäure Cobinamid. Der untere axiale Ligand, das DMB wird separat synthetisiert. Nach der Addition einer Phoshporibosyl-Gruppe aus einem Nikotinsäure-Mononukleotid an DMBI (Dimethylbenzimidazol) entsteht daraus $\alpha$-Ribazol. Im letzten Reaktionsabschnitt wird das $\alpha$-Ribazol mit Adenosylcobinamid-GDP zu Adenosylcobalamin verknüpft. 


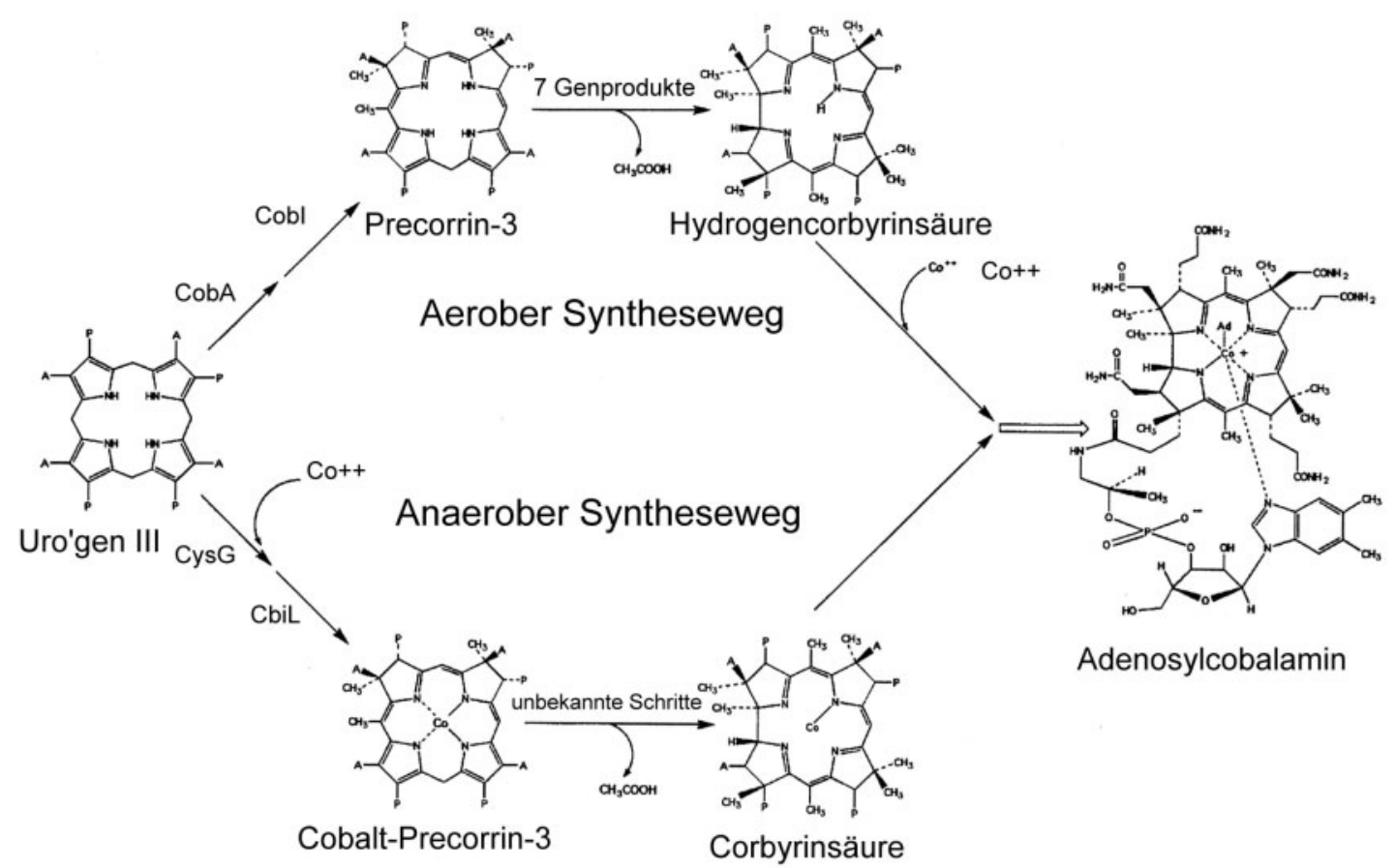

\section{Abbildung 46: Schematische Darstellung der beiden unterschiedlichen Cobalamin-Biosynthesewege aus RAUX et al. (1996)}

Uro'gen: Uroporphyrionogen

Die im Rahmen dieser Arbeit verwendeten $\mathrm{B}_{12}$-Produzenten C. freundii und E. blattae synthetisieren das Coenzym de novo über den anaeroben Syntheseweg. Während KEUTH und BISPING (1994) in ihren Experimenten für $C$. freundii eine $\mathrm{B}_{12}$-Produktionsrate von 114-152 ng $\mathrm{B}_{12}$ pro g Zellen beschrieben haben, liegen aus experimentellen Daten von BECHER aus unserer Arbeitsgruppe Werte im Bereich von 0,05-0,09 mg B $\mathrm{B}_{12} / 1$ Kultur vor. Für E. blattae waren noch keine Daten bezüglich der Synthesrate bekannt.

In den Experimenten im Rahmen dieser Arbeit wurde getestet, ob die Produktion der $\mathrm{B}_{12}$-Bindeproteine Intrinsic Faktor und MutB eine erhöhte Syntheserate von $\mathrm{B}_{12}$ in den Organismen hervorruft. Die Expressionsstudien fanden anaerob mit Glycerin als einziger C-Quelle ( $\mathrm{B}_{12}$-produzierende Bedingungen) statt. Citrobacter freundii und E. blattae gehören zu den Organismen, die anaerob ohne externe Elektronenakzeptoren mit Glycerin als einziger Kohlenstoff- und Energiequelle wachsen können. Glycerin unterliegt dabei einer Disproportionierung. Die Enzyme des oxidativen Zweigs setzen Glycerin zu Dihydroxyacetonphosphat um. Die dabei anfallenden Reduktionsäquivalente werden im reduktiven Zweig verbraucht. Die Coenzym-B $B_{12}$-abhängige Glycerin-Dehydratase bildet dabei aus Glycerin 3-Hydroxypropionaldehyd, der anschließend weiter zu 1,3-Propandiol reduziert wird (DANIEL et al., 1995 a und b, 
ABELES et al., 1961). Durch die $\mathrm{B}_{12}$-Abhängigkeit der Glycerin-Dehydratase ist nur dann ein anaerobes Wachstum von $C$. freundii und $E$. blattae in $\mathrm{B}_{12}$-freiem Mineralmedium mit Glycerin als einziger Kohlenstoff-Quelle möglich, wenn der Organismus das benötigte $\mathrm{B}_{12}$ de novo synthetisiert.

Dabei konnte trotz der schwachen Produktion des Intrinsic Faktors in C. freundii eine maximale Steigerung der $B_{12}$-Produktion um $17 \%$ nachgewiesen werden (siehe 3.6). Die ermittelten $\mathrm{B}_{12}$-Konzentrationen lagen dabei in den Kulturen ohne das Bindeprotein bei 0,09 und mit IF-Bindeprotein bei $0,15 \mathrm{mg} \mathrm{B}_{12} / 1$ Kultur. Die heterologe Produktion von MutB in C. freundii oder E. blattae gelang in großen Mengen und führte zu einer gesteigerten Coenzym-Syntheserate zwischen 28 und $57 \%$ (siehe 3.6.1). Für die E. blattae Stämme wurde dabei eine $\mathrm{B}_{12}$-Konzentration in den Anzuchten ohne MutB von $0,2 \mathrm{mg} / 1 \mathrm{Kultur}$ und mit MutB von $0,3 \mathrm{mg} / 1 \mathrm{Kultur}$ erreicht, die C. freundii Stämme enthielten ohne MutB-Bindeprotein 0,09 und mit MutB 0,11 mg B $12 / 1$ Kultur. Diese Ergebnisse zeigen, dass die Synthese der Fusionsproteine (sigTorA-IF und sigTorA-MutB) eine stärkere $\mathrm{B}_{12}$-Produktion in C. freundii und E. blattae hervorruft. Diese kommt vermutlich durch die Bindung des Coenzym $\mathrm{B}_{12}$ an das Bindeprotein zustande, wodurch der Zelle weniger freies $\mathrm{B}_{12}$ für die benötigten $\mathrm{B}_{12}$-abhängigen Reaktionen zur Verfügung steht.

Außerdem gelang es in Experimenten nachzuweisen, dass im Cytoplasma von C. freundii und $E$. blattae synthetisiertes Coenzym $\mathrm{B}_{12}$ gebunden and das $\mathrm{B}_{12}$-Bindeprotein MutB ins Periplasma transportiert werden konnte (siehe Abbildung 37). Dabei wurden für E. blattae Werte von 8,3 bis $31,0 \mathrm{nM} \mathrm{B}_{12}$ im Periplasma ermittelt und für C. freundii ein Wert von 8,6 $\mathrm{nM} \mathrm{B}_{12}$.

Zusammenfassend lässt sich aus diesen Ergebnissen festhalten, dass generell ein Transport von Coenzym $B_{12}$ gebunden an ein Protein über die Cytoplasmamembran möglich ist. Zum anderen belegt die Cotranslokation von $\mathrm{B}_{12}$ mit der $\mathrm{B}_{12}$-bindenden Untereinheit aus P. shermanii (MutB) die Funktionalität des in dieser Arbeit entwickelten $\mathrm{B}_{12}$-Exporters.

\subsection{Ausblick:}

Der im Rahmen dieser Arbeit entwickelte $B_{12}$-Exporter eröffnet die Möglichkeit für weitere Experimente im Hinblick auf einen effizienteren und vollständigen Export von $\mathrm{B}_{12}$ ins Kulturmedium. Zunächst ist es notwendig, ein System zum Transport des Coenzyms über die äußere Membran zu entwickeln. Das wiederum könnte mit Hilfe des kil-Gen-Systems von MIKSCH et al. (1997b) erfolgen, welches eine kontrollierte Freisetzung von periplasmatischen Enzymen ins Medium ermöglicht. Das Sekretionssystem basiert auf dem permeabilisierenden Effekt des kil-Genproduktes aus 
dem Plasmid ColE1 von E. coli und wird unter einem Stationärphasen-Promotor exprimiert. Dadurch kommt es zu keiner Beeinflussung der Lebensfähigkeit der Zelle, ebenso wenig tritt eine Zellyse auf. Der Einsatz der kil-Gene hatte z. B. in dem $\mathrm{B}_{12}$-produzierenden Klebsiella planticola oder in Acetobacter methanolicus und E. coli zur Sekretion periplasmatischer Proteine ins Medium geführt (MIKSCH et al., 1997c, 1997a und 1999).

Ein anderer Ansatzpunkt wäre es, den konstruierten $\mathrm{B}_{12}$-Exporter in einem Cobalaminsynthetisierenden Gram-positiven Organismus einzusetzen. Das hätte den Vorteil, dass kein extra Proteinexport mehr wie bei Gram-negativen Bakterien über die äußere Membran notwendig wäre. Bacillus megaterium ist zum einen in der Lage $\mathrm{B}_{12} \mathrm{zu}$ synthetisieren (RAUX et al., 1998) und zum anderen ist in einem anderen BacillusStamm bereits der Hinweis für das Vorkommen des Tat-Transportweg beschrieben worden (TJALSMA et al., 2000). Dabei könnte zuerst untersucht werden, ob das in dieser Arbeit konstruierte $\mathrm{B}_{12}$-Exportsystem, bestehend aus der TorA-Signalsequenz und dem $\mathrm{B}_{12}$-Bindeprotein MutB, auch in Bacillus megaterium produziert wird. Im Falle einer Produktion des Fusionsproteins müsste ein Transport ins Medium und anschließend der Cotransport mit Coenzym $\mathrm{B}_{12}$ nachgewiesen werden. Falls es zu keinem Transport des Fusionsproteins kommt, könnte versucht werden die Translokation durch Fusion des $\mathrm{B}_{12}$-Bindeproteins MutB an eine andere Tat-Signalsequenz, wenn möglich aus einem Bacillus-Stamm, zu erzielen.

Weiterhin wäre es denkbar durch den Einsatz eines Organismus mit höherer $\mathrm{B}_{12}$-Syntheserate, die Effizienz des $\mathrm{B}_{12}$-Exports zu verbessern. So sind in der Literatur Produktionsraten von 1,1 bis $\mathrm{zu} 206 \mathrm{mg} \mathrm{B}_{12} / 1$ Medium beschrieben worden (BYKHOVSKY et al., 1998). Der Einsatz des $\mathrm{B}_{12}$-Exporters in einem Organismus, der weit mehr $\mathrm{B}_{12}$ produziert, als die beiden in dieser Arbeit eingesetzten $\mathrm{B}_{12}$-Produzenten C. freundii und E. blattae, könnte zu einer größeren Menge an $\mathrm{B}_{12}$ im Periplasma führen. Außerdem ließe sich die Produktionsrate von $B_{12}$ in den Organismen dieser Arbeit eventuell durch die oft beschriebene Zugabe von Komponenten wie Dimethylbenzimidazol, Aminolävulinsäure oder anderer Vorläufer des Cobalamins erhöhen (MARTENS et al., 2002).

Eine andere Möglichkeit um die Cotranslokation von $\mathrm{B}_{12}$ mit seinem Bindeprotein ins Periplasma oder umgebende Medium zu verbessern, ließe sich eventuell durch den Austausch des $\mathrm{B}_{12}$-Bindeproteins gegen ein Protein mit geringerer Molekularmasse erreichen. Denkbar wäre der Einsatz des nur $30 \mathrm{kDa}$ großen BtuF Proteins. Dabei handelt es sich um das periplasmatisch lokalisierte $\mathrm{B}_{12}$-Bindeprotein, das an der Aufnahme von Cobalaminen in die Zelle beteiligt ist (siehe 4.1) und somit eine hohe Binderate zum $\mathrm{B}_{12}$ aufweist (CARDIEUX et al., 2002). Nach Fusion mit der TorASignalsequenz müsste eingangs die Produktion und im weiteren der Transport ins 
Periplasma von E. blattae oder C. freundii untersucht werden. Anschließend ließe sich durch quantitative Bestimmungen überprüfen, ob eine Cotranslokation von $\mathrm{B}_{12}$ mit $\mathrm{BtuF}$ stattgefunden hat.

Außerdem könnte man testen, ob mit Hilfe des Tat-Systems auch andere an Proteine gebundene Cofaktoren ins Periplasma transloziert werden können. Das wäre besonders im Hinblick auf die Produktion von toxischen Substanzen interessant. So könnten Cofaktor-abhängige für die Zelle sonst toxische Reaktionen im Periplasma ablaufen, wodurch sich unter Umständen ganz neue Möglichkeiten des Stoffumsatzes im Periplasma als Reaktionsraum eröffnen würden. 


\section{Zusammenfassung}

1.) Zur Konstruktion eines bakteriellen $B_{12}$-Exporters wurden die Gene für die Signalsequenz der periplasmatischen Trimethylamin-N-Oxid-Reduktase (sigtorA) aus Escherichia coli und für den $\mathrm{B}_{12}$-bindenden humanen Intrinsic Faktor (if) fusioniert. Die heterologe Expression des Fusionsgens erfolgte unter Kontrolle des durch Arabinose induzierbaren paraBAD-Promotors in verschiedenen E.coliStämmen. Dabei konnte auch nach Variation verschiedenster Parameter nur eine minimale Produktion des sigTorA-IF-Fusionsproteins durch Western-Blot-Analyse detektiert werden. Ähnliche Ergebnisse wurden auch bei der heterologen Produktion des Fusionsproteins in dem $\mathrm{B}_{12}$-produzierenden Enterobakterium C. freundii erzielt.

2.) In Experimenten zum Nachweis der Translokation von sigTorA-IF ins Periplasma war, zur Erhöhung der Detektierbarkeit des nur schwach produzierten Proteins, eine Konzentrierung notwendig. Mit Hilfe des im Zuge der Klonierung angefügten His $_{6}$-Tags konnte das Fusionsprotein durch eine Affinitätschromatographie an $\mathrm{Ni}^{2+}$-NTA-Agarose unter denaturierenden Bedingungen konzentriert werden. Hiernach ließ sich eine geringe Translokation des sigTorA-IF ins Periplasma nachweisen.

3.) Anschließend sollte durch quantitative Bestimmung der Corrinoid-Konzentration ein Cotransport von sigTorA-IF und $\mathrm{B}_{12}$ ins Periplasma von C.freundii nachgewiesen werden. Dieser Nachweis gelang nicht, da aufgrund der geringen Produktion von sigTorA-IF die maximal zu erwartende $\mathrm{B}_{12}$-Menge unterhalb der Nachweisgrenze lag.

Die schwache Produktion des Fusionsproteins führte jedoch zu einer Steigerung der $\mathrm{B}_{12}$-Syntheserate in dem Wirtsorganismus.

4.) Zur Konstruktion eines effizienten $B_{12}$-Exportsystems erschien der Intrinsic Faktor, aufgrund der zu schwachen heterologen Produktion, als nicht geeignet. Daher sollte die Genfusion von sigtor $A$ mit dem Gen eines anderen $\mathrm{B}_{12}$-bindenden Enzyms für die weiteren Experimente verwendet werden. Hierzu wurde die $\mathrm{B}_{12}$-bindende Untereinheit der Methylmalonyl-CoA-Mutase (mutB) aus Propionibacterium shermanii eingesetzt. Aus anderen Arbeiten aus unserer Gruppe (BOLM 2000) lag ein entsprechendes Konstrukt (pMB5) mit der sigtorA-mutB-Genfusion bereits vor. Es konnte in Expressionsversuchen gezeigt werden, dass das korrespondierende Genprodukt in verschiedenen Enterobakterien in großen Mengen heterolog produziert wird. 
5.) In weiteren Experimenten wurde die sigtor-mutB-Fusion anaerob unter $\mathrm{B}_{12}$-produzierenden Bedingungen in $C$. freundii und $E$. blattae untersucht. Für letzteren erfolgte eine Umklonierung der Genfusion in ein für diesen Stamm geeignetes Vektorsystem. Die resultierenden Konstrukte wurden als pTM3 und pTM6 bezeichnet. Der Nachweis der Bildung des Fusionsproteins erfolgte über den angefügten $\mathrm{His}_{6^{-}}$bzw. GFP-Tag durch Western-Blot-Analysen bzw. Fluoreszensmikroskopie. Mit Hilfe dieser Detektionssysteme gelang es sowohl in C. freundii als auch in E. blattae eine starke Produktion des sigTorA-MutBProteins unter $\mathrm{B}_{12}$-produzierenden Bedingungen nachzuweisen. Dieses Ergebnis konnte ebenfalls nach Einfügen eines Strep-TagsII durch Klonierung der Fusionsgene in den Vektor pASK-IBA3 mittels Western-Blot-Analysen in E. blattae erlangt werden.

6.) Experimente zur Translokation des sigTorA-MutB-Fusionsproteins ins Periplasma wurden zunächst in E. coli durchgeführt. Hierbei zeigte sich, dass das Fusionsprotein transloziert wurde, aber ein noch erheblicher Anteil im Cytoplasma und in den Membranen verblieben war. In anschließenden Untersuchungen unter $\mathrm{B}_{12}$-produzierenden Bedingungen, die mit $C$. freundii und E. blattae durchgeführt wurden, konnte eine Translokation des sigTorA-MutB-Proteins ins Periplasma der $\mathrm{B}_{12}$-Produzenten nachgewiesen werden. Im Gegensatz zu den Versuchen mit E. coli blieb dabei jedoch nur ein kleiner Teil des Fusionsproteins im Cytoplasma und in den Membranen zurück. Dies konnte durch Immunolokalisation mit goldmarkierten Antikörpern durch elektronenmikroskopische Analyse belegt werden.

7.) Die quantitative Bestimmung des Corrinoidgehaltes bei C. freundii und E. blattae zeigte, dass die heterologe Produktion von sigTorA-MutB je nach Bedingung zu einer um 28-57\% gesteigerten $B_{12}$-Synthese führte. Ferner konnte eine Cotranslokation von $\mathrm{B}_{12}$ und MutB ins Periplasma von C. freundii und E. blattae in einem Verhältnis von 1,3 bis 5,1 zu 1 nachgewiesen werden.

Diese Untersuchungen bestätigen, dass die hergestellte Genfusion als $\mathrm{B}_{12}$-Exportsystem fungiert. 


\title{
6 Literaturverzeichnis
}

\author{
Abeles R. H., Lee H. A. Jr., 1961
}

An intramolecular oxidation-reduction requiring a vobamide coenzyme. J. Biol. Chem. 236: 2347-2350.

Ansaldi M., Simon G., Lepelletier M., Mejean V. 1999

TorC apocytochrome negatively autoregulates the trimethylamine $\mathrm{N}$-oxide reductase operon in Escherichia coli. J. Bacteriol. 182: 961-966.

Averhoff, B. (1988)

Optimierung der Succinat- und Trimethylenproduktion durch Variation von Wachstumsparametern und Zugabe externer H-Donatoren. Dissertation, Göttingen.

Ballal R. S., Jacobsen D. W., Robinson K., 1997

Homocysteine: update on a new risk factor. Cleve. Clin. J. Med. 64: 543-549.

Banerjee R., 1998

Spectroscopic and molecular genetic characterization of the two mammalian $\mathrm{B}_{12}$-dependent enzymes. In: Vitamin $\mathrm{B}_{12}$ and $\mathrm{B}_{12}$ Proteins. Kräutler B., Duilio A. D., Golding B. T. Wiley-VCH Verlag GmbH, Weinheim.

\section{Benoit S., Abaibou H., Mandrand-Berthelot M.-A., 1998}

Topological analysis of the aerobic membrane bound formate dehydrogenase of Escherichia coli. J. Bacteriol. 180: 6625-6634.

Berg B. L., Li J. and Stewart V., 1991

Nitrate-inducible formate dehydrogenase in Escherichia coli K-12. Nucleotide sequence of the $f d n G H I$ operon and evidence that opal (UGA) encodes selenocystein. J. Biol. Chem. 266: 22380-22385.

Berks B. C., 1996

A common export pathway for proteins binding complex redox cofactors? Mol. Microbiol. 22, No.3: 393404 Microreview.

Berks B. C., Sargent F. and Palmer T. 2000

The Tat protein export pathway. Microreview, Mol. Microbiol. 35, No. 2: 260-274.

Blakley R., 1965

Cobamides and ribonucleotide reduction. I. Cobamide stimulation of ribonucleotidereduction in extracts of Lactobacillus leichmanii. J. Biol. Chem. Vol. 240: 2173-2180. 
Blanche F., Thibaut D., DebusscheL., Hertle R., Zipfel F. and Müller G., 1993

Parallels and decisive differences in vitamin $\mathrm{B}_{12}$ biosynthesis. Angew. Chem. Int. Ed. Engl. 32: 16511653.

Blaylock B. A., Stadtman T. C., 1967

Role of $\mathrm{B}_{12}$ compounds in methane formation. Arch. Dermatol. 80 (4): 719-724.

Blum H., Beier H. and Gross H. J., 1987

Improved silver staining of plant proteins, RNA and DNA in polyacrylamide gels. Electrophoresis 8: 9399.

Bogsch E. G., Sargent F., Stanley N. R., Berks B. C., Robinson C. and Palmer T. 1998

An essential component of a novel bacterial protein export system with homologues in plastids and mitochondria. J. Biol. Chem. Vol 273, No. 29: 18003-18006.

Bogsch E., Brink S. and Robinson C., 1997

Pathway specificity for a $\Delta \mathrm{pH}$-dependent precursor thylakoid lumen protein is governed by a 'secavoidance' motif in the transfer peptide and a 'sec-incompatible' mature protein. EMBO J. Vol. 6, No. 13: $3851-3859$.

Bolhuis A., Mathers J. E., Thomas J. D., Barrett C. M. L. and Robinson C., 2001

TatB and TatC form a functional and structural unit of the twin-arginine translocase from Escherichia coli. J. Biol. Chem. Vol. 276, No. 23: 20213-20219.

Bolm M., 2000

Entwicklung eines $\mathrm{B}_{12}$-Exportersystems für Enterobakterien. Diplomarbeit, Göttingen.

Brada N., Gordon M. M., Shao J.-S., Wen J. and Alpers D. H., 2000

Production of gastric intrinsic factor, transcobalamin, and haptocorrin in opossum kidney cells. AJP Renal Physiol. Vol. 279, No. 6: 1-8.

Bradbeer C., 1991

Cobalamin transport in Escherichia coli. Biofactors. 3: 11-19.

\section{Bradbeer C., Gudmundsdottir A., 1990}

Interdependence of calcium and cobalamin binding by wild-type and mutant BtuB protein in the outer membrane of Escherichia. coli. J. Bacteriol. Vol. 172: 4919-4926. 
Braun V., 1995

Energy-coupled transport and signal transduction through the gram-negative outer membrane via TonBExB-ExD-dependent receptor proteins. FEMS Microbiol. 16: 295-307 Reviews.

Brinks S., Bogsch E. G., Edwards W. R., Hynds P. J., Robinson C., 1998

Targeting of thylakoid proteins by the $\Delta \mathrm{pH}$-driven twin-arginine translocation pathway requires a specific signal in the hydrophobic domain in conjunction with the twin-arginine motif., FEBS Lett. 434: 425-430.

Brüser, T., Deutsmann, R., Dahl, C. (1998)

Evidence against the double-arginine motif as the only determinant for protein translocation by a novel Sec-independent pathway in Escherichia coli. FEMS Microbiol Lett 164: 329-336.

Bulewela L., Forster A., Boehm T., Rabbitts T. H., 1989

A rapid procedure for colony screening using nylon filters. Nucl. Acids. Res. 17: 23-24.

Bykhovsky V. Y., Zaitseva N. I., Eliseev A. A. (1998)

Tetrapyrroles: diversity, biosynthesis, and biotechnology. Appl. Biochem. Microbiol. 34: 1-18.

\section{Cardieux N., Kadner R. J., 1999}

Site-directed disulfide bonding reveals an interaction site between energy-coupling protein TonB and BtuB, the outer membrane cobalamin transporter. Proc. Natl. Acad. Sci. Vol. 96: 10673-10678.

Chaddock A M., Mant A., Karnauchov I., Brink S., Herrmann R. G., Klösgen R. B. and Robinson C., 1995

A new type of signal peptide: central role of a twin-arginine motif in transfer signals for the $\Delta \mathrm{pH}-$ dependent thylakoidal protein translocase. EMBO J., Vol. 14, No. 12: 2715-2722.

Charter Jr. C. W., Kraut J., Freer S. T., Xuong N.-H., Alden R. A. and Bartsch R. G., 1974

Two-angstrom crystal structure of oxidized Chromatium high potential iron protein. J. Biol. Chem. 249: 4214.

Cheah K. C., Harrison S., King R., Crocker L., Wells J. R. E. and Robins A., 1994

Secretion of eucaryotic groeth hormones in Escherichia coli is influenced by the sequence of the mature protein. Gene 138: 9-15.

Christóbal S., de Gier J.-W., Nielsen H. and von Heijne G., 1999

Competition between Sec- and Tat- dependent protein translocation in Escherichia coli. EMBO J. Vol. 18, No. 11: 2982-2990. 
Collier D. N., Bankaitis V. A., Weiss J. B., Bassford Jr. P. J., 1988

The antifolding activity of SecB promotes the export of the E. coli maltose-binding protein . Cell 53: 273283.

Crameri A., Whiehorn E. A., Tate E., Stemmer W. P. C., 1996

Improved green fluorescent protein by molecular evolution using DNA shuffling. Nature Biotechnology Vol. 14: 315-319.

Dalbey R. E. and Robinson C., 1999

Protein translocation into and across the bacterial plasma membrane and the plant thylakoid membrane. TIBS 24: 17-22 reviews.

Daniel R., Bobil T. A., Gottschalk G., 1999

Biochemistry of coenzyme- $\mathrm{B}_{12}$ dependent glycerol and diol dehydratase and organization of the encoding genes. FEMS Microbiol. Reviews 22: 553-566.

Daniel R., Boenigk R., Gottschalk G., 1995a

Purification of 1,3-Propandiol dehydrogenase from Citrobacter freundii and cloning, sequencing and overexpression of the corresponding gene in Escherichia coli. J. Bacteriol. 177: 2151-2156.

Daniel R., Stuerz K., Gottschalk G., 1995b

Biochemical and molecular characterization of the oxidative branch of glycerol utilization by Citrobacter freundii. J. Bacteriol. 177: 4392-4401.

Denèfle P., Kovarik S., Ciora T., Gosselet N., Bénichou J.-C-. Latta M., Guinet F., Ryter A. and Mayaux J.-F., 1989

Heterologous protein export in Escherichia coli: influence of bacterial signal peptides on the export of human interleukin $1 \beta$. Gene 85: 499-510.

Dower, W. J., Miller, J. F., Ragsdale, C. W. (1988)

High efficiency transformation of $E$. coli by high voltage electroporation. Nucl Acids Res 16: 6127-6145.

Dreusch A., Bürgisser D. M., Heitmann C. W. and Zumft W. G., 1997

Lack of copper insertion into unprocessed cytoplasmic nitrous oxide reductase generated by an R20D substitution in the arginine consensus motif of the signal peptide. Biochim. Biophys. Acta.1319: 311-318.

Duda J., Pedziwilk Z., Zodrow K., 1967

Studies on the vitamin $\mathrm{B}_{12}$ content on the leguminous plants. Acta Microbiol. Pol. 6: 233-238. 
Eklund C., Lankford C. E., 1967

Laboratory manual for general microbiology. S. 277. Pentice-Hall Inc., Englewood Cliffs, New Jersey, USA.

Evans P. R. and Mancia F., 1998

Insights on the reaction mechanism of methylmalonyl-CoA-mutase from crystal structure. Kapitel 13: 317-226. In: Vitamin $B_{12}$ and $B_{12}$ Proteins. Kräutler B., Duilio A. D., Golding B. T. Wiley-VCH Verlag $\mathrm{GmbH}$, Weinheim.

Fekkes P. and Driessen A. J. M., 1999

Protein targeting in the bacterial cytoplasmic membrane. Microbiol. and Mol. Biol. Vol. 63, No. 1: 161173.

Golding B. T., Anderson R. J., Ashwell S., Edwards C. H., Garnet I., Kroll F. and Buckel W., 1998 A mechanistic overview of $\mathrm{B}_{12}$-dependent processes. In: Vitamin $\mathrm{B}_{12}$ and $\mathrm{B}_{12}$ Proteins. Kräutler B., Duilio A. D., Golding B. T. Wiley-VCH Verlag GmbH, Weinheim.

Gordon M. M., Russel-Jones G. and Alpers D. H., 1997

Expression of functional intrinsic factor using recombinant baculovirus. Methods in enzymology Vol. 281, [29]: 255-261.

Gordon M. M., Russel-Jones G., Alpers D. H., 1997

Expression of functional Intrinsic Factor using recombinant baculovirus. Methods in Enzymology 281: 255-261.

Green A. A., Hughes W. L., 1955

Protein fraction on the basis of solubility in aqueous solutions of slats and organic solvents. In: Colowick S. P., Kaplan N. O. (Ed.): Methods in enzymology. Vol I: 67-90.

Greene R. J. \& Guarente L., 1987

Subcloning. Methods Enzymol. 152: 512-521.

Halbig D., Wiegert T., Blaudeck N., Freudl R., Sprenger G. A., 1999

The efficient export of NADP-containing glucose-fructose oxidoreductase to the periplasm of Zymomonas mobilis depends both on an intact twin-arginine motif in the signal peptide and on the generation of a structural export signal induced by cofactor binding. Eur. J. Biochem. 263: 543-551.

Hanahan, D. (1983)

Studies on transformation of Escherichia coli with plasmids. J Mol Biol 166: 557-580. 


\section{Hawkes R., 1986}

The dot immunobinding assay. Methods Enzymol. 135: 102-117.

\section{Hinsley A. P., Stanley N. R., Palmer T., Berks B. C., 2001}

A naturally occurring bacterial Tat signal peptide lacking one of the "invariant" arginine residues of the consensus targeting motif. FEBS Lett. 497: 45-49.

Hochschuli E., 1988

Large-scale chromatography of recombinante proteins. J. Chromatogr. 444: 293-302.

Holdeman L. V., Cato E. P., Moore W. E. C., 1977

Anaerobe laboratory manual. $4^{\text {th }}$ ed. Anaerobe Laboratory, Virginian Poly technic Institute and State University, Blacksburg, Virginia.

Holmes, D. S., Quickley, M. (1981)

A rapid boiling method for the preparation of bacterial plasmids. Anal Biochem 114: 193-197.

Hörig J. A., Renz P., 1980

Biosynthesis of vitamin $B_{12}$. Eur. J. Biochem. 105: 587-592.

Inoue, H., Nojima, H., Okayama, H. (1990)

High efficiency transformation of Escherichia coli with plasmids. Gene 96: 23-28.

Ishida A., Kanefusa H., Fujita H., Toraya T., 1994

Microbiological activities of nucleotide loop-modified analogues of vitamin $\mathrm{B}_{12}$. Arch. Microbiol. Vol. 161: 293-299.

Jahn D., Hungerer C., Troup B., 1996

Ungewöhnliche Wege und umweltregulierte Gene der bakteriellen Hämbiosynthese. Naturwissenschaften 83: $389-400$.

Kadner R. J., 1990

Vitamin $\mathrm{B}_{12}$ transport in Escherichia coli: energy coupling between membranes. Mol. Microbiol. Vol 4, No. 12: 2027-2033 microreview.

Kadonoga J. T., Gautier A. E., Straus D. R., Charles A. D., Edge M. D. and Knowles J. R., 1984 The role of the $\beta$-lactamase signal sequence in the secretion of proteins by Escherichia coli. J. Biol. Chem. 259: 2149-2154. 
Keuth S. und Bisping B., 1994

Vitamin $\mathrm{B}_{12}$ production by Citrobacter freundii or Klebsiella pneumoniae during tempeh fermentation and proof of enterotoxin absence by PCR. Appl. Environ. Microbiol. Vol. 60, No. 5: 1495-1499.

Kräutler, 1998

$\mathrm{B}_{12}$-Coenzymes, the Central Theme. Kapitel 1: 1-43.In: Vitamin $\mathrm{B}_{12}$ and $\mathrm{B}_{12}$ Proteins. Kräutler B., Duilio A. D., Golding B. T. Wiley-VCH Verlag GmbH, Weinheim.

Krzycki J. and Zeikus J. G., 1980

Quantification of corrinoids in methanogenic bacteria. Curr. Microbiol. Vol. 3: 243-245.

Kumamoto C. A. and Beckwith J., 1985

Evidence for specificity at an early stepin protein export in Escherichia coli. J. Bacteriol. 163: 267-274.

Kumamoto C. A., 1991

Molecular chaperones and protein translocation across the Escherichia coli inner membrane. Mol. Microbiol. 5: 19-22.

Lawrence J. G. and Roth J. R., 1996

Evolution of coenzyme $\mathrm{B}_{12}$ synthesis among enteric bacteria: evidence for loss and reacquisition of a multigene complex. Genetics. 142: 11-24.

Lawrence J. G., Ochman H. and Hartl D. L., 1991

Molecular and evolutionary relationships amon enteric bacteria. J. Gen. Microbiol. 137: 1911-1921.

Lei S. P., Lin H. C., Wang S. S., Callaway J., Wilcox G. 1987

Characterization of the Erwinia carotovora pelB gene and its product pectate lyase. J Bacteriol 1987 Vol. 169(9):4379-83.

Ludwig M. L. and Matthews R. G., 1997

Structure-based perspectives on $\mathrm{B}_{12}$-dependent enzymes. Annu. Rev. Biochem. 66: 269-313.

Makrides S. C., 1996

Strategies for achieving high-level expression of genes in Escherichia coli. Microbiol. Rev. Vol. 60, No. 3: $512-538$.

Mancia F., Evans P. R., 1998

Conformational changes on the substrate binding to methylmalonyl-coenzyme A mutase and new insights into free radical mechanism. Structure 6: 711-720. 
Mancia F., Keep N. H., Nakagawa A., Leadlay P. F., McSweeney S., Rasmussen B., Bösecke P., Diat O., Evans P. R., 1996

How coenzyme $B_{12}$ radicals are generated: the crystal structure of methylmalonyl-coenzyme A mutase at 2 Å resolution. Structure 4: 339-350.

Margolin W., 2000

Green fluorescent protein as a reporter for macromolecular localisation in bacterial cells. Methods 20: 6272.

Marsh E. N. G., 1999

Coenzyme $\mathrm{B}_{12}$ (cobalamin)-dependent enzymes. Ess. Biochem.34: 139-154.

Martens J.-H., Barg H., Warren M. J., Jahn D., 2002

Microbial production of vitamin $B_{12}$. Appl. Microbiol. Biotechnol. 58: 275-285.

Mayer M. P., 1995

A new set of useful cloning and expression vectors derived from pBlueScript. Gene 163: 41-46.

Méjan V., Iobbi-Nivol C., Lepelletier M., Giordano G., Chippaux M. and Pascal M. C., 1994

TMAO anaerobic respiration in Escherichia coli: involvment of the tor operon. Mol. Micobiol 11: 11691179.

Méjean V., lobbi-Nivol C., Lepelletier M., Giordano G., Chippaux M. and Pascal M.-C., 1994

TMAO anaerobic respiration in Escherichia coli: involvement of the tor operon. Mol. Microbiol. Vol 11, No. 6: 1169-1179.

\section{Miksch G., Friedler E., Dobrowolski P., Friehs K., 1997b}

The kil-gene of the ColE1 plasmid of Escherichia coli controlled by a growths-phase-dependent promoter mediates the secretion of a heterologous protein during the stationary phase. Arch. Microbiol. 167: 143150.

Miksch G., Friedler E., Dobrowolski P., Friehs K., 1997c

Controlled secretion into the culture medium of a hybrid $\beta$-glucanase by Acetobacter methanolicus mediated by the kil gene of Escherichia coli located on a Tn5-derived transposon. Appl. Micobiol. Biotechnol. 47: 530-536.

Miksch G., Neitzel R., Friedler E., Friehs K., Flaschel E., 1997a

Extracellular production of a hybrid $\beta$-glucanase from Bacillus by Escherichia coli under different cultivation conditions in shaking cultures and bioreactors. Appl. Micobiol. Biotechnol. 47: 120-126. 
Miksch G., Neitzel R., Friehs K., Flaschel E., 1999

High-level expression of a recombinant protein in Klebsiella planticola owing to induced secretion into the culture medium. Appl. Microbiol. 167: 143-150.

Minot G. R., Murphy W. P., 1926

Treatment of pernicious anaemia by a special diet. J. Am. Med. Assoc. 87: 470-476.

Mori H. and Cline K., 1998

A signal peptide that directs non-sec transport in bacteria also directs efficient and exclusive transport on the thylakoid delta pH pathway. J. Biol. Chem. Vol. 273. No. 19: 11405-11408.

Müller M., Koch H. G., Beck K., Schafer U., 2001

Protein traffic in bacteria: multiple routes from the ribosome to and across the membrane. Prog. Nucleic. Acid. Res. Mol. Biol. 6: 107-157.

Nexø E., 1998

Cobalamin binding proteins. Kapitel 30: 461-475.

In: Vitamin $B_{12}$ and $B_{12}$ Proteins. Kräutler B., Duilio A. D., Golding B. T. Wiley-VCH Verlag GmbH, Weinheim.

Nivière V., Song A.-L., Voordouw G., 1992

Site-directed mutagenesis of the hydrogenase signal peptide consensus box presents export of $\beta$ Lactamase fusion protein. J. Gen. Microbiol. 138: 2173-2183.

Pfennig , Lippert, K. D. (1966)

Über das Vitamin $B_{12}$-Bedürfnis phototropher Schwefelbakterien. Arch Microbiol 55: 245-256.

Raux E., Lanois A., Levillayer F., Warren M. J., Brody E., Rambach A. and Thermes C., 1996

Salmonella typhimurium cobalamin (vitamin $\mathrm{B}_{12}$ ) biosynthesic genes: functional studies in $S$. typhimurium and Escherichia coli. J. Bacteriol. Vol. 178, No. 3: 753-767.

Raux E., Lanois A., Warren M. J., Rambach A. and Thermes C. 1998.

Cobalamin (vitamin $\mathrm{B}_{12}$ ) biosynthesis: identification and Characterization of characterization of a Bacillus megaterium cob operon. Biochem. J. 335: 159-166.

Raux E., Schubert H. L. and Warren M. J., 2000

Biosynthesis of cobalamin (vitamin $\mathrm{B}_{12}$ ): a bacterial conundrum. CMLS Cell. Mol. Life Sci. 57: 18801893. 
Rickes E. L. Brink N. G., Koniuszy F. R., Wood T. R., Folkers K., 1948

Crystalline vitamin $\mathrm{B}_{12}$. Science 107: 396.

Robinson C., 2000

The twin-arginine translocation system: A novel means of transporting folded proteins in chloroplasts and bacteria. Minireview, Biol. Chem. Vol. 381: 89-93.

Rodrigue A., Chanal A., Beck K., Müller M. and Wu L.-F., 1999

Co-translocation of a periplasmic enzyme complex by a hitchhiker mechanism through the bacterial Tat pathway. J. Biol. Chem. Vol. 274, No. 19: 13223-13228.

Roth J. R., Lawrence J. G. and Bobik T. A., 1996

Cobalamin (coenzyme $\mathrm{B}_{12}$ ): synthesis and biological significance. Annu. Rev. Microbiol. 50: 137-181.

Sambrook, J., Fritsch, E., Maniatis, T. (1989)

Molecular cloning: a laboratory manual (2. Aufl.). Cold Spring Harbor Laboratory, Cold spring Harbor, New York, USA.

Santini C. L., Bernadec A., Zhang M., Chanal A., Ize B., Blanco C., Wu L. F., 2001

Translocation of jellyfish green fluorescent protein via the Tat system of Escherichia coli and change of its periplasmic location in response to osmotic up-shock. J. Biol. Chem. 276 (11): 8159-8164.

Santini C.-L., Bérengère I., Chanal A., Müller M., Giordano G. and Wu L.-F., 1998

A novel sec-independent periplasmic protein in Escherichia coli. EMBO J. Vol. 17, No. 1: 101-112

Sargent F., Bogsch E. G., Stanley N. R., Wexler M., Robinson C., Berks B. C. and Palmer T. 1998 Overlapping functions of components of a bacterial Sec-independent protein export pathway. EMBO J. Vol 17, No.13: 3640-3650.

Sargent F., Gohlke U., de Leeuw E., Stanley N. R., Palmer T., Saibil H. R. and Berks B. C., 2001 Purified components of the Escherichia coli Tat protein transport system form a double-layer ring structure. Eur. J. Bioche. 268: 3361-3367.

Sargent F., Stanley N. R., Berks B. C. and Palmer T., 1999

Sec-independent protein translocation in Escherichia coli. J. Biol. Chem. Vol. 274, No. 51: 36073-36082.

Schägger, H., von Jagow, G. (1987)

Tricine-sodium dedecyl sulfate-polyacrylamide gel electrophoresis for the separation of proteins in the range of 1 to $100 \mathrm{kDa}$. Anal Biochem 166: 368-379. 
Schatz G., Dobberstein B., 1996

Common principles of protein translocation across membranes. Science 271: 1519-1526.

Schneider Z. E. G., Larsen G., Jacobson G., Johnson B. C. and Pawelkiewicz J., 1970

Purification and properties of glycerol dehydratase. J. Biol. Chem. 245: 3388-3396.

Settles A. M. and Martienssen R., 1998

Old an new pathways of protein export in chloroplasts and bacteria. Cell Biol. reviews 8: 494-501.

Silvestro A., Pommier J., Pascal M. C. and Giordano G., 1989

The inducible trimethylamine N-oxide reductase of Escherichia coli K-12: its localization and inducers. Biochim. Biophys. Acta. 994: 208-216.

\section{Stanley R. N., Palmer T. and Berks B. C., 2000}

The twin arginine consensus motif of tat signal peptides is involved in sec-independent protein targeting in Escherichia coli. J. Biol. Chem. Vol. 275, No. 16: 11591-11596.

\section{Studier F. W., Rosenberg A. H., Dunn J. J. \& Dubendorff J. W. 1990}

Use of T7 RNA polymerase to direct expression of cloned genes. Methods Enzymol. 185: 60-89.

\section{Tamaki T., Horinouchi S., Fukaya S., Okumura M., Kawamura Y. and Beppu T., 1989}

Nucleotide sequence of the membrane bound aldehyde dehydrogenase gene von Acetobacter polyoxogenes. J. Biochem. 106: 541-544.

Tang L-H., Chokshi H., Hu C.-B., Gordon M. M. and Alpers, D. H., 1992

The intrinsic factor (IF)-Cobalamin receptor binding site is located in the amino-terminal portion of IF. J. Biol. Chem. Vol. 267, No.32: 22982-22986.

Tjalsma H., Bolhuis A., Jongbloed J. D. H., Bron S. and Maarten van Dijl J., 2000

Signal-peptide dependent protein transport in Bacillus subtilis: a genome-based survey of the secretome. Microbiol. Mol. Biol. Vol 64, No.3: 515-547.

Towbin, H., Staehelin, T., Gordon, J. (1979)

Elektrophoretic transfer of proteins from polyacrylamid gels to nitrocellulose sheets: procedure and some applications. Proc Nat Acad Sci. USA. 76: 4350-4354.

Van Bibber M., Bradbeer C., Clark N. and Roth J. R., 1999

A new class of cobalamin transport mutants $(b t u \mathrm{~F})$ provides genetic evidence for a periplasmic binding protein in Salmonella thyphimurium. J. Bacteriol. Vol. 181, No. 17: 5539-5541. 
Wall J. G. and Plückthun A., 1995

Effects of overexpressing folding modulators on the in vivo folding of heterologous proteins in Escherichia coli. Curr. Oppin. Biotechnol. 6: 507-516.

Warren M. J. and Scott A. I., 1990

Tetrapyrrole assembly and modification into the ligands of biologically functional cofactors. Trend Biochem. Sci. 180: 486-491.

Weiner J. H., Bilous P. T., Shaw, M. G., Lubitz S. P., Frost L., Thomas G. H., Cole J. A. and Turner R. J., 1998

A novel and ubiquitous system for membrane targeting and secretion of cofactor-containing proteins. Cell 93: 93-101.

Wen J., Kinnear M. B., Richardson M. A., Willets N. S., Russel-Jones G. J., Gordon M. M., Alpers D. H., 1999

Functional expression in Pichia pastoris of human and rat intrinsic factor. Biochim. Biophys. Acta 1490: 43-53.

Wickner W., Driessen A. J. M., Hartl F. U., 1991

The enzymology of protein translocation across the Escherichia coli membrane. Annu. Rev. Biochem. 60: 101-124.

Wiegert T., Sahm H. and Sprenger G. A., 1996

Export of the periplasmic NADP-containing glucose-fructose oxidoreductase of Zymomonas mobilis. Arch. Microbiol. 166: 32-41:

Wingfield P. T., 1995

Overview of the purification of recombinant proteins produced in E. coli. In: Current protocols in protein science Vol. 1, Coligan J. E., Dunn B. M., Ploegh H. L., Speicher D. W., Wingfield P. T. John Wiley and Sons, New York Vol. 1: 6.11.-6.1.22.

Wood H. G., 1991

Life with Co or $\mathrm{CO}_{2}$ and $\mathrm{H}_{2}$ as a source of carbon and energy. FASEB J. 5 (2): 156-163 Review.

\section{Woodcock S. C., Raux E., Levillayer F., Thermes C., Rambach A., Warren M. J., 1998}

Effect of mutations in the transmethylase and dehydrogenase/ chelatase domains of sirohaem synthase (CysG) on sirohaem and cobalamin biosynthesis. Biochem. J. 330: 121-129. 
Wu W.-F., Urbanowski M. L. and Stauffer G. V., 1992

Role of the MetR regulatory sytem in vitamin $\mathrm{B}_{12}$-mediated repression of the

Salmonella typhimurium metE gene. J. Bacteriol. Vol. 174, No. 14: 4833-4837.

Wülfing C. and Plückthun A., 1994

Correctly folded T-cell receptor fragments in the periplasm of Escherichia coli - influence of folding catalysts. J. Mol. Biol. 242: 655-669.

Yip T. T., Nakagawa Y., Porath J., 1989

Evaluation of the interaction of peptides with $\mathrm{Cu}$ (II), Ni (II), and $\mathrm{Zn}$ (II) by high-performance immobilized-metal ion affinity chromatography. Anal. Bioche. 183: 159-171.

Zagalak B., 1982

Vitamin $B_{12}$ als biologisch aktive Modellsubstanz, Naturwissenschaften 69: 63-74

Springer Verlag 


\section{Anhang}

\section{Nukleotidsequenz des Inserts von pTM1:}

mit den Erkennungssequenzen: 5'-terminal für $\underline{E c o R I}$ und 3'-terminal für $\underline{\operatorname{HindIII}}$

GAATTCACCATGAACAATAACGATCTCTTTCAGGCATCACGTCGGCGTTTTCTGGCACAACTCGGCGGCT TAACCGTCGCCGGGATGCTGGGGCCGTCATTGTTAACGCCGCGACGTGCGACTGCGGCGCAAGCGGCGAC TGACGTTGTCAGTACCCAGACCCAGAGTTCATGCTCCGTTCCCTCAGCACAGGAGCCCTTGGTCAATGGA ATACAAGTACTCATGGAGAACTCGGTGACTTCATCAGCCTACCCAAACCCCAGCATCCTGATTGCCATGA ATCTGGCCGGAGCCTACAACTTGAAGGCCCAGAAGCTCCTGACTTACCAGCTCATGTCCAGCGACAACAA CGATCTAACCATTGGGCAGCTCGGCCTCACCATCATGGCCCTCACCTCCTCCTGCCGAGACCCTGGGGAT AAAGTATCCATTCTACAAAGACAAATGGAGAACTGGGCACCTTCCAGCCCCAACGCTGAAGCATCAGCCT TCTATGGGCCCAGTCTAGCGATCTTGGCACTGTGCCAGAAGAACTCTGAGGCGACCTTGCCGATAGCCGT CCGCTTTGCCAAGACCCTGCTGGCCAACTCCTCTCCCTTCAATGTAGACACAGGAGCAATGGCAACCTTG GCTCTGACCTGTATGTACAACAAGATCCCTGTAGGTTCAGAGGAAGGTTACAGATCCCTGTTTGGTCAGG TACTAAAGGATATTGTGGAGAAAATCAGCATGAAGATCAAAGATAATGGCATCATTGGAGACATCTACAG TACTGGCCTCGCCATGCAGGCTCTCTCTGTAACACCTGAGCCATCTAAAAAGGAATGGAACTGCAAGAAG ACTACGGATATGATACTCAATGAGATTAAGCAGGGGAAATTCCACAACCCCATGTCCATTGCTCAAATCC TCCCTTCCCTGAAAGGCAAGACATACCTAGATGTGCCCCAGGTCACTTGTAGTCCTGATCATGAGGTACA ACCAACTCTACCCAGCAACCCTGGCCCTGGCCCCACCTCTGCATCTAACATCACTGTCATATACACCATA AATAACCAGCTGAGGGGGGTTGAGCTGCTCTTCAACGAGACCATCAATGTTAGTGTGAAAAGTGGGTCAG TGTTACTTGTTGTCCTAGAGGAAGCACAGCGCAAAAATCCTATGTTCAAATTTGAAACCACAATGACATC TTGGGGCCTTGTCGTCTCTTCTATCAACAATATCGCGGAAAATGTTAATCACAAGACATACTGGCAGTTT CTTAGTGGTGTAACACCTTTGAATGAAGGGGTTGCTGACTACATACCCTTCAACCACGAGCACATCACAG CCAATTTCACACAGTACCACCATCACCATCACCATTAATAAGCTT 


\section{Nukleotidsequenz des Inserts von pTM3:}

mit der Erkennungssequenz: 5'- und 3'- terminal für $\underline{X b a \mathrm{I}}$

TCTAGAGAACAATAACGATCTCTTTCAGGCATCACGTCGGCGTTTTCTGGCACAACTCGGCGGCTTAACC GTCGCCGGGATGCTGGGGCCGTCATTGTTAACGCCGCGACGTGCGACTGCGGCGCAAGCGGCGACTAGCA CTCTGCCCCGTTTTGATTCAGTTGACCTCGGCAATGCCCCGGTTCCTGCTGATGCCGCACGACGCTTCGA GGAACTGGCCGCCAAGGCCGGCACCGGAGAGGCGTGGGAGACGGCCGAGCAGATTCCGGTTGGCACCCTG TTCAACGAAGACGTCTACAAGGACATGGACTGGCTGGACACCTACGCAGGTATCCCGCCGTTCGTCCACG GCCCGTATGCAACCATGTACGCGTTCCGTCCCTGGACGATTCGCCAGTACGCCGGTTTCTCCACGGCCAA GGAGTCGAACGCCTTCTACCGCCGCAACCTTGCGGCCGGCCAGAAGGGCCTGTCGGTTGCCTTCGACCTG CCCACCCACCGTGGCTACGACTCGGACAATCCCCGCGTCGCCGGTGACGTCGGCATGGCCGGTGTGGCCA TCGACTCCATCTATGACATGCGCGAGCTGTTCGCCGGCATTCCGCTGGACCAGATGAGCGTGTCCATGAC CATGAACGGCGCCGTGCTGCCGATCCTGGCCCTCTATGTGGTGACCGCCGAGGAGCAGGGCGTCAAGCCC GAGCAGCTCGCCGGGACGATCCAGAACGACATCCTCAAGGAGTTCATGGTTCGTAACACCTACATCTACC CGCCGCAGCCGAGTATGCGAATCATCTCTGAGATCTTCGCCTACACGAGTGCCAATATGCCGAAGTGGAA TTCGATTTCCATTTCCGGCTACCACATGCAGGAAGCCGGCGCCACGGCCGACATCGAGATGGCCTATACC CTGGCCGACGGTGTTGACTACATCCGCGCCGGCGAGTCGGTGGGCCTCAATGTCGACCAGTTCGCGCCGC GTCTGTCCTTCTTCTGGGGCATCGGCATGAACTTCTTCATGGAGGTTGCCAAGCTGCGTGCCGCGCGCAT GTTGTGGGCCAAGCTGGTGCATCAGTTCGGGCCGAAGAACCCGAAGTCGATGAGCCTGCGCACCCACTCG CAGACCTCCGGTTGGTCGCTGACCGCCCAGGACGTCTACAACAACGTCGTGCGTACCTGCATCGAGGCCA TGGCCGCCACCCAGGGCCATACCCAGTCGCTGCACACGAACTCGCTCGACGAGGCCATCGCCCTGCCGAC CGATTTCAGCGCCCGCATCGCCCGTAACACCCAGCTGTTCCTGCAGCAGGAATCGGGCACGACGCGCGTG ATCGACCCGTGGAGCGGCTCGGCATACGTCGAGGAGCTCACCTGGGACCTGGCCCGCAAGGCATGGGGTC ACATCCAGGAGGTCGAGAAGGTCGGCGGCATGGCCAAGGCCATCGAAAAGGGCATCCCCAAGATGCGCAT CGAGGAAGCCGCCGCCCGCACCCAGGCACGCATCGACTCCGGCCGCCAGCCGCTGATCGGCGTGAACAAG TACCGCCTGGAGCACGAGCCGCCGCTCGATGTGCTCAAGGTGGACAACTCCACGGTGCTCGCCGAGCAGA AGGCCAAGCTGGTCAAGCTGCGCGCCGAGCGCGATCCCGAGAAGGTCAAGGCCGCCCTCGACAAGATCAC CTGGGCCGCCGGCAACCCCGACGACAAGGATCCGGATCGCAACCTGCTGAAGCTGTGCATCGACGCTGGC CGCGCCATGGCGACGGTCGGCGAGATGAGCGACGCGCTCGAGAAGGTCTTCGGACGCTACACCGCCCAGA TTCGCACCATCTCCGGTGTGTACTCGAAGGAAGTGAAGAACACGCCTGAGGTTGAGGAAGCACGCGAGCT CGTTGAGGAATTCGAGCAGGCCGAGGGCCGTCGTCCTCGCATCCTGCTGGCCAAGATGGGCCAGGACGGT CACGACCGTGGCCAGAAGGTCATCGCCACCGCCTATGCCGACCTCGGTTTCGACGTCGACGTGGGCCCGC TGTTCCAGACCCCGGAGGAGACCGCACGTCAGGCCGTCGAGGCCGATGTGCACGTGGTGGGCGTTTCGTC GCTCGCCGGCGGGCATCTGACGCTGGTTCCGGCCCTGCGCAAGGAGCTGGACAAGCTCGGACGTCCCGAC ATCCTCATCACCGTGGGCGGCGTGATCCCTGAGCAGGACTTCGACGAGCTGCGTAAGGACGGCGCCGTGG AGATCTACACCCCCGGCACCGTCATTCCGGAGTCGGCGATCTCGCTGGTCAAGAAACTGCGGGCTTCGCT CGATGCCCACCATCACCATCACCATTAATTCTAGA 


\section{Nukleotidsequenz des Inserts von pTM4:}

mit den Erkennungssequenzen: 5'-terminal für $\underline{E c o R I}$ und 3'-terminal für $\underline{H i n d I I I}$

GAATTCCAGTACCCAGACCCAGAGTTCATGCTCCGTTCCCTCAGCACAGGAGCCCTTGGTCAATGGAATA CAAGTACTCATGGAGAACTCGGTGACTTCATCAGCCTACCCAAACCCCAGCATCCTGATTGCCATGAATC TGGCCGGAGCCTACAACTTGAAGGCCCAGAAGCTCCTGACTTACCAGCTCATGTCCAGCGACAACAACGA TCTAACCATTGGGCAGCTCGGCCTCACCATCATGGCCCTCACCTCCTCCTGCCGAGACCCTGGGGATAAA GTATCCATTCTACAAAGACAAATGGAGAACTGGGCACCTTCCAGCCCCAACGCTGAAGCATCAGCCTTCT ATGGGCCCAGTCTAGCGATCTTGGCACTGTGCCAGAAGAACTCTGAGGCGACCTTGCCGATAGCCGTCCG CTTTGCCAAGACCCTGCTGGCCAACTCCTCTCCCTTCAATGTAGACACAGGAGCAATGGCAACCTTGGCT CTGACCTGTATGTACAACAAGATCCCTGTAGGTTCAGAGGAAGGTTACAGATCCCTGTTTGGTCAGGTAC TAAAGGATATTGTGGAGAAAATCAGCATGAAGATCAAAGATAATGGCATCATTGGAGACATCTACAGTAC TGGCCTCGCCATGCAGGCTCTCTCTGTAACACCTGAGCCATCTAAAAAGGAATGGAACTGCAAGAAGACT ACGGATATGATACTCAATGAGATTAAGCAGGGGAAATTCCACAACCCCATGTCCATTGCTCAAATCCTCC CTTCCCTGAAAGGCAAGACATACCTAGATGTGCCCCAGGTCACTTGTAGTCCTGATCATGAGGTACAACC AACTCTACCCAGCAACCCTGGCCCTGGCCCCACCTCTGCATCTAACATCACTGTCATATACACCATAAAT AACCAGCTGAGGGGGGTTGAGCTGCTCTTCAACGAGACCATCAATGTTAGTGTGAAAAGTGGGTCAGTGT TACTTGTTGTCCTAGAGGAAGCACAGCGCAAAAATCCTATGTTCAAATTTGAAACCACAATGACATCTTG GGGCCTTGTCGTCTCTTCTATCAACAATATCGCGGAAAATGTTAATCACAAGACATACTGGCAGTTTCTT AGTGGTGTAACACCTTTGAATGAAGGGGTTGCTGACTACATACCCTTCAACCACGAGCACATCACAGCCA ATTTCACACAGTACAAGCTT 


\section{Nukleotidsequenz des Inserts von pTM6:}

mit den Erkennungssequenzen: 5'-terminal für $\underline{X b a \mathrm{I}}$ und 3'-terminal für $\underline{\mathrm{ClaI}}$

TCTAGAGAACAATAACGATCTCTTTCAGGCATCACGTCGGCGTTTTCTGGCACAACTCGGCGGCTTAACC GTCGCCGGGATGCTGGGGCCGTCATTGTTAACGCCGCGACGTGCGACTGCGGCGCAAGCGGCgactAGCA CTCTGCCCCGTTTTGATTCAGTTGACCTCGGCAATGCCCCGGTTCCTGCTGATGCCGCACGACGCTTCGA GGAACTGGCCGCCAAGGCCGGCACCGGAGAGGCGTGGGAGACGGCCGAGCAGATTCCGGTTGGCACCCTG TTCAACGAAGACGTCTACAAGGACATGGACTGGCTGGACACCTACGCAGGTATCCCGCCGTTCGTCCACG GCCCGTATGCAACCATGTACGCGTTCCGTCCCTGGACGATTCGCCAGTACGCCGGTTTCTCCACGGCCAA GGAGTCGAACGCCTTCTACCGCCGCAACCTTGCGGCCGGCCAGAAGGGCCTGTCGGTTGCCTTCGACCTG CCCACCCACCGTGGCTACGACTCGGACAATCCCCGCGTCGCCGGTGACGTCGGCATGGCCGGTGTGGCCA TCGACTCCATCTATGACATGCGCGAGCTGTTCGCCGGCATTCCGCTGGACCAGATGAGCGTGTCCATGAC CATGAACGGCGCCGTGCTGCCGATCCTGGCCCTCTATGTGGTGACCGCCGAGGAGCAGGGCGTCAAGCCC GAGCAGCTCGCCGGGACGATCCAGAACGACATCCTCAAGGAGTTCATGGTTCGTAACACCTACATCTACC CGCCGCAGCCGAGTATGCGAATCATCTCTGAGATCTTCGCCTACACGAGTGCCAATATGCCGAAGTGGAA TTCGATTTCCATTTCCGGCTACCACATGCAGGAAGCCGGCGCCACGGCCGACATCGAGATGGCCTATACC CTGGCCGACGGTGTTGACTACATCCGCGCCGGCGAGTCGGTGGGCCTCAATGTCGACCAGTTCGCGCCGC GTCTGTCCTTCTTCTGGGGCATCGGCATGAACTTCTTCATGGAGGTTGCCAAGCTGCGTGCCGCGCGCAT GTTGTGGGCCAAGCTGGTGCATCAGTTCGGGCCGAAGAACCCGAAGTCGATGAGCCTGCGCACCCACTCG CAGACCTCCGGTTGGTCGCTGACCGCCCAGGACGTCTACAACAACGTCGTGCGTACCTGCATCGAGGCCA TGGCCGCCACCCAGGGCCATACCCAGTCGCTGCACACGAACTCGCTCGACGAGGCCATCGCCCTGCCGAC CGATTTCAGCGCCCGCATCGCCCGTAACACCCAGCTGTTCCTGCAGCAGGAATCGGGCACGACGCGCGTG ATCGACCCGTGGAGCGGCTCGGCATACGTCGAGGAGCTCACCTGGGACCTGGCCCGCAAGGCATGGGGTC ACATCCAGGAGGTCGAGAAGGTCGGCGGCATGGCCAAGGCCATCGAAAAGGGCATCCCCAAGATGCGCAT CGAGGAAGCCGCCGCCCGCACCCAGGCACGCATCGACTCCGGCCGCCAGCCGCTGATCGGCGTGAACAAG TACCGCCTGGAGCACGAGCCGCCGCTCGATGTGCTCAAGGTGGACAACTCCACGGTGCTCGCCGAGCAGA AGGCCAAGCTGGTCAAGCTGCGCGCCGAGCGCGATCCCGAGAAGGTCAAGGCCGCCCTCGACAAGATCAC CTGGGCCGCCGGCAACCCCGACGACAAGGATCCGGATCGCAACCTGCTGAAGCTGTGCATCGACGCTGGC CGCGCCATGGCGACGGTCGGCGAGATGAGCGACGCGCTCGAGAAGGTCTTCGGACGCTACACCGCCCAGA TTCGCACCATCTCCGGTGTGTACTCGAAGGAAGTGAAGAACACGCCTGAGGTTGAGGAAGCACGCGAGCT CGTTGAGGAATTCGAGCAGGCCGAGGGCCGTCGTCCTCGCATCCTGCTGGCCAAGATGGGCCAGGACGGT CACGACCGTGGCCAGAAGGTCATCGCCACCGCCTATGCCGACCTCGGTTTCGACGTCGACGTGGGCCCGC TGTTCCAGACCCCGGAGGAGACCGCACGTCAGGCCGTCGAGGCCGATGTGCACGTGGTGGGCGTTTCGTC GCTCGCCGGCGGGCATCTGACGCTGGTTCCGGCCCTGCGCAAGGAGCTGGACAAGCTCGGACGTCCCGAC ATCCTCATCACCGTGGGCGGCGTGATCCCTGAGCAGGACTTCGACGAGCTGCGTAAGGACGGCGCCGTGG AGATCTACACCCCCGGCACCGTCATTCCGGAGTCGGCGATCTCGCTGGTCAAGAAACTGCGGGCTTCGCT CGATGCCCACCATCACCATCACCATATCGATATGGCTAGCAAAGGAGAAGAACTTTTACTGGAGTTGTCC CAATTCTTGTTGAATTAGATGGTGATGTTAATGGGCACAAATTTTCTGTCAGTGGAGAGGGTGAAGGTGA 
TGCTACATACGGAAAGCTTACCCTTAAATTTATTTGCACTACTGGAAAACTACCTGTTCCATGGCCAACA CTTGTCACTACTTTCTCTTATGGTGTTCAATGCTTTTCCCGTTATCCGGATCATATGAAACGGCATGACT TTTTCAAGAGTGCCATGCCCGAAGGTTATGTACAGGAACGCACTATATCTTTCAAAGATGACGGGAACTA CAAGACGCGTGCTGAAGTCAAGTTTGAAGGTGATACCCTTGTTAATCGTATCGAGTTAAAAGGTATTGAT TTTAAAGAAGATGGAAACATTCTCGGACACAAACTCGAGTACAACTATAACTCACACAATGTATACATCA CGGCAGACAAACAAAAGAATGGAATCAAAGCTAACTTCAAAATTCGCCACAACATTGAAGATGGATCCGT TCAACTAGCAGACCATTATCAACAAAATACTCCAATTGGCGATGGCCCTGTCCTTTTACCAGACAACCAT TACCTGTCGACACAATCTGCCCTTTCGAAAGATCCCAACGAAAAGCGTGACCACATGGTCCTTCTTGAGT TTGTAACTGCTGCTGGGATTACACATGGCATGGATGAGCTCTACAAATAATATCGAT 


\section{Danksagung}

Mein herzlicher Dank gilt Herrn Prof. Dr. G. Gottschalk für die Überlassung des Themas, sein stetiges Interesse am Fortgang der Arbeit, die Ermöglichung eines selbständigen wissenschaftlichen Arbeitens und die mir in jeder Hinsicht gewährte Unterstützung.

Herrn Dr. Rolf Daniel danke ich für die Betreuung während der Promotionszeit, die Freiräume bei der Entwicklung neuer Ideen, diverse Tipps und Anregungen in Gesprächen und ganz besonders die intensive, gewissenhafte und schnelle Durchsicht dieser Arbeit.

Weiterhin möchte ich mich bei Ruth Schmitz bedanken, die immer ein offenes Ohr für meine Antikörperprobleme hatte, gern anregende Tipps gab und mir auch so einige Substanzen zur Mitbenutzung zur Verfügung gestellt hat.

Nicht zu vergessen sind die ehemaligen und jetzigen „Laborinsassen“ aus 201, mit denen ich gemeinsam durch manch Höhen und Tiefen der Doktorzeit gegangen bin. So möchte ich mich bei Frank meinem langjährigen Laborbank- und Schreibtischnachbarn für die vielen außergewöhnlichen Gespräche, bei Jessi, die mir durch die Flaschen demonstriert hat, wie herrlich man doch mit sich selber reden kann, und die meinen Schlumpi oft liebevoll versorgt hat, bei Claudi der Katzenliebhaberin, bei Susanne, dem zweiten Joghurt-Fan neben mir, bei Anja mit ihrer „Geheimforschung“, bei der handballspielenden Pflanzen-Tanja, bei dem Computer-Liebhaber Bariş, bei dem leiseTelefonierer Sebastian und bei den ehemaligen Mitgliedern Maike, Corinna, Anke und Tanja für die gute Zusammenarbeit, die lockere, freundschaftliche Atmosphäre und so einige interessante Gespräche bedanken, die mich auf neue Gedanken gebracht haben.

Auch F.F. mit seinem enormen Wissen über die Frauenwelt, M. H., Bata und Kai aus meinem ehemaligen Labor 206 danke ich für so einige überaus erheiternde FreitagNachmittage.

Mit Axel hatte ich in der ganzen Zeit nicht nur viele schöne Teestunden. Deine Sicht der Dinge lenkt einen manchmal in ganz neue, interessante und ungeahnte Bahnen. Wir hatten eine schöne Zeit, VIELEN DANK Axel. 
Herrn Hellwig, Verena, der Wekstattcrew (den Ehemaligen Charlie und Steckel) und allen Institutsangehörigen, die mir mit Rat uns Tat zur Seite gestanden haben, sei an dieser Stelle gedankt.

Ebenso verdient die Mannschaft in der Abteilung der Genomanalyse ein Dankeschön für die Sequenzierung meiner Proben.

Sven danke ich für seine Hilfe bei Problemen mit besonders kleinen oder auch großen PCR-Fragmenten.

Silky und mir ist es doch meistens gelungen, uns immer wieder auch an die anderen wichtigen Dinge des Lebens zu erinnern. Ein Hoch auf uns.

Patrick und Naimeh danke ich für ihre Hilfe bei den Arbeiten am Fluoreszenzphotometer und der AG Braus natürlich für die Benutzung des Gerätes.

Inge von den Emis (Abteilung Prof. Dr. F. Mayer) danke ich für die Bearbeitung meiner Proben und Michael Hoppert für die Beantwortung meiner vielen Fragen.

Meiner Mutter und meinen Großeltern bin ich sehr dankbar, dass sie mir das Studium überhaupt ermöglicht haben und mir mit großen und kleinen Geschenken eine tolle und unvergeßliche Studentenzeit bereitet haben.

Mein Schwesterherz kriegt einen dicken Kuß dafür, dass ich nie vergessen habe, wo ich herkomme - nämlich aus dem Norden.

Anke danke ich für die vielen ablenkenden Mittagessen in der Z-Mensa und für das Korrekturlesen meiner Arbeit.

Um Tilli müssten mich alle beneiden.....! Vielen vielen Dank, dass Du der Mikrobiologie nicht wie geplant völlig den Rücken zugekehrt, sondern bei mir eine Außnahme gemacht hast. Und für Dein offenes Ohr bei aufkommendem allgemeinen Laborfrust, mathematischen und Computer „Problemchen“ und der großen Unterstützung beim Erstellen des Manuskriptes zu dieser Arbeit. Nicht zu vergessen die Direktleitung zu Impress: SOS! Aber auch Dein geniales Kochtalent haben mir so einige Gaumenfreuden bereitet. 


\section{Lebenslauf}

12. März 1971

1977-1981

1981-1982

$1982-1988$

1988-1991

1991

August-September 1992

September 1992

Oktober 1992

September 1993

Oktober 1994

Mai 1997

Juli 1997-August 1998

Januar 1999
September 1991

geboren in Hamburg

Besuch der Heinrich-Hertz-Grundschule in Hamburg

Besuch der Gelehrtenschule des Johanneums, Altsprachliches Gymnasium in Hamburg

Besuch des Detlefsengymnasiums in Glückstadt

Besuch der Kaiser-Karl-Schule in Itzehoe

Abitur

Immatrikulation an der Pädagogischen Hochschule in Kiel für das Lehramtstudium mit zusätzlichem Magisterabschluß; Wahlfächern Deutsch und Geschichte

Industriepraktikum bei der Firma SIHI GmbH \& $\mathrm{Co}$ KG in Itzehoe

Exmatrikulation an der Pädagogischen Hochschule in Kiel

Immatrikulation an der Georg-August-Universität zu Göttingen für das Studienfach Biologie

Pflegepraktikum im Krankenhaus Itzehoe

Diplomvorprüfung in den Fächern Mikrobiologie, Zoologie, Chemie und Physikalische Chemie

Diplomprüfung in Mikrobiologie (Hauptfach), Zoologie und Bodenkunde

Anfertigung der experimentellen Diplomarbeit unter Anleitung von Prof. Dr. Dr. G. Gottschalk und Priv. Doz. Dr. U. Deppenmeier mit dem Titel: „Untersuchung von Gluconobacter oxydans-Stämmen mit mutagenisierter Glucose-Dehydrogenase“

November-Dezember 1998 Laborpraktikum im „Department of Microbiology and Molecular Genetics" bei Prof. Dr. R. P. Gunsalus and der „University of California, Los Angeles“

Beginn der experimentellen Arbeiten zur vorliegenden Dissertation 